Pacific Northwest

National Laboratory

Operated by Battelle for the

U.S. Department of Energy

\title{
RT3D Reaction Modules for Natural and Enhanced Attenuation of Chloroethanes, Chloroethenes, Chloromethanes, and Daughter Products
}

\author{
C. D. Johnson \\ M. J. Truex
}

July 2006

\author{
Prepared for \\ the U.S. Department of Energy \\ under Contract DE-AC05-76RL01830
}




\title{
DISCLAIMER
}

This report was prepared as an account of work sponsored by an agency of the United States Government. Neither the United States Government nor any agency thereof, nor Battelle Memorial Institute, nor any of their employees, makes any warranty, express or implied, or assumes any legal liability or responsibility for the accuracy, completeness, or usefulness of any information, apparatus, product, or process disclosed, or represents that its use would not infringe privately owned rights. Reference herein to any specific commercial product, process, or service by trade name, trademark, manufacturer, or otherwise does not necessarily constitute or imply its endorsement, recommendation, or favoring by the United States Government or any agency thereof, or Battelle Memorial Institute. The views and opinions of authors expressed herein do not necessarily state or reflect those of the United States Government or any agency thereof.

\author{
PACIFIC NORTHWEST NATIONAL LABORATORY \\ operated by \\ BATTELLE \\ for the \\ UNITED STATES DEPARTMENT OF ENERGY \\ under Contract DE-AC05-76RL01830
}

Printed in the United States of America

\author{
Available to DOE and DOE contractors from the \\ Office of Scientific and Technical Information, \\ P.O. Box 62, Oak Ridge, TN 37831-0062; \\ ph: (865) 576-8401 \\ fax: (865) 576-5728 \\ email: reports@adonis.osti.gov
}

\begin{abstract}
Available to the public from the National Technical Information Service, U.S. Department of Commerce, 5285 Port Royal Rd., Springfield, VA 22161 ph: (800) 553-6847 fax: $(703) 605-6900$

email: orders@ntis.fedworld.gov

online ordering: http://www.ntis.gov/ordering.htm
\end{abstract}

This document was printed on recycled paper. 


\title{
RT3D Reaction Modules for Natural and Enhanced Attenuation of Chloroethanes, Chloroethenes, Chloromethanes, and Daughter Products
}

\author{
C. D. Johnson \\ M. J. Truex
}

July 2006

Prepared for

the U.S. Department of Energy

under Contract DE-AC05-76RL01830

Pacific Northwest National Laboratory

Richland, Washington 99352 



\section{Summary}

This document describes a suite of Monitored Natural Attenuation/Enhanced Attenuation (MNA/EA) reaction modules that were developed for addressing complex chlorinated solvent reactions using the RT3D numerical solute transport code. As an introduction, an overview of these MNA/EA reaction modules is presented, including discussions of similarities between reaction modules, the purpose of key reaction parameters, and important considerations for using the reaction modules. Subsequent sections provide the details of the reaction kinetics (conceptual model and equations), data input requirements, and example (batch reactor) results for each reaction module. This document does not discuss reaction module implementation or validation; such information will accompany the software in the form of release notes or a supplement to the RT3D manual. 


\section{Acknowledgment}

This document is a product of the Monitored Natural Attenuation / Enhanced Attenuation for Chlorinated Solvents Technology Alternative Project (MNA/EA Alternative Project). The MNA/EA Alternative Project was sponsored by the U.S. Department of Energy (DOE) Office of Cleanup Technologies and administered by the U.S. Department of Energy Savannah River (SR) Operations Office. The authors appreciate the guidance and support of Claire H. Sink of DOE Headquarters and Karen M. Adams of DOE SR. The authors thank Brian Looney and Karen Vangelas of Savannah River National Laboratory and the MNA/EA Alternative Project Technical Working Group for their review and feedback on the work documented here. 


\section{Contents}

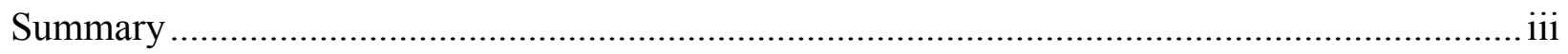

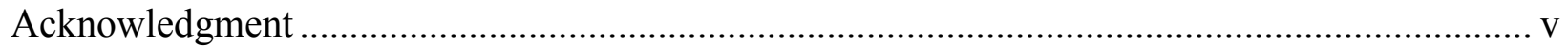

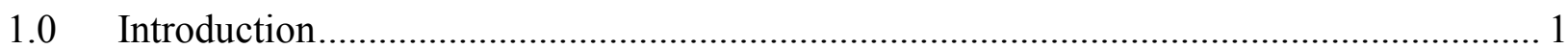

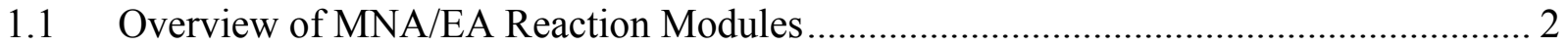

1.2 RT3D MNA/EA Reaction Module Commonalities ......................................................... 10

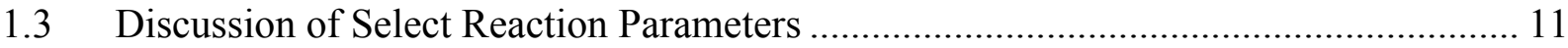

1.4 Important Considerations for Using the RT3D MNA/EA Reaction Modules ................ 15

2.0 Mixed Chloroethene/Chloroethane/Chloromethane Dechlorination ................................ 17

2.1 Conceptual Model for Dechlorination Reactions........................................................... 17

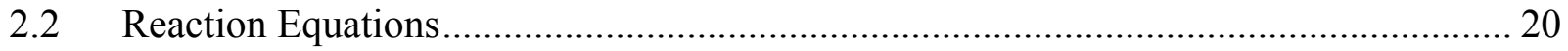

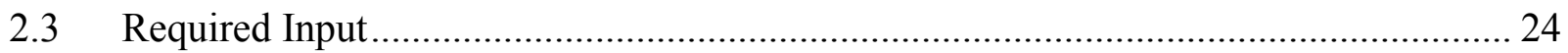

2.4 Example Simulations.......................................................................................... 27

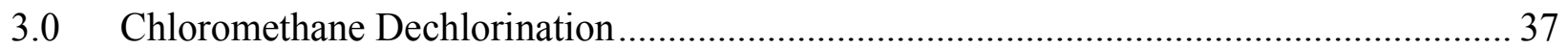

3.1 Conceptual Model for Dechlorination Reactions ............................................................ 37

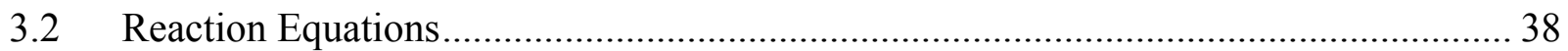

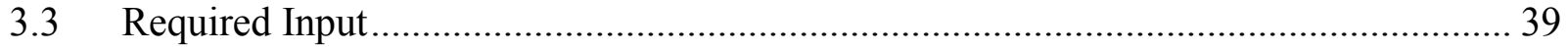

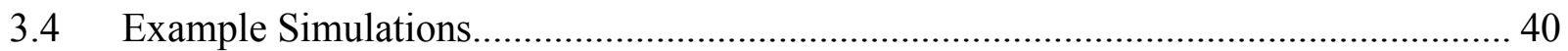

4.0 Dechlorination of 1,1,2,2-Tetrachloroethane and Chloroethenes ....................................... 45

4.1 Conceptual Model for Dechlorination Reactions .......................................................... 45

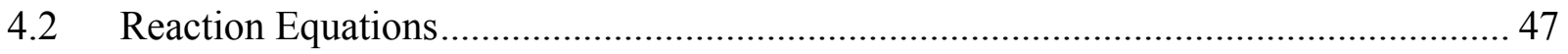

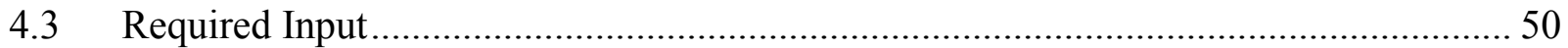

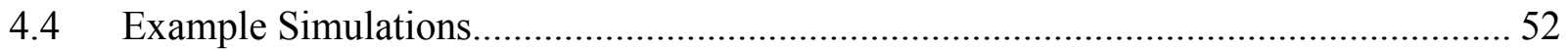

5.0 Dechlorination of 1,1,1,2-Tetrachloroethane and Chloroethenes ..................................... 57

5.1 Conceptual Model for Dechlorination Reactions .......................................................... 57

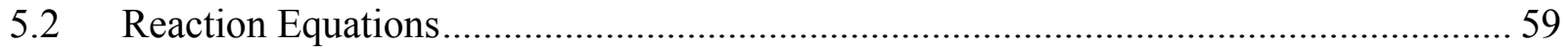

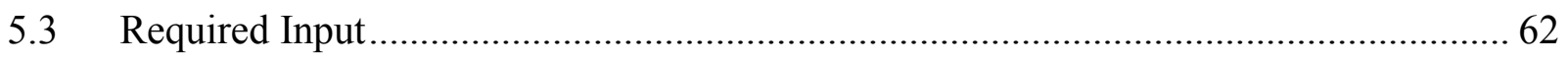

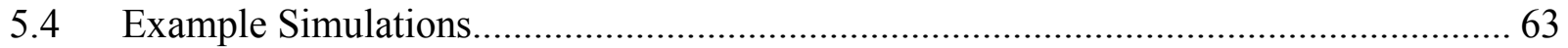




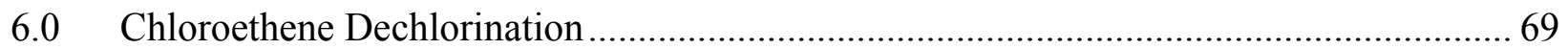

6.1 Conceptual Model for Dechlorination Reactions ............................................................. 69

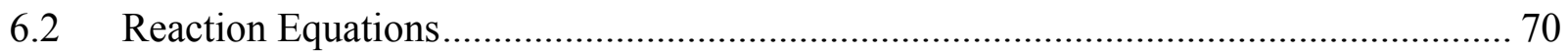

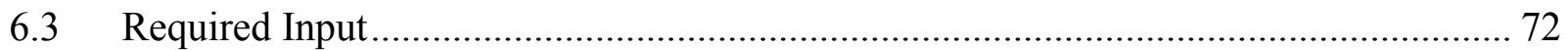

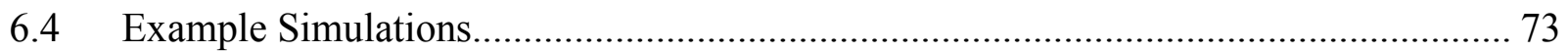

7.0 Redox-Linked Dechlorination of Chloroethenes ......................................................... 79

7.1 Conceptual Model for Dechlorination Reactions ......................................................... 79

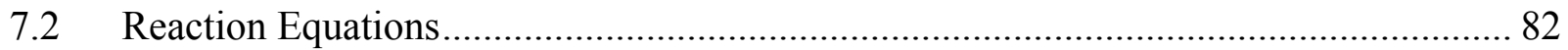

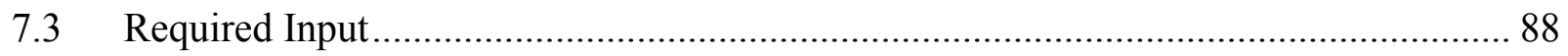

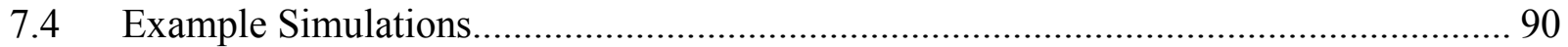

8.0 Substrate-Linked Reductive Dechlorination of Chloroethenes ......................................... 97

8.1 Conceptual Model for Dechlorination Reactions ........................................................... 97

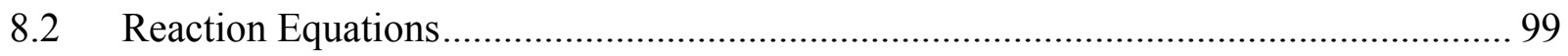

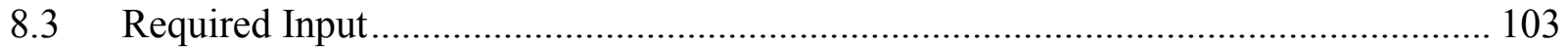

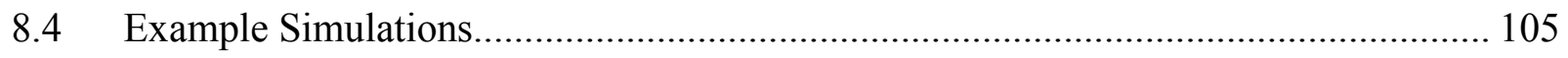

9.0 Cometabolic Aerobic Dechlorination of Chloroethenes................................................. 113

9.1 Conceptual Model for Dechlorination Reactions ......................................................... 113

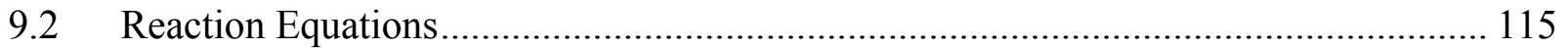

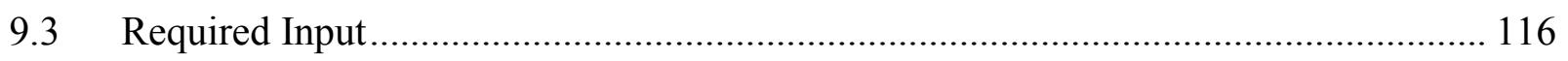

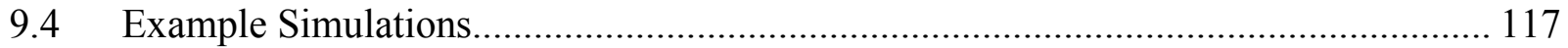

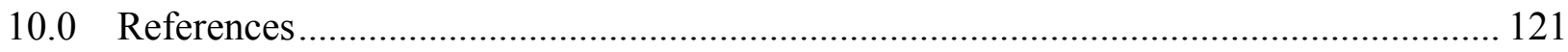




\section{Figures}

1 Flowchart Depicting the Logic for Selection of RT3D MNA/EA Reaction

Modules Based on the Contaminant(s) Present, What Data is Available, and the MNA/EA Scenario under Consideration .................................................... 4

2 Reaction Pathway Network for Chlorinated Ethenes, Ethanes, and Methanes ................... 7

3 Arbitrary Examples of the Curves Obtained for Monod and Inhibition Terms................. 13

4 Example of a Reactive Transport Model Having Multiple Reaction Zones, Each with Differing Reaction Parameter Values .......................................................... 14

5 Conceptual Model for Dechlorination Reactions in the Mixed Chloroethene/ Chloroethane/Chloromethane Dechlorination Reaction Module............................... 19

6 Dechlorination of Mixed Chlorinated Solvents under Anaerobic Conditions Using the Parameter Values Shown in Table 8 ................................................................ 32

7 Dechlorination of Mixed Chlorinated Solvents under Aerobic Conditions Using the Parameter Values Shown in Table 9

8 Dechlorination of Mixed Chlorinated Solvents Using the Parameter Values

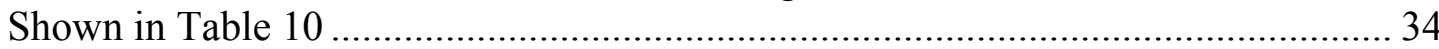

9 Aerobic and Abiotic Degradation Using the Parameter Values Shown in Table 11 .......... 35

10 Conceptual Model for Dechlorination Reactions in the Chloromethane

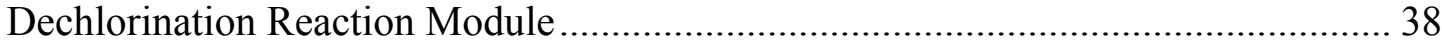

11 Dechlorination of CT Using the Parameter Values Shown in Table 14 .......................... 41

12 Dechlorination of CT Using the Parameter Values Shown in Table 15 ......................... 42

13 Dechlorination of CT Using the Parameter Values Shown in Table 16 ......................... 42

14 Aerobic and Abiotic Degradation Using the Parameter Values Shown in Table 17 .......... 43

15 Conceptual Model for Dechlorination Reactions in the Dechlorination of 1,1,2,2-

Tetrachloroethane and Chloroethenes Reaction Module........................................... 47

16 Dechlorination of 1,1,2,2-TeCA Using the Parameter Values Shown in Table 20 ............ 55

17 Dechlorination of 1,1,2,2-TeCA Using the Parameter Values Shown in Table 21 ............ 55

18 Dechlorination of 1,1,2,2-TeCA Using the Parameter Values Shown in Table 22 ........... 56

19 Aerobic and Abiotic Degradation of Contaminants in the 1,1,2,2-TeCA and PCE

Families Using the Parameter Values Shown in Table 23 .......................................5 56

20 Conceptual Model for Dechlorination Reactions in the Dechlorination of 1,1,1,2Tetrachloroethane and Chloroethenes Reaction Module.......................................... 59

21 Dechlorination of 1,1,1,2-TeCA Using the Parameter Values Shown in Table 26........... 66

22 Dechlorination of 1,1,1,2-TeCA Using the Parameter Values Shown in Table 27........... 66 
23 Dechlorination of 1,1,1,2-TeCA Using the Parameter Values Shown in Table 28 67

24 Aerobic and Abiotic Degradation of Contaminants in the 1,1,1,2-TeCA and PCE Families Using the Parameter Values Shown in Table 29.

25 Conceptual Model for Dechlorination Reactions in the Chloroethene

Dechlorination Reaction Module. 70

26 Dechlorination of PCE Using the Parameter Values Shown in Table 32 ......................... 75

27 Dechlorination of PCE Using the Parameter Values Shown in Table 33 ......................... 76

28 Dechlorination of PCE Using the Parameter Values Shown in Table 34........................ 76

29 Aerobic and Abiotic Degradation Using the Parameter Values Shown in Table 35 .......... 77

30 Conceptual Model for the Dechlorination Reactions of the Redox-Linked Dechlorination of Chloroethenes Reaction Module .............................................. 81

$31 \mathrm{pE}$ Value at Which Each Anaerobic Dechlorination Mechanism Dominates ................... 86

32 Example Simulation 1: Dechlorination of PCE and TCE Using the Parameter Values Shown in Table 39 92

33 Example Simulation 2: Dechlorination of cDCE and VC Using the Parameter Values Shown in Table 39 93

34 Example Simulation 3: Dechlorination of PCE and TCE Using the Parameter Values Shown in Table 40 . 94

35 Example Simulation 4: Dechlorination of PCE and TCE Using the Parameter Values Shown in Table 40 . 95

36 Conceptual Model for the Reductive Dechlorination Reactions of the SubstrateLinked Reductive Dechlorination of Chloroethenes Reaction Module.

37 Conceptual Diagram of the Behavior of the Function Representing a Change in Conditions as a Smooth Transition in the Form of a Sigmoidal Curve.... 100

38 Dechlorination of PCE Using the Parameter Values Shown in Table 43.

39 Concentrations of Organic Acids, Hydrogen, and Methane During Dechlorination of PCE Using the Parameter Values Shown in Table 43

40 Dechlorination of PCE Using the Parameter Values Shown in Table 44. 110

41 Dechlorination of PCE Using the Parameter Values Shown in Table 45. 110

42 Concentrations of Organic Acids, Hydrogen, and Methane During Dechlorination of PCE Using the Parameter Values Shown in Table 45.

43 Conceptual Model for Biomass Growth, Decay, and Cometabolic Degradation Reactions.... 114

44 Dechlorination of TCE Using the Parameter Values Shown in Table 48. 118

45 Dechlorination of VC Using the Parameter Values Shown in Table 48. 


\section{Tables}

1 Chlorinated Contaminant Species Grouped by Contaminant Type.................................. 3

2 Summary of RT3D Reaction Modules ...................................................................... 4

3 Descriptions of Biological and Abiotic Dechlorination Reactions ................................... 8

4 Example of Stoichiometric Dechlorination Yield Resulting From Transformation

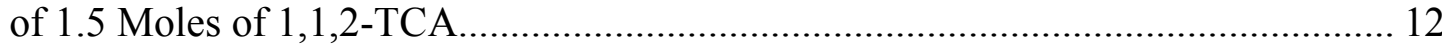

5 Chemical Species Included in the Mixed

Chloroethene/Chloroethane/Chloromethane Dechlorination Reaction

Module 18

6 Reaction Pathways Without Laboratory Data in the Open Literature, but Which Are Included in the RT3D MNA/EA First-Order Reaction Modules

7 Input Parameters for the Mixed Chloroethene/Chloroethane/Chloromethane

Dechlorination Reaction Module.

8 Parameter Values for Example Simulation 1 - Anaerobic Conditions - with the Mixed Chloroethene/Chloroethane/Chloromethane Dechlorination Reaction Module 28

9 Parameter Values for Example Simulation 2 - Aerobic Conditions - with the Mixed Chloroethene/Chloroethane/Chloromethane Dechlorination Reaction Module

10 Parameter Values For Example Simulation 3 - Anaerobic Case Equivalent to Table 20 - With The Mixed Chloroethene/Chloroethane/Chloromethane

Dechlorination Reaction Module. 30

11 Parameter Values for Example Simulation 4 - Aerobic Case Equivalent to Table 23 - with the Mixed Chloroethene/Chloroethane/Chloromethane Dechlorination Reaction Module.

12 Chemical Species Included in the Chloromethane Dechlorination Reaction Module 37

13 Input Parameters for the Chloromethane Dechlorination Reaction Module

14 Parameter Values for Example Simulation 1 - Base Case Anaerobic Conditions with the Chloromethane Dechlorination Reaction Module

15 Parameter Values for Example Simulation 2 - Rates at 10\% of Example Simulation 1 - with the Chloromethane Dechlorination Reaction Module.

16 Parameter Values for Example Simulation 3 - Different F Values Than Example Simulation 1 - with the Chloromethane Dechlorination Reaction Module.

17 Parameter Values for Example Simulation 4 - Base Case Aerobic Conditions with the Chloromethane Dechlorination Reaction Module 
18 Chemical Species Included in the Dechlorination of 1,1,2,2-Tetrachloroethane and Chloroethenes Reaction Module

19 Input Parameters for the Dechlorination of 1,1,2,2-Tetrachloroethane and Chloroethenes Reaction Module.

20 Parameter Values for Example Simulation 1 - Base Case Anaerobic Conditions with the Dechlorination of 1,1,2,2-Tetrachloroethane and Chloroethenes Reaction Module. 53

21 Parameter Values for Example Simulation 2 - Rates at 10\% of Example Simulation 1 - with the Dechlorination of 1,1,2,2-Tetrachloroethane and Chloroethenes Reaction Module

22 Parameter Values for Example Simulation 3 - Different F Values Than Example Simulation 1 - with the Dechlorination of 1,1,2,2-Tetrachloroethane and Chloroethenes Reaction Module.

23 Parameter Values for Example Simulation 4 - Base Case Aerobic Conditions with the Dechlorination of 1,1,2,2-Tetrachloroethane and Chloroethenes Reaction Module. 54

24 Chemical Species Included in the Dechlorination of 1,1,1,2-Tetrachloroethane and Chloroethenes Reaction Module....

25 Input Parameters for the Dechlorination of 1,1,1,2-Tetrachloroethane and Chloroethenes Reaction Module

26 Parameter Values for Example Simulation 1 - Base Case Anaerobic Conditions with the Dechlorination of 1,1,1,2-Tetrachloroethane and Chloroethenes Reaction Module.

27 Parameter Values for Example Simulation 2 - Rates at $10 \%$ of Example Simulation 1 - with the Dechlorination of 1,1,1,2-Tetrachloroethane and Chloroethenes Reaction Module

28 Parameter Values for Example Simulation 3 - Different F Values Than Example Simulation 1 - with the Dechlorination of 1,1,1,2-Tetrachloroethane and Chloroethenes Reaction Module

29 Parameter Values for Example Simulation 4 - Base Case Aerobic Conditions with the Dechlorination of 1,1,1,2-Tetrachloroethane and Chloroethenes Reaction Module. 65

30 Chemical Species Included in the Chloroethene Dechlorination Reaction Module 69

31 Input Parameters for the Chloroethene Dechlorination Reaction Module......................... 73

32 Parameter Values for Example Simulation 1 - Base Case Anaerobic Conditions with the Chloroethene Dechlorination Reaction Module

33 Parameter Values for Example Simulation 2 - Rates at 10\% of Example Simulation 1 - with the Chloroethene Dechlorination Reaction Module..... 
34 Parameter Values for Example Simulation 3 - Different F Values Than Example

Simulation 1 - with the Chloroethene Dechlorination Reaction Module.

35 Parameter Values for Example Simulation 4 - Base Case Aerobic Conditions with the Chloroethene Dechlorination Reaction Module

36 Chemical Species Included in the Redox-Linked Dechlorination of Chloroethenes

Reaction Module 80

37 Free Energy for Chemical Species of Interest 85

38 Input Parameters for the Redox-Linked Dechlorination of Chloroethenes

Reaction Module.

39 Parameter Values for Example Simulations 1 and 2 with the Redox-Linked Dechlorination of Chloroethenes Reaction Module

40 Parameter Values for Example Simulations 3 and 4 with the Redox-Linked Dechlorination of Chloroethenes Reaction Module

41 Chemical Species Included in the Substrate-Linked Reductive Dechlorination of Chloroethenes Reaction Module 98

42 Input Parameters for the Substrate-Linked Reductive Dechlorination of Chloroethenes Reaction Module.

43 Parameter Values for Example Simulation 1 with the Substrate-Linked Reductive Dechlorination of Chloroethenes Reaction Module 106

44 Parameter Values for Example Simulation 2 with the Substrate-Linked Reductive Dechlorination of Chloroethenes Reaction Module

45 Parameter Values for Example Simulation 3 with the Substrate-Linked Reductive Dechlorination of Chloroethenes Reaction Module 108

46 Chemical Species Included in the Cometabolic Aerobic Dechlorination of Chloroethenes Reaction Module

47 Input Parameters for the Cometabolic Aerobic Dechlorination of Chloroethenes Reaction Module.

48 Parameter Values for Example Simulations 1 and 2 with the Cometabolic Aerobic Dechlorination of Chloroethenes Reaction Module 


\subsection{Introduction}

Monitored Natural Attenuation (MNA) is an environmental management strategy that relies on a variety of attenuation processes to destroy, transform, or immobilize contaminants and is implemented at appropriate sites by demonstrating that contaminant plumes have low risk and are either stable or shrinking. Numerical modelling can be one component of an assessment of MNA or Enhanced Attenuation (EA) (i.e., if MNA is not a viable single remedy). Numerical reactive transport modelling provides a tool with which to quantify the relative stability of a contaminant plume, particularly in cases where simpler evaluations are not suitable because of complex hydrology, past activity at the site, multiple contaminant sources, and/or complex reaction of multiple species. Selection of an appropriate model configuration to represent spatial and temporal variations in site-specific attenuation processes can facilitate assessment of the contaminant loading and attenuation capacity (i.e., mass balance) at the site.

RT3D is a numerical code for simulating three-dimensional multi-species reactive transport in groundwater for a user-configured site model [Clement, 1997; Clement et al., 1998; Clement and Johnson, 2002; Johnson et al., 2006]. RT3D can provide information to help analyze the relative importance of different fate and transport processes at an individual site and assess the plume in terms of a mass balance approach. A RT3D model can also be used to estimate the future fate and transport of contaminants. These predictions can be valuable input, along with other site information, in making timely decisions regarding implementation of remedial actions or for planning monitoring activities. A key function of the predictive capability of models is to estimate whether the remedy will meet the remediation goals when this determination cannot be made directly with field data.

The RT3D code solves a system of reactive transport equations for the tracked chemical species using an operator-split strategy to uncouple the advection, dispersion, source/sink mixing, and reaction terms of the governing transport equations [Johnson and Truex, 2006]. These separate terms are encapsulated in so-called "Packages," which delineate portions of the code as well as the required data input. RT3D improved on the publicly available MT3D code (whose more recent versions go by the name MT3DMS [Zheng and Wang, 1999]) by entirely replacing the Reaction Package code. The Reaction Package for RT3D is structured such that the reaction terms split off from the transport equations can be assembled into a reaction module comprised of a set of coupled ordinary differential equations (ODEs). Multiple reaction modules are defined within the RT3D code, with each reaction module encapsulating a set of kinetic equations that describe reaction of specific contaminants. Different approaches for describing contaminant degradation or transformation may be implemented for the same contaminants in different reaction modules.

RT3D versions 1.0 and 2.5 [Clement, 1997; Clement and Johnson, 2002] included a set of general-purpose reaction modules, including BTEX degradation (kinetic and instantaneous), rate-limited sorption, double Monod kinetics, and two simple chlorinated ethene reaction 
modules. Additionally, RT3D has the ability to apply any user-defined reaction kinetics. While this user-defined option provides a means to employ more complex chlorinated solvent reaction kinetics, practitioners may not take advantage of this approach for two primary reasons. Users that configure an RT3D model through the graphical interface of a groundwater modelling software package may overlook the potential of the user-defined reaction module option if that option is absent in the graphical interface. Secondly, even when practitioners are aware of the user-defined reaction module option, they may view it as intimidating because it involves writing and compiling Fortran code.

This document describes a suite of MNA/EA reaction modules that were developed for addressing complex chlorinated solvent reactions using RT3D. As an introduction, an overview of these MNA/EA reaction modules is presented, including discussions of similarities between reaction modules, the purpose of key reaction parameters, and important considerations for using the reaction modules. Subsequent sections provide the details of the reaction kinetics (conceptual model and equations), data input requirements, and example (batch reactor) results for each reaction module. This document does not discuss reaction module implementation or validation; such information will accompany the software in the form of release notes or a supplement to the RT3D manual [Clement, 1997].

\subsection{Overview of MNA/EA Reaction Modules}

Eight RT3D reaction modules were developed for modelling complex chlorinated solvent reaction kinetics as part of evaluating MNA or EA. These eight modules are applicable for simulation of reactive transport of the chlorinated solvent chemicals listed in Table 1. Figure 1 shows the basic decision process for selecting one of these reaction modules for use in assessing MNA applications at a specific site, depending on the contaminant group or groups that are present. In the case where only chloroethenes are of concern, the selection also depends on whether there is enough information and a desire to explicitly model a link between geochemical oxidation/reduction conditions and dechlorination. For MNA/EA sites, chloroethene reductive dechlorination using substrate/biomass-dependent reaction rates or cometabolic aerobic dechlorination can be selected to model the impact of biostimulation on dechlorination. Table 2 summarizes the purpose of the RT3D reaction modules (both the existing ones and those described in this document). Table 2 also lists the total number of chemical species that are tracked, the number of constituents that are in the mobile aqueous phase (versus attached to the immobile soil phase), and the number of reaction parameters required for each reaction module. 
Table 1. Chlorinated Contaminant Species Grouped by Contaminant Type

\begin{tabular}{|c|c|c|c|c|c|}
\hline & Abbreviation & $\begin{array}{l}\text { Contaminant Name } \\
\text { (Synonyms) }\end{array}$ & $\begin{array}{l}\text { Chemical } \\
\text { Formula }\end{array}$ & $\begin{array}{l}\text { CAS } \\
\text { RN }^{\text {a }}\end{array}$ & $\begin{array}{c}\text { Molecular } \\
\text { Weight }^{\text {b }} \\
\text { (g/mol) }\end{array}$ \\
\hline \multirow{6}{*}{ 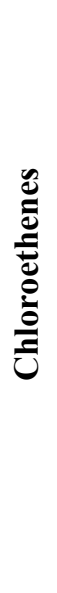 } & PCE & $\begin{array}{l}\text { Tetrachloroethene } \\
\quad \text { (Tetrachloroethylene, Perchloroethene) }\end{array}$ & $\mathrm{CCl}_{2}=\mathrm{CCl}_{2}$ & $127-18-4$ & 165.8334 \\
\hline & TCE & $\begin{array}{l}\text { Trichloroethene } \\
\text { (Trichloroethylene) }\end{array}$ & $\mathrm{CHCl}=\mathrm{CCl}_{2}$ & $79-01-6$ & 131.38834 \\
\hline & 1,2-cis-DCE & $\begin{array}{l}\text { cis-1,2-Dichloroethene } \\
\text { (cis-1,2- Dichloroethylene, cis-DCE, c-DCE) }\end{array}$ & $\mathrm{CHCl}=\mathrm{CHCl}$ & $156-59-2$ & 96.94328 \\
\hline & 1,2-trans-DCE & $\begin{array}{l}\text { trans-1,2-Dichloroethene } \\
\quad \text { (trans-1,2-Dichloroethylene, trans-DCE, t-DCE) }\end{array}$ & $\mathrm{CHCl}=\mathrm{CHCl}$ & $156-60-5$ & 96.94328 \\
\hline & 1,1-DCE & $\begin{array}{l}\text { 1,1-Dichloroethene } \\
\text { (1,1-Dichloroethylene) }\end{array}$ & $\mathrm{CCl}_{2}=\mathrm{CH}_{2}$ & $75-35-4$ & 96.94328 \\
\hline & $\mathrm{VC}$ & $\begin{array}{l}\text { Chloroethene } \\
\text { (Vinyl Chloride, Chloroethylene) }\end{array}$ & $\mathrm{CH}_{2}=\mathrm{CHCl}$ & $75-01-4$ & 62.49822 \\
\hline \multirow{7}{*}{ 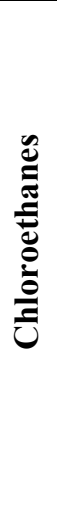 } & $1,1,2,2-\mathrm{TeCA}$ & 1,1,2,2-Tetrachloroethane & $\mathrm{CHCl}_{2}-\mathrm{CHCl}_{2}$ & $79-34-5$ & 167.84928 \\
\hline & $1,1,2-\mathrm{TCA}$ & $\begin{array}{l}\text { 1,1,2-Trichloroethane } \\
\text { (Vinyl Trichloride) }\end{array}$ & $\mathrm{CH}_{2} \mathrm{Cl}-\mathrm{CHCl}_{2}$ & $79-00-5$ & 133.40422 \\
\hline & 1,2-DCA & $\begin{array}{l}\text { 1,2-Dichloroethane } \\
\text { (Ethane Dichloride) }\end{array}$ & $\mathrm{CH}_{2} \mathrm{Cl}-\mathrm{CH}_{2} \mathrm{Cl}$ & $107-06-2$ & 98.95916 \\
\hline & $1,1,1,2-\mathrm{TeCA}$ & 1,1,1,2-Tetrachloroethane & $\mathrm{CHCl}-\mathrm{CCl}_{3}$ & $630-20-6$ & 167.84928 \\
\hline & $1,1,1-\mathrm{TCA}$ & 1,1,1-Trichloroethane & $\mathrm{CH}_{3}-\mathrm{CCl}_{3}$ & $71-55-6$ & 133.40422 \\
\hline & $1,1-\mathrm{DCA}$ & 1,1-Dichloroethane & $\mathrm{CH}_{3}-\mathrm{CHCl}_{2}$ & $75-34-3$ & 98.95916 \\
\hline & $\mathrm{CA}$ & $\begin{array}{l}\text { Chloroethane } \\
\text { (Ethyl Chloride) }\end{array}$ & $\mathrm{CH}_{3}-\mathrm{CH}_{2} \mathrm{Cl}$ & $75-00-3$ & 64.5141 \\
\hline \multirow{4}{*}{ 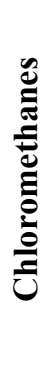 } & CT & $\begin{array}{l}\text { Tetrachloromethane } \\
\text { (Carbon Tetrachloride) }\end{array}$ & $\mathrm{CCl}_{4}$ & $56-23-5$ & 153.8227 \\
\hline & $\mathrm{CF}$ & $\begin{array}{l}\text { Trichloromethane } \\
\text { (Chloroform) }\end{array}$ & $\mathrm{CHCl}_{3}$ & $67-66-3$ & 119.3776 \\
\hline & $\mathrm{DCM}$ & $\begin{array}{l}\text { Dichloromethane } \\
\text { (Methylene Dichloride, Methylene Chloride) }\end{array}$ & $\mathrm{CH}_{2} \mathrm{Cl}_{2}$ & $75-09-2$ & 84.93258 \\
\hline & $\mathrm{CM}$ & $\begin{array}{l}\text { Chloromethane } \\
\text { (Methyl Chloride) }\end{array}$ & $\mathrm{CH}_{3} \mathrm{Cl}$ & $74-87-3$ & 50.48752 \\
\hline
\end{tabular}

a $\quad \mathrm{CAS}=$ Chemical Abstracts Service (see http://www.cas.org/EO/regsys.html)

b Based on International Union of Pure and Applied Chemistry values reported by Loss [2003]. 


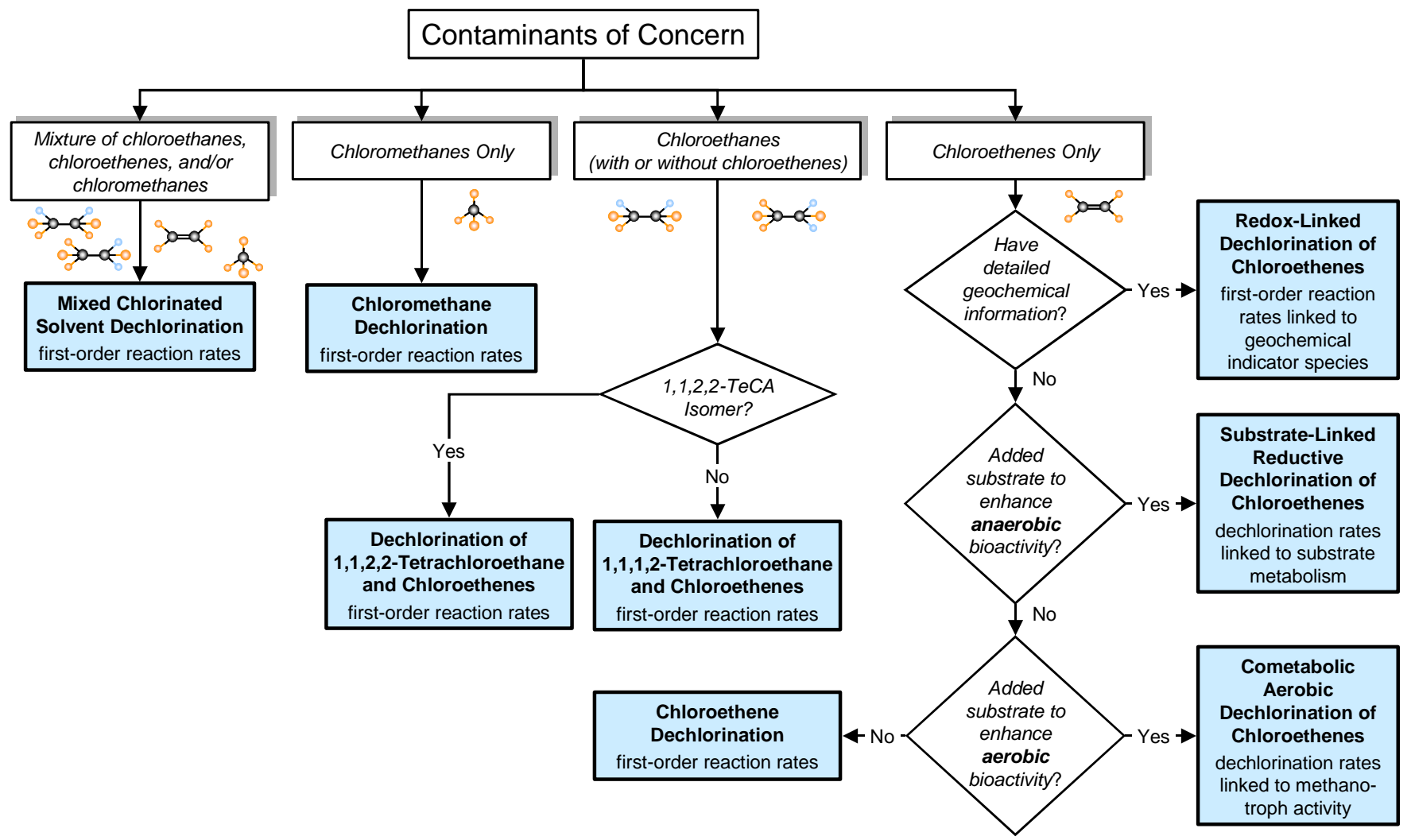

Figure 1. Flowchart Depicting the Logic for Selection of RT3D MNA/EA Reaction Modules Based on the Contaminant(s) Present, What Data is Available, and the MNA/EA Scenario under Consideration

Table 2. Summary of RT3D Reaction Modules (Existing and New)

\begin{tabular}{|c|c|c|c|c|}
\hline 常 & $\begin{array}{c}\text { RT3D Reaction } \\
\text { Module }\end{array}$ & Brief Description / Purpose & $\begin{array}{c}\text { NCOMP } \\
\left(\text { MCOMP) }^{b}\right.\end{array}$ & $\begin{array}{l}\text { Number of } \\
\text { Reaction } \\
\text { Parameters }\end{array}$ \\
\hline$\bullet$ & No Reaction & Simulation of non-reactive tracer. & $\begin{array}{c}\text { user } \\
\text { specified }\end{array}$ & 0 \\
\hline$\bullet$ & $\begin{array}{l}\text { Two-Species } \\
\text { Instantaneous } \\
\text { Reactions }\end{array}$ & $\begin{array}{l}\text { Instantaneous stoichiometric consumption of electron donor } \\
\text { (e.g. hydrocarbon) and electron acceptor (e.g., oxygen) in } \\
\text { each transport time step. BIOPLUME-II type reactions. }\end{array}$ & $2(2)$ & 1 \\
\hline$\bullet$ & $\begin{array}{l}\text { Six Species, First- } \\
\text { Order, Rate- } \\
\text { Limited, BTEX } \\
\text { Degradation using } \\
\text { Sequential Electron } \\
\text { Acceptors }\end{array}$ & $\begin{array}{l}\text { First-order degradation of electron donor (e.g., } \mathrm{BTEX} \text { ) under } \\
\text { up to six electron acceptor regimes, each with it's own } \\
\text { reaction rate. Electron acceptors are utilized in a sequential } \\
\text { manner in the order of } \mathrm{O}_{2}, \mathrm{NO}_{3}^{-}, \mathrm{Fe}^{2+}, \mathrm{SO}_{4}{ }^{2-} \text {, and } \mathrm{CO}_{2} \text { (i.e., } \\
\text { oxygen is the preferred electron acceptor until it is consumed, } \\
\text { then the nitrate regime controls, and so on). }\end{array}$ & $6(6)$ & 21 \\
\hline
\end{tabular}


Table 2. (contd)

\begin{tabular}{|c|c|c|c|}
\hline $\begin{array}{l}\text { RT3D Reaction } \\
\text { Module }\end{array}$ & Brief Description / Purpose & $\begin{array}{c}\text { NCOMP } \\
\left(\text { MCOMP) }^{b}\right.\end{array}$ & $\begin{array}{l}\text { Number of } \\
\text { Reaction } \\
\text { Parameters }\end{array}$ \\
\hline $\begin{array}{l}\text { Rate-Limited } \\
\text { Sorption }\end{array}$ & $\begin{array}{l}\text { Sorption is represented as a mass transfer-limited process that } \\
\text { is a function of a mass transfer rate and the concentration } \\
\text { driving force between aqueous and adsorbed phases. } \\
\text { Equilibrium adsorption should not be used concurrently with } \\
\text { this reaction module. No degradation is included in this } \\
\text { reaction module, only the rate-limited sorption. }\end{array}$ & $2(1)$ & 2 \\
\hline $\begin{array}{l}\text { Double Monod } \\
\text { Model }\end{array}$ & $\begin{array}{l}\text { Reaction between an electron donor and an electron acceptor } \\
\text { that is mediated by actively growing and decaying bacteria. } \\
\text { Bacteria are present in both aqueous and soil phases, where } \\
\text { transfer between phases is based on first-order kinetic } \\
\text { expressions. No specific microscopic biomass structure is } \\
\text { assumed, and diffusional limitations across any soil phase } \\
\text { biofilm are neglected. Permeability and porosity changes } \\
\text { caused by bacterial growth are not accounted for in this } \\
\text { reaction module. }\end{array}$ & $4(3)$ & 8 \\
\hline $\begin{array}{l}\text { Sequential First- } \\
\text { Order Decay }\end{array}$ & $\begin{array}{l}\text { Sequential degradation reactions for up to } 4 \text { chemical species } \\
\text { using first-order reaction kinetics (e.g., PCE } \rightarrow \text { TCE } \rightarrow \\
\text { DCE } \rightarrow \text { VC). }\end{array}$ & $4(4)$ & 7 \\
\hline $\begin{array}{l}\text { Aerobic/Anaerobic } \\
\text { PCE/TCE } \\
\text { Dechlorination }\end{array}$ & $\begin{array}{l}\text { Degradation of chlorinated ethenes (PCE, TCE, DCE, and } \\
\text { VC) via both aerobic and anaerobic pathways, which are } \\
\text { described with first-order reaction kinetics. }\end{array}$ & $6(6)$ & 9 \\
\hline $\begin{array}{l}\text { User-Defined } \\
\text { Kinetics }\end{array}$ & $\begin{array}{l}\text { User-specified reaction kinetics. Any suitable/appropriate } \\
\text { reaction kinetics may be described and implemented with this } \\
\text { reaction module using the approach described in the RT3D } \\
\text { manual [Clement, 1997]. }\end{array}$ & $\begin{array}{l}\text { user } \\
\text { specified; } \\
\text { limited to } \\
100 \text { species }\end{array}$ & $\begin{array}{l}\text { user } \\
\text { specified; } \\
\text { limited to } \\
100 \\
\text { parameters }\end{array}$ \\
\hline $\begin{array}{l}\text { Mixed } \\
\text { Chloroethene/ } \\
\text { Chloroethane/ } \\
\text { Chloromethane } \\
\text { Dechlorination }\end{array}$ & $\begin{array}{l}\text { Dechlorination of a mixture of chloroethene, chloroethane, } \\
\text { and chloromethane compounds using first-order rate } \\
\text { expressions. This reaction module includes aerobic, } \\
\text { anoxic/anaerobic, and abiotic reactions. }\end{array}$ & $18(18)$ & 53 \\
\hline $\begin{array}{l}\text { Chloromethane } \\
\text { Dechlorination }\end{array}$ & $\begin{array}{l}\text { Dechlorination of chloromethane compounds using first- } \\
\text { order rate expressions. This reaction module includes } \\
\text { aerobic, anoxic/anaerobic, and abiotic reactions. }\end{array}$ & $5(5)$ & 9 \\
\hline $\begin{array}{l}\text { Dechlorination of } \\
1,1,2,2- \\
\text { Tetrachloroethane } \\
\text { and Chloroethenes }\end{array}$ & $\begin{array}{l}\text { Dechlorination of 1,1,2,2-tetrachloroethane and chloro- } \\
\text { ethenes using first-order rate expressions. Includes } \\
\text { 1,1,2-TCA and 1,2-DCA. This reaction module includes } \\
\text { aerobic, anoxic/anaerobic, and abiotic reactions. }\end{array}$ & $11(11)$ & 35 \\
\hline
\end{tabular}


Table 2. (contd)

\begin{tabular}{|c|c|c|c|}
\hline $\begin{array}{c}\text { RT3D Reaction } \\
\text { Module }\end{array}$ & Brief Description / Purpose & $\begin{array}{c}\text { NCOMP } \\
(\text { MCOMP })^{b}\end{array}$ & $\begin{array}{c}\text { Number of } \\
\text { Reaction } \\
\text { Parameters }\end{array}$ \\
\hline $\begin{array}{l}\text { Dechlorination of } \\
1,1,1,2- \\
\text { Tetrachloroethane } \\
\text { and Chloroethenes }\end{array}$ & $\begin{array}{l}\text { Dechlorination of 1,1,1,2-tetrachloroethane and chloro- } \\
\text { ethenes using first-order rate expressions. Includes } \\
\text { 1,1,1-TCA and 1,1-DCA. This reaction module includes } \\
\text { aerobic, anoxic/anaerobic, and abiotic reactions. }\end{array}$ & $11(11)$ & 28 \\
\hline $\begin{array}{l}\text { Chloroethene } \\
\text { Dechlorination }\end{array}$ & $\begin{array}{l}\text { Dechlorination of chloroethene compounds using first-order } \\
\text { rate expressions. All DCE isomers are included and } \\
\text { additional pathways are represented (as compared to the } \\
\text { Aerobic/Anaerobic PCE/TCE Dechlorination reaction } \\
\text { module). This module includes aerobic and anoxic/anaerobic } \\
\text { reactions (abiotic reactions are negligible for chlorinated } \\
\text { ethenes). }\end{array}$ & $7(7)$ & 16 \\
\hline $\begin{array}{l}\text { Redox-Linked } \\
\text { Dechlorination of } \\
\text { Chloroethenes }\end{array}$ & $\begin{array}{l}\text { Dechlorination of chloroethene compounds using first-order } \\
\text { rate expressions. This module includes aerobic and } \\
\text { anoxic/anaerobic reactions, where the rate of these reactions } \\
\text { is controlled by the oxidation/reduction conditions in the } \\
\text { aquifer. Oxygen, nitrate, iron, sulfate/sulfide, and methane } \\
\text { are used as indicator compounds to define the geochemical } \\
\text { conditions. The user may choose to fix the spatial } \\
\text { distribution of the geochemical indicator concentrations or } \\
\text { allow the geochemical indicator compounds to undergo } \\
\text { oxidation/reduction to give a time-varying spatial distribution } \\
\text { of geochemical conditions. }\end{array}$ & $15(14)$ & 39 \\
\hline $\begin{array}{l}\text { Substrate-Linked } \\
\text { Reductive } \\
\text { Dechlorination of } \\
\text { Chloroethenes }\end{array}$ & $\begin{array}{l}\text { Reductive dechlorination of chloroethene compounds using } \\
\text { substrate/biomass-dependent reaction rates. The rates of } \\
\text { dechlorination reactions are dependent on substrate (lactate) } \\
\text { consumption and microbial growth. }\end{array}$ & $15(12)$ & 44 \\
\hline $\begin{array}{l}\text { Cometabolic } \\
\text { Aerobic } \\
\text { Dechlorination of } \\
\text { Chloroethenes }\end{array}$ & $\begin{array}{l}\text { Cometabolic dechlorination of TCE, DCE isomers, and VC } \\
\text { by methanotrophic bacteria. The rate of dechlorination is } \\
\text { dependent on the rate of methane consumption and microbial } \\
\text { growth. }\end{array}$ & $8(6)$ & 18 \\
\hline
\end{tabular}

a These reaction modules (marked with a ) were available beginning with RT3D version 1.0 [Clement, 1997].

b NCOMP is the total number of chemical compounds that are tracked and MCOMP is the number of chemical compounds that are mobile (aqueous phase species).

c Reaction parameters must all be of the same type, with either a constant value for all spatial locations or with a variable distribution through the spatial domain. 
Five of the RT3D MNA/EA reaction modules represent the dechlorination reaction pathways for various mixtures of chlorinated ethenes, chlorinated ethanes, and chlorinated methanes. The complex network of biological and abiotic reaction pathways that are represented in these modules are depicted in Figure 2. The five reaction modules represent (1) the full reaction pathway network, (2) the chlorinated methanes only, (3) the 1,1,2,2-TeCA/PCE contaminant families, (4) the 1,1,1,2-TeCA/PCE contaminant families, and (5) the chlorinated ethenes only. The reaction network does not include heterogeneous abiotic reactions or abiotic reactions with half-lives of more than 200 years. Because these reaction modules target MNA conditions, cometabolism pathways (aerobic or anaerobic) are also not included.

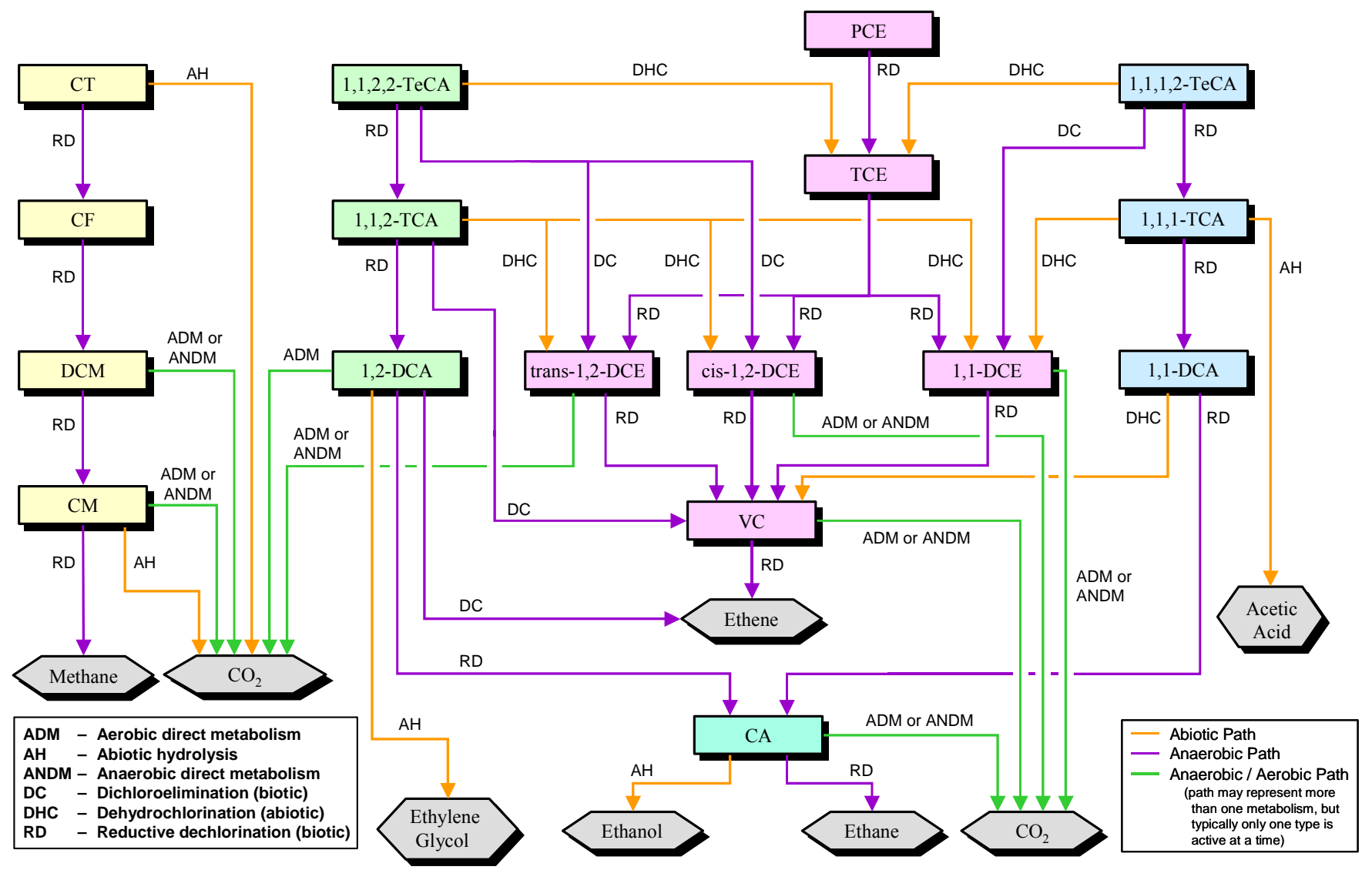

Figure 2. Reaction Pathway Network for Chlorinated Ethenes, Ethanes, and Methanes Heterogeneous abiotic reactions, abiotic pathways with a half-life greater than 200 years, and cometabolic reaction pathways are not included.

Aerobic, anoxic, and anaerobic biological reaction pathways/conditions are all represented using first-order rate expressions. Table 3 describes the types of reaction processes that are noted for the pathways in Figure 2. The spatial distribution of a degradation regime (i.e., aerobic, anoxic, anaerobic, etc.) is delineated via user-specified zones within the RT3D model [e.g., Johnson et al., 2003a; Clement et al., 2000]. Reaction rates should be defined for each zone to represent the 
expected microbial activity of that zone. The relevant reactions for a specific site (as determined by the user) may include all or some of the reaction pathways available in a reaction module. In zones where a reaction pathway is inactive, the spatially variable rate coefficient (and/or stoichiometric yield) is set to zero. For instance, an aerobic zone may have aerobic rate coefficients set to some appropriate value, while in the same zone the rate coefficients for anaerobic reactions would be zero. These five reaction modules also include first-order rate expressions for the abiotic degradation reactions shown in Figure 2.

Table 3. Descriptions of Biological and Abiotic Dechlorination Reactions

\begin{tabular}{|c|c|c|}
\hline Reaction & Abbreviation & Description of Reaction \\
\hline $\begin{array}{l}\text { Aerobic Direct } \\
\text { Metabolism }\end{array}$ & $\mathrm{ADM}$ & $\begin{array}{l}\text { Use of the chlorinated compound as an electron donor for aerobic } \\
\text { metabolism. }\end{array}$ \\
\hline $\begin{array}{l}\text { Anaerobic Direct } \\
\text { Metabolism }\end{array}$ & ANDM & $\begin{array}{l}\text { Use of the chlorinated compound as an electron donor for anaerobic } \\
\text { respiration - typically coupled to iron reduction. }\end{array}$ \\
\hline Abiotic Hydrolysis & $\mathrm{AH}$ & $\begin{array}{l}\text { Homogeneous abiotic dechlorination as an initial reaction step - no } \\
\text { specific reaction for this classification. The primary end product of } \\
\text { this pathway is shown, omitting intermediate reaction steps. }\end{array}$ \\
\hline $\begin{array}{l}\text { Dichloroelimination } \\
\text { (vicinal reduction) }\end{array}$ & $\mathrm{DC}$ & $\begin{array}{l}\text { Dechlorination of a compound where the compound is used as an } \\
\text { electron acceptor, the bacteria may or may not gain energy by } \\
\text { reduction of the compound. This reaction removes two chloride } \\
\text { atoms in an elimination reaction. The more general term for this } \\
\text { reaction is dihaloelimination. }\end{array}$ \\
\hline Dehydrochlorination & $\mathrm{DHC}$ & $\begin{array}{l}\text { This reaction removes one chloride atom and one proton in an } \\
\text { elimination reaction. This reaction is usually referred to as abiotic, } \\
\text { but studies indicate that the reaction can be enhanced/catalyzed by } \\
\text { bacteria [e.g., Maymó-Gatell et al., 1999] and/or minerals (e.g., } \\
\text { clay) [e.g., Cervini-Silva et al., 2003]. The more general term for } \\
\text { this reaction is dehydrohalogenation. Sometimes this type of } \\
\text { reaction is referred to as dehydrodehalogenation. }\end{array}$ \\
\hline $\begin{array}{l}\text { Reductive } \\
\text { Dechlorination } \\
\text { (hydrogenolysis) }\end{array}$ & $\mathrm{RD}$ & $\begin{array}{l}\text { Dechlorination of a compound where the compound is used as an } \\
\text { electron acceptor, the bacteria may or may not gain energy by } \\
\text { reduction of the compound. This reaction removes one chloride } \\
\text { atom from the compound and replaces it with a proton. }\end{array}$ \\
\hline
\end{tabular}

As an alternative to defining fixed spatial zones of activity, a reaction module is provided for first-order dechlorination of chlorinated ethenes by natural attenuation processes where the pathways and rates of transformation are dependent on the oxidation-reduction (redox) conditions. In the presence of oxygen, the reaction module allows aerobic dechlorination of DCE isomers and VC to occur. However, the presence of oxygen or nitrate inhibits the anoxic/anaerobic dechlorination pathways of the reaction module. At low oxygen concentrations, the dominant redox condition for the reaction module is determined based on the concentrations of the three key redox couples: iron (ferrous iron/amorphous ferric hydroxide), 
sulfur (sulfate/sulfide), and methane (methane/ $\mathrm{CO}_{2}$ ). Note that this reaction module does not perform full geochemical equilibrium calculations, but provides a simplified framework to represent the oxidation-reduction conditions in the aquifer. Tracking the redox conditions based on the oxygen, nitrate, iron, sulfur, and methane geochemical indicator species allows the user to model a continuum of reaction regimes whose spatial extent may vary over time as the redox conditions change. Alternately, this reaction module can use a fixed (temporally constant) spatial distribution of dechlorination activity that is defined based on the initial concentrations for the geochemical indicator species.

This redox-dependant reaction module is founded on the assumption that the redox conditions (determined from the key redox couples) control the dechlorination reaction rate. Based on the premise that degradation under natural attenuation conditions occurs as a result of the activity of a widely distributed and essentially constant low concentration population of indigenous bacteria, this reaction module does not track microbial growth. The bacterial species that are active, and hence the rate at which dechlorination occurs, is assumed to be dependent on the geochemical conditions. If sufficient substrate is present at a site to drive bacterial growth dynamics, other reaction modules that consider biomass growth and subsequent impacts to dechlorination rate (e.g., substrate-linked dechlorination) should be used.

Two reaction modules are provided for enhanced attenuation (or accelerated in situ bioremediation). Biostimulation through addition of a readily fermentable substrate is a common approach to increase the dechlorination rates. The substrate-linked reaction module provides a method for modelling the biodegradation rate of chlorinated ethenes as a function of the amount of biomass that grows on the supplied substrate. The substrate is represented by lactate, which may be fermented to propionate, acetate, and hydrogen by fermenting bacteria. Methanogenic bacteria, growing on acetate and hydrogen, drive the reductive dechlorination of the chlorinated ethenes in this reaction module.. Because the anaerobic dechlorination reaction rates are linked to the microbial population, the rates are inherently based on a spatially variable continuum. Aerobic direct metabolism of DCE and VC is represented using first-order rate expressions

The other enhanced attenuation $\mathrm{RT} 3 \mathrm{D}$ reaction module is aerobic cometabolism of chlorinated ethenes (excluding PCE). Cometabolic chlorinated ethene degradation in this reaction module is dependent on the concentration of the chlorinated ethene compound and the concentration of methanotrophic bacteria, is inhibited by methane, requires oxygen, and deactivates biomass (i.e., the module indirectly accounts for destruction of the monooxygenase enzyme by the chlorinated ethene degradation intermediate epoxide compounds). Methanotroph biomass growth occurs in response to the availability of methane and oxygen. As with the substrate-linked reaction module, the dechlorination reaction rates are implicitly spatially variable because of the dependence on the biomass concentration. 


\subsection{RT3D MNA/EA Reaction Module Commonalities}

Although the MNA/EA reaction modules discussed in this document represent different reaction kinetics, they share certain common features/concepts. These common features are presented in this section.

Every MNA/EA reaction module described in this document is configured for chemical species concentrations in units of $\mathrm{mg} / \mathrm{L}$, although the actual kinetic equations are typically based on moles instead of mass. Reaction parameters are requested in convenient units and are internally converted to a molar basis where required.

All of these MNA/EA reaction modules include a conservative tracer as one of the tracked chemical species. This allows the user to assess non-reactive transport without completing a separate model configuration and simulation run. Information on the transport of a conservative tracer can be useful, for example, in the calibration of a model or in assessing "what if" scenarios.

Transformation/degradation reactions of the contaminants (biotic and abiotic) are assumed to occur only for the aqueous phase (dissolved) contaminant mass in all of these MNA/EA reaction modules. Thus, there is no degradation of the sorbed contaminant. This is a conservative assumption in terms of being protective of groundwater receptors. If sorbed-phase contaminant mass is actually degraded for a particular site, then these reaction modules will under predict the rate of mass loss, resulting in a longer transport distance and a longer remediation timeframe (depending on the extent of contaminant partitioning to the soil). Modifications to these reaction modules could be completed to provide a user-defined reaction module that explicitly tracks sorbed-phase contaminants and allows the sorbed phase contaminants to be degraded. Note that this assumption of reaction only for dissolved phase contaminant mass does not imply anything about the nature of the microbial population mediating the degradation (i.e., it does not imply that only aqueous phase microbes act on contaminants while attached microbes do nothing). However, the two Enhanced Attenuation reaction modules explicitly track microbial biomass as attached (immobile) constituents, ignoring the effects of any free-living (suspended) bacteria. While not included in these reaction modules, the impact of attached versus free-living bacteria is an area of ongoing research [e.g., Harvey and Barber, 1992; Holm et al., 1992; Doong et al., 1997; Lehman et al., 2001; Yolcubal et al., 2002; Painter et al., 2005] that could be explored through a user-defined reaction module.

For internal program consistency, the reaction parameters for these MNA/EA reaction modules must be specified in a model configuration as being either all spatially constant or all spatially variable. To implement spatial variability, reaction parameters are allowed to vary within the full 3D reactive transport model domain on a grid cell by grid cell basis. 
These RT3D MNA/EA reaction modules provide a framework for modelling the reaction kinetics at a particular site. Site-specific knowledge from field data and/or laboratory tests should be applied to determine an appropriate model configuration for reaction parameter values. In the absence of site-specific information, generic data or ranges of values from the open literature may be acceptable, but the potential impact of such non-site-specific data on the model output should be discussed.

\subsection{Discussion of Select Reaction Parameters}

Stoichiometric dechlorination yields and reaction rate constants are reaction parameters that are used throughout the MNA/EA reaction modules. Other reaction parameters (such as Monod half saturation constants, inhibition constants, etc.) are more specific to the kinetic formulations of particular reaction modules. The document sections for individual reaction modules include information on all reaction parameters required for that reaction module, but the more common kinds of reaction parameters are described here to give a general sense of the purpose of the parameters.

Stoichiometric dechlorination yields are used in the reaction kinetics to represent the mole fraction of a product (daughter species) produced for every mole of reactant (parent) species transformed by a specific process (i.e., anaerobic dechlorination or abiotic degradation). Stoichiometric yields are constrained to sum up to 1.0 for reaction of a given parent species by a particular type of process. Note however, that some stoichiometric yield values may not be included as a user-specified reaction parameter because the daughter species (e.g., $\mathrm{CO}_{2}$ ) is not explicitly tracked. While all pathways in Figure 2 are possible, some may not occur at a particular site, in which case the stoichiometric dechlorination yield is assigned a value of zero for the inactive pathway. Truex et al. [2002a] provide an example (in a user-defined reaction module) where reductive dechlorination pathways for 1,1,2,2-TeCA and 1,1,2-TCA were not included because those pathways were not observed in microcosm tests with site sediment and groundwater. In cases where there is only one reaction pathway (e.g., reductive dechlorination of PCE to TCE), the stoichiometric dechlorination yield is fixed internal to the reaction module at a value of 1.0 (i.e., the value cannot be altered by the user in the model configuration).

As an example of stoichiometric dechlorination yields, consider dechlorination of 1,1,2-TCA, which may be dechlorinated by both anaerobic and abiotic processes. Table 4 shows the calculated stoichiometric dechlorination yields for a scenario in which a total of 1.5 moles of 1,1,2-TCA are transformed to daughter products in the stated amounts (columns 1 and 2). This type of data (used to determine the stoichiometric dechlorination yield) is typically collected from site-specific microcosms or from literature data. For a microcosm test, the stoichiometric dechlorination yields would be determined along with the site-specific reaction rates by adjusting parameters to fit microcosm data from multiple experiments (i.e., differing conditions, not just replicates). 
Table 4. Example of Stoichiometric Dechlorination Yield Resulting From

Transformation of 1.5 Moles of 1,1,2-TCA

\begin{tabular}{|c|c|c|c|c|}
\hline $\begin{array}{c}\text { Daughter } \\
\text { Species }\end{array}$ & $\begin{array}{c}\text { Moles } \\
\text { Produced }^{\mathrm{a}}\end{array}$ & $\begin{array}{c}\text { Reaction } \\
\text { Type }^{\mathrm{b}}\end{array}$ & $\begin{array}{c}\text { Calculated Stoichiometric } \\
\text { Dechlorination Yield } \\
(\mathrm{mol} / \mathrm{mol})\end{array}$ & Comments \\
\hline cis-DCE & 0.36 & abiotic (AE) & $F a b_{c D C E / 12 T C A}=0.6$ & \multirow{3}{*}{$\begin{array}{l}\text { Sum of Yield } \\
\text { equals } 100 \%\end{array}$} \\
\hline trans-DCE & 0.24 & abiotic (AE) & $F a b_{\triangle D C E / 112 T C A}=0.4$ & \\
\hline 1,1-DCE & 0.0 & abiotic (AE) & $F a b_{11 D C E / 111 T C A}=0.0$ & \\
\hline 1,2-DCA & 0.18 & anaerobic (RD) & Fan $_{11 D C A / 111 T C A}=0.2$ & \multirow{2}{*}{$\begin{array}{l}\text { Sum of Yield } \\
\text { equals } 100 \%\end{array}$} \\
\hline $\mathrm{VC}$ & 0.72 & anaerobic (DC) & $F a n_{V C / 112 T C A}=0.8$ & \\
\hline
\end{tabular}

a These are purely arbitrary numbers for use in this example.

b See Table 3 for a list of reaction types and abbreviations.

As with the stoichiometric dechlorination yields, the reaction rates are generally site specific, although abiotic reaction rates may tend to be more consistent from site to site. Abiotic reaction rates are primarily dependent on the temperature and $\mathrm{pH}$ of the groundwater, while biotic reaction rates are a function of the microbial population and geochemical setting. Many of the reactions in these reaction modules assume that the biological (and abiotic) dechlorination rates can be modeled as first-order processes, implying that the biomass concentration stays constant and electron donor concentration is low (both reasonable assumptions for a MNA site). See the section on the Mixed Chloroethene/Chloroethane/Chloromethane Dechlorination reaction module for further discussion of first-order reaction kinetics.

Dechlorination rates for reactant species are determined from the overall rate at which the compound is decaying under defined conditions, coupled with the amounts of product species that are produced. Field data may be used to determine reaction rates, depending on the history of site activities and how well the subsurface is understood in terms of groundwater flow, dispersion, and adsorption. Laboratory microcosm data from multiple experiments with differing initial conditions can be used to fit the reaction rate parameters and the stoichiometric dechlorination yields. Laboratory microcosm experiments with site sediment and groundwater are useful to examine the reaction kinetics without the convoluting influences of contaminant transport processes (e.g., advection and dispersion). Typically the resultant set of reaction rate parameter values from this calibration against microcosm data will be higher than the rates seen in the field because of differences in the soil/water ratio, temperature, and the disturbed/undisturbed nature of the sediment. However, it may be reasonable to assume that the relative rates of different reaction processes (e.g., the rate of CT transformation relative to the 
rate of CF transformation) consistent between the laboratory and the field. It is then necessary as part of the calibration process for the full three-dimensional reactive transport model to estimate if and what magnitude of a correction factor between the laboratory-derived rates and the rates in the field is required.

Several reaction modules use Monod half saturation constants (e.g., $\mathrm{K}_{\mathrm{s}}$ ) and/or inhibition coefficients (e.g., $\mathrm{k}_{\mathrm{is}}$ ) in the functional forms shown in Equations 1 and 2 for Monod and inhibition terms, respectively. The constants represent the point in a hyperbolic curve where the ordinate has a value of 0.5 . Figure 3 shows example curves (with arbitrary data) for a Monod term and an inhibition term, both with constants of 5.0. These terms are used as multipliers on the kinetic equations regarding bacterial growth rate or dechlorination rate. The Monod term is typically used to account for nutrient limitations - as the concentration of a nutrient decreases, the rate of reaction will decrease. Conversely, the inhibition term restricts the rate of reaction as the concentration of an inhibiting species increases. Lu et al. [1999] provide an example usage of these types of terms for modelling BTEX biodegradation.

$$
\begin{aligned}
& \text { Monod Term } \Rightarrow \frac{[\text { Species }]}{K_{s}+[\text { Species }]} \\
& \text { Inhibition Term } \Rightarrow \frac{k_{i s}}{k_{i s}+[\text { Species }]}
\end{aligned}
$$

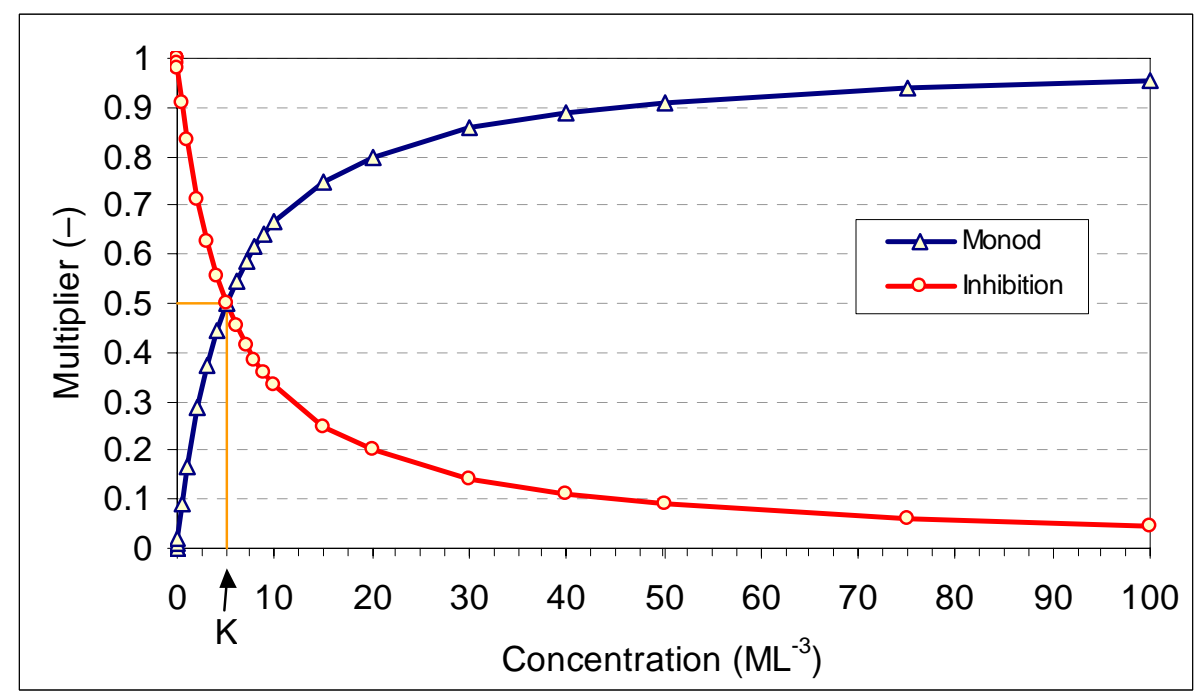

Figure 3. Arbitrary Examples of the Curves Obtained for Monod and Inhibition Terms These terms are typically used as multipliers on the reaction rate to account for nutrient limitations and inhibition effects, respectively. 
Reaction parameters may be defined as spatially constant or spatially variable, depending on site conditions and the available information. For instance, if multiple geochemical settings (as discussed in Johnson et al. [2006]) are identified within the model domain, the parameters in one area can be set to different values than for another area. Reaction parameter values can vary spatially because of differences in geochemistry (e.g., concentrations/types of electron acceptors, anaerobic/anoxic/aerobic setting), temperature, substrate availability, and microbial population (in terms of both numbers of bacteria and types of bacteria). Field-scale geochemical data can be used to assign spatially variable reaction rates to account for variations in biological activity resulting from differences in, for example, substrate or electron acceptor concentrations. Alternately, laboratory microcosm data from different areas of a site may suggest different reaction rates/processes.

Where a reaction pathway is inappropriate for a given spatial location, the dechlorination rate and/or the stoichiometric dechlorination yield for that pathway can be set to zero. Alternately, a specific location may exhibit the reaction pathway, but at a slower rate than another location. Figure 4 shows an example of a reactive transport model having four different reaction zones. In this example, the "Anaerobic Zone-1" has a high anaerobic dechlorination rate and no aerobic reactions occur, "Anaerobic Zone-2" has a lower anaerobic dechlorination rate and no aerobic reactions occur, the "Transition Zone" has a low rates for both anaerobic and aerobic processes, and in the "Aerobic Zone" there is a high rate of aerobic dechlorination and zero anaerobic dechlorination. See Clement et al. [2000] and Johnson et al. [2003a] for examples of applying this zonal approach to specifying reaction parameter values for reactive transport models of actual field sites.

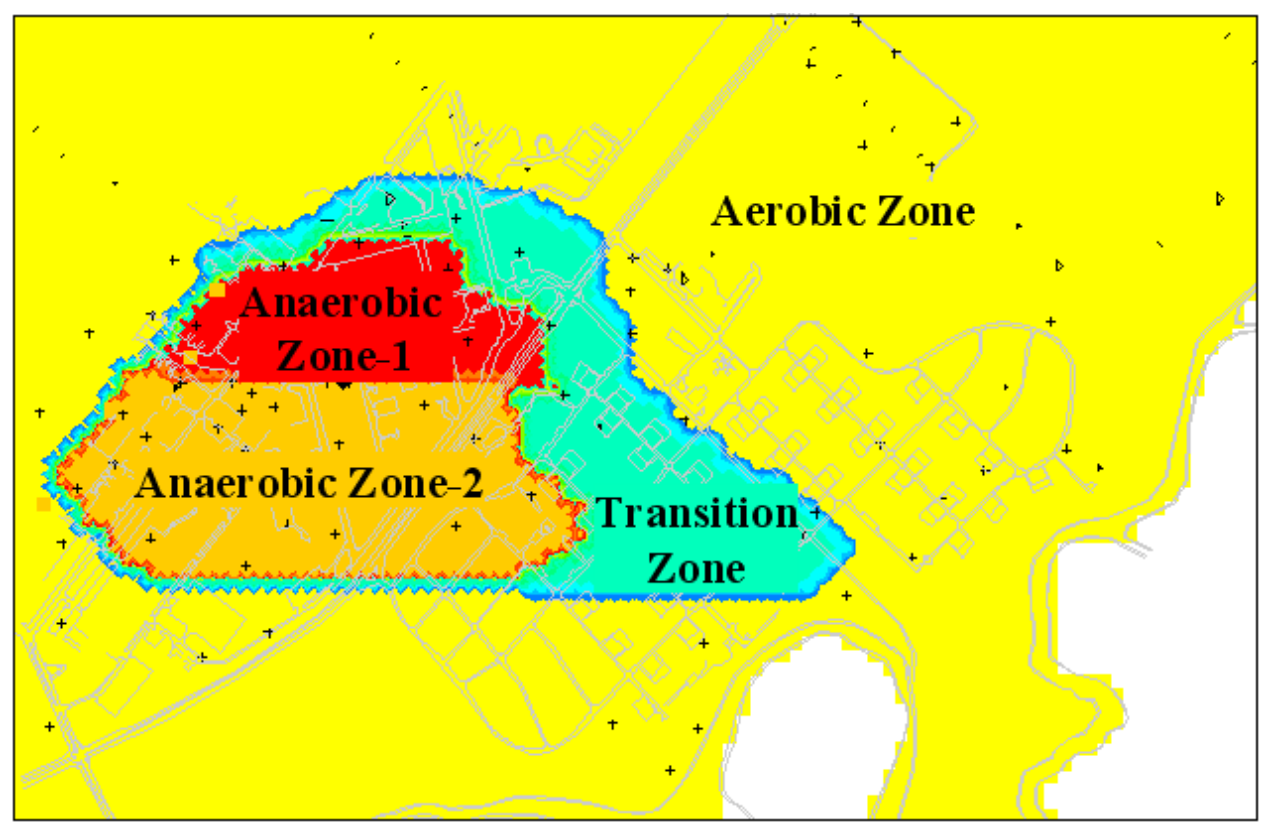

Figure 4. Example of a Reactive Transport Model Having Multiple Reaction Zones, Each with Differing Reaction Parameter Values - Figure adapted from Clement et al. [2000]. 


\subsection{Important Considerations for Using the RT3D MNA/EA Reaction Modules}

The RT3D MNA/EA reaction modules described in this document were developed to provide ready access to more complex reaction scenarios that may be of interest for monitored natural attenuation or enhanced attenuation modelling evaluations. Each of these reaction modules has a clearly stated set of kinetic expressions and associated reaction parameters that incorporate certain assumptions and define one specific approach to representing the stated scenario. In some ways, these reaction modules were designed to provide flexibility in modelling potential complex reaction kinetics. For example, the Dechlorination of 1,1,2,2-Tetrachloroethane and Chloroethenes reaction module includes many reaction pathways, but some number of those pathways may not be needed for a particular site while they are at yet another site. In other ways, the reaction modules represent specific conceptual models, such as the assumption of firstorder kinetics (e.g., Mixed Chloroethene/Chloroethane/Chloromethane Dechlorination) or the linkage of dechlorination rates to the rate of methanogenesis (Substrate-Linked Reductive Dechlorination of Chloroethenes). The user should read this document and fully understand the scope of a given reaction module, including the assumptions and limitations corresponding to the conceptual model/approach. The approach taken here for a given reaction module is only one way of addressing a reaction scenario and may or may not be appropriate for any specific site. It is incumbent on the practitioner to assess the suitability of any RT3D reaction module for a particular application. Additionally, testing and validation of the reaction modules is not included in this report and is the responsibility of the module user.

The descriptions of the MNA/EA reaction modules are written to explain the kinetic expressions that are used in the modules and are in no way intended to imply or assert that these approaches are the "right" or "best" way to represent the reaction kinetics. However, the authors propose that these reaction modules may be useful for MNA/EA at some sites. Indeed, the authors have successfully used prototypes of several of these reaction modules at field sites. A prototype of the Dechlorination of 1,1,2,2-Tetrachloroethane and Chloroethenes reaction module was used to evaluate MNA for a multicomponent dissolved-phase contaminant plume at a National Priorities List site in Louisiana [Truex et al., 2002; Spencer et al., 2002]. Design of an anaerobic accelerated in situ bioremediation system at a U.S. Navy facility in California [Johnson et al., 1999; Leigh et al., 2000] was completed with a prototype of the Substrate-Linked Reductive Dechlorination of Chloroethenes reaction module. The rate of vinyl chloride degradation by anaerobic processes at this U.S. Navy facility was determined to be too slow for the site objectives, thus a prototype of the Cometabolic Aerobic Dechlorination of Chloroethenes reaction module was used to design an aerobic accelerated in situ bioremediation system [Truex et al., 2002b; Johnson et al., 2003b] for sequential anaerobic/aerobic treatment of the site.

In addition to prototype kinetic formulations, the basis of the MNA/EA reaction modules also included literature information and simplified conceptual models to describe the impact of complex processes such as geochemistry on dechlorination. The five RT3D MNA/EA reaction 
modules using first-order reaction kinetic expressions to model dechlorination were configured based on a review of literature to define potential dechlorination reaction mechanisms [Johnson et al., 2006]. The literature review was not intended to be exhaustive, but provides examples of laboratory information that is available to describe the reaction pathways. In the Redox-Linked Dechlorination of Chloroethenes reaction module, the rate of dechlorination is adjusted based on a simplified framework to represent the oxidation-reduction conditions in the aquifer. This module enables the user to link dechlorination rate to the concentration of geochemical indicator species. The module is not a full geochemical model, but provides one potential means for the user to model dechlorination at sites where the oxidation-reduction conditions in the aquifer are spatially or temporally variable. While there are multiple ways to model substrate-linked reductive dechlorination, the Substrate-Linked Reductive Dechlorination of Chloroethenes reaction module specifically links the dechlorination rate to the activity of methanogenic bacteria, similar to Skeen et al. [1995]. The activity of methanogenic bacteria in this reaction module is dependent on the availability of acetate and hydrogen produced from the fermentation of lactate and propionate by other bacteria. The Cometabolic Aerobic Dechlorination of Chloroethenes reaction module uses kinetic expressions from the scientific literature [e.g., Semprini et al., 1991; Alvarez-Cohen and McCarty, 1991; Chang and Alvarez-Cohen, 1996] that describe the cometabolic degradation process with inhibition by methane and with the toxicity effect of the intermediate degradation product on the methanotrophic bacteria.

Example results representing reaction in a batch reactor are provided in this document for all of the MNA/EA reaction modules. These examples demonstrate that the expected behavior is observed under selected conditions. However, it was beyond the scope of the development effort to rigorously test these MNA/EA reaction modules and benchmark them against other numerical codes, analytical solutions, or existing field data. This exercise is left to the practitioner as part of the assessment whether these reaction modules are appropriate for a particular site. The authors intend that future efforts will address these testing and validation issues.

If the conceptual model and/or kinetic expressions of an RT3D reaction module are deemed insufficient or unsuitable for application at a given site, then the user has the option of writing a user-defined reaction module to provide the desired configuration of the kinetic expressions. The user may find that an existing reaction module can serve as a convenient starting point for making modifications. For example, additional reaction mechanisms/pathways that are not currently included in the Mixed Chloroethene/Chloroethane/Chloromethane Dechlorination reaction module may be identified in the future as valid degradation routes, and the Mixed Chloroethene/Chloroethane/Chloromethane Dechlorination reaction module could be supplemented with the new pathway(s) to form a user-defined reaction module. The RT3D manual [Clement, 1997] and version 2.5 update document [Clement and Johnson, 2002] provide information on assembling a user-defined reaction module. Alternately, the authors can be contacted for assistance in developing a new reaction module. 


\subsection{Mixed Chloroethene/Chloroethane/Chloromethane Dechlorination}

\subsection{Conceptual Model for Dechlorination Reactions}

This reaction module describes dechlorination of chloroethanes, chloroethenes, chloromethanes, and related daughter products using first-order rate expressions. The module includes abiotic, aerobic, and anoxic/anaerobic reaction pathways, which the user may selectively turn off by setting the (spatially variable) values of the stoichiometric yields and/or the reaction rate constants to zero. See the section on RT3D MNA/EA Reaction Module Commonalities and the Discussion of Select Reaction Parameters for additional information on features common to all of these MNA/EA reaction modules and explanation of key reaction parameters.

Table 5 lists the chemical species included in this reaction module. Figure 5 shows the conceptual model describing the potential biotic and abiotic degradation pathways of both chlorinated ethene and chlorinated ethane contaminants.

The reaction pathways included in this reaction module are based on a review of literature on dechlorination reaction mechanisms for the chlorinated solvents of interest [Johnson et al., 2006]. The literature review was not intended to be exhaustive, but provides examples of laboratory information that is available to describe the reaction pathways. For convenience, a select set of references that discuss abiotic and biotic reaction pathways for chlorinated solvents are noted in this document [Mabey and Mill, 1978; Vogel et al., 1987; Jeffers et al., 1989; Washington, 1995; Chen et al., 1996; Jeffers et al., 1996; Jeffers and Wolfe, 1996; Lorah and Olsen, 1999; Truex et al., 2001; De Wildeman and Verstraete, 2003; Lorah and Voytek, 2004; Hunkeler et al., 2005]. To make this reaction module more flexible and general, several pathways that were not directly supported by laboratory data in the open literature are included (Table 6). The reaction network does not include heterogeneous abiotic reactions or abiotic reactions with half-lives of more than 200 years. Because this reaction module targets MNA conditions, non-contaminant substrate concentrations are assumed to be low enough that cometabolism pathways (aerobic or anaerobic) should not be included. If reaction mechanisms/pathways that are not currently included in this reaction module are identified as valid or important degradation routes, then such pathways could be included in a user-defined reaction module based on the Mixed Chloroethene/Chloroethane/Chloromethane Dechlorination reaction module. 
Table 5. Chemical Species Included in the Mixed Chloroethene/Chloroethane/Chloromethane Dechlorination Reaction Module

\begin{tabular}{|c|c|c|c|c|c|c|}
\hline No. & Abbreviation ${ }^{a}$ & Chemical Name & Selected Alternate Name & $\begin{array}{c}\text { CAS }^{\mathbf{b}} \\
\text { Registry } \\
\text { Number }\end{array}$ & $\begin{array}{l}\text { Molecular } \\
\text { Weight }^{c} \\
(\mathrm{~g} / \mathrm{mol})\end{array}$ & $\begin{array}{l}\text { Chemical } \\
\text { Formula }\end{array}$ \\
\hline 1 & $1122 \mathrm{TeCA}$ & 1,1,2,2-Tetrachloroethane & $1,1,2,2-\mathrm{TeCA}$ & $79-34-5$ & 167.84928 & $\mathrm{C}_{2} \mathrm{H}_{2} \mathrm{Cl}_{4}$ \\
\hline 2 & $112 \mathrm{TCA}$ & 1,1,2-Trichloroethane & $\begin{array}{l}\text { Vinyl Trichloride; } \\
\text { 1,1,2-TCA }\end{array}$ & $79-00-5$ & 133.40422 & $\mathrm{C}_{2} \mathrm{H}_{3} \mathrm{Cl}_{3}$ \\
\hline 3 & $12 \mathrm{DCA}$ & 1,2-Dichloroethane & $\begin{array}{l}\text { Ethane Dichloride; } \\
\text { 1,2-DCA }\end{array}$ & $107-06-2$ & 98.95916 & $\mathrm{C}_{2} \mathrm{H}_{4} \mathrm{Cl}_{2}$ \\
\hline 4 & $\mathrm{CA}$ & Chloroethane & Ethyl Chloride & $75-00-3$ & 64.5141 & $\mathrm{C}_{2} \mathrm{H}_{5} \mathrm{Cl}$ \\
\hline 5 & $1112 \mathrm{TeCA}$ & 1,1,1,2-Tetrachloroethane & $1,1,1,2-\mathrm{TeCA}$ & $630-20-6$ & 167.84928 & $\mathrm{C}_{2} \mathrm{H}_{2} \mathrm{Cl}_{4}$ \\
\hline 6 & 111TCA & 1,1,1-Trichloroethane & 1,1,1-TCA & $71-55-6$ & 133.40422 & $\mathrm{C}_{2} \mathrm{H}_{3} \mathrm{Cl}_{3}$ \\
\hline 7 & 11DCA & 1,1-Dichloroethane & 1,1-DCA & $75-34-3$ & 98.95916 & $\mathrm{C}_{2} \mathrm{H}_{4} \mathrm{Cl}_{2}$ \\
\hline 8 & PCE & Tetrachloroethene & $\begin{array}{l}\text { Tetrachloroethylene; } \\
\text { Perchloroethylene }\end{array}$ & $127-18-4$ & 165.8334 & $\mathrm{C}_{2} \mathrm{Cl}_{4}$ \\
\hline 9 & TCE & Trichloroethene & Trichloroethylene & $79-01-6$ & 131.38834 & $\mathrm{C}_{2} \mathrm{HCl}_{3}$ \\
\hline 10 & $\mathrm{cDCE}$ & cis-1,2-Dichloroethene & $\begin{array}{l}\text { cis-1,2-Dichloroethylene; } \\
\text { cis-1,2-DCE; cis-DCE }\end{array}$ & $156-59-2$ & 96.94328 & $\mathrm{C}_{2} \mathrm{H}_{2} \mathrm{Cl}_{2}$ \\
\hline 11 & tDCE & trans-1,2-Dichloroethene & $\begin{array}{l}\text { trans-1,2-Dichloroethylene; } \\
\text { trans-1,2-DCE; trans-DCE }\end{array}$ & $156-60-5$ & 96.94328 & $\mathrm{C}_{2} \mathrm{H}_{2} \mathrm{Cl}_{2}$ \\
\hline 12 & $11 \mathrm{DCE}$ & 1,1-Dichloroethene & $\begin{array}{l}\text { 1,1-Dichloroethylene; } \\
\text { Vinylidene Chloride; } \\
\text { 1,1-DCE }\end{array}$ & $75-35-4$ & 96.94328 & $\mathrm{C}_{2} \mathrm{H}_{2} \mathrm{Cl}_{2}$ \\
\hline 13 & $\mathrm{VC}$ & Chloroethene & $\begin{array}{l}\text { Vinyl Chloride; } \\
\text { Chloroethylene }\end{array}$ & $75-01-4$ & 62.49822 & $\mathrm{C}_{2} \mathrm{H}_{3} \mathrm{Cl}$ \\
\hline 14 & CT & Tetrachloromethane & Carbon Tetrachloride & $56-23-5$ & 153.82270 & $\mathrm{CCl}_{4}$ \\
\hline 15 & $\mathrm{CF}$ & Trichloromethane & Chloroform & $67-66-3$ & 119.37764 & $\mathrm{CHCl}_{3}$ \\
\hline 16 & DCM & Dichloromethane & $\begin{array}{l}\text { Methylene Dichloride, } \\
\text { Methylene Chloride }\end{array}$ & $75-09-2$ & 84.93258 & $\mathrm{CH}_{2} \mathrm{Cl}_{2}$ \\
\hline 17 & $\mathrm{CM}$ & Chloromethane & Methyl Chloride & $74-87-3$ & 50.48752 & $\mathrm{CH}_{3} \mathrm{Cl}$ \\
\hline 18 & Tracer & Conservative Tracer & - & N/A & $\mathrm{N} / \mathrm{A}$ & $\mathrm{N} / \mathrm{A}$ \\
\hline
\end{tabular}

a These abbreviations refer to the specific chemicals listed here and should not be confused with different chemicals that may use the same abbreviation in other reaction modules.

${ }^{\text {b }} \mathrm{CAS}=$ Chemical Abstracts Service (see http://www.cas.org/EO/regsys.html)

c Based on International Union of Pure and Applied Chemistry values reported by Loss [2003].

N/A - Not Applicable 


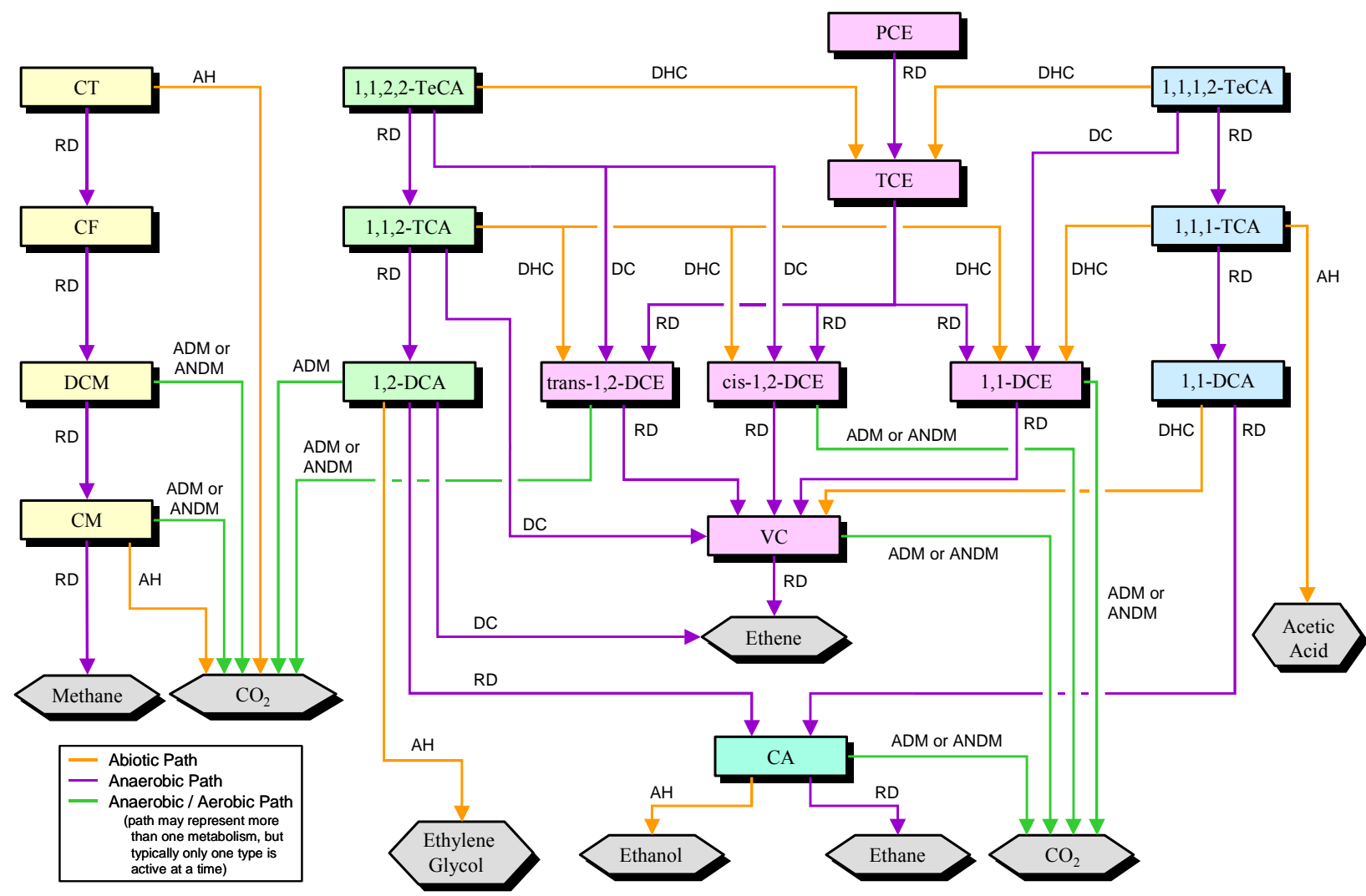

Figure 5. Conceptual Model for Dechlorination Reactions in the Mixed Chloroethene/ Chloroethane/Chloromethane Dechlorination Reaction Module - Species in hexagonal shaded boxes are innocuous products and are not tracked in the reaction module. The reaction types for each pathway are described in Table 3.

Table 6. Reaction Pathways Without Laboratory Data in the Open Literature, but Which Are Included in the RT3D MNA/EA First-Order Reaction Modules

\begin{tabular}{|c|c|c|c|c|}
\hline \multicolumn{3}{|c|}{ Reaction Pathway } & \multirow{2}{*}{$\begin{array}{c}\begin{array}{c}\text { Reaction } \\
\text { Process }\end{array} \\
\text { ANDM }\end{array}$} & \multirow[b]{2}{*}{$\begin{array}{l}\text { Potential pathway because ANDM occurs for cis/trans-1,2- } \\
\text { DCE. }\end{array}$} \\
\hline 1,1-DCE & $\rightarrow$ & $\mathrm{CO}_{2}$ & & \\
\hline $\mathrm{CA}$ & $\rightarrow$ & $\mathrm{CO}_{2}$ & $\mathrm{ADM}$ & Probable, but not documented pathway based on ADM of VC. \\
\hline $\mathrm{CA}$ & $\rightarrow$ & $\mathrm{CO}_{2}$ & ANDM & $\begin{array}{l}\text { Probable, but not documented pathway based on ANDM of } \\
\text { VC. }\end{array}$ \\
\hline $1,1,12,2-\mathrm{TeCA}$ & $\rightarrow$ & $1,1,1-\mathrm{TCA}$ & $\mathrm{RD}$ & $\begin{array}{l}\text { This pathway is listed as a presumptive degradation route in the } \\
\text { literature review figures [Johnson et al., 2006] despite the lack } \\
\text { of laboratory data in the open literature. }\end{array}$ \\
\hline $\mathrm{CM}$ & $\rightarrow$ & $\mathrm{CH}_{4}$ & $\mathrm{RD}$ & $\begin{array}{l}\text { This pathway is listed as a presumptive degradation route in the } \\
\text { literature review figures [Johnson et al., 2006] despite the lack } \\
\text { of laboratory data in the open literature. }\end{array}$ \\
\hline
\end{tabular}


The kinetic relations for the reactions in this reaction module were developed by assuming that the dechlorination kinetics can be approximated as first-order reactions. Some previous studies have shown that first-order kinetics can be reasonable for modeling dechlorination mechanisms at field scales [e.g., U.S. EPA, 1998; Clement et al., 2000] and at low concentrations [Schmidt et al., 1985]. Yet other studies [e.g., Scow et al., 1986] have determined that first-order kinetics were not appropriate. A number of factors (substrate concentration, microbial population density, etc.) can impact the type of model (first-order, Monod, logistic, etc.) that best represents biodegradation of a chemical [Simkins and Alexander, 1984; Alexander, 1985; Schmidt et al., 1985]. The first-order assumption should be assessed [e.g., Bekins et al., 1998] as part of the determination of whether the reaction module is suitable for the intended application.

First-order kinetics express the biodegradation rates as being primarily a function of the concentration of the contaminant. Implicit to the assumption of first-order kinetics is that the microbial population is nongrowing, i.e., the substrate concentration is much less than the Monod half saturation constant. First-order kinetics do not have an explicit dependence on the type or concentration of electron donor, the type or quantity of bacteria present, nutrient limitations, or the geochemical conditions. All of these factors should be evaluated prior to selecting a first-order model to represent biodegradation. Additionally, this reaction module does not include a provision for inhibition by the contaminants; the contaminants are assumed to be present at less than inhibitory concentrations.

If a biostimulation or bioaugmentation technique is used at a site (increasing the quantity of subsurface bacteria) then the assumptions associated with first-order kinetics may not be valid and the user should apply something along the lines of one of the EA reaction modules.

\subsection{Reaction Equations}

The set of ODEs comprising this reaction module are shown in Equations 3 to 20. These ODEs describe the reaction kinetics for the 18 chemical species in Table 5. See Table 7 for a detailed itemization of all reaction parameters used in this reaction module.

$$
\begin{aligned}
& \frac{d C_{1122 T e C A}}{d t}=\left(-k_{1122 n_{12 C A}} \cdot C_{1122 T e C A}-k a b_{1122 T e C A} \cdot C_{1122 T e C A}\right) \\
& \frac{d C_{1112 T e C A}}{d t}=\left(-k_{1112 n_{12 C A}} \cdot C_{1112 T e C A}-k a b_{1112 T e C A} \cdot C_{1112 T e C A}\right) \\
& \frac{d C_{112 T C A}}{d t}=\left(Y_{\frac{112 T C A}{1122 T e C A}} \cdot F \frac{112 T C A}{1122 T e C A} \cdot \operatorname{kan}_{1122 T e C A} \cdot C_{1122 T e C A}-k a n_{112 T C A} \cdot C_{112 T C A}-k a b_{112 T C A} \cdot C_{112 T C A}\right)
\end{aligned}
$$




$$
\begin{aligned}
& \frac{d C_{111 T C A}}{d t}=\left(Y_{\frac{111 T C A}{1112 T e C A}} \cdot F a n_{\frac{111 T C A}{1112 T e C A}} \cdot \mathrm{kan}_{1112 T e C A} \cdot C_{1112 T e C A}-k_{111 T C A} \cdot C_{111 T C A}-k a b_{111 T C A} \cdot C_{111 T C A}\right) \\
& \frac{d C_{12 D C A}}{d t}=\left(\begin{array}{l}
\frac{Y_{12 D C A} \cdot F^{112 T C A}}{\frac{12 D C A}{112 T C A}} \cdot \operatorname{kan}_{112 T C A} \cdot C_{112 T C A} \\
\quad-k a n_{12 D C A} \cdot C_{12 D C A}-k a b_{12 D C A} \cdot C_{12 D C A}-k a e_{12 D C A} \cdot C_{12 D C A}
\end{array}\right) \\
& \frac{d C_{11 D C A}}{d t}=\left(\begin{array}{ll}
Y_{11 D C A} \cdot k a n_{111 T C A} \cdot C_{111 T C A} & \\
& -k a n_{11 D C A} \cdot C_{11 D C A}-k a b_{11 D C A} \cdot C_{11 D C A}
\end{array}\right) \\
& \frac{d C_{C A}}{d t}=\left(\begin{array}{c}
Y_{C A} \cdot F_{\frac{C A}{12 D C A}} \cdot \operatorname{kan}_{12 D C A} \cdot C_{12 D C A}+Y_{\frac{C A}{11 D C A}} \cdot k a n_{11 D C A} \cdot C_{11 D C A} \\
-k a n_{C A} \cdot C_{C A}-k a b_{C A} \cdot C_{C A}-k a e_{C A} \cdot C_{C A}
\end{array}\right) \\
& \frac{d C_{P C E}}{d t}=\left(-k a n_{P C E} \cdot C_{P C E}\right) \\
& \frac{d C_{T C E}}{d t}=\left(\begin{array}{c}
Y_{\frac{T C E}{P C E}} \cdot k a n_{P C E} \cdot C_{P C E}+Y_{\frac{T C E}{1122 T e C A}} \cdot k a b_{1122 T e C A} \cdot C_{1122 T e C A} \\
+Y_{\frac{T C E}{1112 T e C A}} \cdot k a b_{1112 T e C A} \cdot C_{1112 T e C A} \\
-k n_{T C E} \cdot C_{T C E}
\end{array}\right) \\
& \frac{d C_{c D C E}}{d t}=\left(\begin{array}{c}
Y_{\frac{D C E}{1122 T e C A}} \cdot F a n_{\frac{c D C E}{1122 T e C A}} \cdot \mathrm{kan}_{1122 T e C A} \cdot C_{1122 T e C A}+Y_{\frac{D C E}{T C E}} \cdot F_{\frac{c D C E}{T C E}} \cdot k_{a n} \cdot C_{T C E} \cdot C_{T C E} \\
+Y_{\frac{D C E}{112 T C A}} \cdot F a b_{\frac{c D C E}{112 T C A}} \cdot k a b_{112 T C A} \cdot C_{112 T C A} \\
-k_{c a n_{c D C E}} \cdot C_{c D C E}-k a e_{c D C E} \cdot C_{c D C E}
\end{array}\right)
\end{aligned}
$$




$$
\frac{d C_{t D C E}}{d t}=\left(\begin{array}{c}
Y_{\frac{D C E}{1122 T e C A}} \cdot F_{\frac{t D C E}{1122 T e C A}} \cdot k a n_{1122 T e C A} \cdot C_{1122 T e C A}+Y_{\frac{D C E}{T C E}} \cdot F_{\frac{t D C E}{T C E}} \cdot k a n_{T C E} \cdot C_{T C E} \\
+Y_{\frac{D C E}{112 T C A}} \cdot F a b_{\frac{t D C E}{112 T C A}} \cdot k a b_{112 T C A} \cdot C_{112 T C A} \\
-k a n_{t D C E} \cdot C_{t D C E}-k a e_{t D C E} \cdot C_{t D C E}
\end{array}\right)
$$

$$
\frac{d C_{11 D C E}}{d t}=\left(\begin{array}{c}
Y_{\frac{D C E}{T C E}} \cdot F_{\frac{11 D C E}{T C E}} \cdot k a n_{T C E} \cdot C_{T C E}+Y_{\frac{D C E}{112 T C A}} \cdot F_{\frac{11 D C E}{112 T C A}} \cdot k a n_{112 T C A} \cdot C_{112 T C A} \\
+Y_{\frac{D C E}{111 T C A}} \cdot F a b_{\frac{11 D C E}{111 T C A}} \cdot k a b_{111 T C A} \cdot C_{111 T C A} \\
+Y_{\frac{D C E}{1112 T e C A}} \cdot F a n_{\frac{11 D C E}{1112 T e C A}} \cdot k a n_{1112 T C C A} \cdot C_{1112 T e C A} \\
-\operatorname{kan}_{11 D C E} \cdot C_{11 D C E}-k_{11 D C E} \cdot C_{11 D C E}
\end{array}\right)
$$

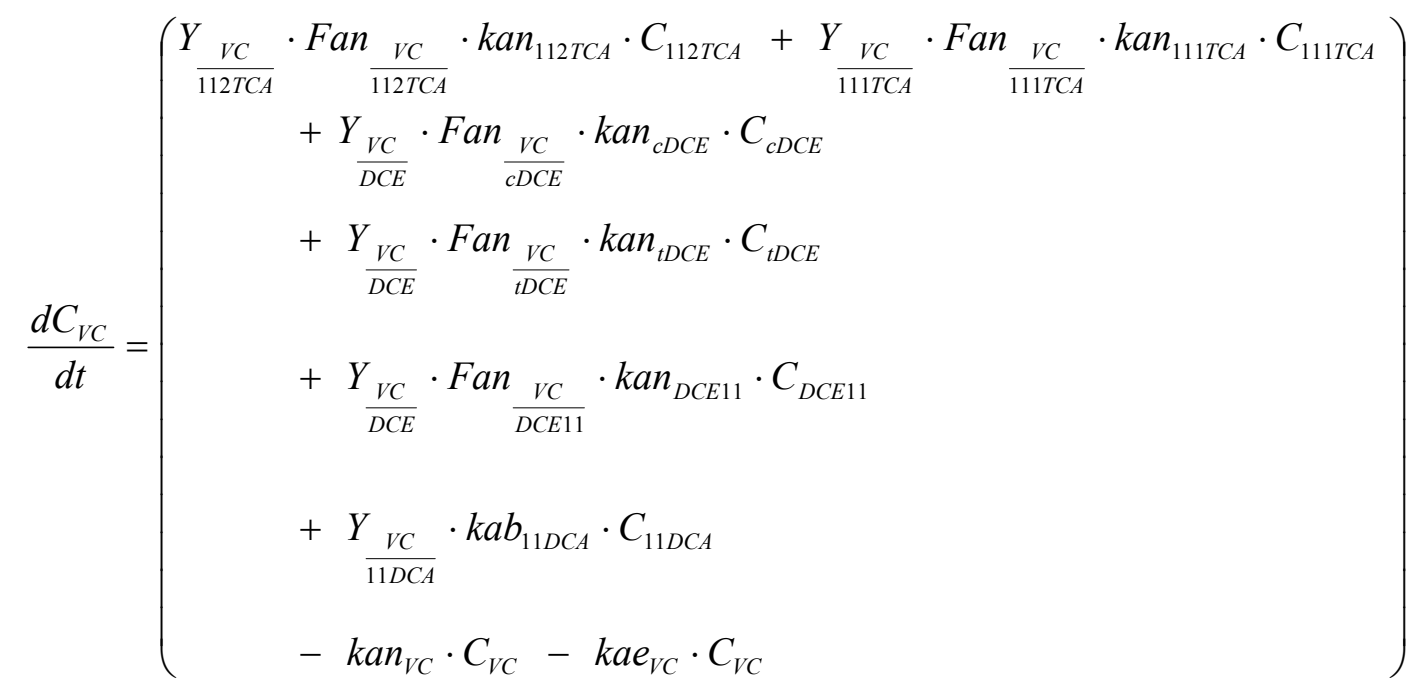

$$
\begin{aligned}
& \frac{d C_{C T}}{d t}=\left(-k_{C T} \cdot C_{C T}-k a b_{C T} \cdot C_{C T}\right) \\
& \frac{d C_{C F}}{d t}=\left(Y_{\frac{C F}{C T}} \cdot k^{2} n_{C T} \cdot C_{C T}-k a n_{C F} \cdot C_{C F}\right)
\end{aligned}
$$




$$
\begin{aligned}
& \frac{d C_{D C M}}{d t}=\left(\begin{array}{c}
\frac{Y_{D C M}}{C F} \cdot k a n_{C F} \cdot C_{C F} \\
-k a n_{D C M} \cdot C_{D C M}-k a e_{D C M} \cdot C_{D C M}
\end{array}\right) \\
& \frac{d C_{C M}}{d t}=\left(\begin{array}{c}
Y_{\frac{C M}{D C M}} \cdot F a n_{\frac{C M}{D C M}} \cdot k a n_{D C M} \cdot C_{D C M} \\
-k a n_{C M} \cdot C_{C M}-k a b_{C M} \cdot C_{C M}-k a e_{C M} \cdot C_{C M}
\end{array}\right) \\
& \frac{d C_{T r a c e r}}{d t}=0.0 \quad \text { (Conservative [non-reactive] tracer.) }
\end{aligned}
$$

The first-order decay rate constants $\left[\mathrm{T}^{-1}\right]$ of the $\mathrm{i}^{\text {th }}$ species are represented in the equations above by the $k_{a n}, k a e_{i}$, and $k a b_{i}$ terms for anaerobic biological reactions, aerobic biological reactions, or abiotic reactions, respectively. The concentration of the $\mathrm{i}^{\text {th }}$ species is represented by the $C_{i}$ term $\left[\mathrm{ML}^{-3}\right]$. The $R_{i}$ terms represent the retardation factor for the $\mathrm{i}^{\text {th }}$ species [unitless].

In cases where multiple daughter products may be produced from dechlorination of a single parent species, the amount of each daughter species that is produced is a function of a mass yield $\left[\mathrm{MM}^{-1}\right]$ and a stoichiometric dechlorination yield [mol/mol]. The mass yield value, $Y_{d / p}$, accounts for the difference in molecular weight between the parent species "p" and the daughter species "d." All isomers of a daughter chemical have the same mass yield. Mass yield values are included in the reaction module code and do not need to be input by the user. The stoichiometric dechlorination yield represents the site-specific stoichiometry for each reaction pathway that occurs as either an anaerobic $\left(F a n_{d / p}\right)$ or an abiotic process $\left(F a b_{d / p}\right)$. The stoichiometric dechlorination yield is the fractional moles of daughter species that are produced by dechlorination of one mole of the parent species. The net yield is the product of the mass yield and the stoichiometric dechlorination yield. To preserve the mass balance, the values of the stoichiometric dechlorination yields are constrained by the relations in Equations 21 to 31 .

$$
\begin{aligned}
& F_{\frac{112 T C A}{1122 T e C A}}+F a n_{\frac{c D C E}{1122 T e C A}}+F a n_{\frac{t D C E}{1122 T e C A}}=1.0 \\
& F a n_{\frac{111 T C A}{1112 T e C A}}+F a n_{\frac{11 D C E}{1112 T e C A}}=1.0 \\
& F a n_{\frac{12 D C A}{112 T C A}}+F a n_{\frac{V C}{112 T C A}}=1.0 \\
& F_{\frac{F_{\frac{c D C E}{T C E}}}{T C}}+\operatorname{Fan}_{\frac{t D C E}{T C E}}+\operatorname{Fan}_{\frac{11 D C E}{T C E}}=1.0
\end{aligned}
$$




$$
\begin{aligned}
& F a b_{\frac{c D C E}{112 T C A}}+F a b_{\frac{t D C E}{112 T C A}}+F a b_{\frac{11 D C E}{112 T C A}}=1.0 \\
& F a b_{\frac{11 D C E}{111 T C A}} \leq 1.0 \\
& \text { Fan }_{\frac{C A}{12 D C A}} \leq 1.0 \\
& \text { Fan }_{\frac{V C}{c D C E}} \leq 1.0 \\
& \text { Fan }_{\frac{V C}{t D C E}} \leq 1.0 \\
& \text { Fan }_{\frac{V C}{11 D C E}} \leq 1.0 \\
& \text { Fan }_{\frac{C M}{D C M}} \leq 1.0
\end{aligned}
$$

\subsection{Required Input}

The reaction parameters for this reaction module are made available to RT3D as part of the input for the Reaction Package. The Reaction Package input file structure is discussed in the RT3D manual and addendum [Clement, 1997; Clement and Johnson, 2002]. The 53 reaction parameters that must be specified for this reaction module are listed in Table 7 in the required order (ID Number) with units and a description. Site-specific knowledge from field data or laboratory tests should be applied to determine an appropriate model configuration for reaction parameters (i.e., the values and the spatial distribution).

Table 7. Input Parameters for the Mixed Chloroethene/Chloroethane/Chloromethane Dechlorination Reaction Module

\begin{tabular}{|c|c|c|c|c|}
\hline \hline $\begin{array}{c}\text { ID } \\
\#\end{array}$ & Parameter & $\begin{array}{c}\text { Fortran } \\
\text { Variable }\end{array}$ & Units & Description \\
\hline 1 & $F a b_{\frac{c D C E}{112 T C A}}$ & fab_cdce_tca2 & $\mathrm{mol} / \mathrm{mol}$ & $\begin{array}{c}\text { Moles of cis-1,2-DCE produced from abiotic decay of one } \\
\text { mole of 1,1,2-TCA }\end{array}$ \\
\hline 2 & $F a b_{\frac{t D C E}{112 T C A}}$ & fab_tdce_tca2 & $\mathrm{mol} / \mathrm{mol}$ & $\begin{array}{c}\text { Moles of trans-1,2-DCE produced from abiotic decay of one } \\
\text { mole of 1,1,2-TCA }\end{array}$ \\
\hline 3 & $F a b_{\frac{11 D C E}{112 T C A}}$ & fab_11dce_tca2 & $\mathrm{mol} / \mathrm{mol}$ & $\begin{array}{c}\text { Moles of 1,1-DCE produced from abiotic decay of one mole } \\
\text { of 1,1,2-TCA }\end{array}$ \\
\hline
\end{tabular}


Table 7. (contd)

\begin{tabular}{|c|c|c|c|c|}
\hline $\begin{array}{l}\text { ID } \\
\#\end{array}$ & Parameter & $\begin{array}{l}\text { Fortran } \\
\text { Variable }\end{array}$ & Units & Description \\
\hline 4 & $F a b_{\frac{11 D C E}{111 T C A}}$ & fab_11dce_tca1 & $\mathrm{mol} / \mathrm{mol}$ & $\begin{array}{l}\text { Moles of 1,1-DCE produced from abiotic decay of one mole } \\
\quad \text { of 1,1,1-TCA }\end{array}$ \\
\hline 5 & Fan $_{\frac{112 T C A}{1122 T e C A}}$ & fan_tca2_teca2 & $\mathrm{mol} / \mathrm{mol}$ & $\begin{array}{l}\text { Moles of 1,1,2-TCA produced from anaerobic decay of one } \\
\text { mole of } 1,1,2,2-\mathrm{TeCA}\end{array}$ \\
\hline 6 & Fan $\frac{c D C E}{1122 T e C A}$ & fan_cdce_teca2 & $\mathrm{mol} / \mathrm{mol}$ & $\begin{array}{l}\text { Moles of cis-1,2-DCE produced from anaerobic decay of one } \\
\text { mole of } 1,1,2,2-\mathrm{TeCA}\end{array}$ \\
\hline 7 & Fan $\frac{t D C E}{1122 T e C A}$ & fan_tdce_teca2 & $\mathrm{mol} / \mathrm{mol}$ & $\begin{array}{l}\text { Moles of trans-1,2-DCE produced from anaerobic decay of } \\
\text { one mole of } 1,1,2,2-\mathrm{TeCA}\end{array}$ \\
\hline 8 & $\operatorname{Fan}_{\frac{12 D C A}{112 T C A}}$ & fan_dca2_tca2 & $\mathrm{mol} / \mathrm{mol}$ & $\begin{array}{l}\text { Moles of 1,2-DCA produced from anaerobic decay of one } \\
\text { mole of 1,1,2-TCA }\end{array}$ \\
\hline 9 & $F_{\frac{V C}{112 T C A}}$ & fan_vc_tca2 & $\mathrm{mol} / \mathrm{mol}$ & $\begin{array}{l}\text { Moles of VC produced from anaerobic decay of one mole of } \\
1,1,2-\mathrm{TCA}\end{array}$ \\
\hline 10 & $\operatorname{Fan}_{\frac{C A}{12 D C A}}$ & fan_ca_dca2 & $\mathrm{mol} / \mathrm{mol}$ & $\begin{array}{l}\text { Moles of CA produced from anaerobic decay of one mole of } \\
\text { 1,2-DCA }\end{array}$ \\
\hline 11 & Fan $_{\frac{111 T C A}{1112 T e C A}}$ & fan_tca1_teca1 & $\mathrm{mol} / \mathrm{mol}$ & $\begin{array}{l}\text { Moles of 1,1,1-TCA produced from anaerobic decay of one } \\
\text { mole of } 1,1,1,2-\mathrm{TeCA}\end{array}$ \\
\hline 12 & Fan $_{\frac{11 D C E}{1112 T e C A}}$ & fan_11dce_teca 1 & $\mathrm{~mol} / \mathrm{mol}$ & $\begin{array}{l}\text { Moles of 1,1-DCE produced from anaerobic decay of one } \\
\text { mole of } 1,1,1,2-\mathrm{TeCA}\end{array}$ \\
\hline 13 & Fan $_{\frac{c D C E}{T C E}}$ & fan_cdce_tce & $\mathrm{mol} / \mathrm{mol}$ & $\begin{array}{l}\text { Moles of cis-1,2-DCE produced from anaerobic decay of one } \\
\text { mole of TCE }\end{array}$ \\
\hline 14 & $\operatorname{Fan}_{\frac{t D C E}{T C E}}$ & fan_tdce_tce & $\mathrm{mol} / \mathrm{mol}$ & $\begin{array}{l}\text { Moles of trans-1,2-DCE produced from anaerobic decay of } \\
\text { one mole of TCE }\end{array}$ \\
\hline 15 & $\operatorname{Fan}_{\frac{11 D C E}{T C E}}$ & fan_11dce_tce & $\mathrm{mol} / \mathrm{mol}$ & $\begin{array}{l}\text { Moles of 1,1-DCE produced from anaerobic decay of one } \\
\text { mole of TCE }\end{array}$ \\
\hline 16 & Fan $_{\frac{V C}{c D C E}}$ & fan_vc_cdce & $\mathrm{mol} / \mathrm{mol}$ & $\begin{array}{l}\text { Moles of VC produced from anaerobic decay of one mole of } \\
\text { cis-1,2-DCE }\end{array}$ \\
\hline 17 & $\operatorname{Fan}_{\frac{V C}{t D C E}}$ & fan_vc_tdce & $\mathrm{mol} / \mathrm{mol}$ & $\begin{array}{l}\text { Moles of VC produced from anaerobic decay of one mole of } \\
\text { trans-1,2-DCE }\end{array}$ \\
\hline 18 & $\operatorname{Fan}_{\frac{V C}{11 D C E}}$ & fan_vc_11dce & $\mathrm{mol} / \mathrm{mol}$ & $\begin{array}{l}\text { Moles of VC produced from anaerobic decay of one mole of } \\
\text { 1,1-DCE }\end{array}$ \\
\hline 19 & $\operatorname{Fan}_{\frac{C M}{D C M}}$ & fan_cm_dcm & $\mathrm{mol} / \mathrm{mol}$ & $\begin{array}{l}\text { Moles of CM produced from anaerobic decay of one mole of } \\
\text { DCM }\end{array}$ \\
\hline 20 & $k a b_{1122 T e C A}$ & kab_teca2 & 1/day & $\begin{array}{l}\text { First-order decay coefficient for abiotic dechlorination of } \\
\quad 1,1,2,2-\mathrm{TeCA}\end{array}$ \\
\hline
\end{tabular}


Table 7. (contd)

\begin{tabular}{|c|c|c|c|c|}
\hline ID & Parameter & $\begin{array}{l}\text { Fortran } \\
\text { Variable }\end{array}$ & Units & Description \\
\hline 21 & $k a b_{112 T C A}$ & kab_tca2 & 1/day & $\begin{array}{l}\text { First-order decay coefficient for abiotic dechlorination of } \\
1,1,2-\mathrm{TCA}\end{array}$ \\
\hline 22 & $k a b_{12 D C A}$ & kab_dca2 & 1/day & $\begin{array}{l}\text { First-order decay coefficient for abiotic dechlorination of 1,2- } \\
\text { DCA }\end{array}$ \\
\hline 23 & $k a b_{C A}$ & kab_ca & 1/day & First-order decay coefficient for abiotic dechlorination of CA \\
\hline 24 & $k a b_{1112 \mathrm{TeCA}}$ & kab_tecal & $1 /$ day & $\begin{array}{l}\text { First-order decay coefficient for abiotic dechlorination of } \\
1,1,1,2-\mathrm{TeCA}\end{array}$ \\
\hline 25 & $k a b_{111 T C A}$ & kab_tcal & $1 /$ day & $\begin{array}{l}\text { First-order decay coefficient for abiotic dechlorination of } \\
\text { 1,1,1-TCA }\end{array}$ \\
\hline 26 & $k a b_{11 D C A}$ & kab_dcal & $1 /$ day & $\begin{array}{l}\text { First-order decay coefficient for abiotic dechlorination of 1,1- } \\
\text { DCA }\end{array}$ \\
\hline 27 & $k a b_{C T}$ & kab_ct & 1/day & First-order decay coefficient for abiotic dechlorination of CT \\
\hline 28 & $k a b_{C M}$ & kab_cm & 1/day & First-order decay coefficient for abiotic dechlorination of $\mathrm{CM}$ \\
\hline 29 & $k a n_{1122 \text { TеCA }}$ & kan_teca2 & 1/day & $\begin{array}{l}\text { First-order decay coefficient for anaerobic dechlorination of } \\
1,1,2,2-\mathrm{TeCA}\end{array}$ \\
\hline 30 & $k a n_{112 T C A}$ & kan_tca2 & 1/day & $\begin{array}{l}\text { First-order decay coefficient for anaerobic dechlorination of } \\
1,1,2-\mathrm{TCA}\end{array}$ \\
\hline 31 & $\operatorname{kan}_{12 D C A}$ & kan_dca2 & 1/day & $\begin{array}{l}\text { First-order decay coefficient for anaerobic dechlorination of } \\
1,2-\mathrm{DCA}\end{array}$ \\
\hline 32 & $k a n_{C A}$ & kan_ca & 1/day & $\begin{array}{l}\text { First-order decay coefficient for anaerobic dechlorination of } \\
\text { CA }\end{array}$ \\
\hline 33 & $\mathrm{kan}_{1112 \mathrm{TeCA}}$ & kan_tecal & 1/day & $\begin{array}{l}\text { First-order decay coefficient for anaerobic dechlorination of } \\
1,1,1,2-\mathrm{TeCA}\end{array}$ \\
\hline 34 & $\operatorname{kan}_{111 T C A}$ & kan_tca 1 & 1/day & $\begin{array}{l}\text { First-order decay coefficient for anaerobic dechlorination of } \\
1,1,1-\mathrm{TCA}\end{array}$ \\
\hline 35 & $\operatorname{kan}_{11 D C A}$ & kan_dca1 & 1/day & $\begin{array}{l}\text { First-order decay coefficient for anaerobic dechlorination of } \\
\text { 1,1-DCA }\end{array}$ \\
\hline 36 & $\operatorname{kan}_{P C E}$ & kan_pce & $1 /$ day & $\begin{array}{l}\text { First-order decay coefficient for anaerobic dechlorination of } \\
\text { PCE }\end{array}$ \\
\hline 37 & $\mathrm{kan}_{T C E}$ & kan_tce & 1/day & $\begin{array}{l}\text { First-order decay coefficient for anaerobic dechlorination of } \\
\text { TCE }\end{array}$ \\
\hline 38 & $k a n_{C D C E}$ & kan_cdce & 1/day & $\begin{array}{l}\text { First-order decay coefficient for anaerobic dechlorination of } \\
\text { cis-1,2-DCE }\end{array}$ \\
\hline 39 & $k a n_{t D C E}$ & kan_tdce & 1/day & $\begin{array}{l}\text { First-order decay coefficient for anaerobic dechlorination of } \\
\text { trans-1,2-DCE }\end{array}$ \\
\hline 40 & $\operatorname{kan}_{11 D C E}$ & kan_11dce & 1/day & $\begin{array}{l}\text { First-order decay coefficient for anaerobic dechlorination of } \\
1,1-D C E\end{array}$ \\
\hline 41 & $k a n_{V C}$ & kan_vc & 1/day & $\begin{array}{l}\text { First-order decay coefficient for anaerobic dechlorination of } \\
\text { VC }\end{array}$ \\
\hline
\end{tabular}


Table 7. (contd)

\begin{tabular}{|c|c|c|c|c|}
\hline $\begin{array}{c}\text { ID } \\
\#\end{array}$ & Parameter & $\begin{array}{c}\text { Fortran } \\
\text { Variable }\end{array}$ & Units & Description \\
\hline 42 & $\operatorname{kan}_{C T}$ & kan_ct & 1/day & $\begin{array}{l}\text { First-order decay coefficient for anaerobic dechlorination of } \\
\text { CT }\end{array}$ \\
\hline 43 & $\operatorname{kan}_{C F}$ & kan_cf & $1 /$ day & $\begin{array}{l}\text { First-order decay coefficient for anaerobic dechlorination of } \\
\text { CF }\end{array}$ \\
\hline 44 & $k a n_{D C M}$ & kan_dcm & 1/day & $\begin{array}{l}\text { First-order decay coefficient for anaerobic dechlorination of } \\
\text { DCM }\end{array}$ \\
\hline 45 & $\operatorname{kan}_{C M}$ & kan_cm & 1/day & $\begin{array}{l}\text { First-order decay coefficient for anaerobic dechlorination of } \\
\text { CM }\end{array}$ \\
\hline 46 & $k a e_{12 D C A}$ & kae_dca2 & 1/day & $\begin{array}{l}\text { First-order decay coefficient for aerobic dechlorination of } \\
\text { DCA }\end{array}$ \\
\hline 47 & $k a e_{C A}$ & kae_ca & 1/day & First-order decay coefficient for aerobic dechlorination of $\mathrm{CA}$ \\
\hline 48 & $k a e_{C D C E}$ & kae_cdce & $1 /$ day & $\begin{array}{l}\text { First-order decay coefficient for aerobic dechlorination of } \\
\text { cis-1,2-DCE }\end{array}$ \\
\hline 49 & $k a e_{t D C E}$ & kae_tdce & 1/day & $\begin{array}{l}\text { First-order decay coefficient for aerobic dechlorination of } \\
\text { trans-1,2-DCE }\end{array}$ \\
\hline 50 & $k a e_{11 D C E}$ & kae_11dce & 1/day & $\begin{array}{l}\text { First-order decay coefficient for aerobic dechlorination of } \\
\text { 1,1-DCE }\end{array}$ \\
\hline 51 & $k a e_{V C}$ & kae_vc & 1/day & First-order decay coefficient for aerobic dechlorination of $\mathrm{VC}$ \\
\hline 52 & $k a e_{D C M}$ & kae_dcm & 1/day & $\begin{array}{l}\text { First-order decay coefficient for aerobic dechlorination of } \\
\text { DCM }\end{array}$ \\
\hline 53 & $k a e_{C M}$ & kae_cm & 1/day & $\begin{array}{l}\text { First-order decay coefficient for aerobic dechlorination of } \\
\text { CM }\end{array}$ \\
\hline
\end{tabular}

\subsection{Example Simulations}

Simulations with this reaction module were conducted with RT3D in a batch reactor (no flow) mode to show examples of how the reaction module simulates the pattern of dechlorination. The parameter values for each example simulation are listed in Tables 8 through 11 . These parameters are arbitrary values and are not directly related to any specific laboratory data. Sitespecific values would need to be determined as part of a calibration process. Results for these example batch simulations are shown in Figures 6 through 9, respectively. 
Table 8. Parameter Values for Example Simulation 1-Anaerobic Conditions - with the Mixed Chloroethene/Chloroethane/Chloromethane Dechlorination Reaction Module

\begin{tabular}{|c|c|c|c|c|c|c|c|}
\hline ID \# & Fortran Variable & Value & Units & ID \# & Fortran Variable & Value & Units \\
\hline 1 & fab_cdce_tca2 & 0.2 & $\mathrm{~mol} / \mathrm{mol}$ & 28 & kab_cm & 0.000094 & 1/day \\
\hline 2 & fab_tdce_tca2 & 0.7 & $\mathrm{~mol} / \mathrm{mol}$ & 29 & kan teca2 & 0.005 & 1/day \\
\hline 3 & fab_11dce_tca2 & 0.1 & $\mathrm{~mol} / \mathrm{mol}$ & 30 & kan_tca2 & 0.01 & 1/day \\
\hline 4 & fab_11dce_tca1 & 0.2 & $\mathrm{~mol} / \mathrm{mol}$ & 31 & kan_dca2 & 0.025 & 1/day \\
\hline 5 & fan_tca2_teca2 & 0.2 & $\mathrm{~mol} / \mathrm{mol}$ & 32 & kan_ca & 0.025 & 1/day \\
\hline 6 & fan_cdce_teca 2 & 0.15 & $\mathrm{~mol} / \mathrm{mol}$ & 33 & kan_tecal & 0.005 & 1/day \\
\hline 7 & fan_tdce_teca2 & 0.05 & $\mathrm{~mol} / \mathrm{mol}$ & 34 & kan_tcal & 0.01 & 1/day \\
\hline 8 & fan_dca2_tca2 & 0.2 & $\mathrm{~mol} / \mathrm{mol}$ & 35 & kan_dcal & 0.025 & 1/day \\
\hline 9 & fan_vc_tca2 & 0.8 & $\mathrm{~mol} / \mathrm{mol}$ & 36 & kan_pce & 0.025 & 1/day \\
\hline 10 & fan_ca_dca2 & 0.2 & $\mathrm{~mol} / \mathrm{mol}$ & 37 & kan_tce & 0.025 & 1/day \\
\hline 11 & fan_tcal_tecal & 0.2 & $\mathrm{~mol} / \mathrm{mol}$ & 38 & kan_cdce & 0.025 & 1/day \\
\hline 12 & fan_11dce_teca 1 & 0.8 & $\mathrm{~mol} / \mathrm{mol}$ & 39 & kan_tdce & 0.025 & 1/day \\
\hline 13 & fan_cdce_tce & 0.8 & $\mathrm{~mol} / \mathrm{mol}$ & 40 & kan_11dce & 0.025 & 1/day \\
\hline 14 & fan_tdce_tce & 0.2 & $\mathrm{~mol} / \mathrm{mol}$ & 41 & kan_vc & 0.0025 & 1/day \\
\hline 15 & fan_11dce_tce & 0 & $\mathrm{~mol} / \mathrm{mol}$ & 42 & kan_ct & 0.005 & 1/day \\
\hline 16 & fan_vc_cdce & 0.8 & $\mathrm{~mol} / \mathrm{mol}$ & 43 & kan_cf & 0.0005 & 1/day \\
\hline 17 & fan_vc_tdce & 0.8 & $\mathrm{~mol} / \mathrm{mol}$ & 44 & kan_dcm & 0.005 & 1/day \\
\hline 18 & fan_vc_11dce & 0.8 & $\mathrm{~mol} / \mathrm{mol}$ & 45 & kan_cm & 0.005 & 1/day \\
\hline 19 & fan_cm_dcm & 0.5 & $\mathrm{~mol} / \mathrm{mol}$ & 46 & kae_dca2 & 0 & 1/day \\
\hline 20 & kab_teca2 & 0.006 & 1/day & 47 & kae_ca & 0 & 1/day \\
\hline 21 & kab_tca2 & 0.0015 & 1/day & 48 & kae_cdce & 0 & 1/day \\
\hline 22 & kab_dca2 & 0.00003 & 1/day & 49 & kae_tdce & 0 & 1/day \\
\hline 23 & kab_ca & 0.001 & 1/day & 50 & kae_11dce & 0 & 1/day \\
\hline 24 & kab_tecal & 0.006 & 1/day & 51 & kae_vc & 0 & 1/day \\
\hline 25 & kab_tcal & 0.001 & 1/day & 52 & kae_dcm & 0 & 1/day \\
\hline 26 & kab_dcal & 0.00005 & 1/day & 53 & kae_cm & 0 & 1/day \\
\hline 27 & kab_ct & 0.000047 & $1 /$ day & & & & \\
\hline
\end{tabular}


Table 9. Parameter Values for Example Simulation 2 -Aerobic Conditions - with the Mixed Chloroethene/Chloroethane/Chloromethane Dechlorination Reaction Module

\begin{tabular}{|c|l|c|c|c|l|c|c|}
\hline \hline ID \# & Fortran Variable & Value & Units & ID \# & Fortran Variable & Value & Units \\
\hline 1 & fab_cdce_tca2 & 0.2 & $\mathrm{~mol} / \mathrm{mol}$ & 28 & kab_cm & 0.000094 & $1 /$ day \\
\hline 2 & fab_tdce_tca2 & 0.8 & $\mathrm{~mol} / \mathrm{mol}$ & 29 & kan_teca 2 & 0 & $1 /$ day \\
\hline 3 & fab_11dce_tca2 & 0.1 & $\mathrm{~mol} / \mathrm{mol}$ & 30 & kan_tca 2 & 0 & $1 /$ day \\
\hline 4 & fab_11dce_tca1 & 0.2 & $\mathrm{~mol} / \mathrm{mol}$ & 31 & kan_dca2 & 0 & $1 /$ day \\
\hline 5 & fan_tca2_teca2 & 0 & $\mathrm{~mol} / \mathrm{mol}$ & 32 & kan_ca & 0 & $1 /$ day \\
\hline 6 & fan_cdce_teca2 & 0 & $\mathrm{~mol} / \mathrm{mol}$ & 33 & kan_teca1 & 0 & $1 /$ day \\
\hline 7 & fan_tce_tcca2 & 0 & $\mathrm{~mol} / \mathrm{mol}$ & 34 & kan_tca1 & 0 & $1 /$ day \\
\hline 8 & fan_dca2_tca2 & 0 & $\mathrm{~mol} / \mathrm{mol}$ & 35 & kan_dcal & 0 & $1 /$ day \\
\hline 9 & fan_vc_tca2 & 0 & $\mathrm{~mol} / \mathrm{mol}$ & 36 & kan_pce & 0 & $1 /$ day \\
\hline 10 & fan_ca_dca2 & 0 & $\mathrm{~mol} / \mathrm{mol}$ & 37 & kan_tce & 0 & $1 /$ day \\
\hline 11 & fan_tca1_teca1 & 0 & $\mathrm{~mol} / \mathrm{mol}$ & 38 & kan_cdce & 0 & $1 /$ day \\
\hline 12 & fan_11dce_teca1 & 0 & $\mathrm{~mol} / \mathrm{mol}$ & 39 & kan_tdce & 0 & $1 /$ day \\
\hline 13 & fan_cdce_tce & 0 & $\mathrm{~mol} / \mathrm{mol}$ & 40 & kan_11dce & 0 & $1 /$ day \\
\hline 14 & fan_tdce_tce & 0 & $\mathrm{~mol} / \mathrm{mol}$ & 41 & kan_vc & 0 & $1 /$ day \\
\hline 15 & fan_11dce_tce & 0 & $\mathrm{~mol} / \mathrm{mol}$ & 42 & kan_ct & 0 & $1 /$ day \\
\hline 16 & fan_vc_cdce & 0 & $\mathrm{~mol} / \mathrm{mol}$ & 43 & kan_cf & 0 & $1 /$ day \\
\hline 17 & fan_vc_tdce & 0 & $\mathrm{~mol} / \mathrm{mol}$ & 44 & kan_dcm & 0 & $1 /$ day \\
\hline 18 & fan_vc_11dce & 0 & $\mathrm{~mol} / \mathrm{mol}$ & 45 & kan_cm & 0 & $1 /$ day \\
\hline 19 & fan_cm_dcm & 0 & $\mathrm{~mol} / \mathrm{mol}$ & 46 & kae_dca 2 & 0.005 & $1 /$ day \\
\hline 20 & kab_teca2 & 0.006 & $1 / \mathrm{day}$ & 47 & kae_ca & 0.005 & $1 /$ day \\
\hline 21 & kab_tca2 & 0.0015 & $1 / \mathrm{day}$ & 48 & kae_cdce & 0.005 & $1 /$ day \\
\hline 22 & kab_dca2 & 0.00003 & $1 / \mathrm{day}$ & 49 & kae_tdce & 0.005 & $1 /$ day \\
\hline 23 & kab_ca & 0.001 & $1 / \mathrm{day}$ & 50 & kae_11dce & 0.005 & $1 /$ day \\
\hline 24 & kab_teca1 & 0.006 & $1 / \mathrm{day}$ & 51 & kae_vc & 0.005 & $1 /$ day \\
\hline 25 & kab_tca1 & 0.001 & $1 / \mathrm{day}$ & 52 & kae_dcm & 0.005 & $1 /$ day \\
\hline 26 & kab_dca1 & 0.00005 & $1 / \mathrm{day}$ & 53 & kae_cm & 0.005 & $1 /$ day \\
\hline 27 & kab_ct & 0.000047 & $1 / \mathrm{day}$ & & & & \\
\hline \hline & & & & & & 05 \\
\hline
\end{tabular}


Table 10. Parameter Values For Example Simulation 3 - Anaerobic Case Equivalent to Table 20 - With The Mixed Chloroethene/Chloroethane/Chloromethane Dechlorination Reaction Module

\begin{tabular}{|c|c|c|c|c|c|c|c|}
\hline ID \# & Fortran Variable & Value & Units & ID \# & Fortran Variable & Value & Units \\
\hline 1 & fab_cdce_tca2 & 0.2 & $\mathrm{~mol} / \mathrm{mol}$ & 28 & kab_cm & 0 & $1 /$ day \\
\hline 2 & fab tdce tca2 & 0.8 & $\mathrm{~mol} / \mathrm{mol}$ & 29 & kan teca2 & 0.005 & $1 /$ day \\
\hline 3 & fab_11dce_tca2 & 0 & $\mathrm{~mol} / \mathrm{mol}$ & 30 & kan_tca2 & 0.01 & $1 /$ day \\
\hline 4 & fab_11dce_tcal & 0 & $\mathrm{~mol} / \mathrm{mol}$ & 31 & kan_dca2 & 0.025 & $1 /$ day \\
\hline 5 & fan tca 2 teca 2 & 0 & $\mathrm{~mol} / \mathrm{mol}$ & 32 & kan ca & 0.025 & $1 /$ day \\
\hline 6 & fan cdce teca2 & 0.2 & $\mathrm{~mol} / \mathrm{mol}$ & 33 & kan tecal & 0 & $1 /$ day \\
\hline 7 & fan_tdce_teca2 & 0 & $\mathrm{~mol} / \mathrm{mol}$ & 34 & kan_tcal & 0 & $1 /$ day \\
\hline 8 & fan dca2 tca2 & 0.2 & $\mathrm{~mol} / \mathrm{mol}$ & 35 & kan dcal & 0 & $1 /$ day \\
\hline 9 & fan vc tca2 & 0.8 & $\mathrm{~mol} / \mathrm{mol}$ & 36 & kan pce & 0.025 & $1 /$ day \\
\hline 10 & fan_ca_dca2 & 0.2 & $\mathrm{~mol} / \mathrm{mol}$ & 37 & kan_tce & 0.025 & $1 /$ day \\
\hline 11 & fan_tca1_tecal & 0 & $\mathrm{~mol} / \mathrm{mol}$ & 38 & kan_cdce & 0.025 & $1 /$ day \\
\hline 12 & fan_11dce_tecal & 0 & $\mathrm{~mol} / \mathrm{mol}$ & 39 & kan_tdce & 0.025 & $1 /$ day \\
\hline 13 & fan_cdce_tce & 0.8 & $\mathrm{~mol} / \mathrm{mol}$ & 40 & kan_11dce & 0.025 & $1 /$ day \\
\hline 14 & fan_tdce_tce & 0.2 & $\mathrm{~mol} / \mathrm{mol}$ & 41 & kan_vc & 0.0025 & $1 /$ day \\
\hline 15 & fan 11 dce tce & 0 & $\mathrm{~mol} / \mathrm{mol}$ & 42 & kan ct & 0 & $1 /$ day \\
\hline 16 & fan_vc_cdce & 0.8 & $\mathrm{~mol} / \mathrm{mol}$ & 43 & kan_cf & 0 & $1 /$ day \\
\hline 17 & fan_vc_tdce & 0.8 & $\mathrm{~mol} / \mathrm{mol}$ & 44 & kan_dcm & 0 & $1 /$ day \\
\hline 18 & fan vc 11dce & 0.8 & $\mathrm{~mol} / \mathrm{mol}$ & 45 & kan $\mathrm{cm}$ & 0 & $1 /$ day \\
\hline 19 & fan_cm_dcm & 0 & $\mathrm{~mol} / \mathrm{mol}$ & 46 & kae_dca2 & 0 & $1 /$ day \\
\hline 20 & kab_teca2 & 0.006 & 1/day & 47 & kae_ca & 0 & $1 /$ day \\
\hline 21 & kab tca2 & 0 & $1 /$ day & 48 & kae cdce & $\overline{0}$ & $1 / \mathrm{day}$ \\
\hline 22 & kab_dca2 & 0.00003 & $1 /$ day & 49 & kae_tdce & 0 & $1 /$ day \\
\hline 23 & kab_ca & 0.001 & $1 /$ day & 50 & kae_11dce & 0 & $1 /$ day \\
\hline 24 & kab tecal & 0 & $1 /$ day & 51 & kae vc & 0 & $1 /$ day \\
\hline 25 & kab_tca1 & 0 & $1 /$ day & 52 & kae_dcm & 0 & $1 /$ day \\
\hline 26 & kab_dcal & 0 & 1/day & 53 & kae_cm & 0 & 1/day \\
\hline 27 & $\mathrm{kab}$ ct & $\overline{0}$ & $1 /$ day & & & & \\
\hline
\end{tabular}


Table 11. Parameter Values for Example Simulation 4-Aerobic Case Equivalent to Table 23 with the Mixed Chloroethene/Chloroethane/Chloromethane Dechlorination Reaction Module

\begin{tabular}{|c|c|c|c|c|c|c|c|}
\hline ID \# & Fortran Variable & Value & Units & ID \# & Fortran Variable & Value & Units \\
\hline 1 & fab_cdce_tca2 & 0.2 & $\mathrm{~mol} / \mathrm{mol}$ & 28 & kab_cm & 0 & 1/day \\
\hline 2 & fab_tdce_tca2 & 0.8 & $\mathrm{~mol} / \mathrm{mol}$ & 29 & kan_teca2 & 0 & 1/day \\
\hline 3 & fab_11dce_tca2 & 0 & $\mathrm{~mol} / \mathrm{mol}$ & 30 & kan_tca2 & 0 & 1/day \\
\hline 4 & fab_11dce_tca1 & 0 & $\mathrm{~mol} / \mathrm{mol}$ & 31 & kan_dca2 & 0 & 1/day \\
\hline 5 & fan_tca2_teca2 & 0 & $\mathrm{~mol} / \mathrm{mol}$ & 32 & kan_ca & 0 & 1/day \\
\hline 6 & fan_cdce_teca2 & 0 & $\mathrm{~mol} / \mathrm{mol}$ & 33 & kan_tecal & 0 & 1/day \\
\hline 7 & fan_tdce_teca 2 & 0 & $\mathrm{~mol} / \mathrm{mol}$ & 34 & kan_tcal & 0 & 1/day \\
\hline 8 & fan_dca2_tca2 & 0 & $\mathrm{~mol} / \mathrm{mol}$ & 35 & kan_dcal & 0 & $1 /$ day \\
\hline 9 & fan_vc_tca2 & 0 & $\mathrm{~mol} / \mathrm{mol}$ & 36 & kan_pce & 0 & 1/day \\
\hline 10 & fan_ca_dca2 & 0 & $\mathrm{~mol} / \mathrm{mol}$ & 37 & kan_tce & 0 & $1 /$ day \\
\hline 11 & fan_tca1_teca1 & 0 & $\mathrm{~mol} / \mathrm{mol}$ & 38 & kan_cdce & 0 & 1/day \\
\hline 12 & fan_11dce_tecal & 0 & $\mathrm{~mol} / \mathrm{mol}$ & 39 & kan_tdce & 0 & 1/day \\
\hline 13 & fan_cdce_tce & 0 & $\mathrm{~mol} / \mathrm{mol}$ & 40 & kan_11dce & 0 & 1/day \\
\hline 14 & fan_tdce_tce & 0 & $\mathrm{~mol} / \mathrm{mol}$ & 41 & kan_vc & 0 & 1/day \\
\hline 15 & fan_11dce_tce & 0 & $\mathrm{~mol} / \mathrm{mol}$ & 42 & kan_ct & 0 & 1/day \\
\hline 16 & fan_vc_cdce & 0 & $\mathrm{~mol} / \mathrm{mol}$ & 43 & kan_cf & 0 & 1/day \\
\hline 17 & fan_vc_tdce & 0 & $\mathrm{~mol} / \mathrm{mol}$ & 44 & kan_dcm & 0 & 1/day \\
\hline 18 & fan_vc_11dce & 0 & $\mathrm{~mol} / \mathrm{mol}$ & 45 & kan_cm & 0 & $1 /$ day \\
\hline 19 & fan_cm_dcm & 0 & $\mathrm{~mol} / \mathrm{mol}$ & 46 & kae_dca2 & 0.005 & 1/day \\
\hline 20 & kab_teca2 & 0.006 & 1/day & 47 & kae_ca & 0.005 & 1/day \\
\hline 21 & kab_tca2 & 0 & 1/day & 48 & kae_cdce & 0.005 & 1/day \\
\hline 22 & kab_dca2 & 0.00003 & 1/day & 49 & kae_tdce & 0.005 & 1/day \\
\hline 23 & kab_ca & 0.001 & 1/day & 50 & kae_11dce & 0.005 & 1/day \\
\hline 24 & kab_teca1 & 0 & 1/day & 51 & kae_vc & 0.005 & 1/day \\
\hline 25 & kab_tcal & 0 & 1/day & 52 & kae_dcm & 0.005 & 1/day \\
\hline 26 & kab_dcal & 0 & 1/day & 53 & kae_cm & 0.005 & 1/day \\
\hline 27 & kab_ct & 0 & 1/day & & & & \\
\hline
\end{tabular}




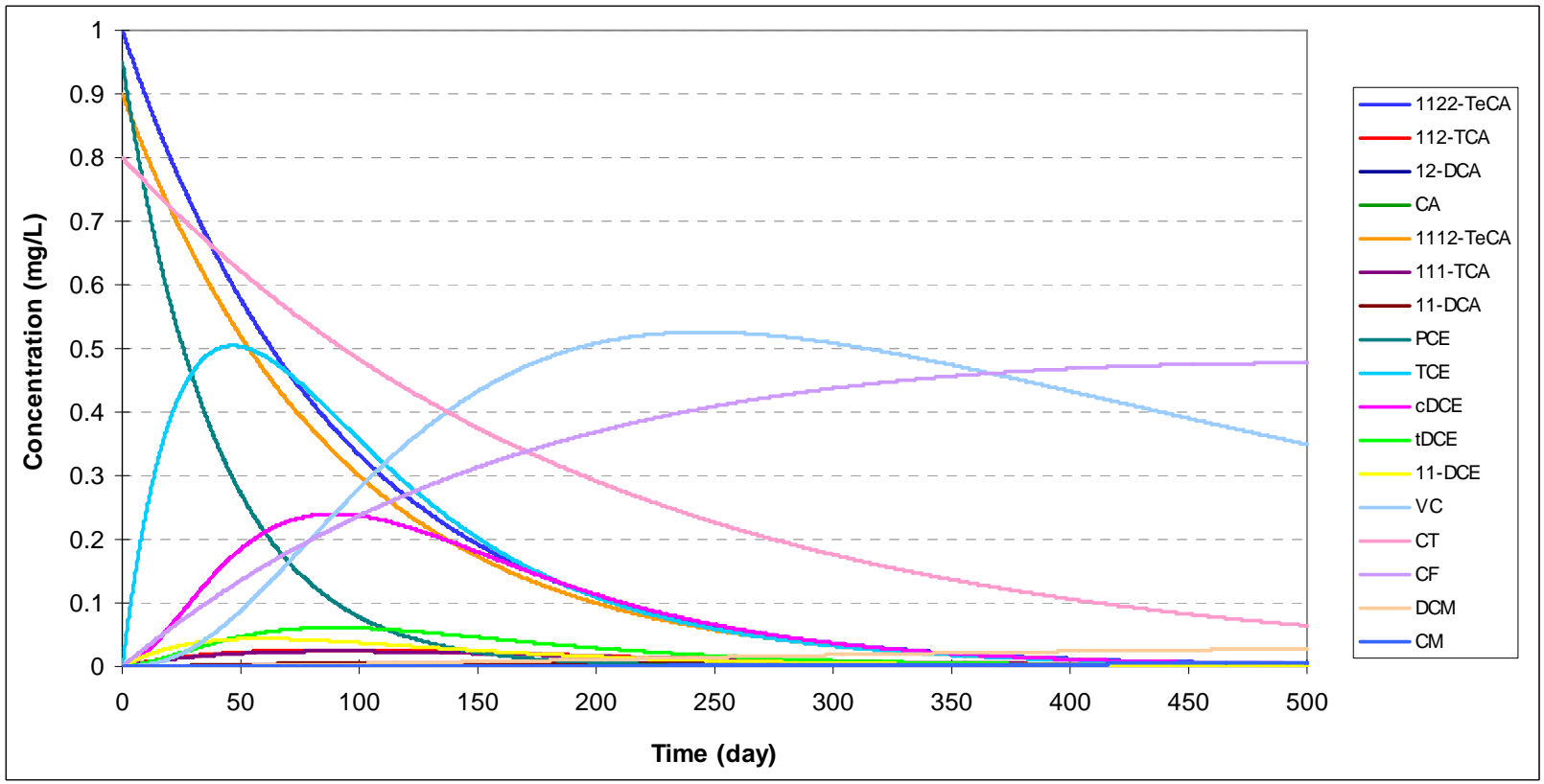

Figure 6. Dechlorination of Mixed Chlorinated Solvents under Anaerobic Conditions Using the Parameter Values Shown in Table 8 - Initial concentrations were set to 1.0, 0.9, 0.95 , and $0.8 \mathrm{mg} / \mathrm{L}$ for $1122 \mathrm{TeCA}, 1112 \mathrm{TeCA}, \mathrm{PCE}$, and CT, respectively. All other species concentrations started at zero. 


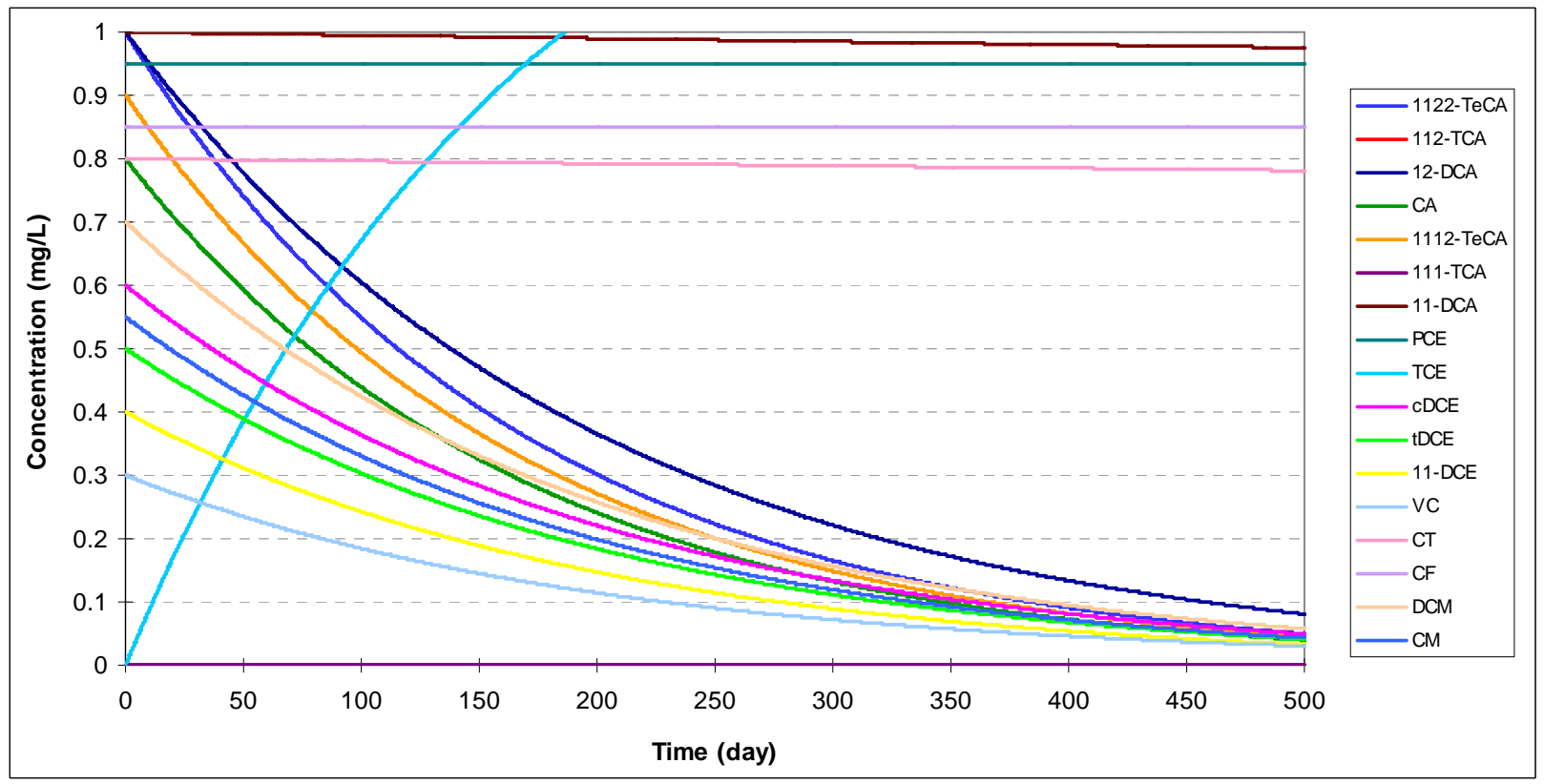

Figure 7. Dechlorination of Mixed Chlorinated Solvents under Aerobic Conditions Using the Parameter Values Shown in Table 9 - Initial concentrations were set to $1.0 \mathrm{mg} / \mathrm{L}$ for 1122TeCA, 12DCA, and 11DCA. Initial concentrations were set to 0.9, 0.95, $0.8,0.8,0.6,0.5,0.4,0.3,0.85,0.7$, and $0.55 \mathrm{mg} / \mathrm{L}$ for $1112 \mathrm{TeCA}, \mathrm{PCE}, \mathrm{CT}, \mathrm{CA}$, $c D C E, t D C E, 11 D C E, V C, C F, D C M$, and $C M$, respectively. All other species concentrations started at zero. 


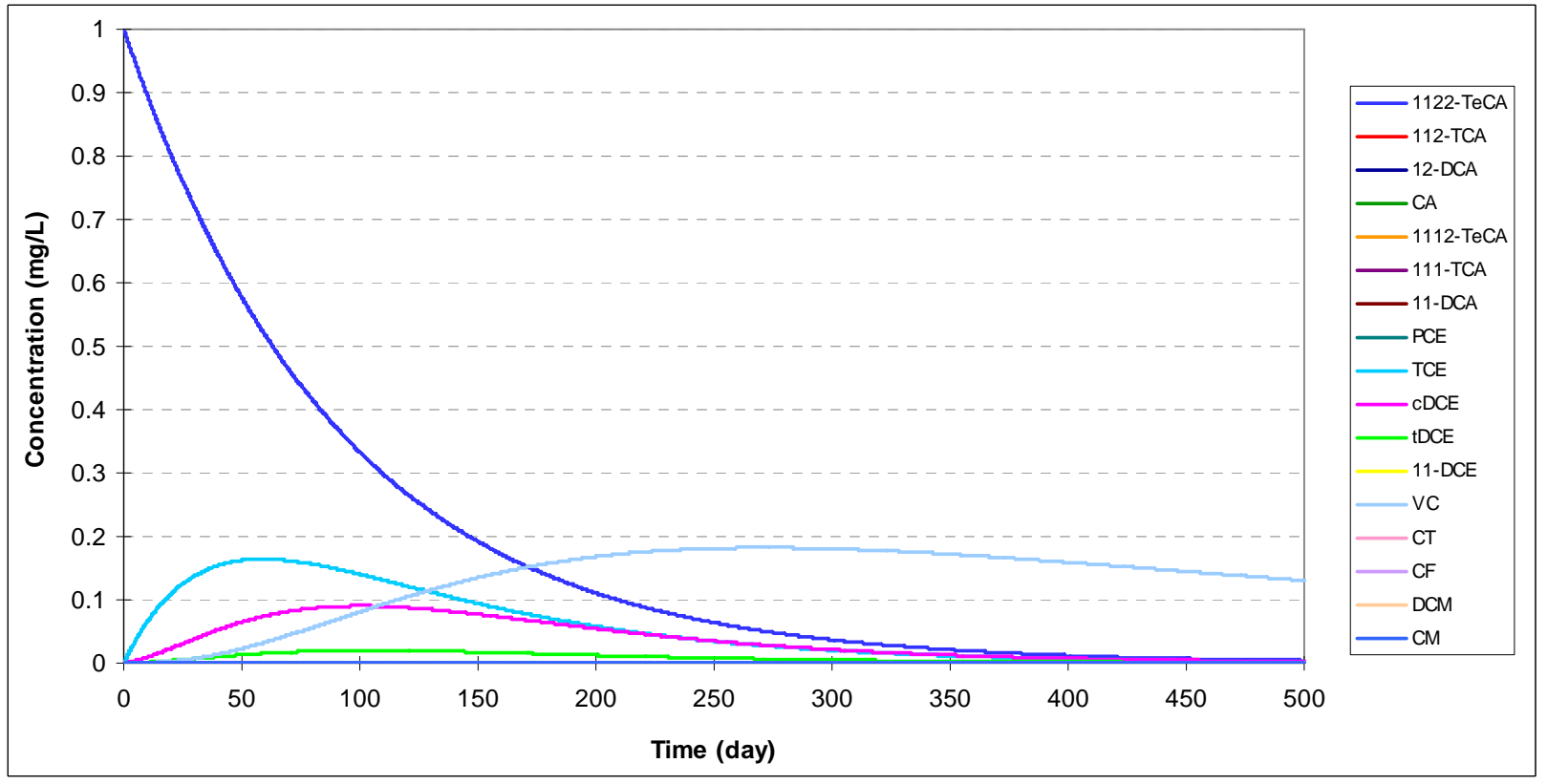

Figure 8. Dechlorination of Mixed Chlorinated Solvents Using the Parameter Values Shown in Table 10 - The initial concentration of $1122 \mathrm{TeCA}$ was set to $1 \mathrm{mg} / \mathrm{L}$. All other species concentrations started at zero. These results are the same as produced by the Dechlorination of 1,1,2,2-Tetrachloroethane and Chloroethenes reaction module (Figure 16). 


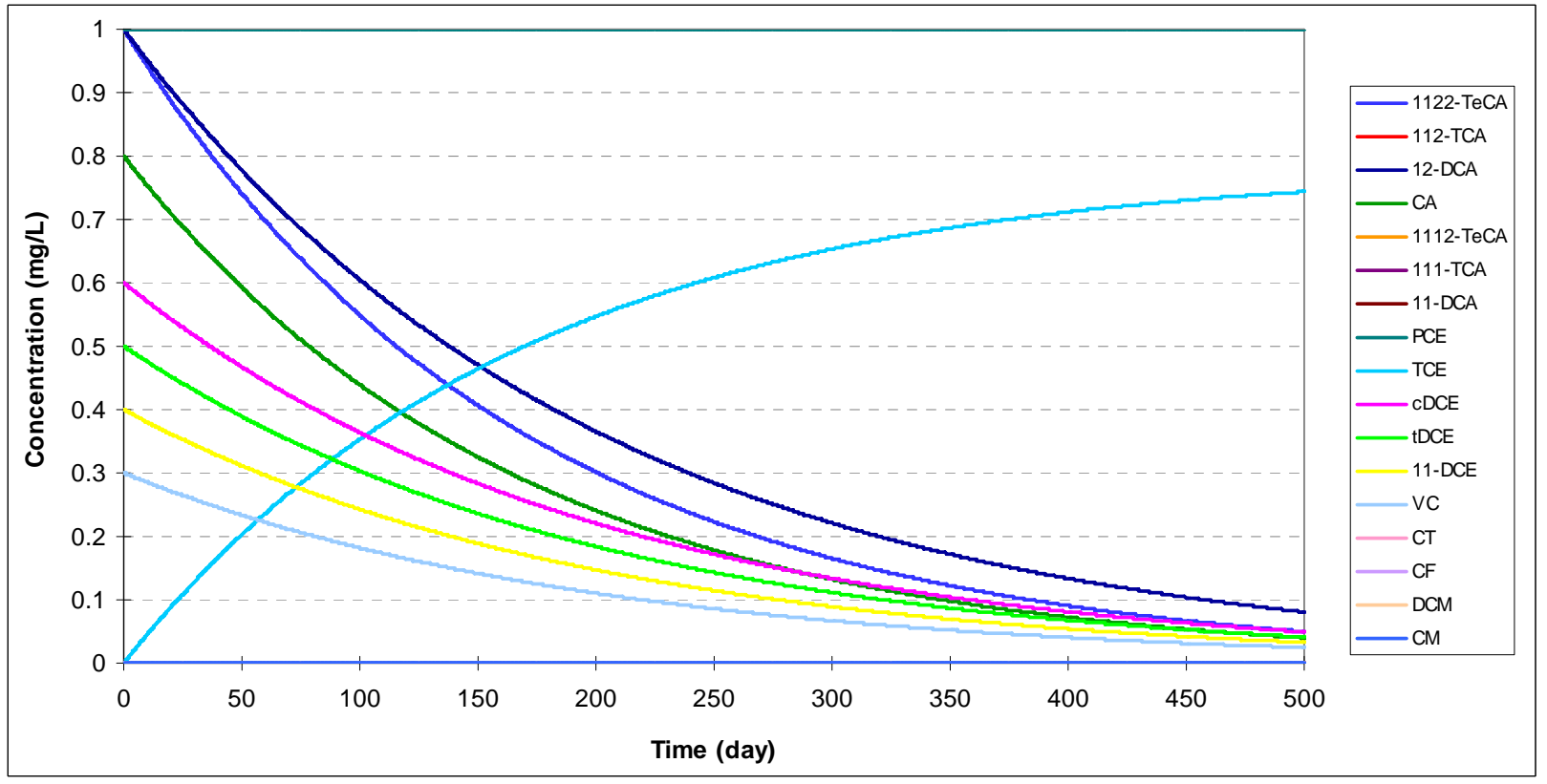

Figure 9. Aerobic and Abiotic Degradation Using the Parameter Values Shown in Table 11 The initial concentrations for 1122TeCA, 12DCA, and PCE were $1.0 \mathrm{mg} / \mathrm{L}$. The initial concentrations were set to $0.8,0.6,0.5,0.4$, and $0.3 \mathrm{mg} / \mathrm{L}$ for $C A, c D C E$, tDCE, $11 D C E$, and VC, respectively. These results are the same as produced by the Dechlorination of 1,1,2,2-Tetrachloroethane and Chloroethenes reaction module (Figure 19). 


\subsection{Chloromethane Dechlorination}

\subsection{Conceptual Model for Dechlorination Reactions}

This reaction module describes dechlorination of carbon tetrachloride (tetrachloromethane) and related daughter products using first-order rate expressions. The module includes abiotic, aerobic, and anoxic/anaerobic reaction pathways, which the user may selectively turn off by setting the (spatially variable) values of the stoichiometric yields and/or the reaction rate constants to zero. See the section on RT3D MNA/EA Reaction Module Commonalities and the Discussion of Select Reaction Parameters for additional information on features common to all of these MNA/EA reaction modules and explanation of key reaction parameters.

Table 12 lists the chemical species included in this reaction module. Figure 10 shows the conceptual model describing the potential biotic and abiotic degradation pathways of chlorinated methane contaminants. See the conceptual model discussion for the Mixed Chloroethene/ Chloroethane/Chloromethane Dechlorination reaction module for information on the development of the reaction pathways and the assumption of first-order reaction kinetics.

Table 12. Chemical Species Included in the Chloromethane Dechlorination Reaction Module

\begin{tabular}{|c|c|c|c|c|c|c|}
\hline No. & Abbreviation $^{\text {a }}$ & Chemical Name & Selected Alternate Name & $\begin{array}{c}\text { CAS }^{\text {b }} \\
\text { Registry } \\
\text { Number }\end{array}$ & $\begin{array}{c}\text { Molecular } \\
\text { Weight }^{c} \\
\text { (g/mol) }\end{array}$ & $\begin{array}{l}\text { Chemical } \\
\text { Formula }\end{array}$ \\
\hline 1 & $\mathrm{CT}$ & Tetrachloromethane & Carbon Tetrachloride & $56-23-5$ & 153.82270 & $\mathrm{CCl}_{4}$ \\
\hline 2 & $\mathrm{CF}$ & Trichloromethane & Chloroform & $67-66-3$ & 119.37764 & $\mathrm{CHCl}_{3}$ \\
\hline 3 & DCM & Dichloromethane & $\begin{array}{l}\text { Methylene Dichloride, } \\
\text { Methylene Chloride }\end{array}$ & $75-09-2$ & 84.93258 & $\mathrm{CH}_{2} \mathrm{Cl}_{2}$ \\
\hline 4 & $\mathrm{CM}$ & Chloromethane & Methyl Chloride & $74-87-3$ & 50.48752 & $\mathrm{CH}_{3} \mathrm{Cl}$ \\
\hline 5 & Tracer & Conservative Tracer & - & N/A & N/A & N/A \\
\hline
\end{tabular}

a These abbreviations refer to the specific chemicals listed here and should not be confused with different chemicals that may use the same abbreviation in other reaction modules.

b $\mathrm{CAS}=$ Chemical Abstracts Service (see http://www.cas.org/EO/regsys.html)

c Based on International Union of Pure and Applied Chemistry values reported by Loss [2003].

N/A - Not Applicable 


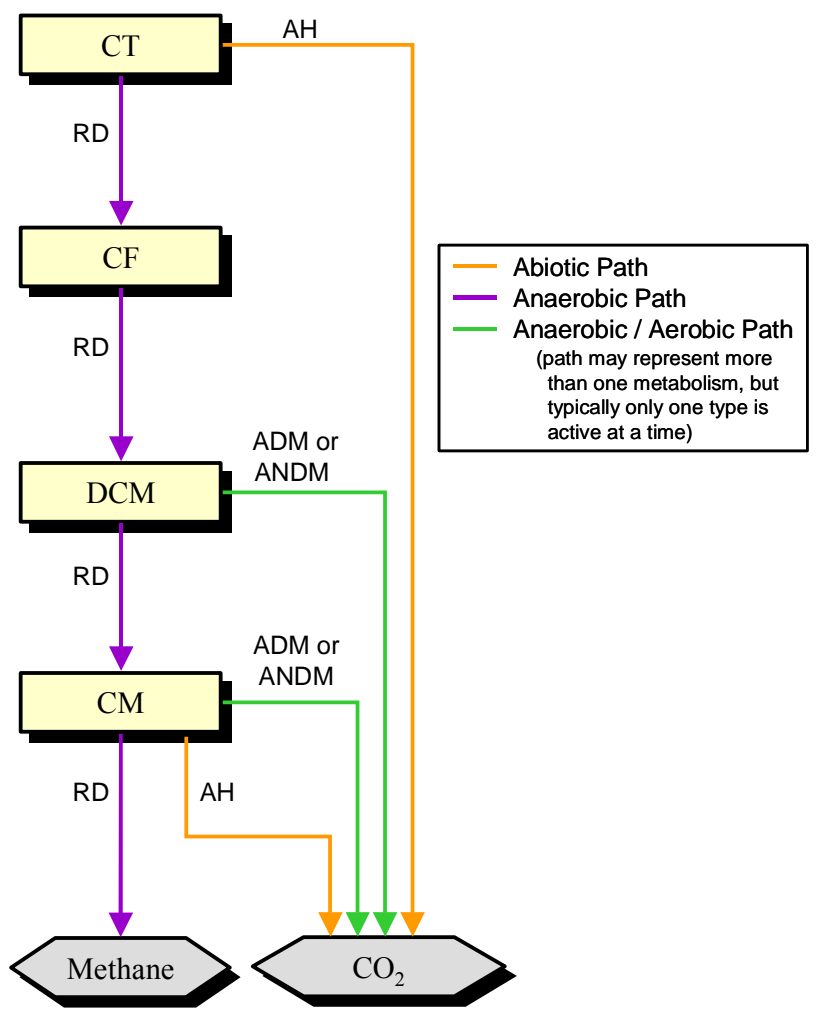

Figure 10. Conceptual Model for Dechlorination Reactions in the Chloromethane Dechlorination Reaction Module - Species in hexagonal shaded boxes are innocuous products and are not tracked in the reaction module. The reaction types for each pathway are described in Table 3.

\subsection{Reaction Equations}

The set of ODEs comprising this reaction module are shown in Equations 32 to 36 . These ODEs describe the reaction kinetics for the 5 chemical species in Table 12. See Table 13 for a detailed itemization of all reaction parameters used in this reaction module.

$$
\begin{aligned}
& \frac{d C_{C T}}{d t}=\left(-k_{C T} \cdot C_{C T}-k a b_{C T} \cdot C_{C T}\right) \\
& \frac{d C_{C F}}{d t}=\left(Y_{C F} \cdot k a n_{C T} \cdot C_{C T}-\operatorname{kan}_{C F} \cdot C_{C F}\right) \\
& \frac{d C_{D C M}}{d t}=\left(\begin{array}{c}
\frac{Y_{D C M}}{C F} \cdot k a n_{C F} \cdot C_{C F} \\
-k^{2} a_{D C M} \cdot C_{D C M}-k a e_{D C M} \cdot C_{D C M}
\end{array}\right)
\end{aligned}
$$




$$
\begin{aligned}
& \frac{d C_{C M}}{d t}=\left(\begin{array}{c}
Y_{C M} \cdot F_{\frac{C M}{D C M}} \cdot \operatorname{kan}_{D C M} \cdot C_{D C M} \\
-k a n_{C M} \cdot C_{C M}-k a b_{C M} \cdot C_{C M}-k a e_{C M} \cdot C_{C M}
\end{array}\right) \\
& \frac{d C_{\text {Tracer }}}{d t}=0.0 \quad \text { (Conservative [non-reactive] tracer.) }
\end{aligned}
$$

The first-order decay rate constants $\left[\mathrm{T}^{-1}\right]$ of the $\mathrm{i}^{\text {th }}$ species are represented in the equations above by the $k a n_{i}, k a e_{i}$, and $k a b_{i}$ terms for anaerobic biological reactions, aerobic biological reactions, or abiotic reactions, respectively. The concentration of the $\mathrm{i}^{\text {th }}$ species is represented by the $C_{i}$ term $\left[\mathrm{ML}^{-3}\right]$. The $R_{i}$ terms represent the retardation factor for the $\mathrm{i}^{\text {th }}$ species [unitless].

In cases where multiple daughter products may be produced from dechlorination of a single parent species, the amount of each daughter species that is produced is a function of a mass yield $\left[\mathrm{MM}^{-1}\right]$ and a stoichiometric dechlorination yield $[\mathrm{mol} / \mathrm{mol}]$. The mass yield value, $Y_{d / p}$, accounts for the difference in molecular weight between the parent species " $p$ " and the daughter species "d." All isomers of a daughter chemical have the same mass yield. Mass yield values are included in the reaction module code and do not need to be input by the user. The stoichiometric dechlorination yield represents the site-specific stoichiometry for each reaction pathway that occurs as either an anaerobic $\left(F a n_{d / p}\right)$ or an abiotic process $\left(F a b_{d / p}\right)$. The stoichiometric dechlorination yield is the fractional moles of daughter species that are produced by dechlorination of one mole of the parent species. The net yield is the product of the mass yield and the stoichiometric dechlorination yield. To preserve the mass balance, the values of the stoichiometric dechlorination yields are constrained by the relation in Equation 37.

$$
\operatorname{Fan}_{\frac{C M}{D C M}} \leq 1.0
$$

\subsection{Required Input}

The reaction parameters for this reaction module are made available to RT3D as part of the input for the Reaction Package. The Reaction Package input file structure is discussed in the RT3D manual and addendum [Clement, 1997; Clement and Johnson, 2002]. The 9 reaction parameters that must be specified for this reaction module are listed in Table 13 in the required order (ID Number) with units and a description. Site-specific knowledge from field data or laboratory tests should be applied to determine an appropriate model configuration for reaction parameters (i.e., the values and the spatial distribution). 
Table 13. Input Parameters for the Chloromethane Dechlorination Reaction Module

\begin{tabular}{|c|c|l|l|l|}
\hline $\begin{array}{c}\text { ID } \\
\#\end{array}$ & Parameter & $\begin{array}{c}\text { Fortran } \\
\text { Variable }\end{array}$ & Units & Description \\
\hline 1 & $\begin{array}{r}\text { Fan } \frac{C M}{D C M} \\
\text { fan_cm_dcm }\end{array}$ & mol/mol & $\begin{array}{c}\text { Moles of CM produced from anaerobic decay of one mole of } \\
\text { DCM }\end{array}$ \\
\hline 2 & $K a b_{C T}$ & kab_ct & $1 /$ day & First-order decay coefficient for abiotic dechlorination of CT \\
\hline 3 & $K a b_{C M}$ & kab_cm & $1 /$ day & First-order decay coefficient for abiotic dechlorination of CM \\
\hline 4 & $K_{C T}$ & kan_ct & $1 /$ day & First-order decay coefficient for anaerobic dechlorination of CT \\
\hline 5 & $K_{C F}$ & kan_cf & $1 /$ day & First-order decay coefficient for anaerobic dechlorination of CF \\
\hline 6 & $K_{D C M}$ & kan_dcm & $1 /$ day & First-order decay coefficient for anaerobic dechlorination of DCM \\
\hline 7 & Kan $_{C M}$ & kan_cm & $1 /$ day & First-order decay coefficient for anaerobic dechlorination of CM \\
\hline 8 & Kae $_{D C M}$ & kae_dcm & $1 /$ day & First-order decay coefficient for aerobic dechlorination of DCM \\
\hline 9 & Kae $_{C M}$ & kae_cm & $1 /$ day & First-order decay coefficient for aerobic dechlorination of CM \\
\hline \hline
\end{tabular}

\subsection{Example Simulations}

Simulations with this reaction module were conducted with RT3D in a batch reactor (no flow) mode to show examples of how the reaction module simulates the pattern of dechlorination. The parameter values for each example simulation are listed in Tables 14 through 17 . These parameters are arbitrary values and are not directly related to any specific laboratory data. Sitespecific values would need to be determined as part of a calibration process. Results for these example batch simulations are shown in the Figures 11 through 14, respectively.

Table 14. Parameter Values for Example Simulation 1 - Base Case Anaerobic Conditions with the Chloromethane Dechlorination Reaction Module

\begin{tabular}{|c|l|c|c|c|l|c|c|}
\hline \hline ID \# & Fortran Variable & Value & Units & ID \# & Fortran Variable & Value & Units \\
\hline 1 & fan_cm_dcm & 0.5 & mol/mol & 6 & kan_dcm & 0.005 & $1 /$ day \\
\hline 2 & kab_ct & 0.000047 & $1 /$ day & 7 & kan_cm & 0.005 & $1 /$ day \\
\hline 3 & kab_cm & 0.000094 & $1 /$ day & 8 & kae_dcm & 0 & $1 /$ day \\
\hline 4 & kan_ct & 0.005 & $1 /$ day & 9 & kae_cm & 0 & $1 /$ day \\
\hline 5 & kan_cf & 0.0005 & 1/day & & & \\
\hline \hline
\end{tabular}

Table 15. Parameter Values for Example Simulation 2 - Rates at 10\% of Example Simulation 1 - with the Chloromethane Dechlorination Reaction Module

\begin{tabular}{|c|l|c|c|c|l|c|c|}
\hline \hline ID \# & Fortran Variable & Value & Units & ID \# & Fortran Variable & Value & Units \\
\hline 1 & fan_cm_dcm & 0.5 & $\mathrm{~mol} / \mathrm{mol}$ & 6 & kan_dcm & 0.0005 & $1 /$ day \\
\hline 2 & kab_ct & 0.0000047 & $1 /$ day & 7 & kan_cm & 0.0005 & $1 /$ day \\
\hline 3 & kab_cm & 0.0000094 & $1 /$ day & 8 & kae_dcm & 0 & $1 /$ day \\
\hline 4 & kan_ct & 0.0005 & $1 /$ day & 9 & kae_cm & 0 & $1 /$ day \\
\hline 5 & kan_cf & 0.00005 & $1 /$ day & \multicolumn{5}{|l}{} \\
\hline \hline
\end{tabular}


Table 16. Parameter Values for Example Simulation 3 -Different F Values Than Example Simulation 1 - with the Chloromethane Dechlorination Reaction Module

\begin{tabular}{|c|l|c|c|c|l|c|c|}
\hline \hline ID \# & Fortran Variable & Value & Units & ID \# & Fortran Variable & Value & Units \\
\hline 1 & fan_cm_dcm & 0.1 & mol/mol & 6 & kan_dcm & 0.005 & $1 /$ day \\
\hline 2 & kab_ct & 0.000047 & $1 /$ day & 7 & kan_cm & 0.005 & $1 /$ day \\
\hline 3 & kab_cm & 0.000094 & $1 /$ day & 8 & kae_dcm & 0 & $1 /$ day \\
\hline 4 & kan_ct & 0.005 & $1 /$ day & 9 & kae_cm & 0 & $1 /$ day \\
\hline 5 & kan_cf & 0.0005 & $1 /$ day & \multicolumn{5}{|l}{} \\
\hline \hline
\end{tabular}

Table 17. Parameter Values for Example Simulation 4 - Base Case Aerobic Conditions - with the Chloromethane Dechlorination Reaction Module

\begin{tabular}{|c|l|c|c|c|l|c|c|}
\hline \hline ID \# & Fortran Variable & Value & Units & ID \# & Fortran Variable & Value & Units \\
\hline 1 & fan_cm_dcm & 0 & $\mathrm{~mol} / \mathrm{mol}$ & 6 & kan_dcm & 0 & $1 /$ day \\
\hline 2 & kab_ct & 0.000047 & $1 / \mathrm{day}$ & 7 & kan_cm & 0 & $1 /$ day \\
\hline 3 & kab_cm & 0.000094 & $1 /$ day & 8 & kae_dcm & 0.005 & $1 /$ day \\
\hline 4 & kan_ct & 0 & $1 /$ day & 9 & kae_cm & 0.005 & $1 /$ day \\
\hline 5 & kan_cf & 0 & $1 /$ day & \multicolumn{5}{|l}{} \\
\hline \hline
\end{tabular}

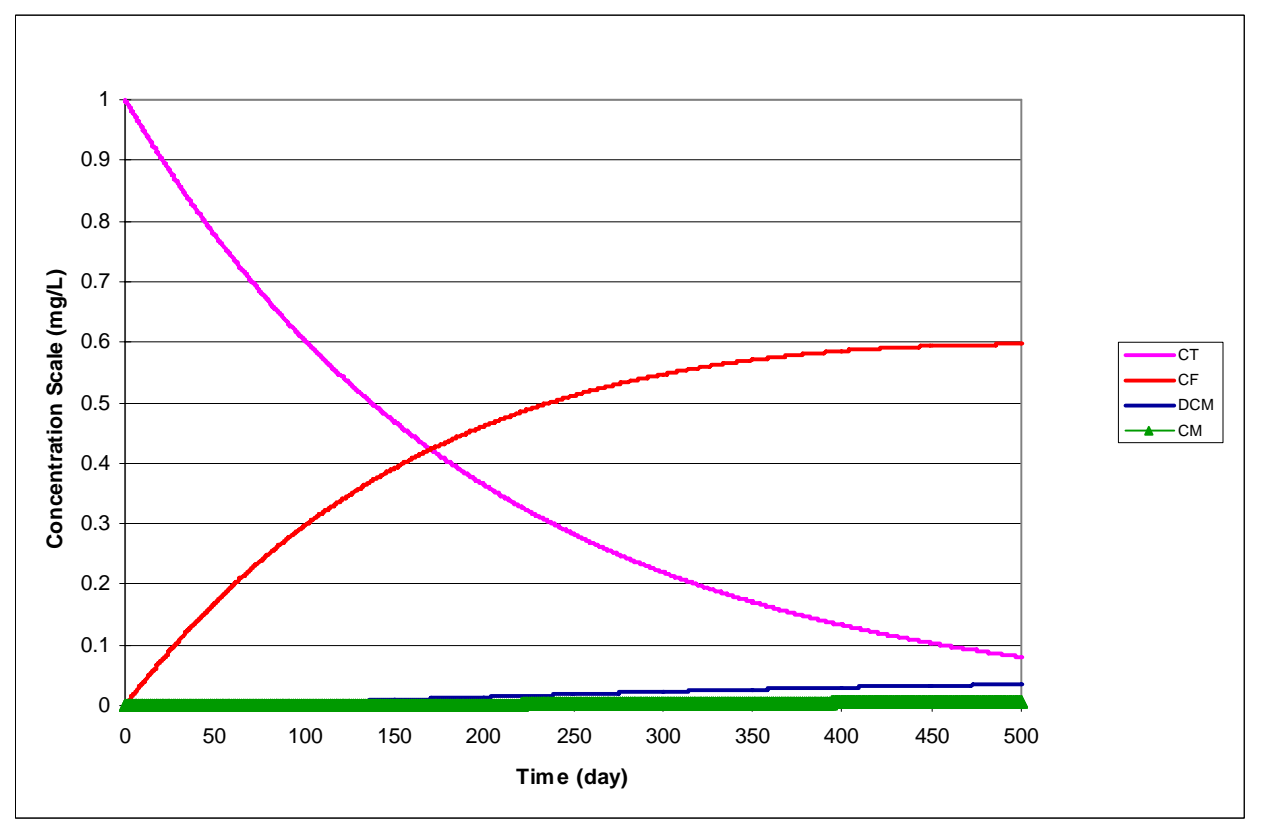

Figure 11. Dechlorination of CT Using the Parameter Values Shown in Table 14 - The initial concentration for CT was $1 \mathrm{mg} / \mathrm{L}$. All other species concentrations started at zero. 


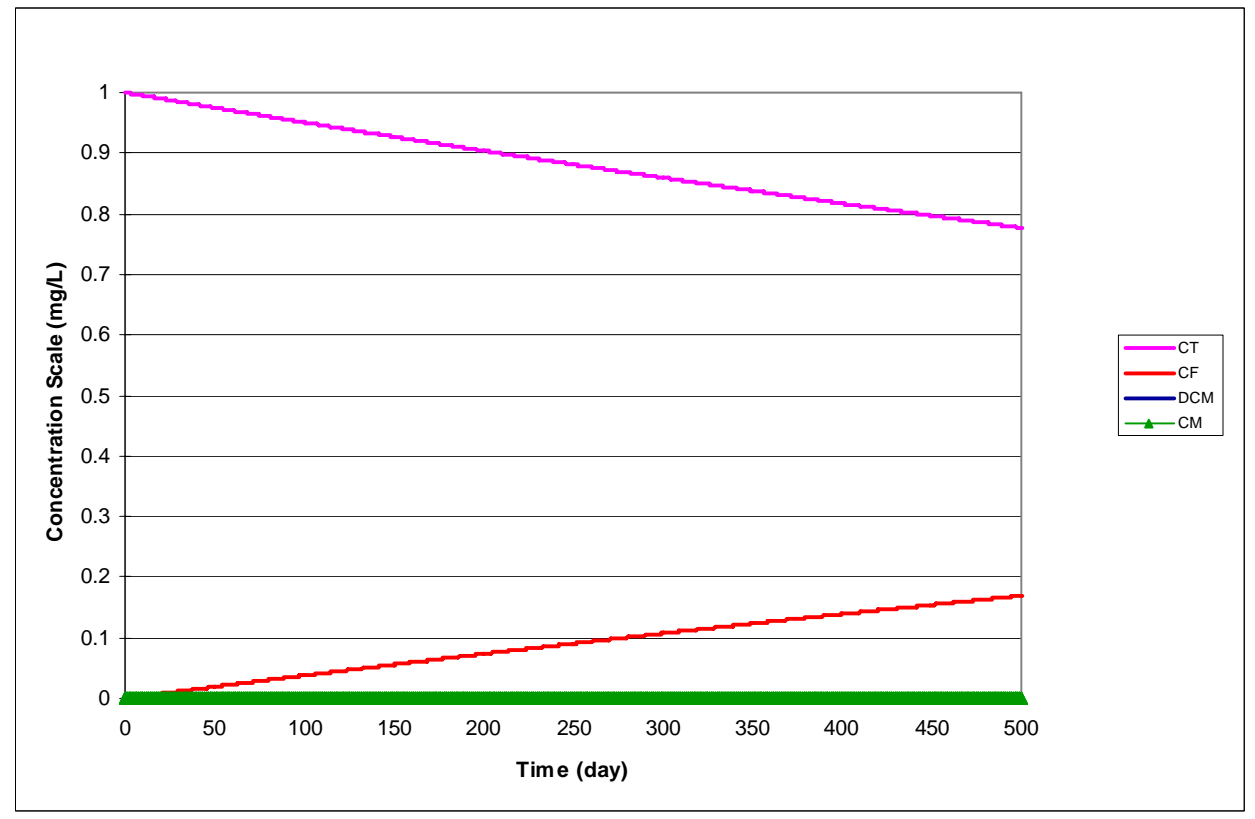

Figure 12. Dechlorination of CT Using the Parameter Values Shown in Table 15 - The initial concentration for CT was $1 \mathrm{mg} / \mathrm{L}$. All other species concentrations started at zero.

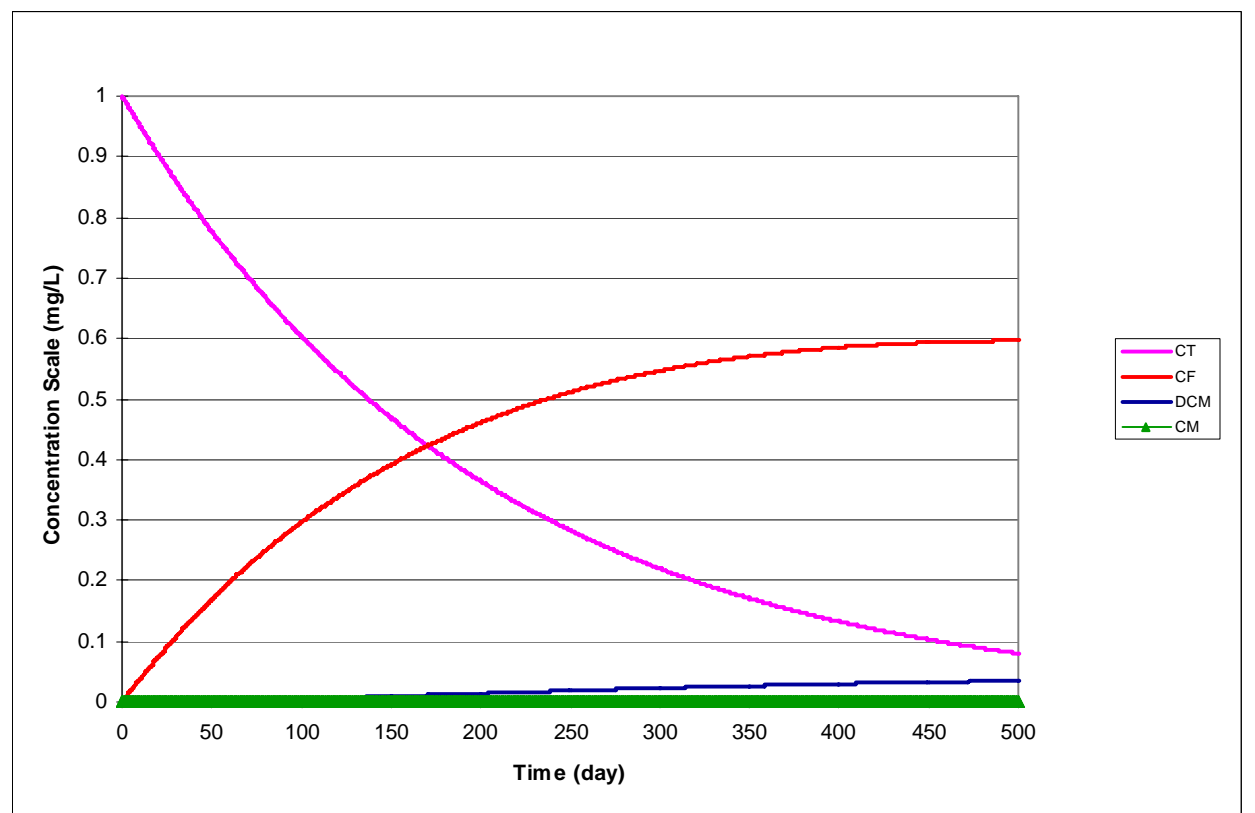

Figure 13. Dechlorination of CT Using the Parameter Values Shown in Table 16 - The initial concentration for CT was $1 \mathrm{mg} / \mathrm{L}$. All other species concentrations started at zero. 


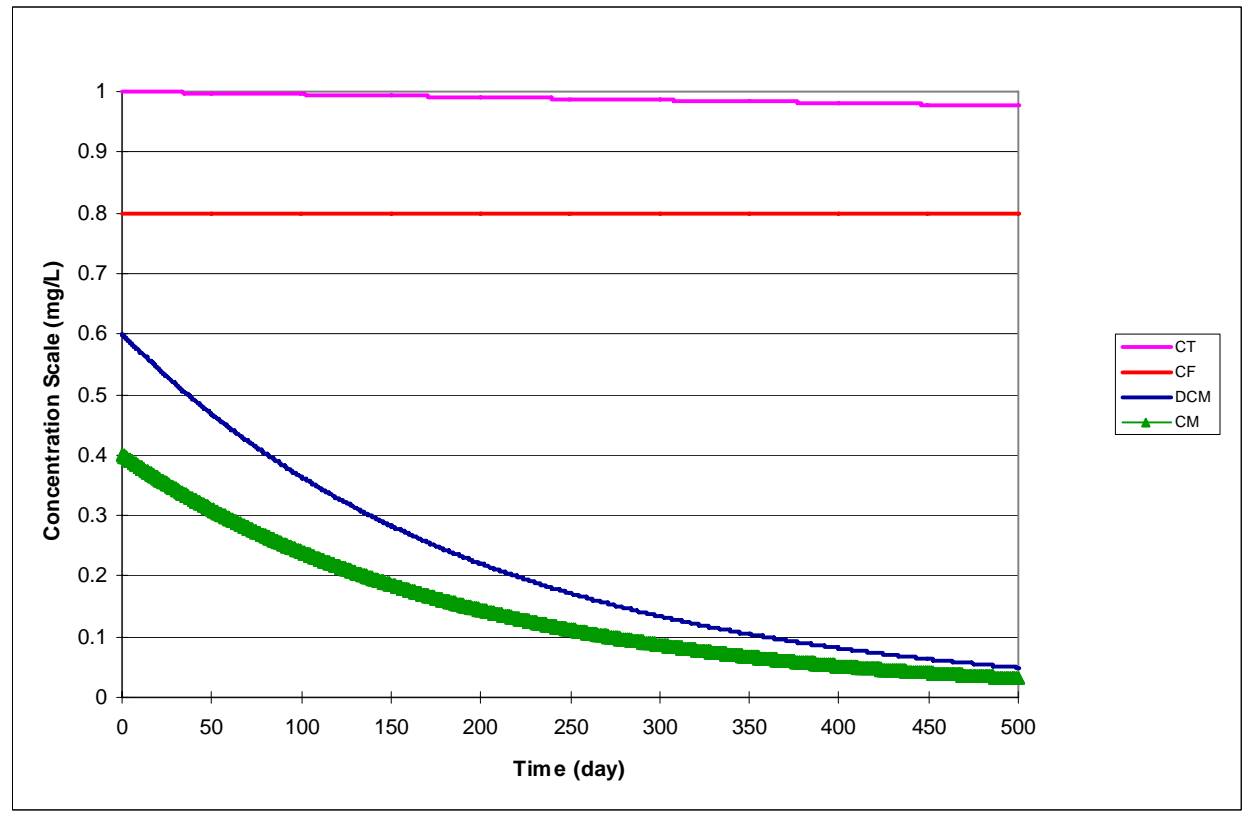

Figure 14. Aerobic and Abiotic Degradation Using the Parameter Values Shown in Table 17 The initial concentrations for CT, CF, DCM, and CM were 1, 0.8, 0.6, and $0.4 \mathrm{mg} / \mathrm{L}$, respectively. 


\subsection{Dechlorination of 1,1,2,2-Tetrachloroethane and Chloroethenes}

\subsection{Conceptual Model for Dechlorination Reactions}

This reaction module describes dechlorination of 1,1,2,2-tetrachloroethane, tetrachloroethene, and related daughter products (including 1,1,2-TCA and 1,2-DCA) using first-order rate expressions. The module includes abiotic, aerobic, and anoxic/anaerobic reaction pathways, which the user may selectively turn off by setting the (spatially variable) values of the stoichiometric yields and/or the reaction rate constants to zero. See the section on RT3D MNA/EA Reaction Module Commonalities and the Discussion of Select Reaction Parameters for additional information on features common to all of these MNA/EA reaction modules and explanation of key reaction parameters.

Table 18 lists the chemical species included in this reaction module. Dechlorination reactions for chlorinated ethane contaminants can result in formation of chlorinated ethene species, so this reaction module combines the reaction pathways for these two groups of contaminants. Figure 15 shows the conceptual model describing the potential biotic and abiotic degradation pathways of both chlorinated ethene and chlorinated ethane contaminants. See the conceptual model discussion for the Mixed Chloroethene/ Chloroethane/Chloromethane Dechlorination reaction module for information on the development of the reaction pathways and the assumption of firstorder reaction kinetics. 
Table 18. Chemical Species Included in the Dechlorination of 1,1,2,2-Tetrachloroethane and Chloroethenes Reaction Module

\begin{tabular}{|c|c|c|c|c|c|c|}
\hline No. & Abbreviation $^{\mathbf{a}}$ & Chemical Name & Selected Alternate Name & $\begin{array}{c}\text { CAS }^{b} \\
\text { Registry } \\
\text { Number }\end{array}$ & $\begin{array}{c}\text { Molecular } \\
\text { Weight }^{\mathrm{c}} \\
(\mathrm{g} / \mathrm{mol})\end{array}$ & $\begin{array}{l}\text { Chemical } \\
\text { Formula }\end{array}$ \\
\hline 1 & TeCA & 1,1,2,2-Tetrachloroethane & $1,1,2,2-\mathrm{TeCA}$ & $79-34-5$ & 167.84928 & $\mathrm{C}_{2} \mathrm{H}_{2} \mathrm{Cl}_{4}$ \\
\hline 2 & TCA & 1,1,2-Trichloroethane & $\begin{array}{l}\text { Vinyl Trichloride; } \\
\text { 1,1,2-TCA }\end{array}$ & $79-00-5$ & 133.40422 & $\mathrm{C}_{2} \mathrm{H}_{3} \mathrm{Cl}_{3}$ \\
\hline 3 & DCA & 1,2-Dichloroethane & $\begin{array}{l}\text { Ethane Dichloride; } \\
\text { 1,2-DCA }\end{array}$ & $107-06-2$ & 98.95916 & $\mathrm{C}_{2} \mathrm{H}_{4} \mathrm{Cl}_{2}$ \\
\hline 4 & $\mathrm{CA}$ & Chloroethane & Ethyl Chloride & $75-00-3$ & 64.5141 & $\mathrm{C}_{2} \mathrm{H}_{5} \mathrm{Cl}$ \\
\hline 5 & PCE & Tetrachloroethene & $\begin{array}{l}\text { Tetrachloroethylene; } \\
\text { Perchloroethylene }\end{array}$ & $127-18-4$ & 165.8334 & $\mathrm{C}_{2} \mathrm{Cl}_{4}$ \\
\hline 6 & TCE & Trichloroethene & Trichloroethylene & 79-01-6 & 131.38834 & $\mathrm{C}_{2} \mathrm{HCl}_{3}$ \\
\hline 7 & cDCE & cis-1,2-Dichloroethene & $\begin{array}{l}\text { cis-1,2-Dichloroethylene; } \\
\text { cis-1,2-DCE; cis-DCE }\end{array}$ & $156-59-2$ & 96.94328 & $\mathrm{C}_{2} \mathrm{H}_{2} \mathrm{Cl}_{2}$ \\
\hline 8 & $\mathrm{tDCE}$ & trans-1,2-Dichloroethene & $\begin{array}{l}\text { trans-1,2-Dichloroethylene; } \\
\text { trans-1,2-DCE; trans-DCE }\end{array}$ & $156-60-5$ & 96.94328 & $\mathrm{C}_{2} \mathrm{H}_{2} \mathrm{Cl}_{2}$ \\
\hline 9 & 11DCE & 1,1-Dichloroethene & $\begin{array}{l}\text { Vinylidene Chloride; } \\
\text { 1,1-DCE }\end{array}$ & $75-35-4$ & 96.94328 & $\mathrm{C}_{2} \mathrm{H}_{2} \mathrm{Cl}_{2}$ \\
\hline 10 & $\mathrm{VC}$ & Chloroethene & Vinyl Chloride & 75-01-4 & 62.49822 & $\mathrm{C}_{2} \mathrm{H}_{3} \mathrm{Cl}$ \\
\hline 11 & Tracer & Conservative Tracer & - & $\mathrm{N} / \mathrm{A}$ & $\mathrm{N} / \mathrm{A}$ & $\mathrm{N} / \mathrm{A}$ \\
\hline
\end{tabular}

a These abbreviations refer to the specific chemicals listed here and should not be confused with different chemicals that may use the same abbreviation in other reaction modules.

${ }^{\mathrm{b}} \mathrm{CAS}=$ Chemical Abstracts Service (see http://www.cas.org/EO/regsys.html)

${ }^{c}$ Based on International Union of Pure and Applied Chemistry values reported by Loss [2003].

N/A - Not Applicable 


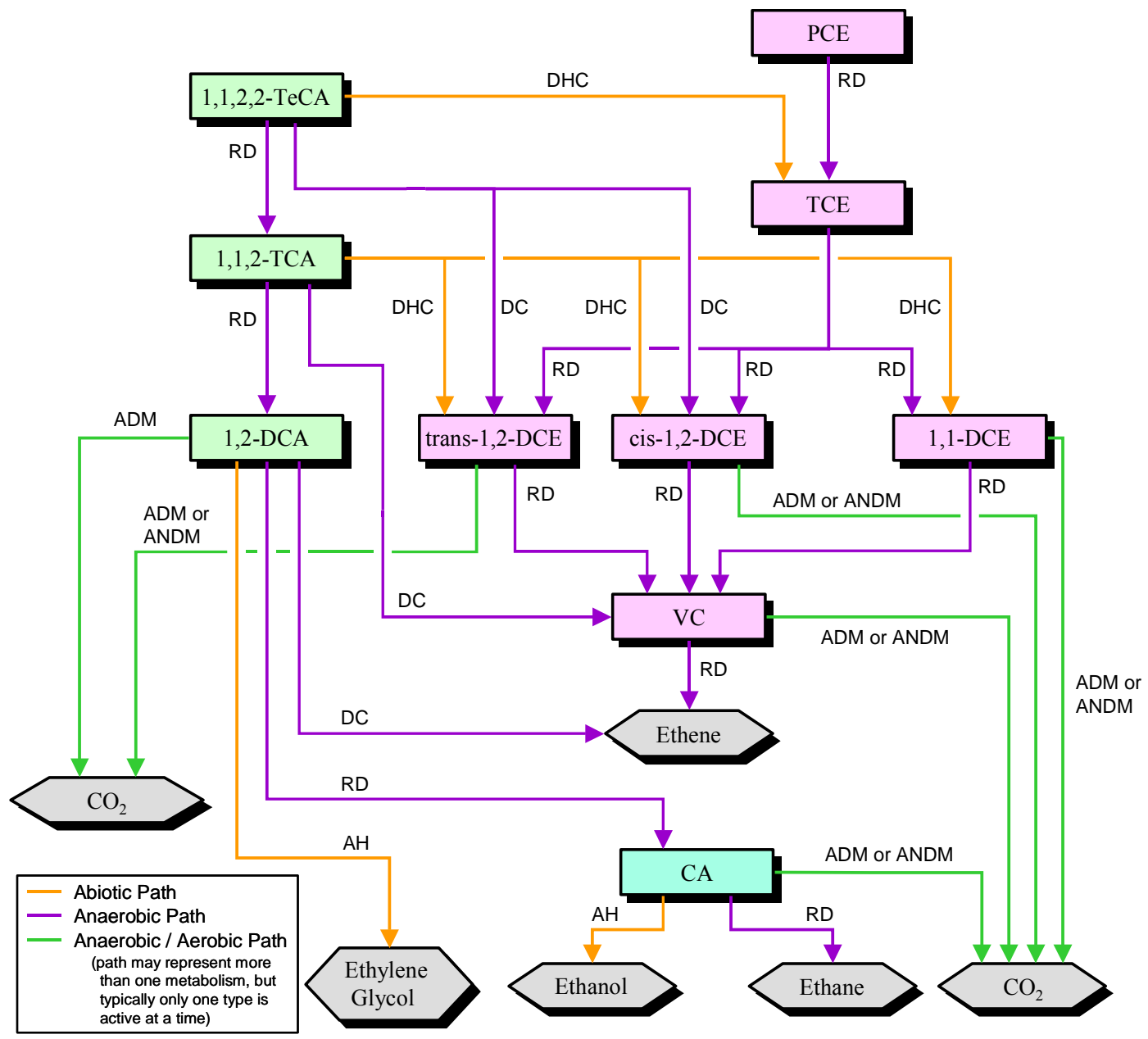

Figure 15. Conceptual Model for Dechlorination Reactions in the Dechlorination of 1,1,2,2Tetrachloroethane and Chloroethenes Reaction Module - Species in hexagonal shaded boxes are innocuous products and are not tracked in the reaction module. The reaction types for each pathway are described in Table 3.

\subsection{Reaction Equations}

The set of ODEs comprising this reaction module are shown in Equations 38 to 48. These ODEs describe the reaction kinetics for the 11 chemical species in Table 18. See Table 19 for a detailed itemization of all reaction parameters used in this reaction module.

$$
\begin{aligned}
& \frac{d C_{T e C A}}{d t}=\left(-k a n_{T e C A} \cdot C_{T e C A}-k a b_{T e C A} \cdot C_{T e C A}\right) \\
& \frac{d C_{T C A}}{d t}=\left(Y_{\frac{T C A}{T e C A}} \cdot F a n_{\frac{T C A}{T e C A}} \cdot k a n_{T e C A} \cdot C_{T e C A}-k a n_{T C A} \cdot C_{T C A}-k a b_{T C A} \cdot C_{T C A}\right)
\end{aligned}
$$


$\frac{d C_{D C A}}{d t}=\left(\begin{array}{l}Y_{\frac{D C A}{T C A}} \cdot \operatorname{Fan}_{\frac{D C A}{T C A}} \cdot \operatorname{kan}_{T C A} \cdot C_{T C A} \\ \quad-k a n_{D C A} \cdot C_{D C A}-k a b_{D C A} \cdot C_{D C A}-k a e_{D C A} \cdot C_{D C A}\end{array}\right)$

$\frac{d C_{C A}}{d t}=\left(\begin{array}{rl}Y_{C A} \cdot F^{D C A} & \frac{F_{C A}}{D C A} \\ \quad & k a n_{D C A} \cdot C_{D C A} \\ & -k a n_{C A} \cdot C_{C A}-k a b_{C A} \cdot C_{C A}-k a e_{C A} \cdot C_{C A}\end{array}\right)$

$\frac{d C_{P C E}}{d t}=\left(-k a n_{P C E} \cdot C_{P C E}\right)$

$\frac{d C_{T C E}}{d t}=\left(Y_{\frac{T C E}{P C E}} \cdot \mathrm{kan}_{P C E} \cdot C_{P C E}+Y_{\frac{T C E}{T e C A}} \cdot k a b_{T e C A} \cdot C_{T e C A}-k a n_{T C E} \cdot C_{T C E}\right)$

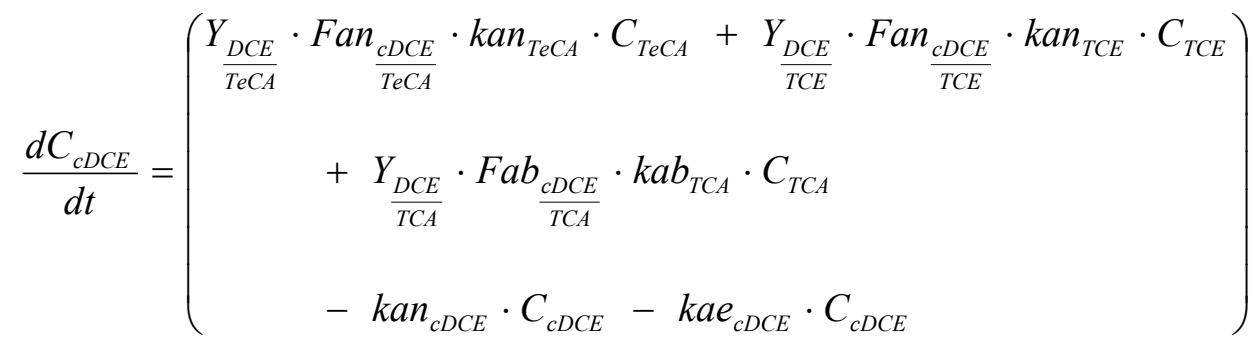

$\frac{d C_{t D C E}}{d t}=\left(\begin{array}{c}Y_{\frac{D C E}{T e C A}} \cdot F_{\frac{t D C E}{T e C A}} \cdot \mathrm{kan}_{T e C A} \cdot C_{T e C A}+Y_{\frac{D C E}{T C E}} \cdot \operatorname{Fan}_{\frac{t D C E}{T C E}} \cdot \mathrm{kan}_{T C E} \cdot C_{T C E} \\ +Y_{\frac{D C E}{T C A}} \cdot F a b_{\frac{t D C E}{T C A}} \cdot k a b_{T C A} \cdot C_{T C A} \\ -k a n_{t D C E} \cdot C_{t D C E}-k a e_{t D C E} \cdot C_{t D C E}\end{array}\right)$

$\frac{d C_{11 D C E}}{d t}=\left(\begin{array}{c}Y_{\frac{D C E}{T C E}} \cdot \operatorname{Fan}_{\frac{11 D C E}{T C E}} \cdot \mathrm{kan}_{T C E} \cdot C_{T C E}+Y_{\frac{D C E}{T C A}} \cdot F a b_{\frac{11 D C E}{T C A}} \cdot k a b_{T C A} \cdot C_{T C A} \\ -k a n_{11 D C E} \cdot C_{11 D C E}-k a e_{11 D C E} \cdot C_{11 D C E}\end{array}\right)$ 


$$
\begin{aligned}
& \frac{d C_{V C}}{d t}=\left(\begin{array}{c}
Y_{\frac{V C}{T C A}} \cdot F a n_{\frac{V C}{T C A}} \cdot \operatorname{kan}_{T C A} \cdot C_{T C A}+Y_{\frac{V C}{D C E}} \cdot F_{\frac{V C}{c D C E}} \cdot k a n_{C D C E} \cdot C_{C D C E} \\
+Y_{\frac{V C}{D C E}} \cdot F a n_{\frac{V C}{t D C E}} \cdot k a n_{t D C E} \cdot C_{t D C E} \\
+Y_{\frac{V C}{D C E}} \cdot F a n_{\frac{V C}{11 D C E}} \cdot \mathrm{kan}_{11 D C E} \cdot C_{11 D C E} \\
-k_{V C n_{V C}} \cdot C_{V C}-\mathrm{kae}_{V C} \cdot C_{V C}
\end{array}\right) \\
& \frac{d C_{\text {Tracer }}}{d t}=0.0 \quad \text { (Conservative [non-reactive] tracer.) }
\end{aligned}
$$

The first-order decay rate constants $\left[\mathrm{T}^{-1}\right]$ of the $\mathrm{i}^{\text {th }}$ species are represented in the equations above by the $k a n_{i}, k a e_{i}$, and $k a b_{i}$ terms for anaerobic biological reactions, aerobic biological reactions, or abiotic reactions, respectively. The concentration of the $\mathrm{i}^{\text {th }}$ species is represented by the $C_{i}$ term $\left[\mathrm{ML}^{-3}\right]$. The $R_{i}$ terms represent the retardation factor for the $\mathrm{i}^{\text {th }}$ species [unitless].

In cases where multiple daughter products may be produced from dechlorination of a single parent species, the amount of each daughter species that is produced is a function of a mass yield $\left[\mathrm{MM}^{-1}\right]$ and a stoichiometric dechlorination yield [mol/mol]. The mass yield value, $Y_{d / p}$, accounts for the difference in molecular weight between the parent species " $p$ " and the daughter species "d." All isomers of a daughter chemical have the same mass yield. Mass yield values are included in the reaction module code and do not need to be input by the user. The stoichiometric dechlorination yield represents the site-specific stoichiometry for each reaction pathway that occurs as either an anaerobic $\left(F a n_{d / p}\right)$ or an abiotic process $\left(F a b_{d / p}\right)$. The stoichiometric dechlorination yield is the fractional moles of daughter species that are produced by dechlorination of one mole of the parent species. The net yield is the product of the mass yield and the stoichiometric dechlorination yield. To preserve the mass balance, the values of the stoichiometric dechlorination yields are constrained by the relations in Equations 49 to 56.

$$
\begin{aligned}
& F a n_{\frac{T C A}{T e C A}}+F a n_{\frac{c D C E}{T e C A}}+F a n_{\frac{t D C E}{T e C A}}=1.0 \\
& F a n_{\frac{D C A}{T C A}}+F a n_{\frac{V C}{T C A}}=1.0 \\
& F a n_{\frac{c D C E}{T C E}}+F a n_{\frac{t D C E}{T C E}}+F a n_{\frac{11 D C E}{T C E}}=1.0 \\
& F a b_{\frac{c D C E}{T C A}}+F a b_{\frac{t D C E}{T C A}}+F a b_{\frac{11 D C E}{T C A}}=1.0
\end{aligned}
$$




$$
\begin{aligned}
& \text { Fan }_{\frac{C A}{D C A}} \leq 1.0 \\
& \text { Fan }_{\frac{V C}{c D C E}} \leq 1.0 \\
& \text { Fan }_{\frac{V C}{t D C E}} \leq 1.0 \\
& \text { Fan }_{\frac{V C}{11 D C E}} \leq 1.0
\end{aligned}
$$

\subsection{Required Input}

The reaction parameters for this reaction module are made available to RT3D as part of the input for the Reaction Package. The Reaction Package input file structure is discussed in the RT3D manual and addendum [Clement, 1997; Clement and Johnson, 2002]. The 35 reaction parameters that must be specified for this reaction module are listed in Table 19 in the required order (ID Number) with units and a description. Site-specific knowledge from field data or laboratory tests should be applied to determine an appropriate model configuration for reaction parameters (i.e., the values and the spatial distribution).

Table 19. Input Parameters for the Dechlorination of 1,1,2,2-Tetrachloroethane and Chloroethenes Reaction Module

\begin{tabular}{|c|c|c|c|l|}
\hline \hline $\begin{array}{c}\text { ID } \\
\#\end{array}$ & Parameter & $\begin{array}{c}\text { Fortran } \\
\text { Variable }\end{array}$ & Units & Description \\
\hline 1 & $F a b_{\frac{c D C E}{T C A}}$ & fab_cdce_tca & $\mathrm{mol} / \mathrm{mol}$ & $\begin{array}{c}\text { Moles of cis-1,2-DCE produced from abiotic decay of one mole } \\
\text { of TCA }\end{array}$ \\
\hline 2 & $F a b_{\frac{t D C E}{T C A}}$ & fab_tdce_tca & $\mathrm{mol} / \mathrm{mol}$ & $\begin{array}{c}\text { Moles of trans-1,2-DCE produced from abiotic decay of one } \\
\text { mole of TCA }\end{array}$ \\
\hline 3 & $F a b_{\frac{11 D C E}{T C A}}$ & fab_11dce_tca & $\mathrm{mol} / \mathrm{mol}$ & $\begin{array}{c}\text { Moles of 1,1-DCE produced from abiotic decay of one mole of } \\
\text { TCA }\end{array}$ \\
\hline 5 & $F a n_{\frac{T C A}{T e C A}}$ & fan_tca_teca & $\mathrm{mol} / \mathrm{mol}$ & $\begin{array}{c}\text { Moles of TCA produced from anaerobic decay of one mole of } \\
\text { TeCA }\end{array}$ \\
\hline 6 & $F_{\frac{c D C E}{T e C A}}$ & fan_cdce_teca & $\mathrm{mol} / \mathrm{mol}$ & $\begin{array}{c}\text { Moles of cis-1,2-DCE produced from anaerobic decay of one } \\
\text { mole of TeCA }\end{array}$ \\
\hline 7 & $F_{T a C A}$ & fan_tdce_teca & $\mathrm{mol} / \mathrm{mol}$ & $\begin{array}{c}\text { Moles of trans-1,2-DCE produced from anaerobic decay of one } \\
\text { mole of TeCA }\end{array}$ \\
\hline
\end{tabular}


Table 19. (contd)

\begin{tabular}{|c|c|c|c|c|}
\hline $\begin{array}{l}\text { ID } \\
\#\end{array}$ & Parameter & $\begin{array}{l}\text { Fortran } \\
\text { Variable }\end{array}$ & Units & Description \\
\hline 8 & $\operatorname{Fan}_{\frac{V C}{T C A}}$ & fan_vc_tca & $\mathrm{mol} / \mathrm{mol}$ & $\begin{array}{l}\text { Moles of VC produced from anaerobic decay of one mole of } \\
\text { TCA }\end{array}$ \\
\hline 9 & $\operatorname{Fan}_{\frac{C A}{D C A}}$ & fan_ca_dca & $\mathrm{mol} / \mathrm{mol}$ & $\begin{array}{l}\text { Moles of CA produced from anaerobic decay of one mole of } \\
\text { DCA }\end{array}$ \\
\hline 10 & $\operatorname{Fan}_{\frac{c D C E}{T C E}}$ & fan_cdce_tce & $\mathrm{mol} / \mathrm{mol}$ & $\begin{array}{l}\text { Moles of cis-1,2-DCE produced from anaerobic decay of one } \\
\text { mole of TCE }\end{array}$ \\
\hline 11 & $\operatorname{Fan}_{\frac{t D C E}{T C E}}$ & fan_tdce_tce & $\mathrm{mol} / \mathrm{mol}$ & $\begin{array}{l}\text { Moles of trans-1,2-DCE produced from anaerobic decay of one } \\
\text { mole of TCE }\end{array}$ \\
\hline 12 & $\operatorname{Fan}_{\frac{11 D C E}{T C E}}$ & fan_11dce_tce & $\mathrm{mol} / \mathrm{mol}$ & $\begin{array}{l}\text { Moles of 1,1-DCE produced from anaerobic decay of one mole } \\
\quad \text { of TCE }\end{array}$ \\
\hline 13 & Fan $_{\frac{V C}{c D C E}}$ & fan_vc_cdce & $\mathrm{mol} / \mathrm{mol}$ & $\begin{array}{l}\text { Moles of VC produced from anaerobic decay of one mole of } \\
\text { cis-1,2-DCE }\end{array}$ \\
\hline 14 & Fan $_{\frac{V C}{t D C E}}$ & fan_vc_tdce & $\mathrm{mol} / \mathrm{mol}$ & $\begin{array}{l}\text { Moles of VC produced from anaerobic decay of one mole of } \\
\text { trans-1,2-DCE }\end{array}$ \\
\hline 15 & Fan $_{\frac{V C}{11 D C E}}$ & fan_vc_11dce & $\mathrm{mol} / \mathrm{mol}$ & $\begin{array}{l}\text { Moles of VC produced from anaerobic decay of one mole of } \\
\text { 1,1-DCE }\end{array}$ \\
\hline 16 & $k a b_{\text {TeCA }}$ & kab_teca & $1 /$ day & First-order decay coefficient for abiotic dechlorination of $\mathrm{TeCA}$ \\
\hline 17 & $k a b_{T C A}$ & kab_tca & 1/day & First-order decay coefficient for abiotic dechlorination of TCA \\
\hline 18 & $k a b_{D C A}$ & kab_dca & 1/day & First-order decay coefficient for abiotic dechlorination of DCA \\
\hline 19 & $k a b_{C A}$ & kab_ca & 1/day & First-order decay coefficient for abiotic dechlorination of CA \\
\hline 20 & $\mathrm{kan}_{T e C A}$ & kan_teca & $1 /$ day & $\begin{array}{l}\text { First-order decay coefficient for anaerobic dechlorination of } \\
\text { TeCA }\end{array}$ \\
\hline 21 & $\operatorname{kan}_{T C A}$ & kan_tca & $1 /$ day & $\begin{array}{l}\text { First-order decay coefficient for anaerobic dechlorination of } \\
\text { TCA }\end{array}$ \\
\hline 22 & $\operatorname{kan}_{D C A}$ & kan_dca & 1/day & $\begin{array}{l}\text { First-order decay coefficient for anaerobic dechlorination of } \\
\text { DCA }\end{array}$ \\
\hline 23 & $k^{\prime a n} n_{C A}$ & kan_ca & 1/day & First-order decay coefficient for anaerobic dechlorination of $\mathrm{CA}$ \\
\hline 24 & $\operatorname{kan}_{P C E}$ & kan_pce & $1 /$ day & $\begin{array}{l}\text { First-order decay coefficient for anaerobic dechlorination of } \\
\quad \text { PCE }\end{array}$ \\
\hline 25 & $\operatorname{kan}_{T C E}$ & kan_tce & 1/day & $\begin{array}{l}\text { First-order decay coefficient for anaerobic dechlorination of } \\
\text { TCE }\end{array}$ \\
\hline 26 & $k a n_{C D C E}$ & kan_cdce & 1/day & $\begin{array}{l}\text { First-order decay coefficient for anaerobic dechlorination of } \\
\text { cis-1,2-DCE }\end{array}$ \\
\hline 27 & $k^{\prime} a n_{t D C E}$ & kan_tdce & 1/day & $\begin{array}{l}\text { First-order decay coefficient for anaerobic dechlorination of } \\
\text { trans-1,2-DCE }\end{array}$ \\
\hline
\end{tabular}


Table 19. (contd)

\begin{tabular}{|c|c|c|c|c|}
\hline $\begin{array}{c}\text { ID } \\
\#\end{array}$ & Parameter & $\begin{array}{c}\text { Fortran } \\
\text { Variable }\end{array}$ & Units & Description \\
\hline 28 & $k a n_{11 D C E}$ & kan_11dce & 1/day & $\begin{array}{l}\text { First-order decay coefficient for anaerobic dechlorination of } \\
\text { 1,1-DCE }\end{array}$ \\
\hline 29 & $\mathrm{kan}_{V C}$ & kan_vc & $1 /$ day & First-order decay coefficient for anaerobic dechlorination of $\mathrm{VC}$ \\
\hline 30 & $k a e_{D C A}$ & kae_dca & $1 /$ day & First-order decay coefficient for aerobic dechlorination of DCA \\
\hline 31 & $k a e_{C A}$ & kae_ca & 1/day & First-order decay coefficient for aerobic dechlorination of CA \\
\hline 32 & $k a e_{C D C E}$ & kae_cdce & 1/day & $\begin{array}{l}\text { First-order decay coefficient for aerobic dechlorination of } \\
\text { cis-1,2-DCE }\end{array}$ \\
\hline 33 & $k a e_{t D C E}$ & kae_tdce & 1/day & $\begin{array}{l}\text { First-order decay coefficient for aerobic dechlorination of } \\
\text { trans-1,2-DCE }\end{array}$ \\
\hline 34 & $k a e_{11 D C E}$ & kae_11dce & 1/day & $\begin{array}{l}\text { First-order decay coefficient for aerobic dechlorination of } \\
\text { 1,1-DCE }\end{array}$ \\
\hline 35 & $k a e_{V C}$ & kae_vc & 1/day & First-order decay coefficient for aerobic dechlorination of $\mathrm{VC}$ \\
\hline
\end{tabular}

\subsection{Example Simulations}

Simulations with this reaction module were conducted with RT3D in a batch reactor (no flow) mode to show examples of how the reaction module simulates the pattern of dechlorination. The parameter values for each example simulation are listed in Tables 20 through 23 . These parameters are arbitrary values and are not directly related to any specific laboratory data. Sitespecific values would need to be determined as part of a calibration process. Results for these example batch simulations are shown in the Figures 16 through 19, respectively. 
Table 20. Parameter Values for Example Simulation 1 - Base Case Anaerobic Conditions with the Dechlorination of 1,1,2,2-Tetrachloroethane and Chloroethenes Reaction Module

\begin{tabular}{|c|l|c|c|c|l|c|c|}
\hline \hline ID \# & Fortran Variable & Value & Units & ID \# & Fortran Variable & Value & Units \\
\hline 1 & fab_cdce_tca & 0.2 & $\mathrm{~mol} / \mathrm{mol}$ & 19 & kab_ca & 0.001 & $1 /$ day \\
\hline 2 & fab_tdce_tca & 0.8 & $\mathrm{~mol} / \mathrm{mol}$ & 20 & kan_teca & 0.005 & $1 /$ day \\
\hline 3 & fab_11dce_tca & 0 & $\mathrm{~mol} / \mathrm{mol}$ & 21 & kan_tca & 0.01 & $1 /$ day \\
\hline 4 & fan_tca_teca & 0 & $\mathrm{~mol} / \mathrm{mol}$ & 22 & kan_dca & 0.025 & $1 /$ day \\
\hline 5 & fan_cdce_teca & 0.2 & $\mathrm{~mol} / \mathrm{mol}$ & 23 & kan_ca & 0.025 & $1 /$ day \\
\hline 6 & fan_tdce_teca & 0 & $\mathrm{~mol} / \mathrm{mol}$ & 24 & kan_pce & 0.025 & $1 /$ day \\
\hline 7 & fan_dca_tca & 0.2 & $\mathrm{~mol} / \mathrm{mol}$ & 25 & kan_tce & 0.025 & $1 /$ day \\
\hline 8 & fan_vctca & 0.8 & $\mathrm{~mol} / \mathrm{mol}$ & 26 & kan_cdce & 0.025 & $1 /$ day \\
\hline 9 & fan_ca_dca & 0.2 & $\mathrm{~mol} / \mathrm{mol}$ & 27 & kan_tdce & 0.025 & $1 /$ day \\
\hline 10 & fan_cdce_tce & 0.8 & $\mathrm{~mol} / \mathrm{mol}$ & 28 & kan_11dce & 0.025 & $1 /$ day \\
\hline 11 & fan_tdce_tce & 0.2 & $\mathrm{~mol} / \mathrm{mol}$ & 29 & kan_vc & 0.0025 & $1 /$ day \\
\hline 12 & fan_11dce_tce & 0 & $\mathrm{~mol} / \mathrm{mol}$ & 30 & kae_dca & 0 & $1 /$ day \\
\hline 13 & fan_vc_cdce & 0.8 & $\mathrm{~mol} / \mathrm{mol}$ & 31 & kae_ca & 0 & $1 /$ day \\
\hline 14 & fan_vcttce & 0.8 & $\mathrm{~mol} / \mathrm{mol}$ & 32 & kae_cdce & 0 & $1 /$ day \\
\hline 15 & fan_vc_11dce & 0.8 & $\mathrm{~mol} / \mathrm{mol}$ & 33 & kae_tdce & 0 & $1 /$ day \\
\hline 16 & kab_teca & 0.006 & $1 /$ day & 34 & kae_11dce & 0 & $1 /$ day \\
\hline 17 & kab_tca & 0 & $1 /$ day & 35 & kae_vc & 0 & $1 /$ day \\
\hline 18 & kab_dca & 0.00003 & $1 /$ day & & & & \\
\hline \hline
\end{tabular}

Table 21. Parameter Values for Example Simulation 2 - Rates at $10 \%$ of Example Simulation 1 - with the Dechlorination of 1,1,2,2-Tetrachloroethane and Chloroethenes Reaction Module

\begin{tabular}{|c|l|c|c|c|l|c|c|}
\hline \hline ID \# & Fortran Variable & Value & Units & ID \# & Fortran Variable & Value & Units \\
\hline 1 & fab_cdce_tca & 0.2 & $\mathrm{~mol} / \mathrm{mol}$ & 19 & kab_ca & 0.0001 & $1 /$ day \\
\hline 2 & fab_tdce_tca & 0.8 & $\mathrm{~mol} / \mathrm{mol}$ & 20 & kan_teca & 0.0005 & $1 /$ day \\
\hline 3 & fab_11dce_tca & 0 & $\mathrm{~mol} / \mathrm{mol}$ & 21 & kan_tca & 0.001 & $1 /$ day \\
\hline 4 & fan_tca_teca & 0 & $\mathrm{~mol} / \mathrm{mol}$ & 22 & kan_dca & 0.0025 & $1 /$ day \\
\hline 5 & fan_cdce_teca & 0.2 & $\mathrm{~mol} / \mathrm{mol}$ & 23 & kan_ca & 0.0025 & $1 /$ day \\
\hline 6 & fan_tdce_teca & 0 & $\mathrm{~mol} / \mathrm{mol}$ & 24 & kan_pce & 0.0025 & $1 /$ day \\
\hline 7 & fan_dca_tca & 0.2 & $\mathrm{~mol} / \mathrm{mol}$ & 25 & kan_tce & 0.0025 & $1 /$ day \\
\hline 8 & fan_vctca & 0.8 & $\mathrm{~mol} / \mathrm{mol}$ & 26 & kan_cdce & 0.0025 & $1 /$ day \\
\hline 9 & fan_ca_dca & 0.2 & $\mathrm{~mol} / \mathrm{mol}$ & 27 & kan_tdce & 0.0025 & $1 /$ day \\
\hline 10 & fan_cdce_tce & 0.8 & $\mathrm{~mol} / \mathrm{mol}$ & 28 & kan_11dce & 0.0025 & $1 /$ day \\
\hline 11 & fan_tdce_tce & 0.2 & $\mathrm{~mol} / \mathrm{mol}$ & 29 & kan_vc & 0.00025 & $1 /$ day \\
\hline 12 & fan_11dce_tce & 0 & $\mathrm{~mol} / \mathrm{mol}$ & 30 & kae_dca & 0 & $1 /$ day \\
\hline 13 & fan_vc_cdce & 0.8 & $\mathrm{~mol} / \mathrm{mol}$ & 31 & kaeca & 0 & $1 /$ day \\
\hline 14 & fan_vc_tdce & 0.8 & $\mathrm{~mol} / \mathrm{mol}$ & 32 & kae_cdce & 0 & $1 /$ day \\
\hline 15 & fan_vc_11dce & 0.8 & $\mathrm{~mol} / \mathrm{mol}$ & 33 & kae_tdce & 0 & $1 /$ day \\
\hline 16 & kab_teca & 0.0006 & $1 / \mathrm{day}$ & 34 & kae_1ldce & 0 & $1 /$ day \\
\hline 17 & kab_tca & 0 & $1 / \mathrm{day}$ & 35 & kae_vc & 0 & $1 /$ day \\
\hline 18 & kab_dca & 0.000003 & $1 / \mathrm{day}$ & & & & \\
\hline \hline
\end{tabular}


Table 22. Parameter Values for Example Simulation 3 -Different F Values Than Example Simulation 1 - with the Dechlorination of 1,1,2,2-Tetrachloroethane and Chloroethenes Reaction Module.

\begin{tabular}{|c|c|c|c|c|c|c|c|}
\hline ID \# & Fortran Variable & Value & Units & ID \# & Fortran Variable & Value & Units \\
\hline 1 & fab_cdce_tca & 0.2 & $\mathrm{~mol} / \mathrm{mol}$ & 19 & kab_ca & 0.001 & 1/day \\
\hline 2 & fab_tdce_tca & 0.8 & $\mathrm{~mol} / \mathrm{mol}$ & 20 & kan_teca & 0.005 & 1/day \\
\hline 3 & fab_11dce_tca & 0 & $\mathrm{~mol} / \mathrm{mol}$ & 21 & kan_tca & 0.01 & 1/day \\
\hline 4 & fan_tca_teca & 0.8 & $\mathrm{~mol} / \mathrm{mol}$ & 22 & kan_dca & 0.025 & 1/day \\
\hline 5 & fan_cdce_teca & 0 & $\mathrm{~mol} / \mathrm{mol}$ & 23 & kan_ca & 0.025 & 1/day \\
\hline 6 & fan_tdce_teca & 0.2 & $\mathrm{~mol} / \mathrm{mol}$ & 24 & kan_pce & 0.025 & 1/day \\
\hline 7 & fan_dca_tca & 0.8 & $\mathrm{~mol} / \mathrm{mol}$ & 25 & kan_tce & 0.025 & 1/day \\
\hline 8 & fan_vc_tca & 0.2 & $\mathrm{~mol} / \mathrm{mol}$ & 26 & kan_cdce & 0.025 & 1/day \\
\hline 9 & fan_ca_dca & 0.8 & $\mathrm{~mol} / \mathrm{mol}$ & 27 & kan_tdce & 0.025 & 1/day \\
\hline 10 & fan_cdce_tce & 0.2 & $\mathrm{~mol} / \mathrm{mol}$ & 28 & kan_11dce & 0.025 & 1/day \\
\hline 11 & fan_tdce_tce & 0 & $\mathrm{~mol} / \mathrm{mol}$ & 29 & kan_vc & 0.0025 & 1/day \\
\hline 12 & fan_11dce_tce & 0.8 & $\mathrm{~mol} / \mathrm{mol}$ & 30 & kae_dca & 0 & 1/day \\
\hline 13 & fan_vc_cdce & 0.2 & $\mathrm{~mol} / \mathrm{mol}$ & 31 & kae_ca & 0 & 1/day \\
\hline 14 & fan_vc_tdce & 0.2 & $\mathrm{~mol} / \mathrm{mol}$ & 32 & kae_cdce & 0 & 1/day \\
\hline 15 & fan_vc_11dce & 0.2 & $\mathrm{~mol} / \mathrm{mol}$ & 33 & kae_tdce & 0 & $1 /$ day \\
\hline 16 & kab_teca & 0.006 & 1/day & 34 & kae_11dce & 0 & 1/day \\
\hline 17 & kab_tca & 0 & 1/day & 35 & kae_vc & 0 & 1/day \\
\hline 18 & kab_dca & 0.00003 & 1/day & & & & \\
\hline
\end{tabular}

Table 23. Parameter Values for Example Simulation 4 - Base Case Aerobic Conditions - with the Dechlorination of 1,1,2,2-Tetrachloroethane and Chloroethenes Reaction Module

\begin{tabular}{|c|c|c|c|c|c|c|c|}
\hline ID \# & Fortran Variable & Value & Units & ID \# & Fortran Variable & Value & Units \\
\hline 1 & fab_cdce_tca & 0.2 & $\mathrm{~mol} / \mathrm{mol}$ & 19 & kab_ca & 0.001 & 1/day \\
\hline 2 & fab_tdce_tca & 0.8 & $\mathrm{~mol} / \mathrm{mol}$ & 20 & kan_teca & 0 & 1/day \\
\hline 3 & fab_11dce_tca & 0 & $\mathrm{~mol} / \mathrm{mol}$ & 21 & kan_tca & 0 & 1/day \\
\hline 4 & fan_tca_teca & 0 & $\mathrm{~mol} / \mathrm{mol}$ & 22 & kan_dca & 0 & 1/day \\
\hline 5 & fan_cdce_teca & 0 & $\mathrm{~mol} / \mathrm{mol}$ & 23 & kan_ca & 0 & 1/day \\
\hline 6 & fan_tdce_teca & 0 & $\mathrm{~mol} / \mathrm{mol}$ & 24 & kan_pce & 0 & 1/day \\
\hline 7 & fan_dca_tca & 0 & $\mathrm{~mol} / \mathrm{mol}$ & 25 & kan_tce & 0 & 1/day \\
\hline 8 & fan_vc_tca & 0 & $\mathrm{~mol} / \mathrm{mol}$ & 26 & kan_cdce & 0 & 1/day \\
\hline 9 & fan_ca_dca & 0 & $\mathrm{~mol} / \mathrm{mol}$ & 27 & kan_tdce & 0 & 1/day \\
\hline 10 & fan_cdce_tce & 0 & $\mathrm{~mol} / \mathrm{mol}$ & 28 & kan_11dce & 0 & 1/day \\
\hline 11 & fan_tdce_tce & 0 & $\mathrm{~mol} / \mathrm{mol}$ & 29 & kan_vc & 0 & 1/day \\
\hline 12 & fan_11dce_tce & 0 & $\mathrm{~mol} / \mathrm{mol}$ & 30 & kae_dca & 0.005 & 1/day \\
\hline 13 & fan_vc_cdce & 0 & $\mathrm{~mol} / \mathrm{mol}$ & 31 & kae_ca & 0.005 & 1/day \\
\hline 14 & fan_vc_tdce & 0 & $\mathrm{~mol} / \mathrm{mol}$ & 32 & kae_cdce & 0.005 & 1/day \\
\hline 15 & fan_vc_11dce & 0 & $\mathrm{~mol} / \mathrm{mol}$ & 33 & kae_tdce & 0.005 & 1/day \\
\hline 16 & kab_teca & 0.006 & 1/day & 34 & kae_11dce & 0.005 & 1/day \\
\hline 17 & kab_tca & 0 & 1/day & 35 & kae_vc & 0.005 & 1/day \\
\hline 18 & kab_dca & 0.00003 & 1/day & & & & \\
\hline
\end{tabular}




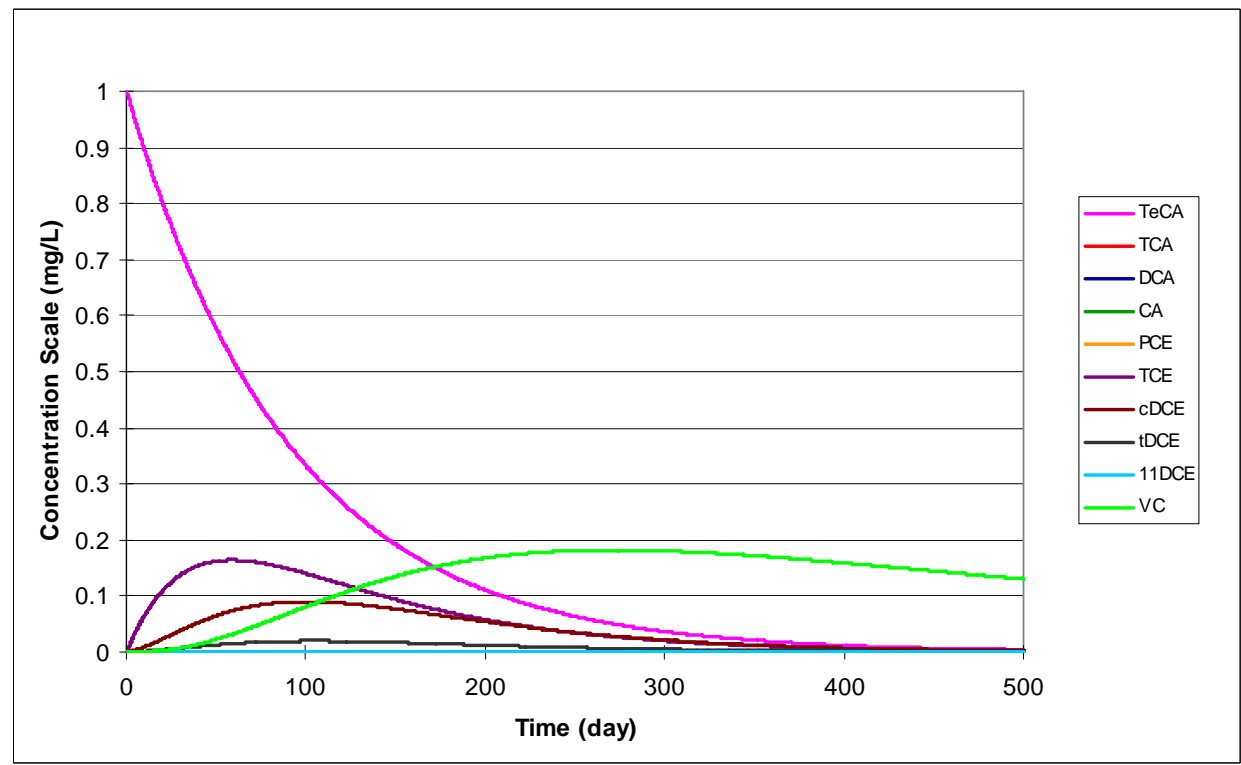

Figure 16. Dechlorination of 1,1,2,2-TeCA Using the Parameter Values Shown in Table 20 The initial concentration for TeCA was $1 \mathrm{mg} / \mathrm{L}$. All other species concentrations started at zero. In the results, the concentrations of TCA, DCA, CA, PCE, and $11 D C E$ are zero.

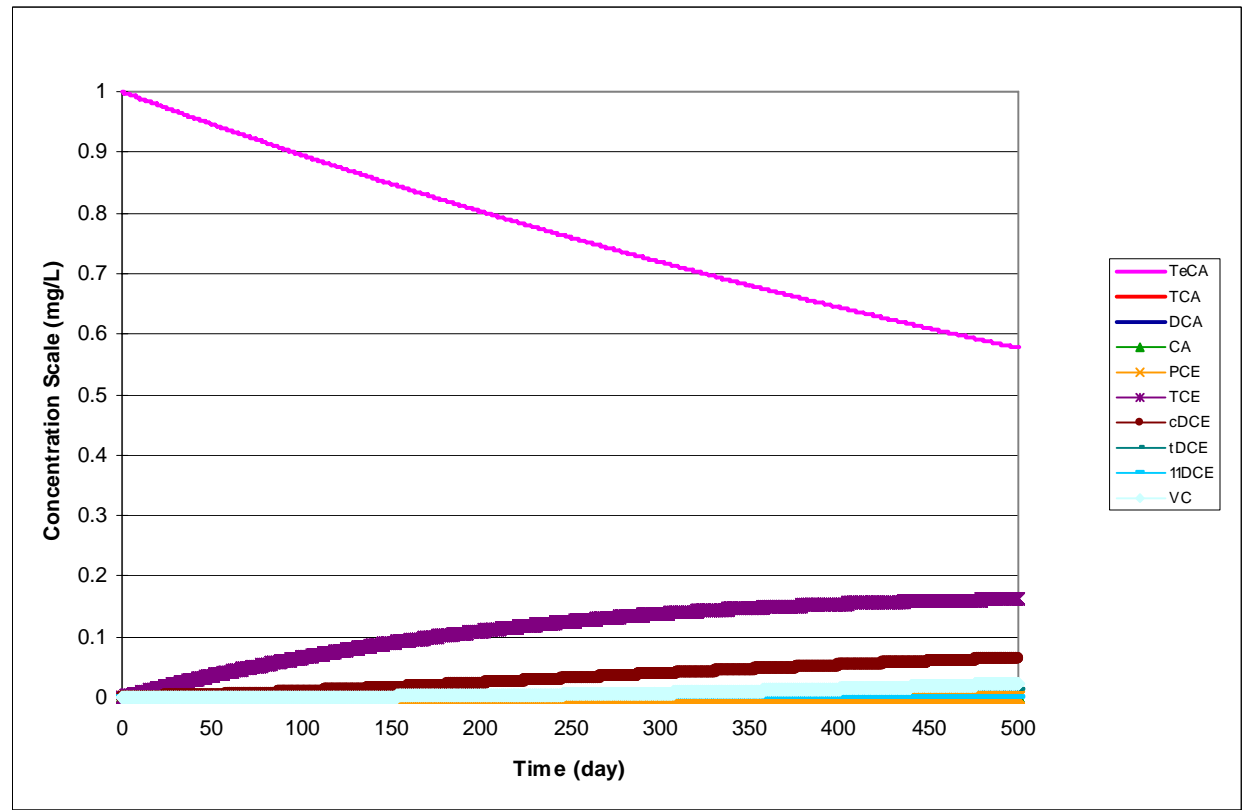

Figure 17. Dechlorination of 1,1,2,2-TeCA Using the Parameter Values Shown in Table 21 The initial concentration for TeCA was $1 \mathrm{mg} / \mathrm{L}$. All other species concentrations started at zero. 


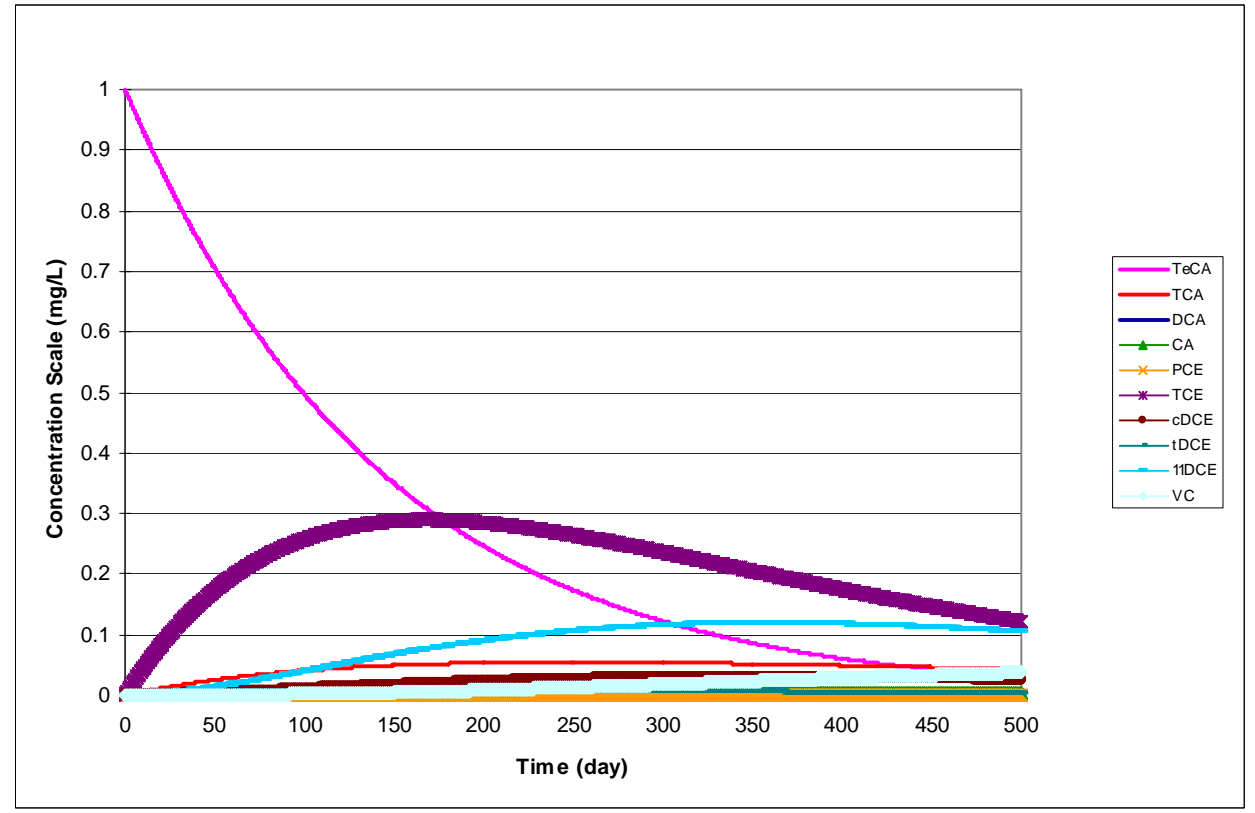

Figure 18. Dechlorination of 1,1,2,2-TeCA Using the Parameter Values Shown in Table $22-$ The initial concentration for TeCA was $1 \mathrm{mg} / \mathrm{L}$. All other species concentrations started at zero.

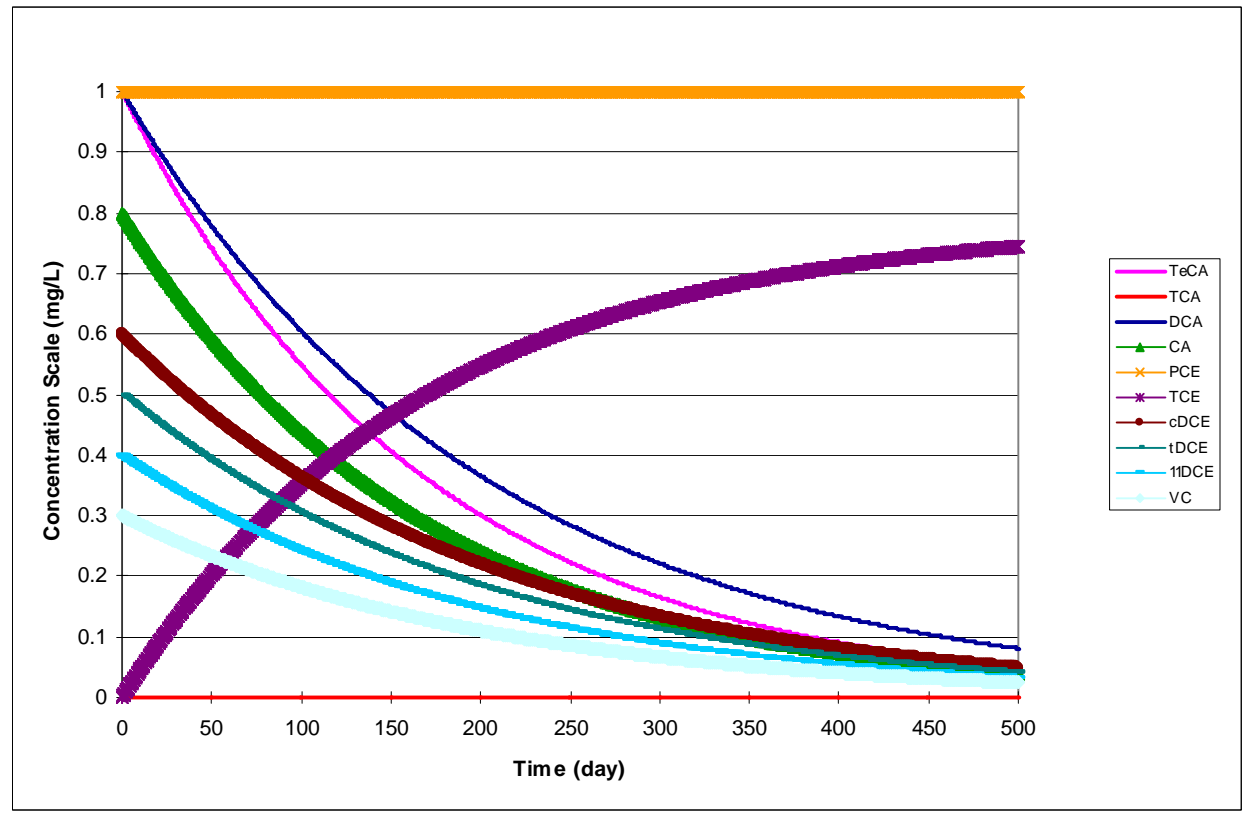

Figure 19. Aerobic and Abiotic Degradation of Contaminants in the 1,1,2,2-TeCA and PCE Families Using the Parameter Values Shown in Table 23 - The initial concentrations for TeCA, TCA, DCA, CA, PCE, TCE, cDCE, tDCE, 11DCE, and VC were $1,0,1,0.8,1,0,0.6,0.5,0.4$, and $0.3 \mathrm{mg} / L$, respectively. 


\subsection{Dechlorination of 1,1,1,2-Tetrachloroethane and Chloroethenes}

\subsection{Conceptual Model for Dechlorination Reactions}

This reaction module describes dechlorination of 1,1,1,2-tetrachloroethane, tetrachloroethene, and related daughter products (including 1,1,1-TCA and 1,1-DCA) using first-order rate expressions. The module includes abiotic, aerobic, and anoxic/anaerobic reaction pathways, which the user may selectively turn off by setting the (spatially variable) values of the stoichiometric yields and/or the reaction rate constants to zero. See the section on RT3D MNA/EA Reaction Module Commonalities and the Discussion of Select Reaction Parameters for additional information on features common to all of these MNA/EA reaction modules and explanation of key reaction parameters.

Table 24 lists the chemical species included in this reaction module. Dechlorination reactions for chlorinated ethane contaminants can result in formation of chlorinated ethene species, so this reaction module combines the reaction pathways for these two groups of contaminants. Figure 20 shows the conceptual model describing the potential biotic and abiotic degradation pathways of both chlorinated ethene and chlorinated ethane contaminants. See the conceptual model discussion for the Mixed Chloroethene/ Chloroethane/Chloromethane Dechlorination reaction module for information on the development of the reaction pathways and the assumption of firstorder reaction kinetics. 
Table 24. Chemical Species Included in the Dechlorination of 1,1,1,2-Tetrachloroethane and Chloroethenes Reaction Module

\begin{tabular}{|c|c|c|c|c|c|c|}
\hline No. & Abbreviation $^{a}$ & Chemical Name & Selected Alternate Name & $\begin{array}{c}\text { CAS }^{\mathbf{b}} \\
\text { Registry } \\
\text { Number }\end{array}$ & $\begin{array}{c}\text { Molecular } \\
\text { Weight }^{\mathrm{c}} \\
(\mathrm{g} / \mathrm{mol})\end{array}$ & $\begin{array}{l}\text { Chemical } \\
\text { Formula }\end{array}$ \\
\hline 1 & $\mathrm{TeCA}$ & 1,1,1,2-Tetrachloroethane & $1,1,1,2-\mathrm{TeCA}$ & & 167.84928 & $\mathrm{C}_{2} \mathrm{H}_{2} \mathrm{Cl}_{4}$ \\
\hline 2 & TCA & 1,1,1-Trichloroethane & $1,1,1-\mathrm{TCA}$ & & 133.40422 & $\mathrm{C}_{2} \mathrm{H}_{3} \mathrm{Cl}_{3}$ \\
\hline 3 & DCA & 1,1-Dichloroethane & 1,1-DCA & & 98.95916 & $\mathrm{C}_{2} \mathrm{H}_{4} \mathrm{Cl}_{2}$ \\
\hline 4 & $\mathrm{CA}$ & Chloroethane & Ethyl Chloride & $75-00-3$ & 64.5141 & $\mathrm{C}_{2} \mathrm{H}_{5} \mathrm{Cl}$ \\
\hline 5 & PCE & Tetrachloroethene & $\begin{array}{l}\text { Tetrachloroethylene; } \\
\text { Perchloroethylene }\end{array}$ & $127-18-4$ & 165.8334 & $\mathrm{C}_{2} \mathrm{Cl}_{4}$ \\
\hline 6 & TCE & Trichloroethene & Trichloroethylene & 79-01-6 & 131.38834 & $\mathrm{C}_{2} \mathrm{HCl}_{3}$ \\
\hline 7 & $\mathrm{cDCE}$ & cis-1,2-Dichloroethene & $\begin{array}{l}\text { cis-1,2-Dichloroethylene; } \\
\text { cis-1,2-DCE; cis-DCE }\end{array}$ & $156-59-2$ & 96.94328 & $\mathrm{C}_{2} \mathrm{H}_{2} \mathrm{Cl}_{2}$ \\
\hline 8 & $\mathrm{tDCE}$ & trans-1,2-Dichloroethene & $\begin{array}{l}\text { trans-1,2-Dichloroethylene; } \\
\text { trans-1,2-DCE; trans-DCE }\end{array}$ & $156-60-5$ & 96.94328 & $\mathrm{C}_{2} \mathrm{H}_{2} \mathrm{Cl}_{2}$ \\
\hline 9 & 11DCE & 1,1-Dichloroethene & $\begin{array}{l}\text { Vinylidene Chloride; } \\
\text { 1,1-DCE }\end{array}$ & $75-35-4$ & 96.94328 & $\mathrm{C}_{2} \mathrm{H}_{2} \mathrm{Cl}_{2}$ \\
\hline 10 & $\mathrm{VC}$ & Chloroethene & Vinyl Chloride & $75-01-4$ & 62.49822 & $\mathrm{C}_{2} \mathrm{H}_{3} \mathrm{Cl}$ \\
\hline 11 & Tracer & Conservative Tracer & - & $\mathrm{N} / \mathrm{A}$ & $\mathrm{N} / \mathrm{A}$ & $\mathrm{N} / \mathrm{A}$ \\
\hline
\end{tabular}

a These abbreviations refer to the specific chemicals listed here and should not be confused with different chemicals that may use the same abbreviation in other reaction modules.

${ }^{\mathrm{b}} \mathrm{CAS}=$ Chemical Abstracts Service (see http://www.cas.org/EO/regsys.html)

${ }^{c}$ Based on International Union of Pure and Applied Chemistry values reported by Loss [2003].

N/A - Not Applicable 


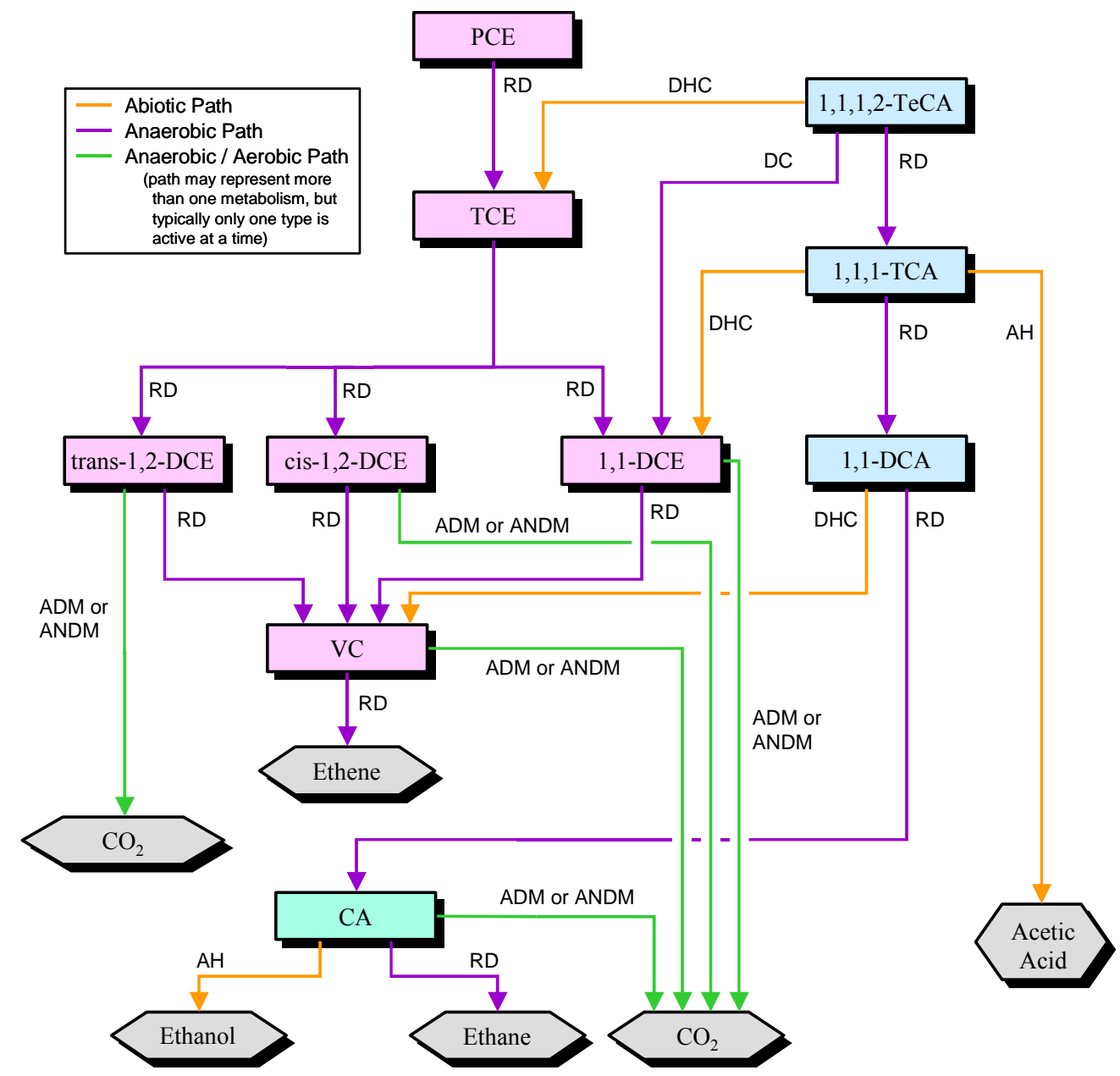

Figure 20. Conceptual Model for Dechlorination Reactions in the Dechlorination of 1,1,1,2Tetrachloroethane and Chloroethenes Reaction Module - Species in hexagonal shaded boxes are innocuous products and are not tracked in the reaction module. The reaction types for each pathway are described in Table 3.

\subsection{Reaction Equations}

The set of ODEs comprising this reaction module are shown in Equations 57 to 67. These ODEs describe the reaction kinetics for the 11 chemical species in Table 24. See Table 25 for a detailed itemization of all reaction parameters used in this reaction module.

$$
\begin{aligned}
& \frac{d C_{T e C A}}{d t}=\left(-k a n_{T e C A} \cdot C_{T e C A}-k a b_{T e C A} \cdot C_{T e C A}\right) \\
& \frac{d C_{T C A}}{d t}=\left(Y_{\frac{T C A}{T e C A}} \cdot \operatorname{Fan}_{\frac{T C A}{T e C A}} \cdot k a n_{T e C A} \cdot C_{T e C A}-k a n_{T C A} \cdot C_{T C A}-k a b_{T C A} \cdot C_{T C A}\right)
\end{aligned}
$$




$$
\begin{aligned}
& \frac{d C_{D C A}}{d t}=\left(\begin{array}{l}
Y_{\frac{D C A}{T C A}} \cdot \operatorname{kan}_{T C A} \cdot C_{T C A} \\
\quad-k a n_{D C A} \cdot C_{D C A}-k a b_{D C A} \cdot C_{D C A}
\end{array}\right) \\
& \frac{d C_{C A}}{d t}=\left(\begin{array}{l}
Y_{\frac{C A}{D C A}} \cdot \operatorname{kan}_{D C A} \cdot C_{D C A} \\
\quad-k a n_{C A} \cdot C_{C A}-k a b_{C A} \cdot C_{C A}-k a e_{C A} \cdot C_{C A}
\end{array}\right) \\
& \frac{d C_{P C E}}{d t}=\left(-k a n_{P C E} \cdot C_{P C E}\right) \\
& \frac{d C_{T C E}}{d t}=\left(\begin{array}{c}
\frac{Y_{T C E} \cdot k a n_{P C E}}{P C E} C_{P C E} \\
\quad+Y_{\frac{T C E}{T e C A}} \cdot k a b_{T e C A} \cdot C_{T e C A}-k a n_{T C E} \cdot C_{T C E}
\end{array}\right) \\
& \frac{d C_{c D C E}}{d t}=\left(\begin{array}{cc}
Y_{\frac{D C E}{T C E}} \cdot \text { Fan }_{\frac{c D C E}{T C E}} \cdot \mathrm{kan}_{T C E} \cdot C_{T C E} \\
& \quad-\mathrm{kan}_{c D C E} \cdot C_{c D C E}-\mathrm{kae}_{c D C E} \cdot C_{c D C E}
\end{array}\right) \\
& \frac{d C_{t D C E}}{d t}=\left(\begin{array}{c}
Y_{\frac{D C E}{T C E}} \cdot F_{\frac{t D C E}{T C E}} \cdot \operatorname{kan}_{T C E} \cdot C_{T C E} \\
\quad-k a n_{t D C E} \cdot C_{t D C E}-k_{t D e} \cdot C_{t D C E}
\end{array}\right) \\
& \frac{d C_{11 D C E}}{d t}=\left(\begin{array}{c}
Y_{\frac{D C E}{T C E}} \cdot F_{\frac{11 D C E}{T C E}} \cdot \mathrm{kan}_{T C E} \cdot C_{T C E}+Y_{\frac{D C E}{T e C A}} \cdot F_{\frac{11 D C E}{T e C A}} \cdot \mathrm{kan}_{T e C A} \cdot C_{T e C A} \\
+Y_{\frac{D C E}{T C A}} \cdot F a b_{\frac{11 D C E}{T C A}} \cdot k a b_{T C A} \cdot C_{T C A} \\
-k_{11 n_{1 D C E}} \cdot C_{11 D C E}-k e_{11 D C E} \cdot C_{11 D C E}
\end{array}\right)
\end{aligned}
$$




$$
\begin{aligned}
& \frac{d C_{V C}}{d t}=\left(\begin{array}{c}
Y_{\frac{V C}{D C E}} \cdot F a n_{\frac{V C}{c D C E}} \cdot k a n_{c D C E} \cdot C_{c D C E} \\
+Y_{\frac{V C}{D C E}} \cdot F a n_{\frac{V C}{t D C E}} \cdot k a n_{t D C E} \cdot C_{t D C E} \\
+Y_{\frac{V C}{D C E}} \cdot F a n_{\frac{V C}{11 D C E}} \cdot k a n_{11 D C E} \cdot C_{11 D C E} \\
+Y_{\frac{V C}{D C A}} \cdot k a b_{D C A} \cdot C_{D C A} \\
-k_{V a n_{V C}} \cdot C_{V C}-k_{V a e_{V C}} \cdot C_{V C}
\end{array}\right) \\
& \frac{d C_{\text {Tracer }}}{d t}=0.0 \quad \text { (Conservative [non-reactive] tracer.) }
\end{aligned}
$$

The first-order decay rate constants $\left[\mathrm{T}^{-1}\right]$ of the $\mathrm{i}^{\text {th }}$ species are represented in the equations above by the $k a n_{i}, k a e_{i}$, and $k a b_{i}$ terms for anaerobic biological reactions, aerobic biological reactions, or abiotic reactions, respectively. The concentration of the $\mathrm{i}^{\text {th }}$ species is represented by the $C_{i}$ term $\left[\mathrm{ML}^{-3}\right]$. The $R_{i}$ terms represent the retardation factor for the $\mathrm{i}^{\text {th }}$ species [unitless].

In cases where multiple daughter products may be produced from dechlorination of a single parent species, the amount of each daughter species that is produced is a function of a mass yield $\left[\mathrm{MM}^{-1}\right]$ and a stoichiometric dechlorination yield [mol/mol]. The mass yield value, $Y_{d / p}$, accounts for the difference in molecular weight between the parent species "p" and the daughter species "d." All isomers of a daughter chemical have the same mass yield. Mass yield values are included in the reaction module code and do not need to be input by the user. The stoichiometric dechlorination yield represents the site-specific stoichiometry for each reaction pathway that occurs as either an anaerobic $\left(F a n_{d / p}\right)$ or an abiotic process $\left(F a b_{d / p}\right)$. The stoichiometric dechlorination yield is the fractional moles of daughter species that are produced by dechlorination of one mole of the parent species. The net yield is the product of the mass yield and the stoichiometric dechlorination yield. To preserve the mass balance, the values of the stoichiometric dechlorination yields are constrained by the relations in Equations 68 to 73 .

$$
\begin{aligned}
& F a n_{\frac{T C A}{T e C A}}+F a n_{\frac{11 D C E}{T e C A}}=1.0 \\
& F a b_{\frac{11 D C E}{T C A}} \leq 1.0 \\
& F a n_{\frac{c D C E}{T C E}}+F a n_{\frac{t D C E}{T C E}}+F a n_{\frac{11 D C E}{T C E}}=1.0
\end{aligned}
$$




$$
\begin{aligned}
& \text { Fan }_{\frac{V C}{c D C E}} \leq 1.0 \\
& \text { Fan }_{\frac{V C}{t D C E}} \leq 1.0 \\
& \text { Fan }_{\frac{V C}{11 D C E}} \leq 1.0
\end{aligned}
$$

\subsection{Required Input}

The reaction parameters for this reaction module are made available to RT3D as part of the input for the Reaction Package. The Reaction Package input file structure is discussed in the RT3D manual and addendum [Clement, 1997; Clement and Johnson, 2002]. The 28 reaction parameters that must be specified for this reaction module are listed in Table 25 in the required order (ID Number) with units and a description. Site-specific knowledge from field data or laboratory tests should be applied to determine an appropriate model configuration for reaction parameters (i.e., the values and the spatial distribution).

\begin{tabular}{|c|c|c|c|c|}
\hline $\begin{array}{c}\text { ID } \\
\#\end{array}$ & Parameter & $\begin{array}{l}\text { Fortran } \\
\text { Variable }\end{array}$ & Units & Description \\
\hline 1 & $F a b_{\frac{11 D C E}{T C A}}$ & fab_11dce_tca & $\mathrm{mol} / \mathrm{mol}$ & $\begin{array}{l}\text { Moles of 1,1-DCE produced from abiotic decay of one mole of } \\
\text { TCA }\end{array}$ \\
\hline 2 & $\operatorname{Fan}_{\frac{T C A}{T e C A}}$ & fan_tca_teca & $\mathrm{mol} / \mathrm{mol}$ & $\begin{array}{l}\text { Moles of TCA produced from anaerobic decay of one mole of } \\
\text { TeCA }\end{array}$ \\
\hline 3 & $\operatorname{Fan}_{\frac{11 D C E}{T e C A}}$ & fan_11dce_teca & $\mathrm{mol} / \mathrm{mol}$ & $\begin{array}{l}\text { Moles of 1,1-DCE produced from anaerobic decay of one mole } \\
\quad \text { of TeCA }\end{array}$ \\
\hline 4 & $\operatorname{Fan}_{\frac{c D C E}{T C E}}$ & fan_cdce_tce & $\mathrm{mol} / \mathrm{mol}$ & $\begin{array}{l}\text { Moles of cis-1,2-DCE produced from anaerobic decay of one } \\
\text { mole of TCE }\end{array}$ \\
\hline 5 & $\operatorname{Fan}_{\frac{t D C E}{T C E}}$ & fan_tdce_tce & $\mathrm{mol} / \mathrm{mol}$ & $\begin{array}{l}\text { Moles of trans-1,2-DCE produced from anaerobic decay of one } \\
\text { mole of TCE }\end{array}$ \\
\hline 6 & $\operatorname{Fan}_{\frac{11 D C E}{T C E}}$ & fan_11dce_tce & $\mathrm{mol} / \mathrm{mol}$ & $\begin{array}{l}\text { Moles of 1,1-DCE produced from anaerobic decay of one mole } \\
\quad \text { of TCE }\end{array}$ \\
\hline 7 & $\operatorname{Fan}_{\frac{V C}{c D C E}}$ & fan_vc_cdce & $\mathrm{mol} / \mathrm{mol}$ & $\begin{array}{l}\text { Moles of VC produced from anaerobic decay of one mole of } \\
\text { cis-1,2-DCE }\end{array}$ \\
\hline 8 & Fan $_{\frac{V C}{t D C E}}$ & fan_vc_tdce & $\mathrm{mol} / \mathrm{mol}$ & $\begin{array}{l}\text { Moles of VC produced from anaerobic decay of one mole of } \\
\text { trans-1,2-DCE }\end{array}$ \\
\hline
\end{tabular}

Table 25. Input Parameters for the Dechlorination of 1,1,1,2-Tetrachloroethane and Chloroethenes Reaction Module 
Table 25. (contd)

\begin{tabular}{|c|c|c|c|c|}
\hline $\begin{array}{c}\text { ID } \\
\#\end{array}$ & Parameter & $\begin{array}{l}\text { Fortran } \\
\text { Variable }\end{array}$ & Units & Description \\
\hline 9 & Fan $\frac{V C}{11 D C E}$ & fan_vc_11dce & $\mathrm{mol} / \mathrm{mol}$ & $\begin{array}{l}\text { Moles of VC produced from anaerobic decay of one mole of } \\
\text { 1,1-DCE }\end{array}$ \\
\hline 10 & $k a b_{\text {TeCA }}$ & kab_teca & $1 /$ day & First-order decay coefficient for abiotic dechlorination of TeCA \\
\hline 11 & $k a b_{T C A}$ & kab_tca & 1/day & First-order decay coefficient for abiotic dechlorination of TCA \\
\hline 12 & $k a b_{D C A}$ & kab_dca & $1 /$ day & First-order decay coefficient for abiotic dechlorination of DCA \\
\hline 13 & $k a b_{C A}$ & kab_ca & $1 /$ day & First-order decay coefficient for abiotic dechlorination of CA \\
\hline 14 & $k a n_{T e C A}$ & kan_teca & 1/day & $\begin{array}{l}\text { First-order decay coefficient for anaerobic dechlorination of } \\
\text { TeCA }\end{array}$ \\
\hline 15 & $k a n_{T C A}$ & kan_tca & 1/day & $\begin{array}{l}\text { First-order decay coefficient for anaerobic dechlorination of } \\
\text { TCA }\end{array}$ \\
\hline 16 & $k a n_{D C A}$ & kan_dca & $1 /$ day & $\begin{array}{l}\text { First-order decay coefficient for anaerobic dechlorination of } \\
\text { DCA }\end{array}$ \\
\hline 17 & $k a n_{C A}$ & kan_ca & $1 /$ day & First-order decay coefficient for anaerobic dechlorination of $\mathrm{CA}$ \\
\hline 18 & $\operatorname{kan}_{P C E}$ & kan_pce & $1 /$ day & $\begin{array}{l}\text { First-order decay coefficient for anaerobic dechlorination of } \\
\quad \text { PCE }\end{array}$ \\
\hline 19 & $\operatorname{kan}_{T C E}$ & kan_tce & $1 /$ day & $\begin{array}{l}\text { First-order decay coefficient for anaerobic dechlorination of } \\
\text { TCE }\end{array}$ \\
\hline 20 & $k a n_{C D C E}$ & kan_cdce & 1/day & $\begin{array}{l}\text { First-order decay coefficient for anaerobic dechlorination of } \\
\text { cis-1,2-DCE }\end{array}$ \\
\hline 21 & $k a n_{t D C E}$ & kan_tdce & $1 /$ day & $\begin{array}{l}\text { First-order decay coefficient for anaerobic dechlorination of } \\
\text { trans-1,2-DCE }\end{array}$ \\
\hline 22 & $\mathrm{kan}_{11 D C E}$ & kan_11dce & $1 /$ day & $\begin{array}{l}\text { First-order decay coefficient for anaerobic dechlorination of } \\
1,1-\mathrm{DCE}\end{array}$ \\
\hline 23 & $\mathrm{kan}_{V C}$ & kan_vc & 1/day & First-order decay coefficient for anaerobic dechlorination of $\mathrm{VC}$ \\
\hline 24 & $k a e_{C A}$ & kae_ca & 1/day & First-order decay coefficient for aerobic dechlorination of CA \\
\hline 25 & $k a e_{C D C E}$ & kae_cdce & $1 /$ day & $\begin{array}{l}\text { First-order decay coefficient for aerobic dechlorination of } \\
\text { cis-1,2-DCE }\end{array}$ \\
\hline 26 & $k a e_{t D C E}$ & kae_tdce & 1/day & $\begin{array}{l}\text { First-order decay coefficient for aerobic dechlorination of } \\
\text { trans-1,2-DCE }\end{array}$ \\
\hline 27 & $k a e_{11 D C E}$ & kae_11dce & $1 /$ day & $\begin{array}{l}\text { First-order decay coefficient for aerobic dechlorination of } \\
\text { 1,1-DCE }\end{array}$ \\
\hline 28 & $k a e_{V C}$ & kae_vc & $1 /$ day & First-order decay coefficient for aerobic dechlorination of VC \\
\hline
\end{tabular}

\subsection{Example Simulations}

Simulations with this reaction module were conducted with RT3D in a batch reactor (no flow) mode to show examples of how the reaction module simulates the pattern of dechlorination. The parameter values for each example simulation are listed in Tables 26 through 29 . These 
parameters are arbitrary values and are not directly related to any specific laboratory data. Sitespecific values would need to be determined as part of a calibration process. Results for these example batch simulations are shown in the Figures 21 through 24, respectively.

Table 26. Parameter Values for Example Simulation 1 - Base Case Anaerobic Conditions with the Dechlorination of 1,1,1,2-Tetrachloroethane and Chloroethenes Reaction Module

\begin{tabular}{|c|c|c|c|c|c|c|c|}
\hline ID \# & Fortran Variable & Value & Units & ID \# & Fortran Variable & Value & Units \\
\hline 1 & fab_11dce_tca & 0.2 & $\mathrm{~mol} / \mathrm{mol}$ & 15 & kan_tca & 0.01 & 1/day \\
\hline 2 & fan_tca_teca & 0.2 & $\mathrm{~mol} / \mathrm{mol}$ & 16 & kan_dca & 0.025 & 1/day \\
\hline 3 & fan_11dce teca & 0.8 & $\mathrm{~mol} / \mathrm{mol}$ & 17 & kan_ca & 0.025 & 1/day \\
\hline 4 & fan_cdce_tce & 0.8 & $\mathrm{~mol} / \mathrm{mol}$ & 18 & kan_pce & 0.025 & $1 /$ day \\
\hline 5 & fan_tdce_tce & 0.2 & $\mathrm{~mol} / \mathrm{mol}$ & 19 & kan_tce & 0.025 & 1/day \\
\hline 6 & fan_11dce_tce & 0 & $\mathrm{~mol} / \mathrm{mol}$ & 20 & kan_cdce & 0.025 & 1/day \\
\hline 7 & fan_vc_cdce & 0.8 & $\mathrm{~mol} / \mathrm{mol}$ & 21 & kan_tdce & 0.025 & $1 /$ day \\
\hline 8 & fan_vc_tdce & 0.8 & $\mathrm{~mol} / \mathrm{mol}$ & 22 & kan_11dce & 0.025 & 1/day \\
\hline 9 & fan_vc_11dce & 0.8 & $\mathrm{~mol} / \mathrm{mol}$ & 23 & kan_vc & 0.0025 & $1 /$ day \\
\hline 10 & kab_teca & 0.006 & 1/day & 24 & kae_ca & 0 & 1/day \\
\hline 11 & kab_tca & 0 & 1/day & 25 & kae_cdce & 0 & 1/day \\
\hline 12 & kab_dca & 0.00003 & 1/day & 26 & kae_tdce & 0 & 1/day \\
\hline 13 & kab_ca & 0.001 & 1/day & 27 & kae_11dce & 0 & 1/day \\
\hline 14 & kan_teca & 0.005 & 1/day & 28 & kae_vc & 0 & 1/day \\
\hline
\end{tabular}

Table 27. Parameter Values for Example Simulation 2 - Rates at 10\% of Example Simulation 1 - with the Dechlorination of 1,1,1,2-Tetrachloroethane and Chloroethenes Reaction Module

\begin{tabular}{|c|c|c|c|c|c|c|c|}
\hline ID \# & Fortran Variable & Value & Units & ID \# & Fortran Variable & Value & Units \\
\hline 1 & fab_11dce_tca & 0.2 & $\mathrm{~mol} / \mathrm{mol}$ & 15 & kan_tca & 0.001 & 1/day \\
\hline 2 & fan_tca_teca & 0.2 & $\mathrm{~mol} / \mathrm{mol}$ & 16 & kan_dca & 0.0025 & 1/day \\
\hline 3 & fan_11dce teca & 0.8 & $\mathrm{~mol} / \mathrm{mol}$ & 17 & kan_ca & 0.0025 & 1/day \\
\hline 4 & fan_cdce_tce & 0.8 & $\mathrm{~mol} / \mathrm{mol}$ & 18 & kan_pce & 0.0025 & 1/day \\
\hline 5 & fan_tdce_tce & 0.2 & $\mathrm{~mol} / \mathrm{mol}$ & 19 & kan_tce & 0.0025 & 1/day \\
\hline 6 & fan_11dce_tce & 0 & $\mathrm{~mol} / \mathrm{mol}$ & 20 & kan_cdce & 0.0025 & 1/day \\
\hline 7 & fan_vc_cdce & 0.8 & $\mathrm{~mol} / \mathrm{mol}$ & 21 & kan_tdce & 0.0025 & 1/day \\
\hline 8 & fan_vc_tdce & 0.8 & $\mathrm{~mol} / \mathrm{mol}$ & 22 & kan_11dce & 0.0025 & 1/day \\
\hline 9 & fan_vc_11dce & 0.8 & $\mathrm{~mol} / \mathrm{mol}$ & 23 & kan_vc & 0.00025 & 1/day \\
\hline 10 & kab_teca & 0.0006 & 1/day & 24 & kae_ca & 0 & 1/day \\
\hline 11 & kab_tca & 0 & 1/day & 25 & kae_cdce & 0 & 1/day \\
\hline 12 & kab_dca & 0.000003 & 1/day & 26 & kae_tdce & 0 & 1/day \\
\hline 13 & kab_ca & 0.0001 & $1 /$ day & 27 & kae_11dce & 0 & 1/day \\
\hline 14 & kan_teca & 0.0005 & 1/day & 28 & kae_vc & 0 & 1/day \\
\hline
\end{tabular}


Table 28. Parameter Values for Example Simulation 3 -Different F Values Than Example Simulation 1 - with the Dechlorination of 1,1,1,2-Tetrachloroethane and Chloroethenes

\section{Reaction Module}

\begin{tabular}{|c|c|c|c|c|c|c|c|}
\hline ID \# & Fortran Variable & Value & Units & ID \# & Fortran Variable & Value & Units \\
\hline 1 & fab_11dce_tca & 0.8 & $\mathrm{~mol} / \mathrm{mol}$ & 15 & kan_tca & 0.01 & 1/day \\
\hline 2 & fan_tca_teca & 0.2 & $\mathrm{~mol} / \mathrm{mol}$ & 16 & kan_dca & 0.025 & $1 /$ day \\
\hline 3 & fan_11dce_teca & 0.8 & $\mathrm{~mol} / \mathrm{mol}$ & 17 & kan_ca & 0.025 & 1/day \\
\hline 4 & fan_cdce_tce & 0.2 & $\mathrm{~mol} / \mathrm{mol}$ & 18 & kan_pce & 0.025 & 1/day \\
\hline 5 & fan_tdce_tce & 0 & $\mathrm{~mol} / \mathrm{mol}$ & 19 & kan_tce & 0.025 & 1/day \\
\hline 6 & fan_11dce_tce & 0.8 & $\mathrm{~mol} / \mathrm{mol}$ & 20 & kan_cdce & 0.025 & 1/day \\
\hline 7 & fan_vc_cdce & 0.2 & $\mathrm{~mol} / \mathrm{mol}$ & 21 & kan_tdce & 0.025 & 1/day \\
\hline 8 & fan_vc_tdce & 0.2 & $\mathrm{~mol} / \mathrm{mol}$ & 22 & kan_11dce & 0.025 & 1/day \\
\hline 9 & fan_vc_11dce & 0.2 & $\mathrm{~mol} / \mathrm{mol}$ & 23 & kan_vc & 0.0025 & 1/day \\
\hline 10 & kab_teca & 0.006 & 1/day & 24 & kae_ca & 0 & 1/day \\
\hline 11 & kab_tca & 0 & 1/day & 25 & kae_cdce & 0 & 1/day \\
\hline 12 & kab_dca & 0.00003 & 1/day & 26 & kae_tdce & 0 & 1/day \\
\hline 13 & kab_ca & 0.001 & 1/day & 27 & kae_11dce & 0 & 1/day \\
\hline 14 & kan_teca & 0.005 & 1/day & 28 & kae_vc & 0 & 1/day \\
\hline
\end{tabular}

Table 29. Parameter Values for Example Simulation 4 - Base Case Aerobic Conditions - with the Dechlorination of 1,1,1,2-Tetrachloroethane and Chloroethenes Reaction Module

\begin{tabular}{|c|c|c|c|c|c|c|c|}
\hline ID \# & Fortran Variable & Value & Units & ID \# & Fortran Variable & Value & Units \\
\hline 1 & fab_11dce_tca & 0.2 & $\mathrm{~mol} / \mathrm{mol}$ & 15 & kan_tca & 0 & $\overline{1 / \text { day }}$ \\
\hline 2 & fan_tca teca & 0 & $\mathrm{~mol} / \mathrm{mol}$ & 16 & kan_dca & 0 & 1/day \\
\hline 3 & fan_11dce teca & 0 & $\mathrm{~mol} / \mathrm{mol}$ & 17 & kan_ca & 0 & 1/day \\
\hline 4 & fan_cdce_tce & 0 & $\mathrm{~mol} / \mathrm{mol}$ & 18 & kan_pce & 0 & 1/day \\
\hline 5 & fan_tdce_tce & 0 & $\mathrm{~mol} / \mathrm{mol}$ & 19 & kan_tce & 0 & 1/day \\
\hline 6 & fan 11 dce tce & 0 & $\mathrm{~mol} / \mathrm{mol}$ & 20 & kan_cdce & 0 & 1/day \\
\hline 7 & fan $v c$ cdce & 0 & $\mathrm{~mol} / \mathrm{mol}$ & 21 & kan tdce & 0 & 1/day \\
\hline 8 & fan_vc_tdce & 0 & $\mathrm{~mol} / \mathrm{mol}$ & 22 & kan_11dce & 0 & 1/day \\
\hline 9 & fan_vc_11dce & 0 & $\mathrm{~mol} / \mathrm{mol}$ & 23 & kan_vc & 0 & 1/day \\
\hline 10 & kab teca & 0.006 & 1/day & 24 & kae ca & 0.005 & 1/day \\
\hline 11 & kab_tca & 0 & 1/day & 25 & kae_cdce & 0.005 & 1/day \\
\hline 12 & kab_dca & 0.00003 & 1/day & 26 & kae_tdce & 0.005 & 1/day \\
\hline 13 & kab_ca & 0.001 & 1/day & 27 & kae_11dce & 0.005 & 1/day \\
\hline 14 & kan teca & 0 & 1/day & 28 & $\mathrm{kae} \mathrm{vc}$ & 0.005 & 1/day \\
\hline
\end{tabular}




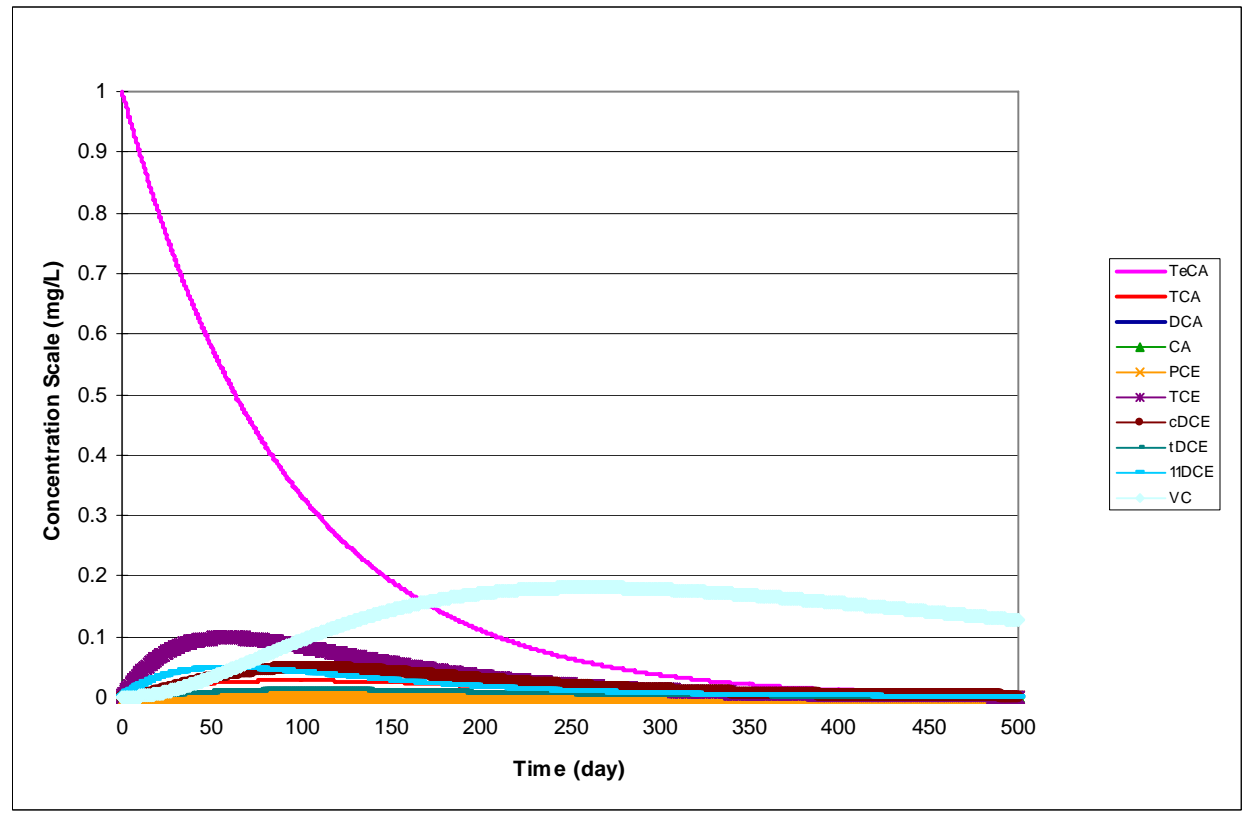

Figure 21. Dechlorination of 1,1,1,2-TeCA Using the Parameter Values Shown in Table 26 The initial concentration for TeCA was $1 \mathrm{mg} / \mathrm{L}$. All other species concentrations started at zero.

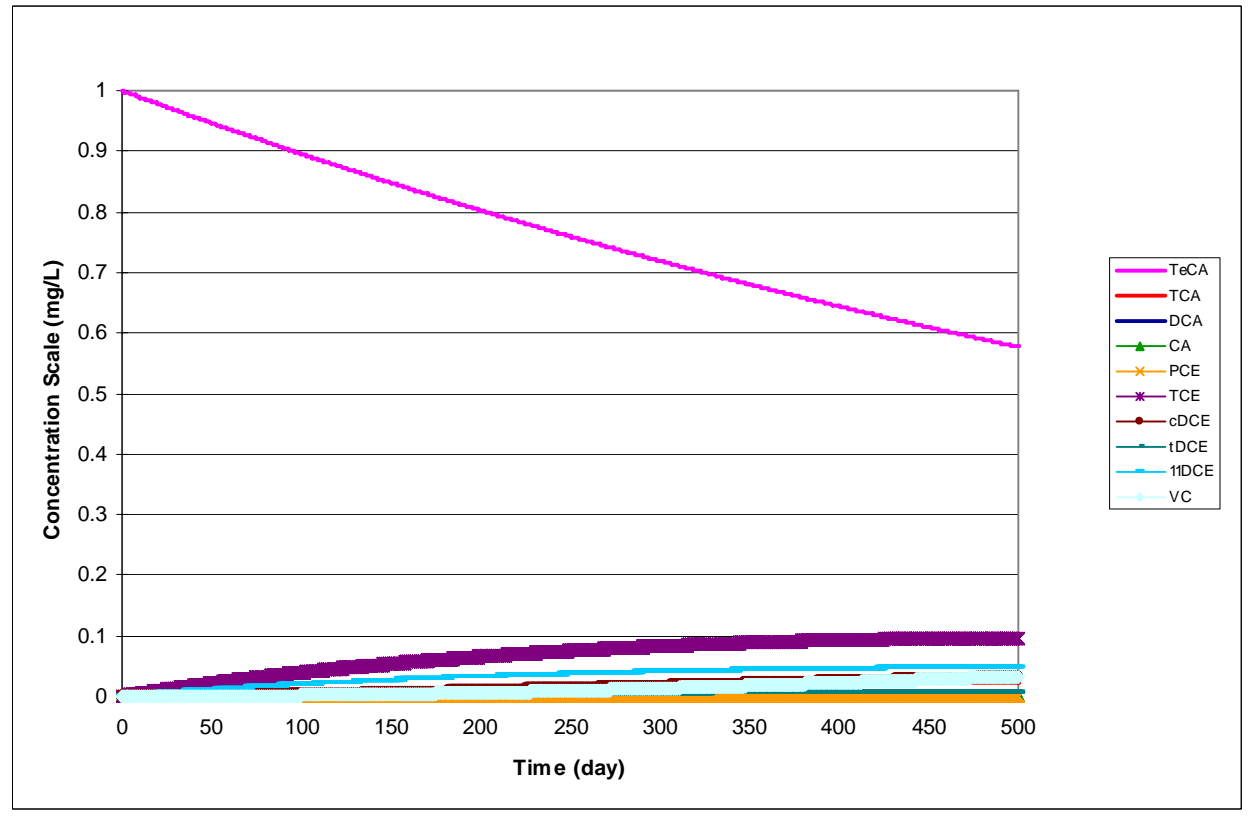

Figure 22. Dechlorination of 1,1,1,2-TeCA Using the Parameter Values Shown in Table 27 The initial concentration for TeCA was $1 \mathrm{mg} / \mathrm{L}$. All other species concentrations started at zero. 


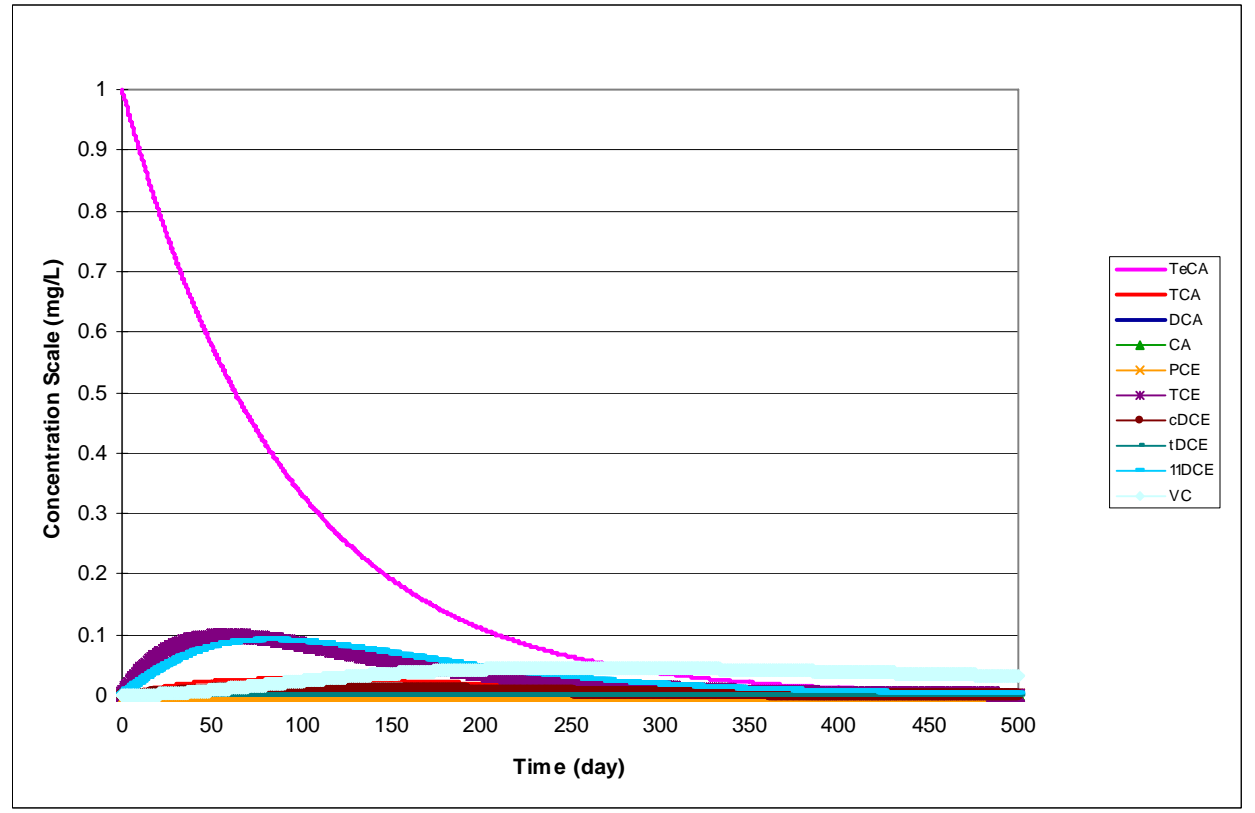

Figure 23. Dechlorination of 1,1,1,2-TeCA Using the Parameter Values Shown in Table 28 The initial concentration for TeCA was $1 \mathrm{mg} / \mathrm{L}$. All other species concentrations started at zero.

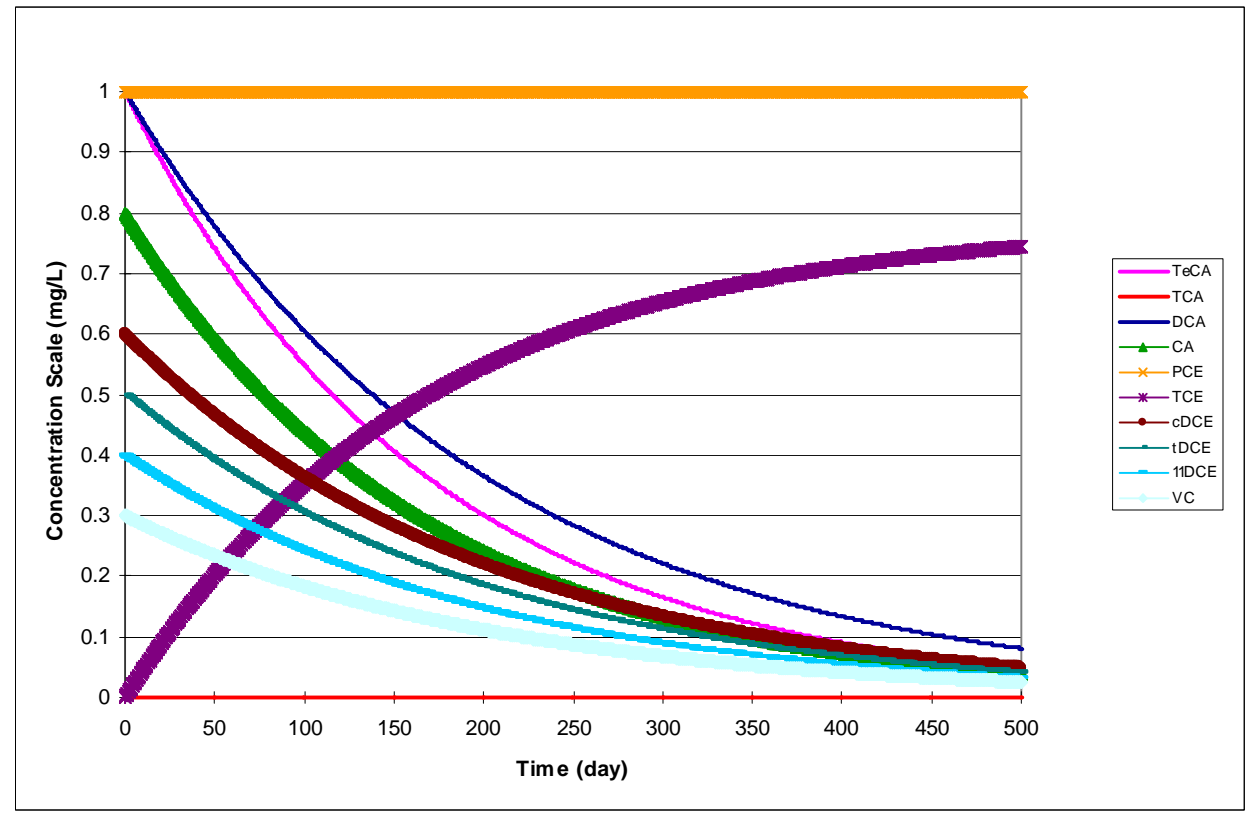

Figure 24. Aerobic and Abiotic Degradation of Contaminants in the 1,1,1,2-TeCA and PCE Families Using the Parameter Values Shown in Table 29 - The initial concentrations for TeCA, TCA, DCA, CA, PCE, TCE, cDCE, tDCE, 11DCE, and VC were $1,0,1,0.8,1,0,0.6,0.5,0.4$, and $0.3 \mathrm{mg} / \mathrm{L}$, respectively. 


\subsection{Chloroethene Dechlorination}

\subsection{Conceptual Model for Dechlorination Reactions}

This reaction module describes dechlorination of tetrachloroethene, and related daughter products using first-order rate expressions. The module includes both aerobic and anoxic/anaerobic reaction pathways, which the user may selectively turn off by setting the (spatially variable) values of the stoichiometric yields and/or the reaction rate constants to zero. See the section on RT3D MNA/EA Reaction Module Commonalities and the Discussion of Select Reaction Parameters for additional information on features common to all of these MNA/EA reaction modules and explanation of key reaction parameters.

Table 30 lists the chemical species included in this reaction module. Figure 25 shows the conceptual model describing the potential biotic degradation pathways of both chlorinated ethene contaminants. Note that abiotic degradation reactions for chlorinated ethene compounds are negligible, thus they are not included. See the conceptual model discussion for the Mixed Chloroethene/ Chloroethane/Chloromethane Dechlorination reaction module for information on the development of the reaction pathways and the assumption of first-order reaction kinetics.

Table 30. Chemical Species Included in the Chloroethene Dechlorination Reaction Module

\begin{tabular}{|c|c|c|c|c|c|c|}
\hline No. & Abbreviation ${ }^{a}$ & Chemical Name & Selected Alternate Name & $\begin{array}{c}\text { CAS }^{\mathbf{b}} \\
\text { Registry } \\
\text { Number }\end{array}$ & $\begin{array}{c}\text { Molecular } \\
\text { Weight }^{c} \\
\text { (g/mol) }\end{array}$ & $\begin{array}{l}\text { Chemical } \\
\text { Formula }\end{array}$ \\
\hline 1 & PCE & Tetrachloroethene & $\begin{array}{l}\text { Tetrachloroethylene; } \\
\text { Perchloroethylene }\end{array}$ & $127-18-4$ & 165.8334 & $\mathrm{C}_{2} \mathrm{Cl}_{4}$ \\
\hline 2 & TCE & Trichloroethene & Trichloroethylene & $79-01-6$ & 131.38834 & $\mathrm{C}_{2} \mathrm{HCl}_{3}$ \\
\hline 3 & $\mathrm{cDCE}$ & cis-1,2-Dichloroethene & $\begin{array}{l}\text { cis-1,2-Dichloroethylene; } \\
\text { cis-1,2-DCE; cis-DCE }\end{array}$ & $156-59-2$ & 96.94328 & $\mathrm{C}_{2} \mathrm{H}_{2} \mathrm{Cl}_{2}$ \\
\hline 4 & $\mathrm{tDCE}$ & trans-1,2-Dichloroethene & $\begin{array}{l}\text { trans-1,2-Dichloroethylene; } \\
\text { trans-1,2-DCE; trans-DCE }\end{array}$ & $156-60-5$ & 96.94328 & $\mathrm{C}_{2} \mathrm{H}_{2} \mathrm{Cl}_{2}$ \\
\hline 5 & 11DCE & 1,1-Dichloroethene & $\begin{array}{l}\text { Vinylidene Chloride; } \\
\text { 1,1-DCE }\end{array}$ & $75-35-4$ & 96.94328 & $\mathrm{C}_{2} \mathrm{H}_{2} \mathrm{Cl}_{2}$ \\
\hline 6 & $\mathrm{VC}$ & Chloroethene & Vinyl Chloride & $75-01-4$ & 62.49822 & $\mathrm{C}_{2} \mathrm{H}_{3} \mathrm{Cl}$ \\
\hline 7 & Tracer & Conservative Tracer & - & N/A & $\mathrm{N} / \mathrm{A}$ & N/A \\
\hline
\end{tabular}

a These abbreviations refer to the specific chemicals listed here and should not be confused with different chemicals that may use the same abbreviation in other reaction modules.

b $\mathrm{CAS}=$ Chemical Abstracts Service (see http://www.cas.org/EO/regsys.html)

c Based on International Union of Pure and Applied Chemistry values reported by Loss [2003].

N/A - Not Applicable 


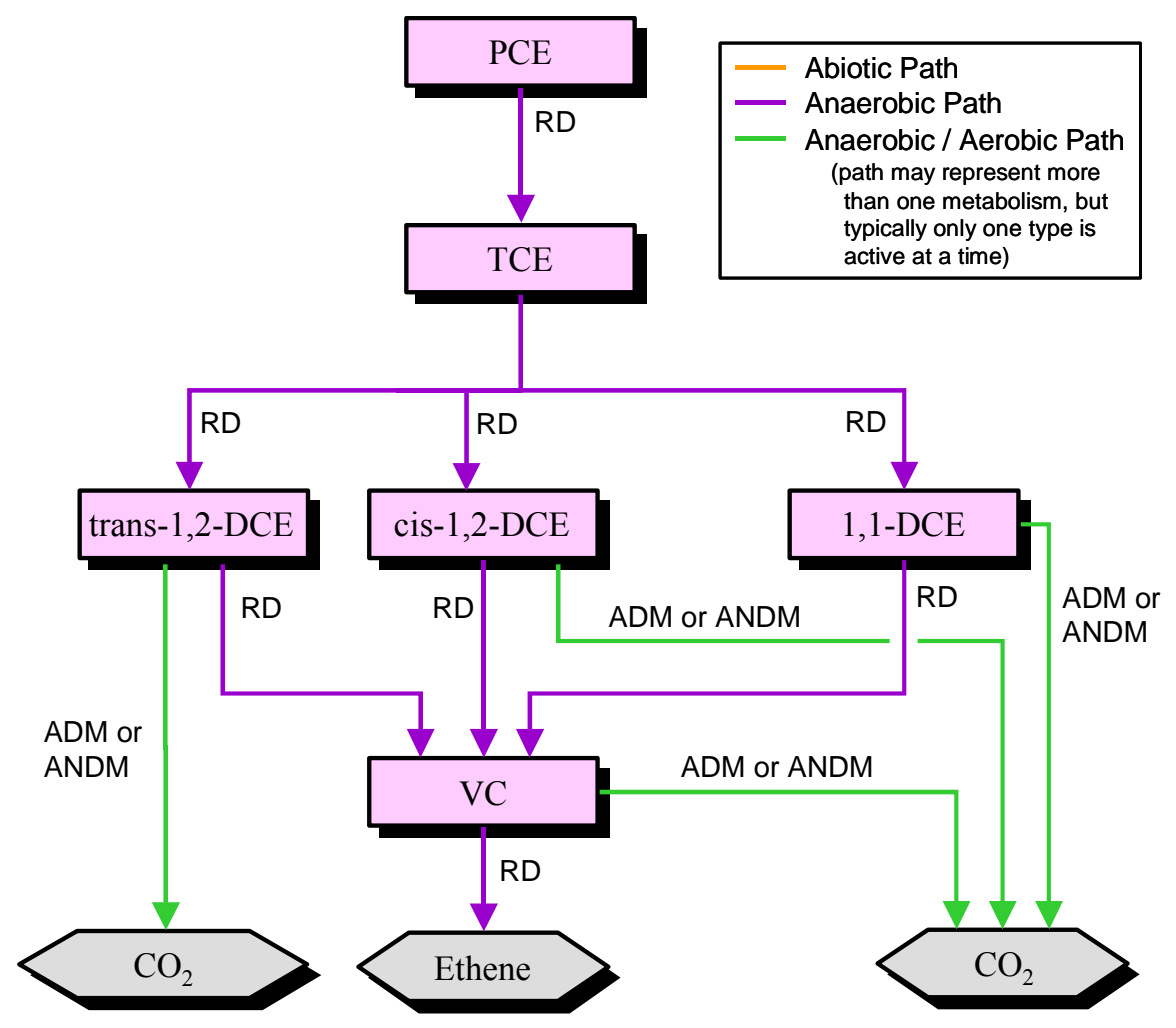

Figure 25. Conceptual Model for Dechlorination Reactions in the Chloroethene Dechlorination Reaction Module - Species in hexagonal shaded boxes are innocuous products and are not tracked in the reaction module. The reaction types for each pathway are described in Table 3.

\subsection{Reaction Equations}

The set of ODEs comprising this reaction module are shown in Equations 74 to 80. These ODEs describe the reaction kinetics for the 7 chemical species in Table 30. See Table 31 for a detailed itemization of all reaction parameters used in this reaction module.

$$
\begin{aligned}
& \frac{d C_{P C E}}{d t}=\left(-k_{P C E} \cdot C_{P C E}\right) \\
& \frac{d C_{T C E}}{d t}=\left(\begin{array}{c}
Y_{T C E} \cdot k_{P C E} \cdot C_{P C E} \\
-k_{T C n_{T C E}} \cdot C_{T C E}
\end{array}\right)
\end{aligned}
$$




$$
\begin{aligned}
& \frac{d C_{c D C E}}{d t}=\left(\begin{array}{cc}
Y_{\frac{D C E}{T C E}} \cdot \operatorname{Fan}_{\frac{c D C E}{T C E}} \cdot \mathrm{kan}_{T C E} \cdot C_{T C E} \\
\\
\quad-\mathrm{kan}_{c D C E} \cdot C_{c D C E}-\mathrm{kae}_{c D C E} \cdot C_{c D C E}
\end{array}\right) \\
& \frac{d C_{t D C E}}{d t}=\left(\begin{array}{c}
Y_{\frac{D C E}{T C E}} \cdot \operatorname{Fan}_{\frac{t D C E}{T C E}} \cdot \operatorname{kan}_{T C E} \cdot C_{T C E} \\
\quad-k a n_{t D C E} \cdot C_{t D C E}-k a e_{t D C E} \cdot C_{t D C E}
\end{array}\right)
\end{aligned}
$$

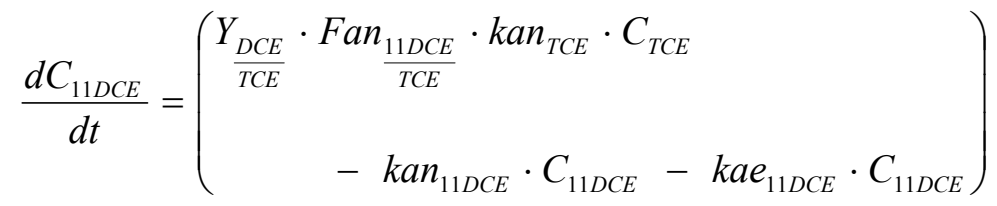

$$
\begin{aligned}
& \frac{d C_{V C}}{d t}=\left(\begin{array}{c}
Y_{\frac{V C}{D C E}} \cdot F_{\frac{V C}{c D C E}} \cdot \mathrm{kan}_{c D C E} \cdot C_{c D C E} \\
+Y_{\frac{V C}{D C E}} \cdot F_{\frac{V C}{t D C E}} \cdot k a n_{t D C E} \cdot C_{t D C E} \\
+Y_{\frac{V C}{D C E}} \cdot F a n_{\frac{V C}{11 D C E}} \cdot k a n_{11 D C E} \cdot C_{11 D C E} \\
-k_{V a n_{V C}} \cdot C_{V C}-\mathrm{kae}_{V C} \cdot C_{V C}
\end{array}\right) \\
& \frac{d C_{\text {Tracer }}}{d t}=0.0 \quad \text { (Conservative [non-reactive] tracer.) }
\end{aligned}
$$

The first-order decay rate constants $\left[\mathrm{T}^{-1}\right]$ of the $\mathrm{i}^{\text {th }}$ species are represented in the equations above by the $k a n_{i}, k a e_{i}$, and $k a b_{i}$ terms for anaerobic biological reactions, aerobic biological reactions, or abiotic reactions, respectively. The concentration of the $\mathrm{i}^{\text {th }}$ species is represented by the $C_{i}$ term $\left[\mathrm{ML}^{-3}\right]$. The $R_{i}$ terms represent the retardation factor for the $\mathrm{i}^{\text {th }}$ species [unitless].

In cases where multiple daughter products may be produced from dechlorination of a single parent species, the amount of each daughter species that is produced is a function of a mass yield $\left[\mathrm{MM}^{-1}\right]$ and a stoichiometric dechlorination yield $[\mathrm{mol} / \mathrm{mol}]$. The mass yield value, $Y_{d / p}$, accounts for the difference in molecular weight between the parent species " $\mathrm{p}$ " and the daughter species "d." All isomers of a daughter chemical have the same mass yield. Mass yield values are included in the reaction module code and do not need to be input by the user. The stoichiometric dechlorination yield represents the site-specific stoichiometry for each reaction pathway that occurs as either an anaerobic $\left(F a n_{d / p}\right)$ or an abiotic process $\left(F a b_{d / p}\right)$. The 
stoichiometric dechlorination yield is the fractional moles of daughter species that are produced by dechlorination of one mole of the parent species. The net yield is the product of the mass yield and the stoichiometric dechlorination yield. To preserve the mass balance, the values of the stoichiometric dechlorination yields are constrained by the relations in Equations 81 to 84 .

$$
\begin{aligned}
& F a n_{\frac{c D C E}{T C E}}+F a n_{\frac{t D C E}{T C E}}+F a n_{\frac{D C E 11}{T C E}}=1.0 \\
& F a n_{\frac{V C}{C D C E}} \leq 1.0 \\
& F a n_{\frac{V C}{t D C E}} \leq 1.0 \\
& \operatorname{Fan}_{\frac{V C}{D C E 11}} \leq 1.0
\end{aligned}
$$

\subsection{Required Input}

The reaction parameters for this reaction module are made available to RT3D as part of the input for the Reaction Package. The Reaction Package input file structure is discussed in the RT3D manual and addendum [Clement, 1997; Clement and Johnson, 2002]. The 16 reaction parameters that must be specified for this reaction module are listed in Table 31 in the required order (ID Number) with units and a description. Site-specific knowledge from field data or laboratory tests should be applied to determine an appropriate model configuration for reaction parameters (i.e., the values and the spatial distribution). 
Table 31. Input Parameters for the Chloroethene Dechlorination Reaction Module

\begin{tabular}{|c|c|c|c|c|}
\hline $\begin{array}{l}\text { ID } \\
\#\end{array}$ & Parameter & $\begin{array}{l}\text { Fortran } \\
\text { Variable }\end{array}$ & Units & Description \\
\hline 1 & $\operatorname{Fan}_{\frac{c D C E}{T C E}}$ & fan_cdce_tce & $\mathrm{mol} / \mathrm{mol}$ & $\begin{array}{l}\text { Moles of cis-1,2-DCE produced from anaerobic decay of one } \\
\text { mole of TCE }\end{array}$ \\
\hline 2 & $F_{\frac{t D C E}{T C E}}$ & fan_tdce_tce & $\mathrm{mol} / \mathrm{mol}$ & $\begin{array}{l}\text { Moles of trans-1,2-DCE produced from anaerobic decay of one } \\
\text { mole of TCE }\end{array}$ \\
\hline 3 & $\operatorname{Fan}_{\frac{11 D C E}{T C E}}$ & fan_11dce_tce & $\mathrm{mol} / \mathrm{mol}$ & $\begin{array}{l}\text { Moles of 1,1-DCE produced from anaerobic decay of one mole } \\
\quad \text { of TCE }\end{array}$ \\
\hline 4 & Fan $_{\frac{V C}{c D C E}}$ & fan_vc_cdce & $\mathrm{mol} / \mathrm{mol}$ & $\begin{array}{l}\text { Moles of VC produced from anaerobic decay of one mole of } \\
\text { cis-1,2-DCE }\end{array}$ \\
\hline 5 & $\operatorname{Fan}_{\frac{V C}{t D C E}}$ & fan_vc_tdce & $\mathrm{mol} / \mathrm{mol}$ & $\begin{array}{l}\text { Moles of VC produced from anaerobic decay of one mole of } \\
\text { trans-1,2-DCE }\end{array}$ \\
\hline 6 & $\operatorname{Fan}_{\frac{V C}{11 D C E}}$ & fan_vc_11dce & $\mathrm{mol} / \mathrm{mol}$ & $\begin{array}{l}\text { Moles of VC produced from anaerobic decay of one mole of } \\
\text { 1,1-DCE }\end{array}$ \\
\hline 7 & $\operatorname{kan}_{P C E}$ & kan_pce & 1/day & $\begin{array}{l}\text { First-order decay coefficient for anaerobic dechlorination of } \\
\text { PCE }\end{array}$ \\
\hline 8 & $k a n_{T C E}$ & kan_tce & $1 /$ day & $\begin{array}{l}\text { First-order decay coefficient for anaerobic dechlorination of } \\
\text { TCE }\end{array}$ \\
\hline 9 & $k a n_{C D C E}$ & kan_cdce & 1/day & $\begin{array}{l}\text { First-order decay coefficient for anaerobic dechlorination of } \\
\text { cis-1,2-DCE }\end{array}$ \\
\hline 10 & $k a n_{t D C E}$ & kan_tdce & 1/day & $\begin{array}{l}\text { First-order decay coefficient for anaerobic dechlorination of } \\
\text { trans-1,2-DCE }\end{array}$ \\
\hline 11 & $k a n_{11 D C E}$ & kan_11dce & 1/day & $\begin{array}{l}\text { First-order decay coefficient for anaerobic dechlorination of } \\
1,1-\mathrm{DCE}\end{array}$ \\
\hline 12 & ${k \mathrm{kan}_{V C}}$ & kan_vc & $1 /$ day & First-order decay coefficient for anaerobic dechlorination of $\mathrm{VC}$ \\
\hline 13 & $k a e_{C D C E}$ & kae_cdce & $1 /$ day & $\begin{array}{l}\text { First-order decay coefficient for aerobic dechlorination of } \\
\text { cis-1,2-DCE }\end{array}$ \\
\hline 14 & $k a e_{t D C E}$ & kae_tdce & $1 /$ day & $\begin{array}{l}\text { First-order decay coefficient for aerobic dechlorination of } \\
\text { trans-1,2-DCE }\end{array}$ \\
\hline 15 & $k a e_{1 I D C E}$ & kae_11dce & $1 /$ day & $\begin{array}{l}\text { First-order decay coefficient for aerobic dechlorination of } \\
\text { 1,1-DCE }\end{array}$ \\
\hline 16 & $k a e_{V C}$ & kae_vc & 1/day & First-order decay coefficient for aerobic dechlorination of $\mathrm{VC}$ \\
\hline
\end{tabular}

\subsection{Example Simulations}

Simulations with this reaction module were conducted with RT3D in a batch reactor (no flow) mode to show examples of how the reaction module simulates the pattern of dechlorination. The parameter values for each example simulation are listed in Tables 32 through 35 . These 
parameters are arbitrary values and are not directly related to any specific laboratory data. Sitespecific values would need to be determined as part of a calibration process. Results for these example batch simulations are shown in the Figures 26 through 29, respectively.

Table 32. Parameter Values for Example Simulation 1 - Base Case Anaerobic Conditions with the Chloroethene Dechlorination Reaction Module

\begin{tabular}{|c|l|c|c|c|l|c|c|}
\hline \hline ID \# & Fortran Variable & Value & Units & ID \# & Fortran Variable & Value & Units \\
\hline 1 & fan_cdce_tce & 0.8 & $\mathrm{~mol} / \mathrm{mol}$ & 9 & kan_cdce & 0.005 & $1 /$ day \\
\hline 2 & fan_tdce_tce & 0.2 & $\mathrm{~mol} / \mathrm{mol}$ & 10 & kan_tdce & 0.005 & $1 /$ day \\
\hline 3 & fan_11dce_tce & 0 & $\mathrm{~mol} / \mathrm{mol}$ & 11 & kan_11dce & 0.005 & $1 /$ day \\
\hline 4 & fan_vc_cdce & 0.8 & $\mathrm{~mol} / \mathrm{mol}$ & 12 & kan_vc & 0.0025 & $1 /$ day \\
\hline 5 & fan_vc_tdce & 0.8 & $\mathrm{~mol} / \mathrm{mol}$ & 13 & kae_cdce & 0 & $1 /$ day \\
\hline 6 & fan_vc_11dce & 0.8 & $\mathrm{~mol} / \mathrm{mol}$ & 14 & kae_tdce & 0 & $1 /$ day \\
\hline 7 & kan_pce & 0.025 & $1 /$ day & 15 & kae_11dce & 0 & $1 /$ day \\
\hline 8 & kan_tce & 0.025 & $1 /$ day & 16 & kae_vc & 0 & $1 /$ day \\
\hline \hline
\end{tabular}

Table 33. Parameter Values for Example Simulation 2 - Rates at 10\% of Example Simulation 1 - with the Chloroethene Dechlorination Reaction Module

\begin{tabular}{|c|l|c|c|c|l|c|c|}
\hline \hline ID \# & Fortran Variable & Value & Units & ID \# & Fortran Variable & Value & Units \\
\hline 1 & fan_cdce_tce & 0.8 & $\mathrm{~mol} / \mathrm{mol}$ & 9 & kan_cdce & 0.0005 & $1 /$ day \\
\hline 2 & fan_tdce_tce & 0.2 & $\mathrm{~mol} / \mathrm{mol}$ & 10 & kan_tdce & 0.0005 & $1 /$ day \\
\hline 3 & fan_11dce_tce & 0 & $\mathrm{~mol} / \mathrm{mol}$ & 11 & kan_11dce & 0.0005 & $1 /$ day \\
\hline 4 & fan_vc_cdce & 0.8 & $\mathrm{~mol} / \mathrm{mol}$ & 12 & kan_vc & 0.00025 & $1 /$ day \\
\hline 5 & fan_vc_tdce & 0.8 & $\mathrm{~mol} / \mathrm{mol}$ & 13 & kae_cdce & 0 & $1 /$ day \\
\hline 6 & fan_vc_11dce & 0.8 & $\mathrm{~mol} / \mathrm{mol}$ & 14 & kae_tdce & 0 & $1 /$ day \\
\hline 7 & kan_pce & 0.0025 & $1 /$ day & 15 & kae_11dce & 0 & $1 /$ day \\
\hline 8 & kan_tce & 0.0025 & $1 /$ day & 16 & kae_vc & 0 & $1 /$ day \\
\hline \hline
\end{tabular}

Table 34. Parameter Values for Example Simulation 3 -Different F Values Than Example Simulation 1 - with the Chloroethene Dechlorination Reaction Module

\begin{tabular}{|c|l|c|c|c|l|c|c|}
\hline \hline ID \# & Fortran Variable & Value & Units & ID \# & Fortran Variable & Value & Units \\
\hline 1 & fan_cdce_tce & 0.2 & $\mathrm{~mol} / \mathrm{mol}$ & 9 & kan_cdce & 0.005 & $1 /$ day \\
\hline 2 & fan_tdce_tce & 0 & $\mathrm{~mol} / \mathrm{mol}$ & 10 & kan_tdce & 0.005 & $1 /$ day \\
\hline 3 & fan_11dce_tce & 0.8 & $\mathrm{~mol} / \mathrm{mol}$ & 11 & kan_11dce & 0.005 & $1 /$ day \\
\hline 4 & fan_vc_cdce & 0.2 & $\mathrm{~mol} / \mathrm{mol}$ & 12 & kan_vc & 0.0025 & $1 /$ day \\
\hline 5 & fan_vc_tdce & 0.2 & $\mathrm{~mol} / \mathrm{mol}$ & 13 & kae_cdce & 0 & $1 /$ day \\
\hline 6 & fan_vc_11dce & 0.2 & $\mathrm{~mol} / \mathrm{mol}$ & 14 & kae_tdce & 0 & $1 /$ day \\
\hline 7 & kan_pce & 0.025 & $1 /$ day & 15 & kae_11dce & 0 & $1 /$ day \\
\hline 8 & kan_tce & 0.025 & $1 /$ day & 16 & kae_vc & 0 & $1 /$ day \\
\hline \hline
\end{tabular}


Table 35. Parameter Values for Example Simulation 4 - Base Case Aerobic Conditions - with the Chloroethene Dechlorination Reaction Module

\begin{tabular}{|c|l|c|c|c|l|c|c|}
\hline \hline ID \# & Fortran Variable & Value & Units & ID \# & Fortran Variable & Value & Units \\
\hline 1 & fan_cdce_tce & 0 & $\mathrm{~mol} / \mathrm{mol}$ & 9 & kan_cdce & 0 & $1 /$ day \\
\hline 2 & fan_tdce_tce & 0 & $\mathrm{~mol} / \mathrm{mol}$ & 10 & kan_tdce & 0 & $1 /$ day \\
\hline 3 & fan_11dce_tce & 0 & $\mathrm{~mol} / \mathrm{mol}$ & 11 & kan_11dce & 0 & $1 /$ day \\
\hline 4 & fan_vc_cdce & 0 & $\mathrm{~mol} / \mathrm{mol}$ & 12 & kan_vc & 0 & $1 /$ day \\
\hline 5 & fan_vc_tdce & 0 & $\mathrm{~mol} / \mathrm{mol}$ & 13 & kae_cdce & 0.005 & $1 /$ day \\
\hline 6 & fan_vc_11dce & 0 & $\mathrm{~mol} / \mathrm{mol}$ & 14 & kae_tdce & 0.005 & $1 /$ day \\
\hline 7 & kan_pce & 0 & $1 /$ day & 15 & kae_11dce & 0.005 & $1 /$ day \\
\hline 8 & kan_tce & 0 & $1 /$ day & 16 & kae_vc & 0.005 & $1 /$ day \\
\hline \hline
\end{tabular}

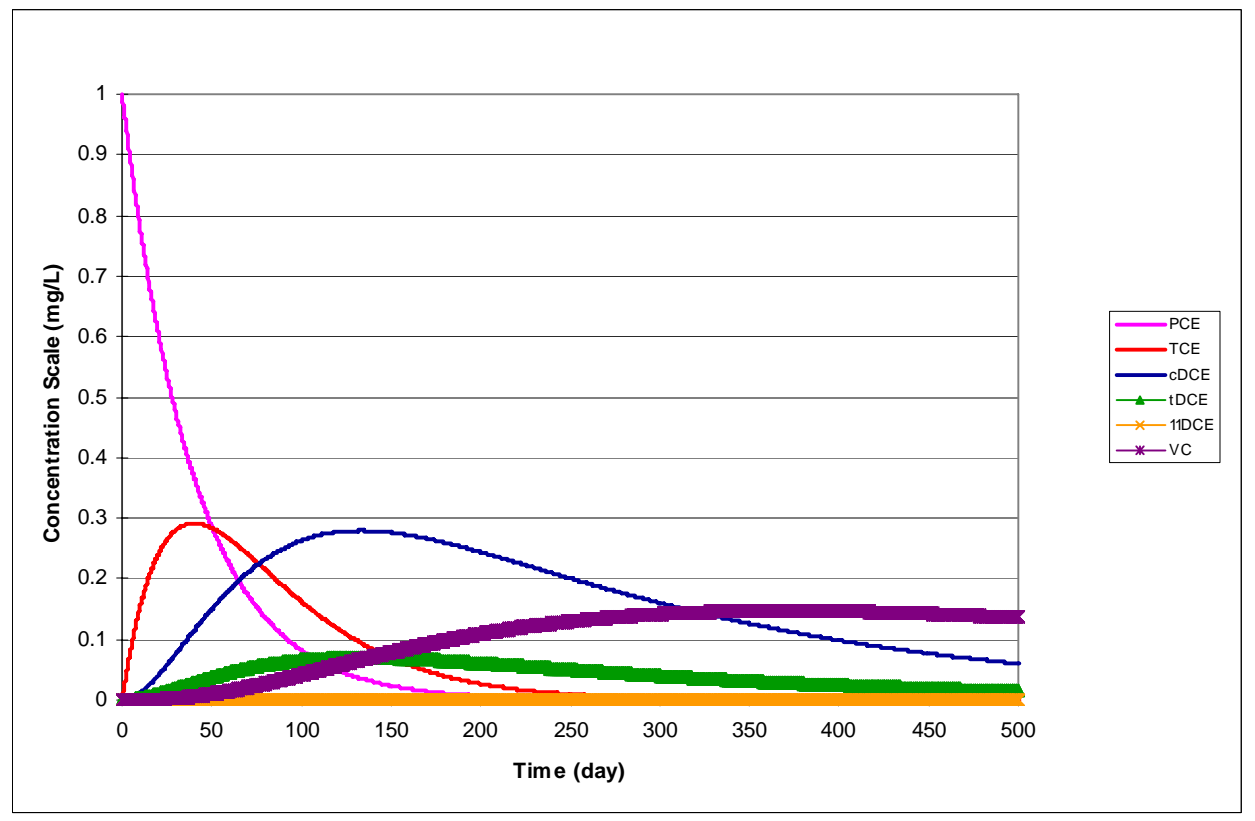

Figure 26. Dechlorination of PCE Using the Parameter Values Shown in Table 32 - The initial concentration for PCE was $1 \mathrm{mg} / L$. All other species concentrations started at zero. 


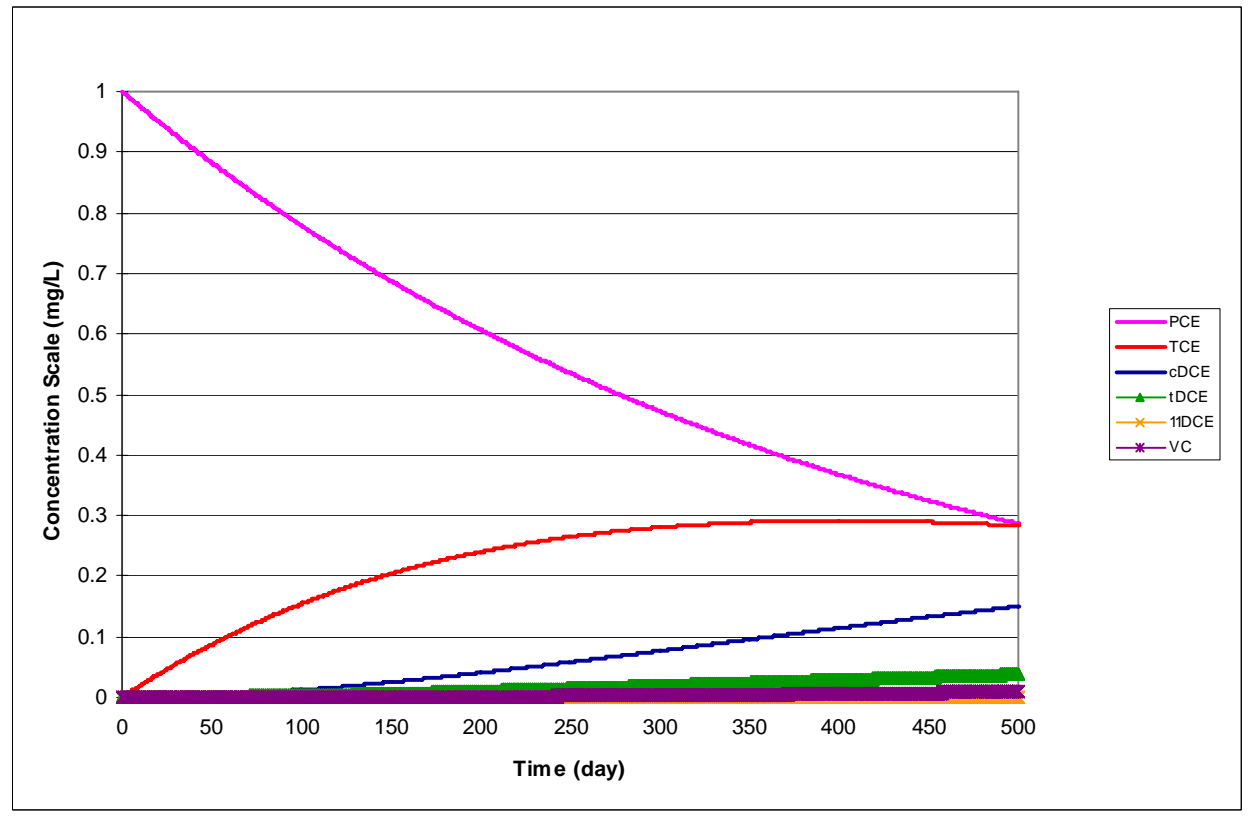

Figure 27. Dechlorination of PCE Using the Parameter Values Shown in Table 33 - The initial concentration for PCE was $1 \mathrm{mg} / \mathrm{L}$. All other species concentrations started at zero.

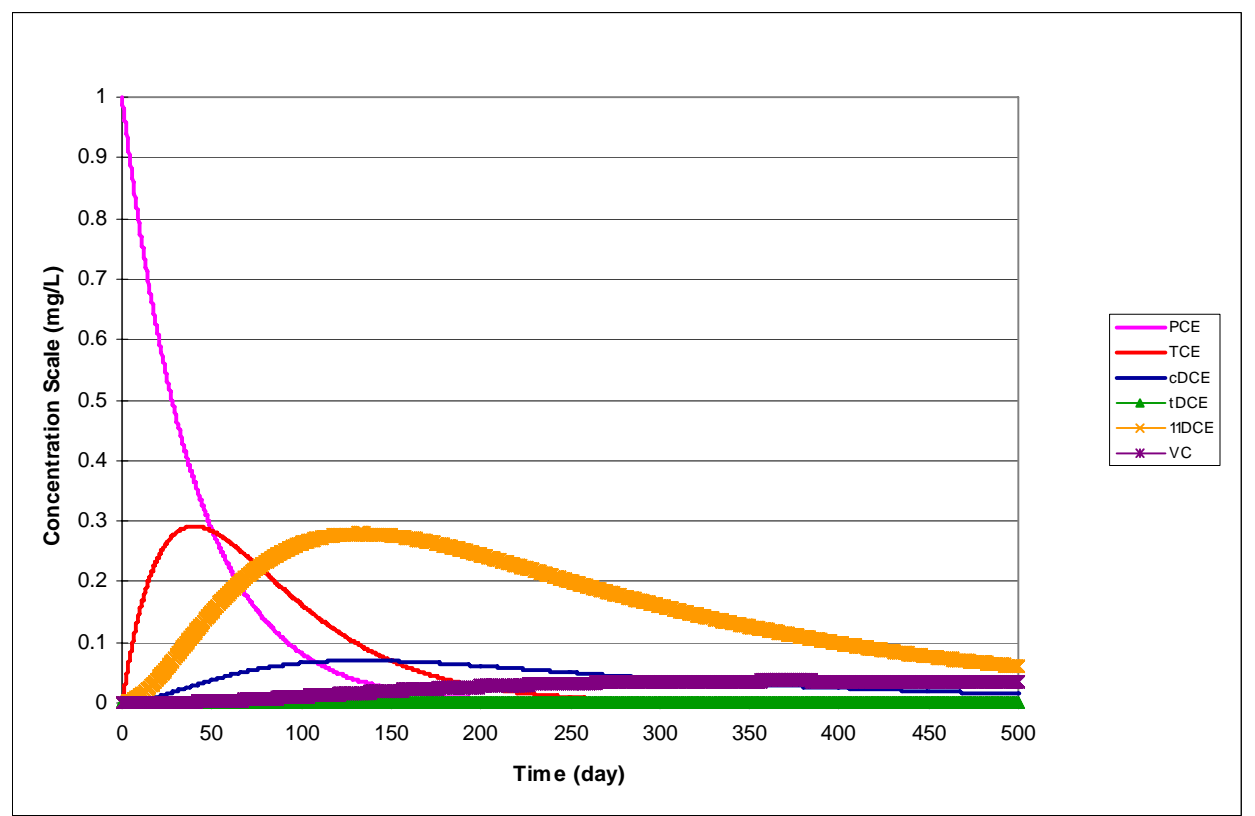

Figure 28. Dechlorination of PCE Using the Parameter Values Shown in Table 34 - The initial concentration for PCE was $1 \mathrm{mg} / \mathrm{L}$. All other species concentrations started at zero. 


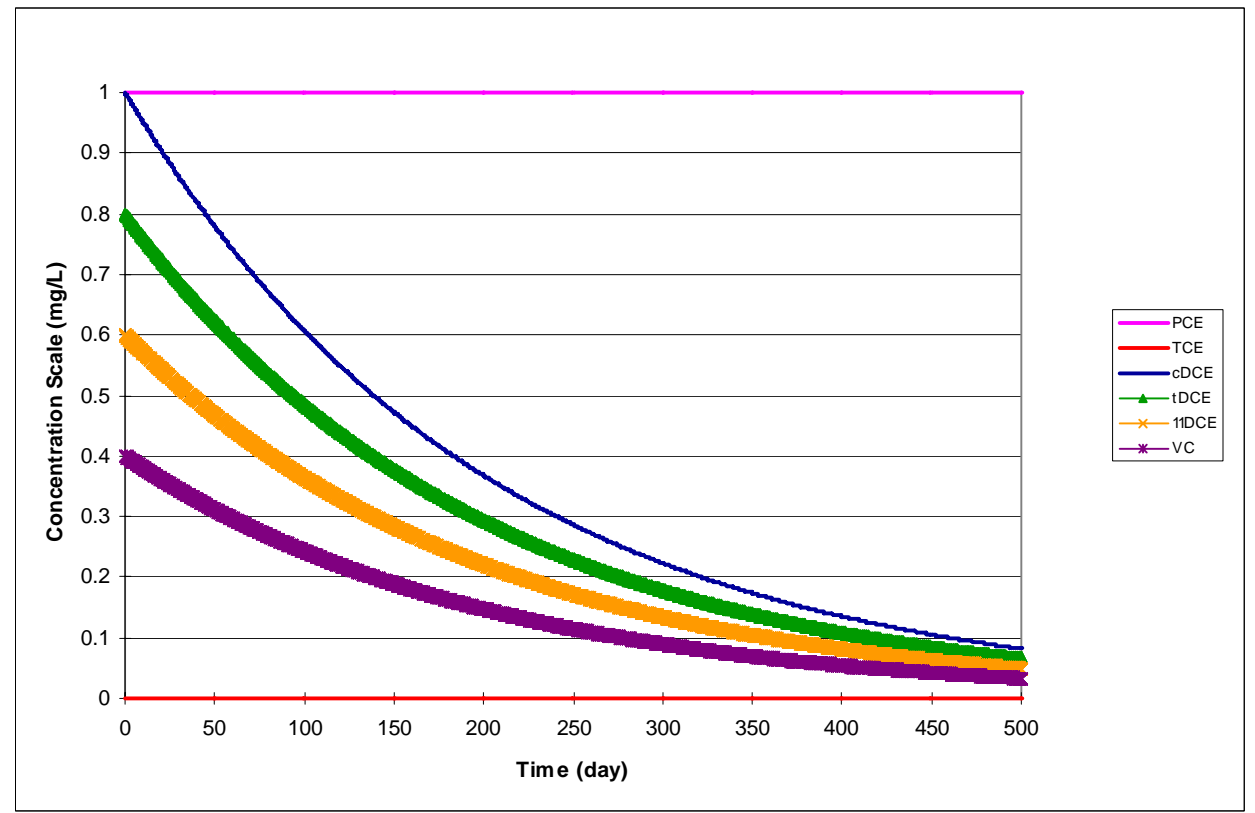

Figure 29. Aerobic and Abiotic Degradation Using the Parameter Values Shown in Table 35 The initial concentrations for PCE, TCE, cDCE, tDCE, 11DCE, and VC were 1, 0, 1, 0.8, 0.6, and $0.4 \mathrm{mg} / \mathrm{L}$, respectively. 


\subsection{Redox-Linked Dechlorination of Chloroethenes}

\subsection{Conceptual Model for Dechlorination Reactions}

This reaction module describes dechlorination of chlorinated ethene compounds by natural attenuation processes where the pathway and rate of transformation is dependent on the oxidation-reduction conditions. The reaction module adjusts the rate of dechlorination based on a simplified framework to represent the oxidation-reduction conditions in the aquifer. This module enables the user to link dechlorination rate to the concentration of geochemical indicator species. The module is not a full geochemical model, but provides one potential means for the user to model dechlorination at sites where the oxidation-reduction conditions in the aquifer are spatially or temporally variable. The module includes both aerobic and anoxic/anaerobic reaction pathways using first-order rate expressions (see the conceptual model description of the Mixed Chloroethene/ Chloroethane/Chloromethane Dechlorination reaction module for discussion on the assumption of first-order reaction kinetics). When oxygen is present, aerobic dechlorination of DCE isomers and VC can occur. If the oxygen concentration is below 0.1 $\mathrm{mg} / \mathrm{L}$, aerobic dechlorination is inhibited. At low concentrations of oxygen (dependent on a user-specified oxygen inhibition coefficient), anoxic/anaerobic dechlorination pathways are possible with rates depending on the concentration of key redox couples. Nitrate and oxygen inhibit all of the anoxic/anaerobic dechlorination pathways. The three key redox couples included in the module are iron (ferrous iron/amorphous ferric hydroxide), sulfur (sulfate/sulfide), and methane (methane/ $\mathrm{CO}_{2}$ ). The redox conditions, as indicated by a calculated $\mathrm{pE}$ value, are based on the relative concentrations of these species in each grid cell. The reaction module is based on the assumption that the redox conditions related to the key redox couples control the dechlorination reaction rate. Biological activity is not modeled explicitly under the premise that the biological activity related to natural attenuation occurs based on the low, widely distributed concentration of indigenous bacteria at a rate dependent on the geochemical conditions. The concentration of bacteria is assumed to remain constant. If sufficient substrate is present at a site to drive bacterial growth dynamics, other reaction modules that consider biomass growth and subsequent impacts to dechlorination rate should be used.

The concentrations of redox couples can be set as initial conditions with any desired spatial distribution (e.g., by interpolation of data at multiple monitoring wells). The redox species concentrations can then either 1) stay static during the simulation, or 2) vary during the simulation based on reactions of the redox species with oxygen or a user defined carbon source (modeled as a generic carbon compound). If the model is configured for varying redox couples, oxygen is also consumed by the carbon source or by oxidation of ferrous iron, sulfide, or methane. The user can enter a different first-order dechlorination rate for iron-dominated, sulfurdominated, and methane-dominated redox conditions. 
Table 36 lists the chemical species included in this reaction module. Figure 30 shows the conceptual model describing the degradation reactions modeled in this reaction module. Note that the carbon dioxide concentration is set to a constant value in the reaction module (because a buffered system is assumed). Thus, the methane-dominated redox condition is dependent only on variations in methane concentration. Ferric iron is modeled as an immobile species and all other species are mobile.

Table 36. Chemical Species Included in the Redox-Linked Dechlorination of Chloroethenes Reaction Module

\begin{tabular}{|c|c|c|c|c|c|c|}
\hline No. & Abbreviation $^{\text {a }}$ & Chemical Name & Selected Alternate Name & $\begin{array}{c}\text { CAS }^{\text {b }} \\
\text { Registry } \\
\text { Number }\end{array}$ & $\begin{array}{c}\text { Molecular } \\
\text { Weight }^{c} \\
\text { (g/mol) }\end{array}$ & $\begin{array}{l}\text { Chemical } \\
\text { Formula }\end{array}$ \\
\hline 1 & PCE & Tetrachloroethene & $\begin{array}{l}\text { Tetrachloroethylene; } \\
\text { Perchloroethylene }\end{array}$ & $127-18-4$ & 165.83340 & $\mathrm{C}_{2} \mathrm{Cl}_{4}$ \\
\hline 2 & TCE & Trichloroethene & Trichloroethylene & $79-01-6$ & 131.38834 & $\mathrm{C}_{2} \mathrm{HCl}_{3}$ \\
\hline 3 & cDCE & cis-1,2-Dichloroethene & $\begin{array}{l}\text { cis-1,2-Dichloroethylene; } \\
\text { cis-1,2-DCE; cis-DCE }\end{array}$ & $156-59-2$ & 96.94328 & $\mathrm{C}_{2} \mathrm{H}_{2} \mathrm{Cl}_{2}$ \\
\hline 4 & $\mathrm{tDCE}$ & trans-1,2-Dichloroethene & $\begin{array}{l}\text { trans-1,2-Dichloroethylene; } \\
\text { trans-1,2-DCE; trans-DCE }\end{array}$ & $156-60-5$ & 96.94328 & $\mathrm{C}_{2} \mathrm{H}_{2} \mathrm{Cl}_{2}$ \\
\hline 5 & 11DCE & 1,1-Dichloroethene & $\begin{array}{l}\text { Vinylidene Chloride; } \\
1,1-\mathrm{DCE}\end{array}$ & $75-35-4$ & 96.94328 & $\mathrm{C}_{2} \mathrm{H}_{2} \mathrm{Cl}_{2}$ \\
\hline 6 & $\mathrm{VC}$ & Chloroethene & Vinyl Chloride & $75-01-4$ & 62.49822 & $\mathrm{C}_{2} \mathrm{H}_{3} \mathrm{Cl}$ \\
\hline 7 & OXY & Oxygen (dimer) & Dissolved Oxygen & $7782-44-7$ & 31.9988 & $\mathrm{O}_{2}$ \\
\hline 8 & NIT & Nitrate anion & - & $14797-55-8$ & 62.0049 & $\mathrm{NO}_{3}^{-}$ \\
\hline 9 & FE2 & Ferrous Iron cation & Iron (II) & $15438-31-0$ & 55.8450 & $\mathrm{Fe}^{2+}$ \\
\hline 10 & $\mathrm{SO} 4$ & Sulfate anion & Sulphate & $14808-79-8$ & 96.0626 & $\mathrm{SO}_{4}^{2-}$ \\
\hline 11 & HS & Hydrosulfide & Bisulfide & $15035-72-0$ & 33.07294 & $\mathrm{HS}^{-}$ \\
\hline 12 & $\mathrm{CH} 4$ & Methane & - & $74-82-8$ & 16.04246 & $\mathrm{CH}_{4}$ \\
\hline 13 & DOC & Carbon Source $^{\mathrm{d}}$ & Dissolved Organic Carbon & $\mathrm{N} / \mathrm{A}$ & 30.02598 & $\mathrm{CH}_{2} \mathrm{O}$ \\
\hline 14 & Tracer & Conservative Tracer & - & N/A & N/A & $\mathrm{N} / \mathrm{A}$ \\
\hline 15 & FE3 & $\begin{array}{l}\text { Ferric Hydroxide } \\
\text { (amorphous) }\end{array}$ & $\begin{array}{l}\text { iron hydroxide; ferric iron; } \\
\text { iron (III) }\end{array}$ & $1309-33-7$ & 106.86702 & $\mathrm{Fe}(\mathrm{OH})_{3}$ \\
\hline
\end{tabular}

a These abbreviations refer to the specific chemicals listed here and should not be confused with different chemicals that may use the same abbreviation in other reaction modules.

${ }^{\text {b }}$ CAS $=$ Chemical Abstracts Service (see http://www.cas.org/EO/regsys.html)

c Based on International Union of Pure and Applied Chemistry values reported by Loss [2003].

${ }^{\mathrm{d}}$ Dissolved organic carbon is represented by a simple hydrocarbon (based on the generic formula for an organic compound of $\mathrm{C}_{n} \mathrm{H}_{2 n} \mathrm{O}_{n}$ with $\mathrm{n}=1$ ). Concentration of actual dissolved organic carbon must be converted to this basis for this reaction module.

N/A - Not Applicable 


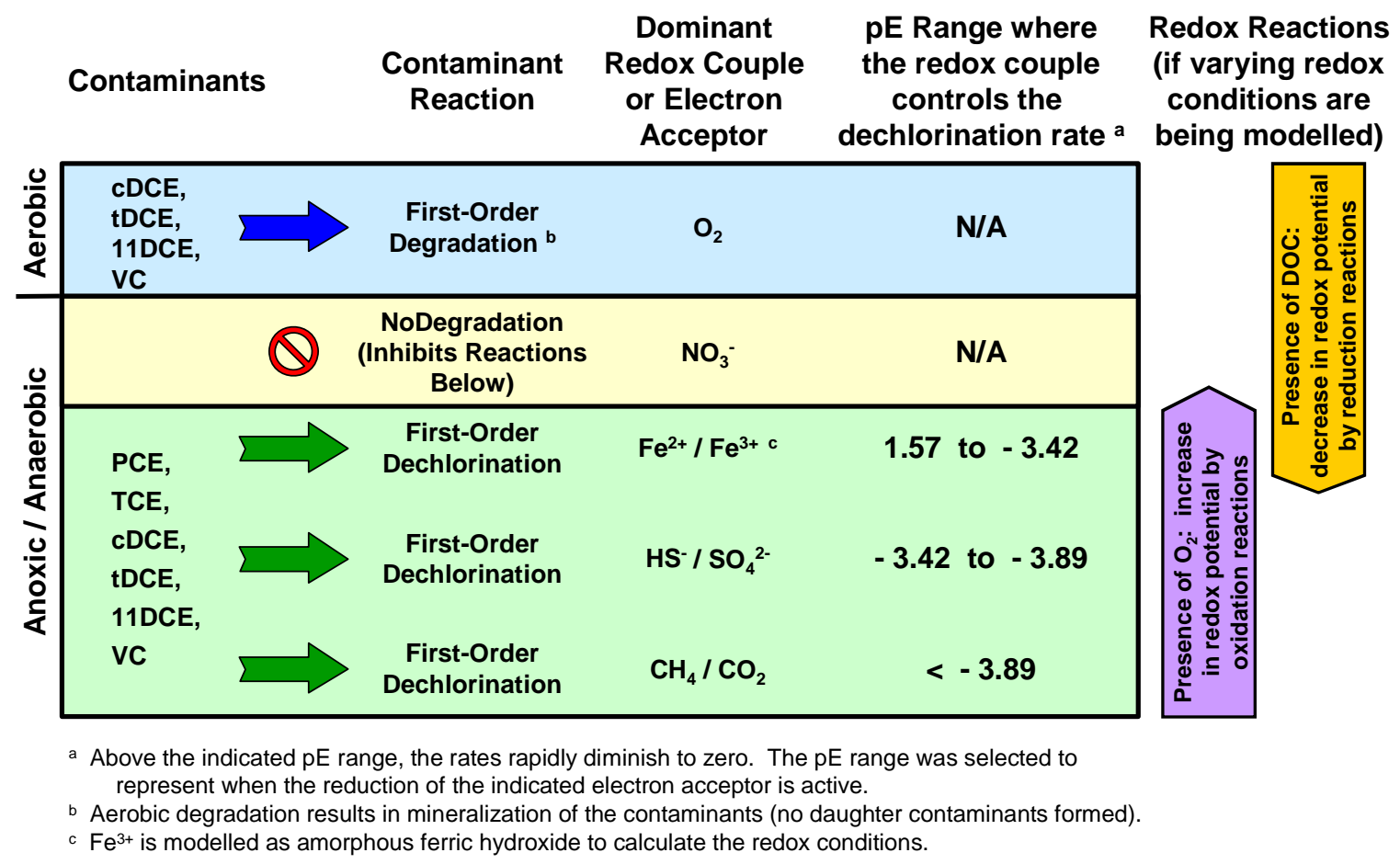

Figure 30. Conceptual Model for the Dechlorination Reactions of the Redox-Linked Dechlorination of Chloroethenes Reaction Module

The conceptual model considers the rate of dechlorination or aerobic degradation as a function of the oxidation-reduction potential (at a fixed $\mathrm{pH}$ of 7) as controlled by key redox species that are commonly measured. These redox species also indicate the classes of microbial processes in the subsurface that are important for dechlorination or contaminant degradation reactions. The aerobic redox condition and associated degradation reactions are indicated sufficiently by the concentration of oxygen. When oxygen concentration is very low or oxygen is absent, anaerobic redox is divided into four different conditions. If nitrate is present at some location within the model domain, all other anaerobic reactions at that location are inhibited based on a userspecified inhibition coefficient. If nitrate is not present or has been depleted below the inhibitory level, anaerobic dechlorination can proceed at rates depending on the dominant electron acceptor process. The dominant electron acceptor process is defined by the relative concentrations of the redox couples shown in Figure 30. For iron, the redox potential is only a function of the ferrous iron concentration because ferric iron is only present as a solid. Ferric iron concentration are only important if the user desires to track changes in redox couples as impacted through oxidation by oxygen or through reduction by a carbon source. The sulfur redox potential is defined by the relative concentrations of sulfate and hydrosulfide (or dissolved sulfide converted to the equivalent hydrosulfide concentration based on the $\mathrm{pH}$ ). The lowest possible redox potential occurs when methane is being produced. This redox couple uses a fixed dissolved $\mathrm{CO}_{2}$ concentration in the reaction module such that the redox potential only varies as a function of the methane concentration. The module calculates the redox potential for each anaerobic redox 
couple and the redox potential is set to the minimum value calculated for the three couples. Based on this minimum calculated redox potential, the module calculates dechlorination rates with the user-defined dechlorination rate coefficient associated with the redox range listed in Figure 30.

\subsection{Reaction Equations}

The basic functionality of this reaction module is described in this section for the 15 chemical species in Table 36. See Table 38 for a detailed itemization of all reaction parameters used in this reaction module.

The user must input a flag value to define the simulation as having static redox conditions or varying redox conditions. Static redox conditions may be useful if a user would like to interpolate available geochemical data and then let the module compute the distribution of related reaction rates. This rate distribution would then be used throughout the timeframe of the simulations. Use of static conditions may be suitable if it is unlikely that there will be significant changes in geochemical conditions over the duration of the simulation. By setting the flag to a value of "1" for static redox conditions, the reaction module computes the reaction rates in the first time step of the simulation based on the concentration distribution at the first time step (nominally the initial conditions). The module then holds these reaction rates constant throughout the simulation time period, though the rates will be spatially variable according to the input distribution of redox indicators. The module also sets the concentration of the redox indicators to zero after the first time step so that transport of these species is not tracked. By setting the flag to a value of " 0 " for varying redox conditions, the reaction module uses the full set of reactions described below at each time step to determine the dechlorination rates and associated concentration changes for each time step in the simulation.

If oxygen is present, the module first uses instantaneous (equilibrium) stoichiometric reactions (Equations 85 to 88 ) to deplete oxygen by sequential reaction with dissolved DOC, FE2, HS, and/or $\mathrm{CH} 4$ to the point where either all oxygen is consumed or all of these compounds are consumed. The initial concentrations (denoted as [Species]) for DOC, FE2, HS, CH4, and OXY are reduced to the post-oxidation concentrations [Species] $]_{\mathrm{ox}}$, which are used in the subsequent $\mathrm{pE}$ and dechlorination rate calculations.

$$
\begin{aligned}
& 1 \mathrm{CH}_{2} \mathrm{O}+1 \mathrm{O}_{2} \rightarrow 1 \mathrm{CO}_{2}+1 \mathrm{H}_{2} \mathrm{O} \\
& 4 \mathrm{Fe}^{2+}+8 \mathrm{OH}^{-}+2 \mathrm{H}_{2} \mathrm{O}+1 \mathrm{O}_{2} \rightarrow 4 \mathrm{Fe}(\mathrm{OH})_{3} \\
& 1 \mathrm{HS}^{-}+1 \mathrm{OH}^{-}+2 \mathrm{O}_{2} \rightarrow 1 \mathrm{SO}_{4}^{2-}+1 \mathrm{H}_{2} \mathrm{O} \\
& 1 \mathrm{CH}_{4}+2 \mathrm{O}_{2} \rightarrow 1 \mathrm{CO}_{2}+2 \mathrm{H}_{2} \mathrm{O}
\end{aligned}
$$


The initial oxygen concentration (prior to any oxidation reactions) inhibits anaerobic dechlorination reactions, as does the nitrate concentration (Equations 89 and 90). Oxygen must be present after the oxidation reactions for aerobic degradation of DCE isomers and VC to occur, which is enforced using the Monod term in Equation 91. However, the module does not consider consumption of oxygen during DCE isomer or VC oxidation.

$$
\begin{aligned}
& \text { OxyInhib }=\left(\frac{k_{i o}}{k_{i o}+[O X Y]}\right) \\
& \text { NitInhib }=\left(\frac{k_{i n}}{k_{i n}+[N I T]}\right) \\
& \text { OxyPromo }=\left(\frac{[O X Y]_{o x}}{K_{O 2}+[O X Y]_{o x}}\right)
\end{aligned}
$$

If the initial oxygen concentration is greater than $0.1 \mathrm{mg} / \mathrm{L}$, then reduction of electron acceptors is not allowed in the same transport time step where they just underwent oxidization (i.e., rates of electron acceptor reduction are set to zero). If the initial oxygen concentration in a transport time step is less than $0.1 \mathrm{mg} / \mathrm{L}$, then electron acceptors will undergo reduction at a rate depending on the electron acceptor and DOC concentration and inhibited by the initial oxygen concentration. Electron acceptors are sequentially inhibited based on $10 \%$ of the Monod half-saturation coefficient for nitrate and the Monod half-saturation coefficients for iron and sulfate. The DOC Monod half-saturation coefficient is defined as $1.0 \mathrm{E}-4 \mathrm{~mol} / \mathrm{L}$ for nitrate, iron, and sulfate and as 1.0 E-5 mol/L for methane. Equations 92 through 95 define the rates of electron acceptor reduction when the initial oxygen concentration is less than $0.1 \mathrm{mg} / \mathrm{L}$.

$$
\begin{aligned}
& r_{N I T}=k_{N I T} \cdot\left(\frac{[N I T]}{K_{n}+[N I T]}\right) \cdot\left(\frac{[D O C]_{o x}}{10^{-4}+[D O C]_{o x}}\right) \cdot \text { OxyInhib } \\
& r_{F E 3}=k_{F E 3} \cdot\left(\frac{[F E 3]_{o x}}{K_{f}+[F E 3]_{o x}}\right) \cdot\left(\frac{[D O C]_{o x}}{10^{-4}+[D O C]_{o x}}\right) \cdot \text { OxyInhib } \cdot\left(\frac{0.1 \cdot K_{n}}{0.1 \cdot K_{n}+[N I T]}\right) \\
& r_{S O 4}=k_{S O 4} \cdot\left(\frac{[S O 4]_{o x}}{K_{s}+[S O 4]_{o x}}\right) \cdot\left(\frac{[D O C]_{o x}}{10^{-4}+[D O C]_{o x}}\right) \cdot \text { OxyInhib } \cdot\left(\frac{0.1 \cdot K_{n}}{0.1 \cdot K_{n}+[N I T]}\right) \cdot\left(\frac{K_{f}}{K_{f}+[F E 3]_{o x}}\right) \\
& r_{C H 4}=\mu_{C H 4} \cdot\left(\frac{[D O C]_{o x}}{10^{-5}+[D O C]_{o x}}\right) \cdot \text { OxyInhib } \cdot\left(\frac{0.1 \cdot K_{n}}{0.1 \cdot K_{n}+[N I T]}\right) \cdot\left(\frac{K_{f}}{K_{f}+[F E 3]_{o x}}\right) \cdot\left(\frac{K_{s}}{K_{s}+[S O 4]_{o x}}\right)
\end{aligned}
$$


Three redox couples are represented in this reaction module:

1. $\mathrm{Fe}$ iron (ferrous iron / amorphous ferric hydroxide)

2. S sulfur (sulfate / hydrosulfide)

3. $\mathrm{C}$ methane (methane $/ \mathrm{CO}_{2}$ )

The redox potential $(\mathrm{pE})$ of a redox couple is calculated from the Nernst equation (Equation 96) using the number of electrons transferred $\left(N_{e}\right)$ and the product of the reactant species concentrations to the power of the respective stoichiometric coefficients $\left(b_{i}\right)$ divided by the product of the product species concentrations to the power of the respective stoichiometric coefficients $\left(b_{j}\right)$ [Drever, 1988]. Assuming dilute aqueous solution, species concentrations are used in place of chemical activities. For solid species (e.g., $\left.\mathrm{Fe}(\mathrm{OH})_{3}\right)$, the chemical activity is taken as 1.0. Equation 97 [Drever, 1988] is used to calculate the $\mathrm{pE}^{\circ}$ at standard conditions ( $298.15 \mathrm{~K}, 1 \mathrm{~atm}$, and unit activity) based on tabulated values of $\Delta \mathrm{G}^{\circ}$ ( $\mathrm{R}$ is the gas constant, equal to $\left.8.314472 \mathrm{~J} \cdot \mathrm{K}^{-1} \cdot \mathrm{mol}^{-1}\right)$. Free energies for the species important to the three redox couples of interest are given in Table 37. The reactions for these three redox couples are listed in Equations 98 to 100 along with calculated values for the terms of the $\mathrm{pE}^{\circ}$ equation. The $\mathrm{pE}$ for each anaerobic redox couple is thus calculated for a $\mathrm{pH}$ of 7 (i.e., $\left[\mathrm{H}^{+}\right]=10^{-7} \mathrm{~mol} / \mathrm{L}$ ) using Equations 101 to 103 (substituting in $\mathrm{pE}^{\circ}$ values). These equations assume that the system is well buffered, thus the $\mathrm{pH}$ is constant and the concentration of $\mathrm{CO}_{2}$ is constant at a value of $0.001 \mathrm{~mol} / \mathrm{L}$. At a very low concentration of a reduced species (FE2, HS, or CH4), the pE is set to an arbitrarily high value of 8.0 to prevent numerical problems. To avoid dealing with negative $\mathrm{pE}$ numbers in this reaction module, the $\mathrm{pE}$ values are shifted upwards by 10 units to obtain $\mathrm{pE}^{\prime}$ (i.e., $\mathrm{pE}^{\prime}=\mathrm{pE}+10$ ). The dominant redox couple is determined as the minimum of these three $\mathrm{pE}^{\prime}$ values (Equation 104).

$$
\begin{aligned}
& p E=p E^{\circ}+\frac{1}{N_{e}} \cdot \log _{10}\left(\frac{\prod_{i=1}^{\# \text { reactants }}\left[\text { reactant }_{i}\right]^{b_{i}}}{\prod_{j=1}^{\text {products }}\left[\text { product }_{j}\right]^{b_{j}}}\right) \\
& p E^{\circ}=\frac{1}{N_{e}} \cdot \log _{10}\left(K_{e q}\right)=\frac{1}{N_{e}} \cdot \log _{10}\left(\frac{-\Delta G^{\circ}}{R \cdot T}\right)=\frac{1}{N_{e}} \cdot \frac{\log _{e}\left(\frac{-\Delta G^{\circ}}{R \cdot T}\right)}{\log _{e}(10)}
\end{aligned}
$$


Table 37. Free Energy for Chemical Species of Interest [Drever, 1988]

\begin{tabular}{|c|c|}
\hline \hline Chemical Species & $\Delta \mathrm{G}^{\circ}(\mathrm{kJ})$ \\
\hline $\mathrm{H}_{2} \mathrm{O}$ & -237.13 \\
\hline $\mathrm{Fe}(\mathrm{OH})_{3}$ & -696.5 \\
\hline $\mathrm{Fe}^{2+}$ & -85.35 \\
\hline $\mathrm{SO}_{4}{ }^{2-}$ & -744.53 \\
\hline $\mathrm{HS}^{-}$ & 12.08 \\
\hline $\mathrm{CO}_{2}$ & -394.36 \\
\hline $\mathrm{CH}_{4}$ & -50.72 \\
\hline \hline
\end{tabular}

$$
\begin{aligned}
1 \mathrm{Fe}(\mathrm{OH})_{3}+1 \mathrm{e}^{-}+3 \mathrm{H}^{+} & \rightleftarrows 1 \mathrm{Fe}^{2+}+3 \mathrm{H}_{2} \mathrm{O} \\
1 \mathrm{SO}_{4}^{2-}+8 \mathrm{e}^{-}+9 \mathrm{H}^{+} & \rightleftarrows 1 \mathrm{HS}^{-}+4 \mathrm{H}_{2} \mathrm{O} \\
1 \mathrm{CO}_{2}+8 \mathrm{e}^{-}+8 \mathrm{H}^{+} & \rightleftarrows 1 \mathrm{CH}_{4}+2 \mathrm{H}_{2} \mathrm{O}
\end{aligned}
$$

\begin{tabular}{c|c|c}
$\ln \left(\mathrm{K}_{\mathrm{eq}}\right)$ & $\mathrm{N}_{\mathrm{e}}$ & $\mathrm{pE}^{\circ}$ \\
\hline 40.5 & 1 & 17.57
\end{tabular}

\begin{tabular}{l|l|l}
77.5 & 8 & 4.20
\end{tabular}

\begin{tabular}{l|l|l}
52.7 & 8 & 2.86
\end{tabular}

$$
\begin{array}{ll}
p E_{F}=17.57+\log _{10}\left(\frac{10^{-21}}{[F E 2]_{o x}}\right) & \text { (for FE2 }>10^{-7} \mathrm{~mol} / \mathrm{L} ; p E_{F} \equiv 8.0 \text { otherwise) } \\
p E_{S}=4.20+\left(\frac{1}{8}\right) \cdot \log _{10}\left(\frac{[S O 4]_{o x} \cdot 10^{-63}}{[H S]_{o x}}\right) & \text { (for } \mathrm{HS}>10^{-7} \mathrm{~mol} / \mathrm{L} ; p E_{S} \equiv 8.0 \text { otherwise) } \\
p E_{C}=2.86+\left(\frac{1}{8}\right) \cdot \log _{10}\left(\frac{[\mathrm{CO} 2] \cdot 10^{-56}}{[C H 4]_{o x}}\right) & \text { (for } \mathrm{CH} 4>10^{-7} \mathrm{~mol} / \mathrm{L} ; p E_{C} \equiv 8.0 \text { otherwise) } \\
p E_{\text {dominant }}^{\prime}=\operatorname{Minimum}\left(p E_{F}^{\prime}, p E_{S}^{\prime}, p E_{C}^{\prime}\right) &
\end{array}
$$

As the $\mathrm{pE}^{\prime}$ value for an aqueous solution decreases, the redox conditions are controlled by the iron, sulfur, and methane couples beginning at $\mathrm{pE}^{\prime}$ values of $11.57,6.58$, and 6.11 , respectively. Based on the dominant redox couple (i.e., $\mathrm{pE}_{\text {dominant) }}$ ), fractional activities (pctFe, pctS, and pctC for iron, sulfur, and methane, respectively) are determined for each redox couple from the curves shown in Figure 31. "Fractional activities" (not to be confused with chemical activity) are assigned as values from 0.0 to 1.0 and are multipliers on the reaction rates (as discussed below). For a fractional activity of 1.0, the regime is fully active. When multiple regimes are active, only the leftmost regime on the $\mathrm{pE}^{\prime}$ scale is allowed to impact the dechlorination rates (except in 
transition zones, which are small). A sigmoidal function is used to provide a smooth (albeit steep) transition at the control points instead of using a step function (i.e., if/then logic). Sigmoidal function parameters (steepness and inflection point) were selected based on a $0.1 \mathrm{pE}^{\prime}$ unit change (i.e., the transition zone) where the fractional activity value changes from 0.0 to 1.0.

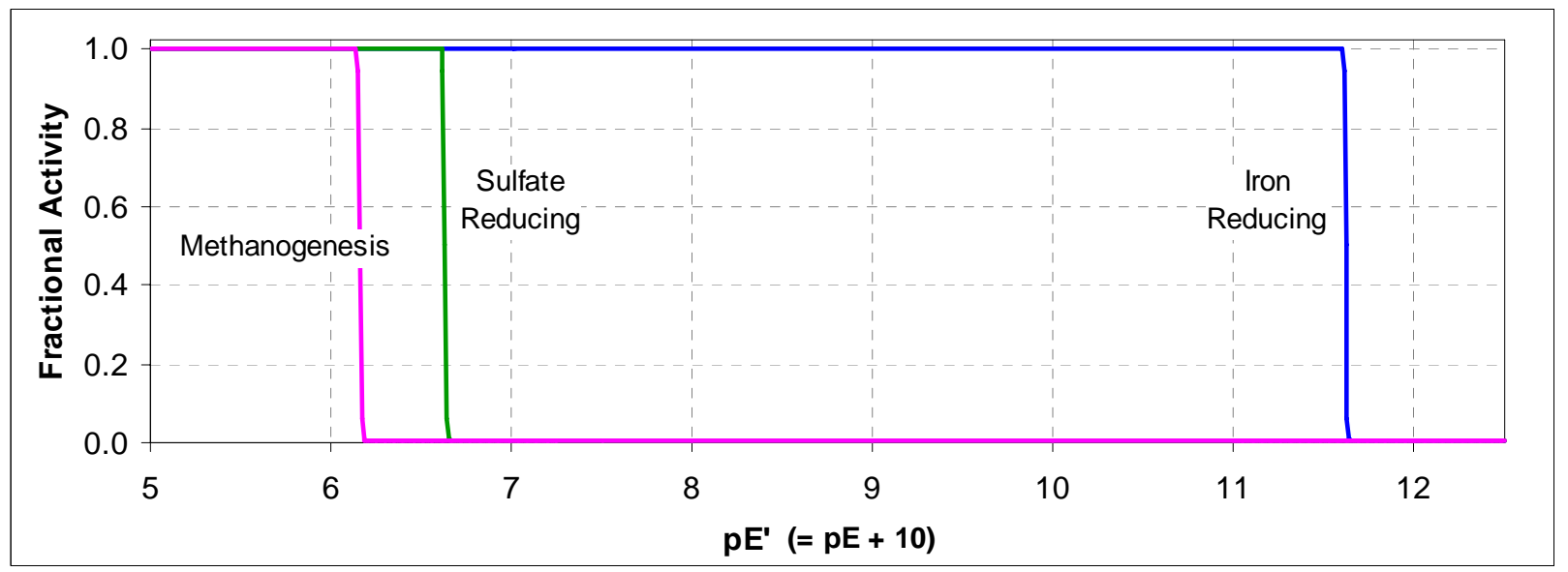

Figure 31. $p E$ Value (On a Shifted Scale) at Which Each Anaerobic Dechlorination Mechanism Dominates

Anaerobic dechlorination rates are calculated based on the contaminant concentration, the inhibition from oxygen and nitrate, and the user-defined dechlorination rate coefficient associated with the dominant redox couple. Equations 105 to 110 describe the anaerobic dechlorination rates. These equations are implemented such that the dechlorination rates for only one redox regime apply (except in the small transition zone windows, where multiple regimes may apply at less than full activity). For example, at a $\mathrm{pE}$ 'dominant value of 6.5 , the fractional activities from Figure 31 for iron, sulfur, and methane, respectively, are 1.0, 1.0, and 0.0. The dechlorination rate in this example is that for sulfate $\left(\mathrm{kan}_{\mathrm{Fe}}+\mathrm{kan}_{\mathrm{S}}-\mathrm{kan}_{\mathrm{Fe}}+0.0=\mathrm{kan}_{\mathrm{S}}\right)$

$$
\begin{aligned}
& \operatorname{ran}_{P C E}=[P C E] \cdot \text { OxyInhib } \cdot \text { NitInhib }
\end{aligned}
$$

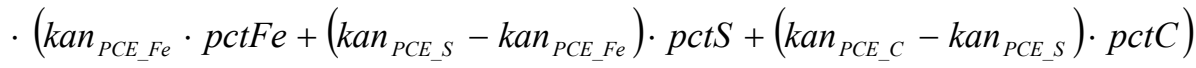

$$
\begin{aligned}
& \operatorname{ran}_{T C E}=[T C E] \cdot \text { OxyInhib } \cdot \text { NitInhib } \\
& \cdot\left(k_{T n_{T C E} F e} \cdot p c t F e+\left(k a n_{T C E_{-} S}-k a n_{T C E_{-} F e}\right) \cdot p c t S+\left(k a n_{\text {TCE } C}-k a n_{\text {TCE_- }}\right) \cdot p c t C\right) \\
& \operatorname{ran}_{C D C E}=[c D C E] \cdot \text { OxyInhib } \cdot \text { NitInhib }
\end{aligned}
$$

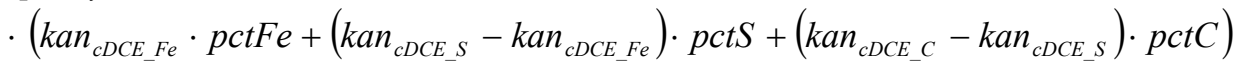

$$
\begin{aligned}
& \operatorname{ran}_{t D C E}=[t D C E] \cdot \text { OxyInhib } \cdot \text { NitInhib } \\
& \cdot\left(k a n_{t D C E_{-} F e} \cdot p c t F e+\left(k a n_{t D C E_{-} S}-k a n_{t D C E_{-} F_{e}}\right) \cdot p c t S+\left(k a n_{t D C E_{-} C}-k a n_{t D C E_{-} S}\right) \cdot p c t C\right)
\end{aligned}
$$




$$
\begin{aligned}
& \operatorname{ran}_{\text {IIDCE }}=[11 D C E] \cdot \text { OxyInhib } \cdot \text { NitInhib } \\
& \cdot\left(k_{11 D C E_{-} F e} \cdot p c t F e+\left(k_{11 D C E_{-} S}-k a n_{1 I D C E_{-} F e}\right) \cdot p c t S+\left(k_{11 D n_{-} C}-k a n_{1 I D C E_{-} S}\right) \cdot p c t C\right) \\
& \operatorname{ran}_{V C}=[V C] \cdot \text { OxyInhib } \cdot \text { NitInhib } \\
& \cdot\left(k a n_{V C_{-} F e} \cdot p c t F e+\left(k a n_{V C_{-} S}-k a n_{V C_{-} F e}\right) \cdot p c t S+\left(k a n_{V C_{-} C}-k a n_{V C_{-} S}\right) \cdot p c t C\right)
\end{aligned}
$$

The set of differential equations describing the reaction kinetics for all species is given in Equations 111 through 125.

$$
\begin{aligned}
& \frac{d[P C E]}{d t}=-\operatorname{ran}_{P C E} \\
& \frac{d[T C E]}{d t}=-\operatorname{ran}_{T C E}+\operatorname{ran}_{P C E} \\
& \frac{d[c D C E]}{d t}=-\operatorname{ran}_{c D C E}+\operatorname{ran}_{T C E} \cdot F_{c D C E / T C E}-k a e_{c D C E} \cdot \text { OxyPromo } \cdot[c D C E] \\
& \frac{d[t D C E]}{d t}=-\operatorname{ran}_{t D C E}+\operatorname{ran}_{T C E} \cdot F_{t D C E / T C E}-k a e_{t D C E} \cdot \text { OxyPromo } \cdot[t D C E]
\end{aligned}
$$

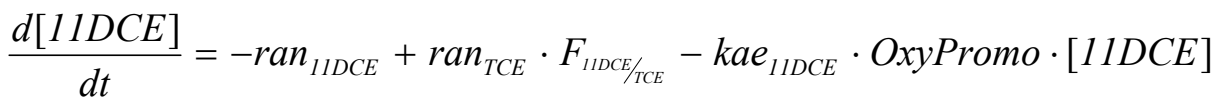

$$
\begin{aligned}
& \frac{d[V C]}{d t}=-\operatorname{ran}_{V C}+\operatorname{ran}_{C D C E} \cdot F_{V C / C D C E}+\operatorname{ran}_{t D C E} \cdot F_{V C / I D C E}+\operatorname{ran}_{I I D C E} \cdot F_{V C / I D C E}-\operatorname{kae}_{V C} \cdot \text { OxyPromo } \cdot[V C] \\
& \frac{d[O X Y]}{d t}=0.0 \\
& \text { (Oxygen is consumed by equilibrium oxidation reactions, but kinetic } \\
& \text { consumption of oxygen during DCE or VC biodegradation is not tracked } \\
& \text { because those are modeled as first-order processes.) } \\
& \frac{d[N I T]}{d t}=-r_{N I T} \cdot[N I T] \\
& \frac{d[F E 2]}{d t}=r_{F E 3} \cdot[F E 3]_{o x} \\
& \frac{d[S O 4]}{d t}=-r_{S O 4} \cdot[S O 4]_{o x} \\
& \frac{d[H S]}{d t}=r_{S O 4} \cdot[S O 4]_{o x}
\end{aligned}
$$




$$
\begin{aligned}
& \frac{d[\mathrm{CH} 4]}{d t}=r_{C H 4} \\
& \frac{d[D O C]}{d t}=-r_{N I T} \cdot F_{D O C / N I T} \cdot[N I T]_{O x}-r_{F E 3} \cdot F_{D O C / F E 3} \cdot[F E 3]_{O x}-r_{S O 4} \cdot F_{D O C / S O 4} \cdot[S O 4]_{O x} \\
& \frac{d[\text { Tracer }]}{d t}=0.0 \quad \text { (Conservative [non-reactive] tracer.) } \\
& \frac{d[F E 3]}{d t}=-r_{F E 3} \cdot[F E 3]_{O x}
\end{aligned}
$$

\subsection{Required Input}

The reaction parameters for this reaction module are made available to RT3D as part of the input for the Reaction Package. The Reaction Package input file structure is discussed in the RT3D manual and addendum [Clement, 1997; Clement and Johnson, 2002]. The 39 reaction parameters that must be specified for this reaction module are listed in Table 38 in the required order (ID Number) with units and a description. Site-specific knowledge from field data or laboratory tests should be applied to determine an appropriate model configuration for reaction parameters (i.e., the values and the spatial distribution).

Table 38. Input Parameters for the Redox-Linked Dechlorination of Chloroethenes Reaction Module

\begin{tabular}{|c|c|l|l|l|}
\hline \hline $\begin{array}{c}\text { ID } \\
\#\end{array}$ & Parameter & \multicolumn{1}{|c|}{$\begin{array}{c}\text { Fortran } \\
\text { Variable }\end{array}$} & Units & Description \\
\hline 1 & IsStatic & IsStatic & -- & $\begin{array}{c}\text { Value to signify whether the redox-dependant dechlorination } \\
\text { rates are to be held constant (static) after an initial } \\
\text { determination (1) or if the spatial distribution of redox } \\
\text { conditions will be allowed to vary over time (0). }\end{array}$ \\
\hline 2 & $F_{C D C E / T C E}$ & f_cdce_tce & mol/mol & $\begin{array}{c}\text { Molar stoichiometry of conversion from TCE to cDCE (based } \\
\text { on site specific observation) }\end{array}$ \\
\hline 3 & $F_{t D C E / T C E}$ & f_tdce_tce & mol $/ \mathrm{mol}$ & $\begin{array}{c}\text { Molar stoichiometry of conversion from TCE to tDCE (based } \\
\text { on site specific observation) }\end{array}$ \\
\hline 4 & $F_{I I D C E} / T C E$ & f_11dce_tce & $\mathrm{mol} / \mathrm{mol}$ & $\begin{array}{c}\text { Molar stoichiometry of conversion from TCE to 11DCE (based } \\
\text { on site specific observation) }\end{array}$ \\
\hline 5 & $F_{V C / C D C E}$ & f_vc_cdce & $\mathrm{mol} / \mathrm{mol}$ & $\begin{array}{c}\text { Molar stoichiometry of conversion from cDCE to VC (based on } \\
\text { site specific observation) }\end{array}$ \\
\hline 6 & $F_{V C / T C E}$ & f_vc_tdce & $\mathrm{mol} / \mathrm{mol}$ & $\begin{array}{c}\text { Molar stoichiometry of conversion from tDCE to VC (based on } \\
\text { site specific observation) }\end{array}$ \\
\hline
\end{tabular}


Table 38. (contd)

\begin{tabular}{|c|c|c|c|c|}
\hline ID & Parameter & $\begin{array}{l}\text { Fortran } \\
\text { Variable }\end{array}$ & Units & Description \\
\hline 7 & $F_{V C / I D C E}$ & f_vc_11dce & $\mathrm{mol} / \mathrm{mol}$ & $\begin{array}{l}\text { Molar stoichiometry of conversion from 11DCE to VC (based } \\
\text { on site specific observation) }\end{array}$ \\
\hline 8 & $K_{O 2}$ & Ko2 & $\mathrm{mg} / \mathrm{L}$ & $\begin{array}{l}\text { Monod half-saturation coefficient for oxygen as part of aerobic } \\
\text { dechlorination reactions }\end{array}$ \\
\hline 9 & $K_{n}$ & $\mathrm{Kn}$ & $\mathrm{mg} / \mathrm{L}$ & Monod half-saturation coefficient for nitrate reduction \\
\hline 10 & $K_{f}$ & $\mathrm{Kf}$ & $\mathrm{mg} / \mathrm{L}$ & Monod half-saturation coefficient for iron reduction \\
\hline 11 & $K_{s}$ & $\mathrm{Ks}$ & $\mathrm{mg} / \mathrm{L}$ & Monod half-saturation coefficient for sulfate reduction \\
\hline 12 & $k_{\text {io }}$ & kio & $\mathrm{mg} / \mathrm{L}$ & Inhibition coefficient for oxygen on anaerobic activity \\
\hline 13 & $k_{\text {in }}$ & kin & $\mathrm{mg} / \mathrm{L}$ & Inhibition coefficient for nitrate on anaerobic activity \\
\hline 14 & $k a n_{P C E_{-} F e}$ & kan_pce_Fe & $1 /$ day & $\begin{array}{l}\text { First-order decay coefficient for anaerobic dechlorination of } \\
\text { PCE under iron dominated redox potential }\end{array}$ \\
\hline 15 & $k a n_{P C E_{-} S}$ & kan_pce_S & $1 /$ day & $\begin{array}{l}\text { First-order decay coefficient for anaerobic dechlorination of } \\
\text { PCE under sulfur dominated redox potential }\end{array}$ \\
\hline 16 & $k a n_{P C E_{-} C}$ & kan_pce_C & $1 /$ day & $\begin{array}{l}\text { First-order decay coefficient for anaerobic dechlorination of } \\
\text { PCE under methane dominated redox potential }\end{array}$ \\
\hline 17 & $k a n_{T C E_{-} F e}$ & kan_tce_Fe & $1 /$ day & $\begin{array}{l}\text { First-order decay coefficient for anaerobic dechlorination of } \\
\text { TCE under iron dominated redox potential }\end{array}$ \\
\hline 18 & $k a n_{T C E \_} S$ & kan_tce_S & 1/day & $\begin{array}{l}\text { First-order decay coefficient for anaerobic dechlorination of } \\
\text { TCE under sulfur dominated redox potential }\end{array}$ \\
\hline 19 & $\operatorname{kan}_{T C E_{-} C}$ & kan_tce_C & $1 /$ day & $\begin{array}{l}\text { First-order decay coefficient for anaerobic dechlorination of } \\
\text { TCE under methane dominated redox potential }\end{array}$ \\
\hline 20 & $k a n_{C D C E_{-} F e}$ & kan_cdce_Fe & $1 /$ day & $\begin{array}{l}\text { First-order decay coefficient for anaerobic dechlorination of } \\
\text { cDCE under iron dominated redox potential }\end{array}$ \\
\hline 21 & $k a n_{C D C E_{-} S}$ & kan_cdce_S & $1 /$ day & $\begin{array}{l}\text { First-order decay coefficient for anaerobic dechlorination of } \\
\text { cDCE under sulfur dominated redox potential }\end{array}$ \\
\hline 22 & $k a n_{C D C E_{-} C}$ & kan_cdce_C & $1 /$ day & $\begin{array}{l}\text { First-order decay coefficient for anaerobic dechlorination of } \\
\text { cDCE under methane dominated redox potential }\end{array}$ \\
\hline 23 & $k a n_{t D C E_{-} F e}$ & kan_tdce_Fe & $1 /$ day & $\begin{array}{l}\text { First-order decay coefficient for anaerobic dechlorination of } \\
\text { tDCE under iron dominated redox potential }\end{array}$ \\
\hline 24 & $k a n_{t D C E S}$ & kan_tdce_S & $1 /$ day & $\begin{array}{l}\text { First-order decay coefficient for anaerobic dechlorination of } \\
\text { tDCE under sulfur dominated redox potential }\end{array}$ \\
\hline 25 & $k a n_{t D C E_{-} C}$ & kan_tdce_C & $1 /$ day & $\begin{array}{l}\text { First-order decay coefficient for anaerobic dechlorination of } \\
\text { tDCE under methane dominated redox potential }\end{array}$ \\
\hline 26 & $\operatorname{kan}_{\text {IIDCE_Fe }_{-}}$ & kan_11dce_Fe & $1 /$ day & $\begin{array}{l}\text { First-order decay coefficient for anaerobic dechlorination of } \\
\text { 11DCE under iron dominated redox potential }\end{array}$ \\
\hline 27 & $k a n_{11 D C E_{-} S}$ & kan_11dce_S & $1 /$ day & $\begin{array}{l}\text { First-order decay coefficient for anaerobic dechlorination of } \\
\text { 11DCE under sulfur dominated redox potential }\end{array}$ \\
\hline
\end{tabular}


Table 38. (contd)

\begin{tabular}{|c|c|c|c|c|}
\hline $\begin{array}{c}\text { ID } \\
\#\end{array}$ & Parameter & $\begin{array}{l}\text { Fortran } \\
\text { Variable }\end{array}$ & Units & Description \\
\hline 28 & $\operatorname{kan}_{11 D C E \_}$ & kan_11dce_C & $1 /$ day & $\begin{array}{l}\text { First-order decay coefficient for anaerobic dechlorination of } \\
\text { 11DCE under methane dominated redox potential }\end{array}$ \\
\hline 29 & $k a n_{V C_{-} F e}$ & kan_vc_Fe & $1 /$ day & $\begin{array}{l}\text { First-order decay coefficient for anaerobic dechlorination of } \mathrm{VC} \\
\text { under iron dominated redox potential }\end{array}$ \\
\hline 30 & $\operatorname{kan}_{V C_{-} S}$ & kan_vc_S & 1/day & $\begin{array}{l}\text { First-order decay coefficient for anaerobic dechlorination of } \mathrm{VC} \\
\text { under sulfur dominated redox potential }\end{array}$ \\
\hline 31 & $\mathrm{kan}_{V C_{-} C}$ & kan_vc_C & $1 /$ day & $\begin{array}{l}\text { First-order decay coefficient for anaerobic dechlorination of } \mathrm{VC} \\
\text { under methane dominated redox potential }\end{array}$ \\
\hline 32 & $k a e_{C D C E}$ & kae_cdce & 1/day & $\begin{array}{l}\text { First-order decay coefficient for aerobic dechlorination of } \\
\text { cis-1,2-DCE }\end{array}$ \\
\hline 33 & $k a e_{t D C E}$ & kae_tdce & $1 /$ day & $\begin{array}{l}\text { First-order decay coefficient for aerobic dechlorination of } \\
\text { trans-1,2-DCE }\end{array}$ \\
\hline 34 & $k_{a e_{11 D C E}}$ & kae_11dce & $1 /$ day & $\begin{array}{l}\text { First-order decay coefficient for aerobic dechlorination of } \\
\text { 1,1-DCE }\end{array}$ \\
\hline 35 & $k a e_{V C}$ & kae_vc & 1/day & First-order decay coefficient for aerobic dechlorination of VC \\
\hline 36 & $k_{N I T}$ & kNit & 1/day & Maximum rate of nitrate reduction \\
\hline 37 & $k_{F E 3}$ & $\mathrm{kFe} 3$ & 1/day & Maximum rate of iron reduction \\
\hline 38 & $k_{\mathrm{SO} 4}$ & $\mathrm{kSO} 4$ & $1 /$ day & Maximum rate of sulfate reduction \\
\hline 39 & $\mu_{\mathrm{CH} 4}$ & $\mathrm{uCH} 4$ & $\mathrm{mg} /$ day & Maximum rate of methane production \\
\hline
\end{tabular}

\subsection{Example Simulations}

Simulations with this reaction module were conducted with RT3D in a batch reactor (no flow) mode to show examples of how the reaction module simulates the pattern of dechlorination. The parameter values for each example simulation are listed in Tables 39 and 40. These parameters are arbitrary values and are not directly related to any specific laboratory data. Site-specific values would need to be determined as part of a calibration process. Results for these example batch simulations are shown in the Figures 32 through 35, respectively. 
Table 39. Parameter Values for Example Simulations 1 and 2 with the Redox-Linked Dechlorination of Chloroethenes Reaction Module

\begin{tabular}{|c|l|c|c|c|l|c|c|}
\hline \hline ID \# & Fortran Variable & Value & Units & ID \# & Fortran Variable & Value & Units \\
\hline 1 & IsStatic & 0 & -- & 21 & kan_cdce_S & 0.0045 & $1 /$ day \\
\hline 2 & f_cdce_tce & 1 & $\mathrm{~mol} / \mathrm{mol}$ & 22 & kan_cdce_C & 0.005 & $1 /$ day \\
\hline 3 & f_tdce_tce & 0 & $\mathrm{~mol} / \mathrm{mol}$ & 23 & kan_tdce_Fe & 0 & $1 /$ day \\
\hline 4 & f_11dce_tce & 0 & $\mathrm{~mol} / \mathrm{mol}$ & 24 & kan_tdce_S & 0 & $1 /$ day \\
\hline 5 & f_vc_cdce & 1 & $\mathrm{~mol} / \mathrm{mol}$ & 25 & kan_tdce_C & 0 & $1 /$ day \\
\hline 6 & f_vc_tdce & 1 & $\mathrm{~mol} / \mathrm{mol}$ & 26 & kan_11dce_Fe & 0 & $1 /$ day \\
\hline 7 & f_vc_11dce & 1 & $\mathrm{~mol} / \mathrm{mol}$ & 27 & kan_11dce_S & 0 & $1 /$ day \\
\hline 8 & Ko2 & 0.5 & $\mathrm{mg} / \mathrm{L}$ & 28 & kan_11dce_C & 0 & $1 /$ day \\
\hline 9 & Kn & 0.5 & $\mathrm{mg} / \mathrm{L}$ & 29 & kan_vc_Fe & 0.001 & $1 /$ day \\
\hline 10 & Kf & 0.05 & $\mathrm{mg} / \mathrm{L}$ & 30 & kan_vc_S & 0.0005 & $1 /$ day \\
\hline 11 & Ks & 0.1 & $\mathrm{mg} / \mathrm{L}$ & 31 & kan_vc_C & 0.0005 & $1 /$ day \\
\hline 12 & kio & 0.1 & $\mathrm{mg} / \mathrm{L}$ & 32 & kae_cdce & 0.01 & $1 /$ day \\
\hline 13 & kin & 1 & $\mathrm{mg} / \mathrm{L}$ & 33 & kae_tdce & 0 & $1 /$ day \\
\hline 14 & kan_pce_Fe & 0.0005 & $1 /$ day & 34 & kae_11dce & 0 & $1 /$ day \\
\hline 15 & kan_pce_S & 0.001 & $1 /$ day & 35 & kae_vc & 0.01 & $1 /$ day \\
\hline 16 & kan_pce_C & 0.005 & $1 /$ day & 36 & kNit & 0 & $1 /$ day \\
\hline 17 & kan_tce_Fe & 0.001 & $1 /$ day & 37 & kFe3 & 0 & $1 /$ day \\
\hline 18 & kan_tce_S & 0.001 & $1 /$ day & 38 & kSO4 & 0 & $1 /$ day \\
\hline 19 & kan_tce_C & 0.004 & $1 /$ day & 39 & uCH4 & 0 & mg/day \\
\hline 20 & kan_cdce_Fe & 0.004 & $1 /$ day & & & & \\
\hline \hline
\end{tabular}

Table 40. Parameter Values for Example Simulations 3 and 4 with the Redox-Linked Dechlorination of Chloroethenes Reaction Module

\begin{tabular}{|c|l|c|c|c|l|c|c|}
\hline \hline ID \# & Fortran Variable & Value & Units & ID \# & Fortran Variable & Value & Units \\
\hline 1 & IsStatic & 0 & -- & 21 & kan_cdce_S & 0.0045 & $1 /$ day \\
\hline 2 & f_cdce_tce & 1 & $\mathrm{~mol} / \mathrm{mol}$ & 22 & kan_cdce_C & 0.005 & $1 /$ day \\
\hline 3 & f_tdce_tce & 0 & $\mathrm{~mol} / \mathrm{mol}$ & 23 & kan_tdce_Fe & 0 & $1 /$ day \\
\hline 4 & f_11dce_tce & 0 & $\mathrm{~mol} / \mathrm{mol}$ & 24 & kan_tdce_S & 0 & $1 /$ day \\
\hline 5 & f_vc_cdce & 1 & $\mathrm{~mol} / \mathrm{mol}$ & 25 & kan_tdce_C & 0 & $1 /$ day \\
\hline 6 & f_vc_tdce & 1 & $\mathrm{~mol} / \mathrm{mol}$ & 26 & kan_11dce_Fe & 0 & $1 /$ day \\
\hline 7 & f_vc_11dce & 1 & $\mathrm{~mol} / \mathrm{mol}$ & 27 & kan_11dce_S & 0 & $1 /$ day \\
\hline 8 & Ko2 & 0.5 & $\mathrm{mg} / \mathrm{L}$ & 28 & kan_11dce_C & 0 & $1 /$ day \\
\hline 9 & Kn & 0.5 & $\mathrm{mg} / \mathrm{L}$ & 29 & kan_vc_Fe & 0.001 & $1 /$ day \\
\hline 10 & Kf & 0.05 & $\mathrm{mg} / \mathrm{L}$ & 30 & kan_vc_S & 0.0005 & $1 /$ day \\
\hline 11 & Ks & 0.1 & $\mathrm{mg} / \mathrm{L}$ & 31 & kan_vc_C & 0.0005 & $1 /$ day \\
\hline 12 & kio & 0.1 & $\mathrm{mg} / \mathrm{L}$ & 32 & kae_cdce & 0.01 & $1 /$ day \\
\hline 13 & kin & 1 & $\mathrm{mg} / \mathrm{L}$ & 33 & kae_tdce & 0 & $1 /$ day \\
\hline 14 & kan_pce_Fe & 0.0005 & $1 /$ day & 34 & kae_11dce & 0 & $1 /$ day \\
\hline 15 & kan_pce_S & 0.001 & $1 /$ day & 35 & kae_vc & 0.01 & $1 /$ day \\
\hline 16 & kan_pce_C & 0.005 & $1 /$ day & 36 & kNit & 0.1 & $1 /$ day \\
\hline 17 & kan_tce_Fe & 0.001 & $1 /$ day & 37 & kFe3 & 0.1 & $1 /$ day \\
\hline 18 & kan_tce_S & 0.001 & $1 /$ day & 38 & kSO4 & 0.1 & $1 /$ day \\
\hline 19 & kan_tce_C & 0.004 & $1 /$ day & 39 & uCH4 & 0.1 & mg/day \\
\hline 20 & kan_cdce_Fe & 0.004 & $1 /$ day & & & & \\
\hline \hline
\end{tabular}




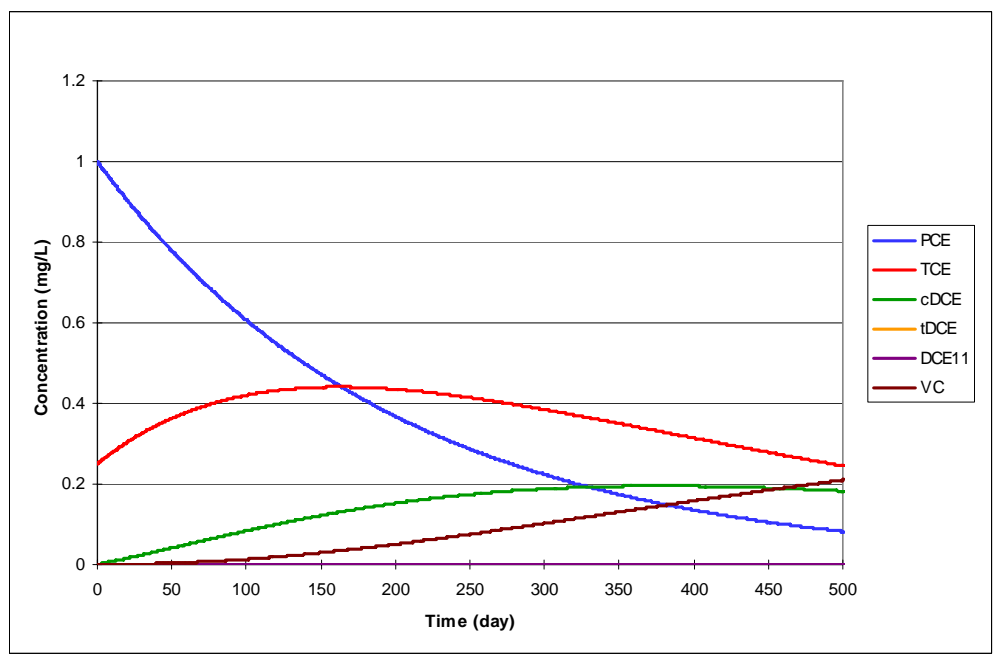

(a)

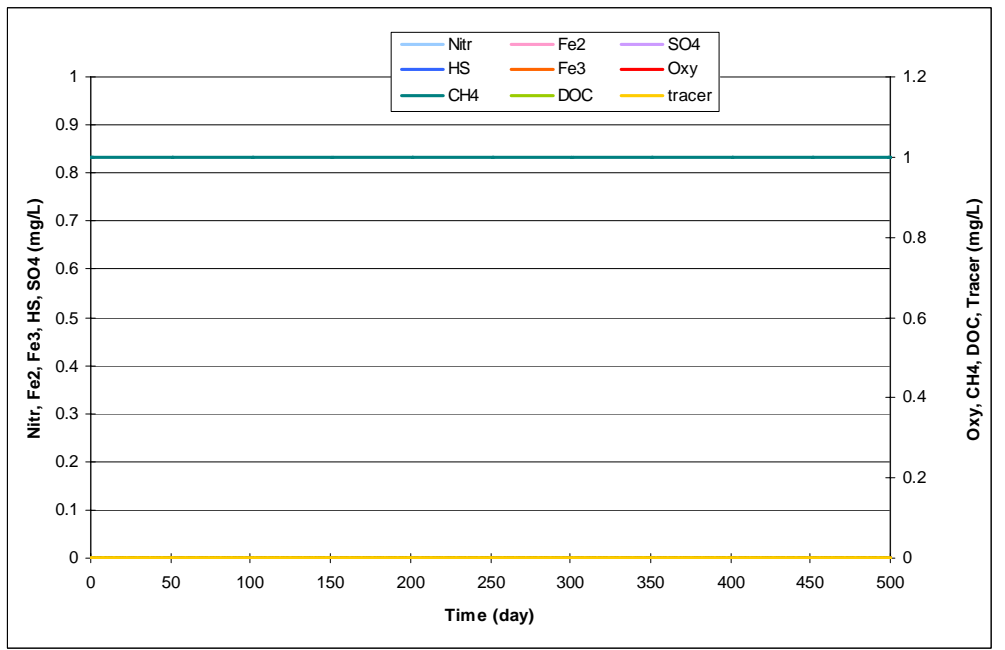

(b)

Figure 32. Example Simulation 1: Dechlorination of PCE and TCE Using the Parameter Values Shown in Table 39 - The initial concentration for PCE, TCE, and methane were $1,0.25$, and $1 \mathrm{mg} / \mathrm{L}$, respectively. All other species concentrations started at zero. Note that the concentrations of redox species remain constant in this simulation. Figure (a) shows chlorinated solvent concentration. Figure (b) shows the concentration of other species. 


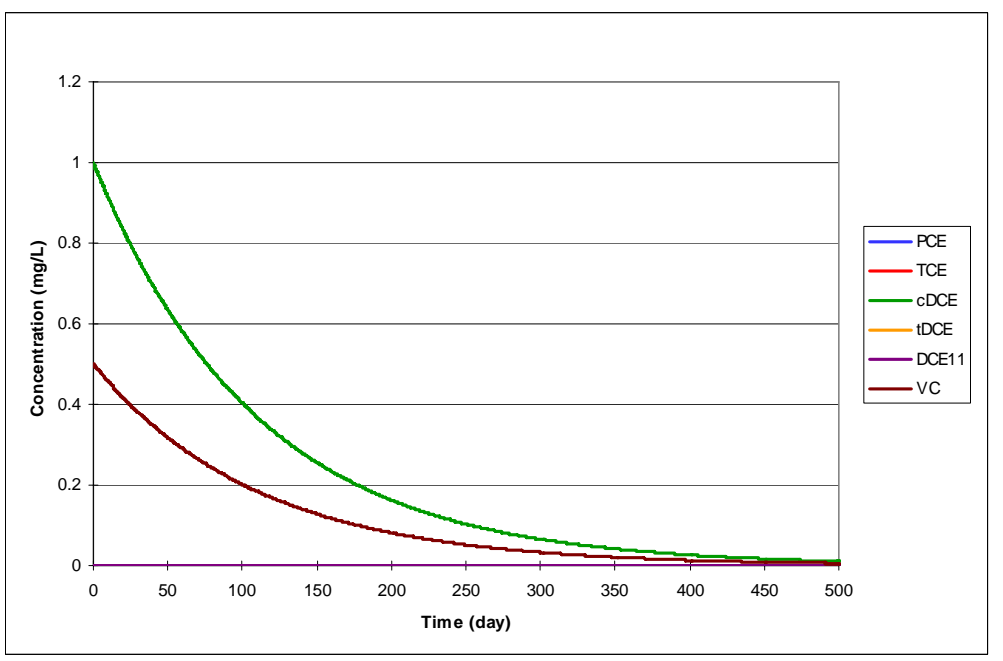

(a)

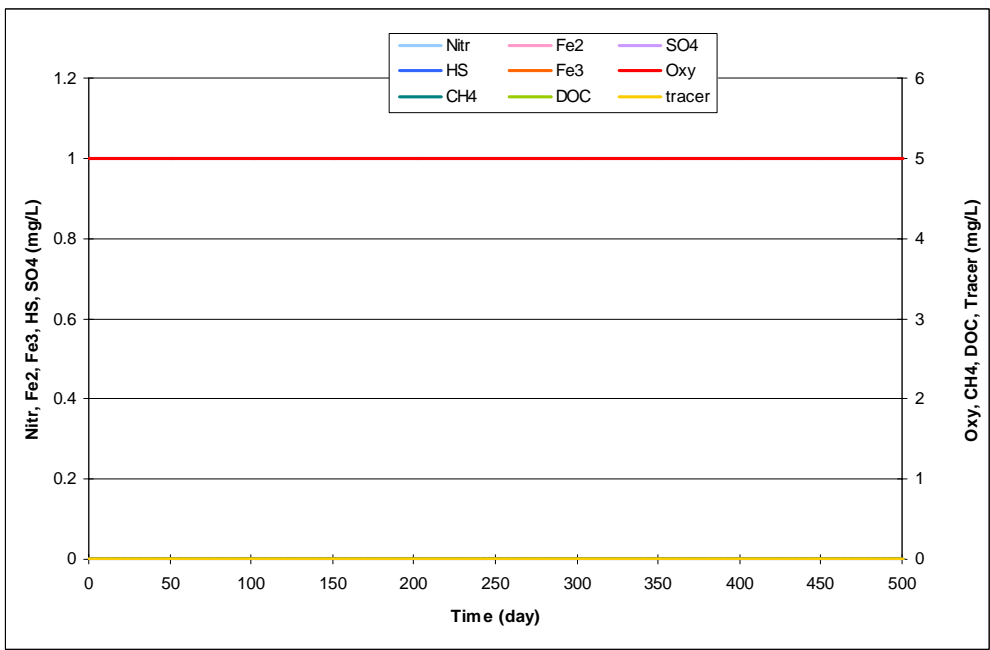

(b)

Figure 33. Example Simulation 2: Dechlorination of $c D C E$ and VC Using the Parameter Values Shown in Table 39 - The initial concentration for cDCE, VC, oxygen, and nitrate were $1,0.5,5$, and $1 \mathrm{mg} / \mathrm{L}$, respectively. All other species concentrations started at zero. Note that the concentrations of redox species remain constant in this simulation. Figure (a) shows chlorinated solvent concentration. Figure (b) shows the concentration of other species. 


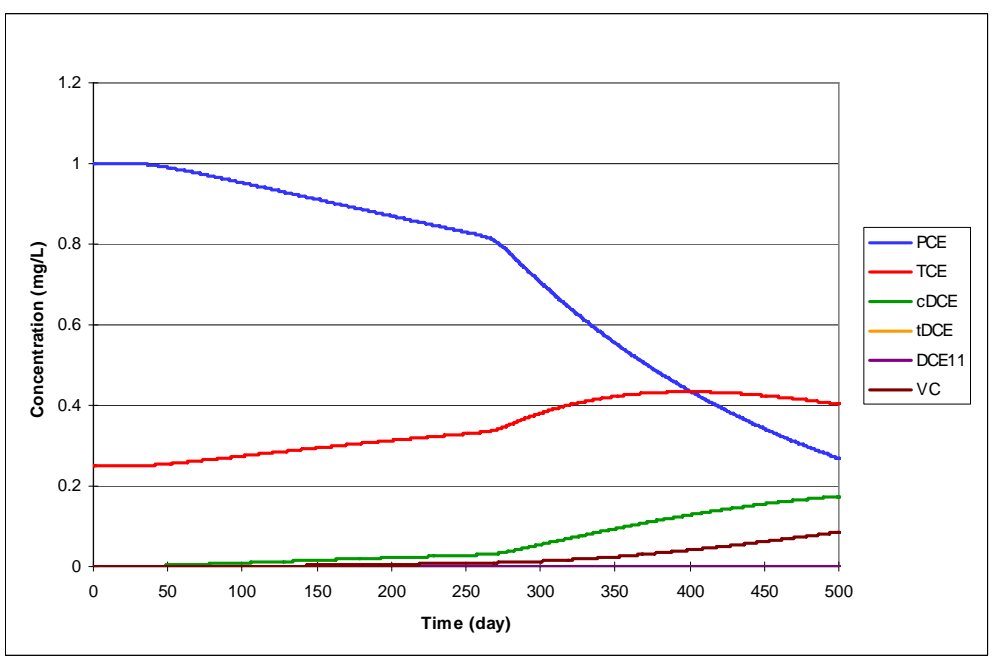

(a)

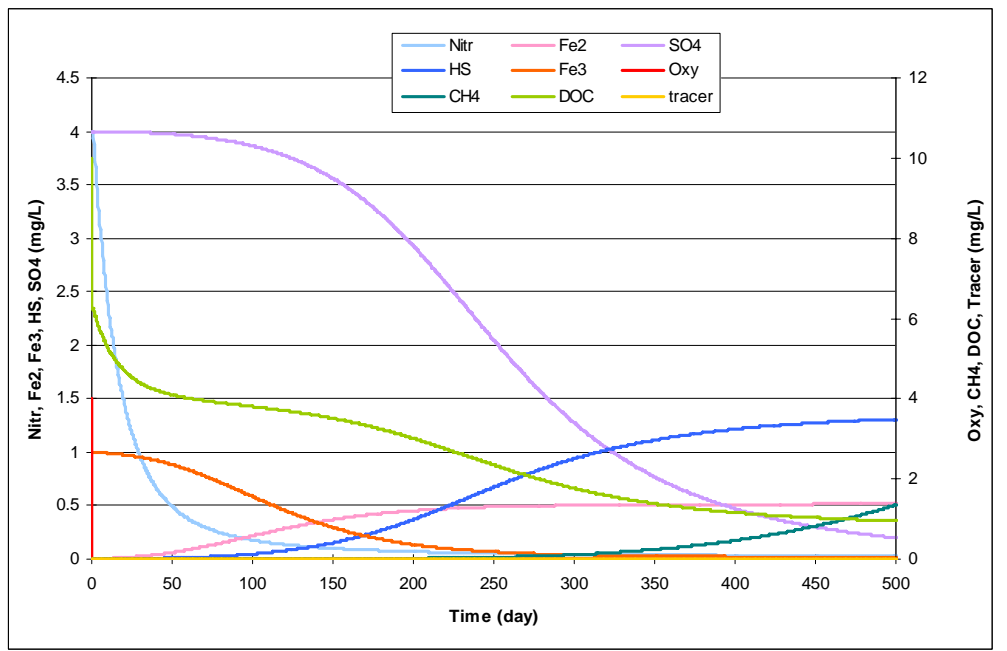

(b)

Figure 34. Example Simulation 3: Dechlorination of PCE and TCE Using the Parameter Values Shown in Table 40 - The initial concentration for PCE, TCE, oxygen, nitrate, sulfate, dissolved organic carbon, and iron(III) were 1, 0.25, 4, 4, 4, 10, and $1 \mathrm{mg} / \mathrm{L}$, respectively. All other species concentrations started at zero. Note that the concentrations of redox species vary in this simulation according to oxidation processes and the reduction rate input parameters. Figure (a) shows chlorinated solvent concentration. Figure (b) shows the concentration of other species. 


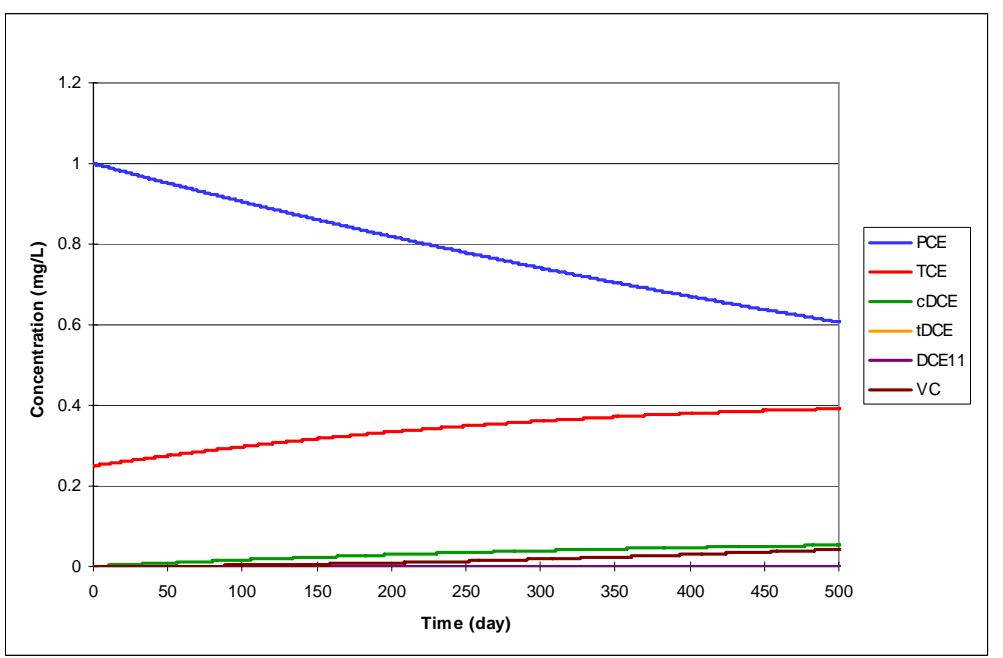

(a)

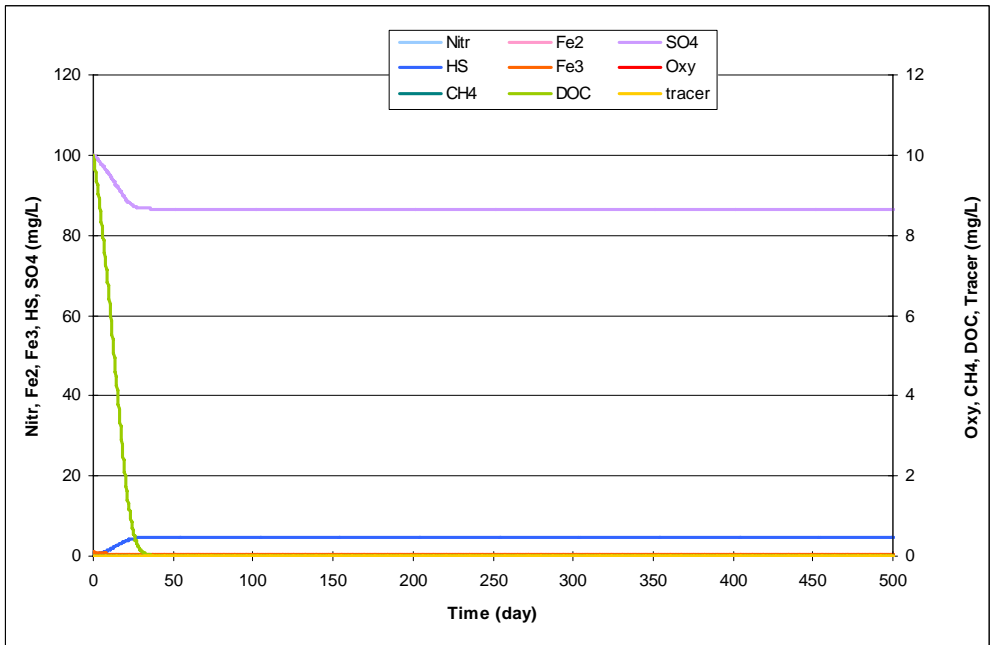

(b)

Figure 35. Example Simulation 4: Dechlorination of PCE and TCE Using the Parameter Values Shown in Table 40 - The initial concentration for PCE, TCE, sulfate, dissolved organic carbon, and iron(III) were 1, 0.25, 100, 10, and $1 \mathrm{mg} / \mathrm{L}$, respectively. All other species concentrations started at zero. Note that the concentrations of redox species vary in this simulation according to oxidation processes and the reduction rate input parameters. Figure (a) shows chlorinated solvent concentration. Figure (b) shows the concentration of other species. 


\subsection{Substrate-Linked Reductive Dechlorination of Chloroethenes}

\subsection{Conceptual Model for Dechlorination Reactions}

This reaction module describes reductive dechlorination of chlorinated ethene compounds linked to substrate metabolism (biostimulation) and corresponding biomass activity. The module includes an explicit description of biomass growth in response to consumption of lactate, propionate, acetate, hydrogen, and/or decaying biomass and separately models the metabolic activity of methanogens and other anaerobes able to metabolize lactate fermentation products. Both types of biomass will decay over time according to a user-specified decay rate. This reaction module does not account for changes in porosity/permeability resulting from biomass growth, although the total biomass is also tracked so that the modeler can assess the potential for biological fouling of the aquifer. If required, macroscopic models for biomass-affected porous media properties [Clement et al., 1996] could be combined with this module as a user-defined reaction module to account for changes in porosity/permeability. All anaerobic activity is inhibited by oxygen. Oxygen is depleted by lactate, propionate, or acetate through a stoichiometric reaction. Biomass growth is modeled with a Monod kinetic form, is dependent on substrate concentration, and is inhibited by high concentrations of organic acids. Reductive dechlorination of chlorinated ethene compounds is dependent on the concentration of the chlorinated ethene compound and methanogen biomass, and is inhibited by presence of higherchlorinated ethene compounds (e.g., TCE inhibits the DCE dechlorination rate). Aerobic degradation of DCE and VC are modeled as first-order reactions (see the conceptual model description of the Mixed Chloroethene/ Chloroethane/Chloromethane Dechlorination reaction module for discussion on the assumption of first-order reaction kinetics).

The linkage of dechlorination to methanogenesis, similar to Skeen et al. [1995], is intended to provide a simplified conceptual model representing dechlorinating activity under methanogenic redox conditions, as an alternative to a detailed representation of all reaction mechanisms that may be involved.

Table 41 lists the chemical species included in this reaction module. Figure 36 shows the conceptual model describing the degradation reactions modeled in this reaction module. 
Table 41. Chemical Species Included in the Substrate-Linked Reductive Dechlorination of Chloroethenes Reaction Module

\begin{tabular}{|c|c|c|c|c|c|c|}
\hline No. & Abbreviation ${ }^{a}$ & Chemical Name & $\begin{array}{c}\text { Selected Alternate } \\
\text { Name }\end{array}$ & $\begin{array}{c}\text { CAS }^{\mathbf{b}} \\
\text { Registry } \\
\text { Number }\end{array}$ & $\begin{array}{c}\text { Molecular } \\
\text { Weight }^{c} \\
(\mathrm{~g} / \mathbf{m o l})\end{array}$ & $\begin{array}{l}\text { Chemical } \\
\text { Formula }\end{array}$ \\
\hline 1 & LAC & Lactate & $\begin{array}{l}\text { 2-hydroxy-propanoic } \\
\text { acid (ion) }\end{array}$ & $\begin{array}{c}113-21-3 \\
\text { (lactic acid: } \\
50-21-5 \text { ) }\end{array}$ & 89.0700 & $\mathrm{C}_{3} \mathrm{H}_{5} \mathrm{O}_{3}^{-}$ \\
\hline 2 & PRO & Propionate & Propanoic acid (ion) & $\begin{array}{c}72-03-7 \\
\text { (propionic } \\
\text { acid: } \\
79-09-4 \text { ) }\end{array}$ & 73.0706 & $\mathrm{C}_{3} \mathrm{H}_{5} \mathrm{O}_{2}^{-}$ \\
\hline 3 & $\mathrm{ACE}$ & Acetate & Acetic acid (ion) & $\begin{array}{c}71-50-1 \\
\text { (acetic acid: } \\
64-19-7 \text { ) }\end{array}$ & 59.04402 & $\mathrm{C}_{2} \mathrm{H}_{3} \mathrm{O}_{2}^{-}$ \\
\hline 4 & $\mathrm{H} 2$ & Hydrogen & - & $1333-74-0$ & 2.01588 & $\mathrm{H}_{2}$ \\
\hline 5 & MET & Methane & - & $74-82-8$ & 16.04246 & $\mathrm{CH}_{4}$ \\
\hline 6 & PCE & Tetrachloroethene & Perchloroethylene & $127-18-4$ & 165.83340 & $\mathrm{C}_{2} \mathrm{Cl}_{4}$ \\
\hline 7 & TCE & Trichloroethene & Trichloroethylene & 79-01-6 & 131.38834 & $\mathrm{C}_{2} \mathrm{HCl}_{3}$ \\
\hline 8 & DCE & $\begin{array}{l}\text { Dichloroethene (all } \\
\text { isomers) }\end{array}$ & Dichloroethylene & $156-59-2$ & 96.94328 & $\mathrm{C}_{2} \mathrm{H}_{2} \mathrm{Cl}_{2}$ \\
\hline 9 & $\mathrm{VC}$ & Chloroethene & Vinyl Chloride & 75-01-4 & 62.49822 & $\mathrm{C}_{2} \mathrm{H}_{3} \mathrm{Cl}$ \\
\hline 10 & ETH & Ethene & ethylene & $74-85-1$ & 28.05316 & $\mathrm{C}_{2} \mathrm{H}_{4}$ \\
\hline 11 & OXY & Oxygen (dimer) & dissolved oxygen & $7782-44-7$ & 31.9988 & $\mathrm{O}_{2}$ \\
\hline 12 & Tracer & Conservative Tracer & - & N/A & N/A & $\mathrm{N} / \mathrm{A}$ \\
\hline 13 & Biol & Fermentors & - & N/A & 113.11458 & $\mathrm{C}_{5} \mathrm{H}_{7} \mathrm{O}_{2} \mathrm{~N}$ \\
\hline 14 & Bio2 & Methanogens & - & N/A & 113.11458 & $\mathrm{C}_{5} \mathrm{H}_{7} \mathrm{O}_{2} \mathrm{~N}$ \\
\hline 15 & BioT & Total Biomass & - & $\mathrm{N} / \mathrm{A}$ & 113.11458 & $\mathrm{C}_{5} \mathrm{H}_{7} \mathrm{O}_{2} \mathrm{~N}$ \\
\hline
\end{tabular}

a These abbreviations refer to the specific chemicals listed here and should not be confused with different chemicals that may use the same abbreviation in other reaction modules.

b $\mathrm{CAS}=$ Chemical Abstracts Service (see http://www.cas.org/EO/regsys.html)

c Based on International Union of Pure and Applied Chemistry values reported by Loss [2003].

N/A - Not Applicable 


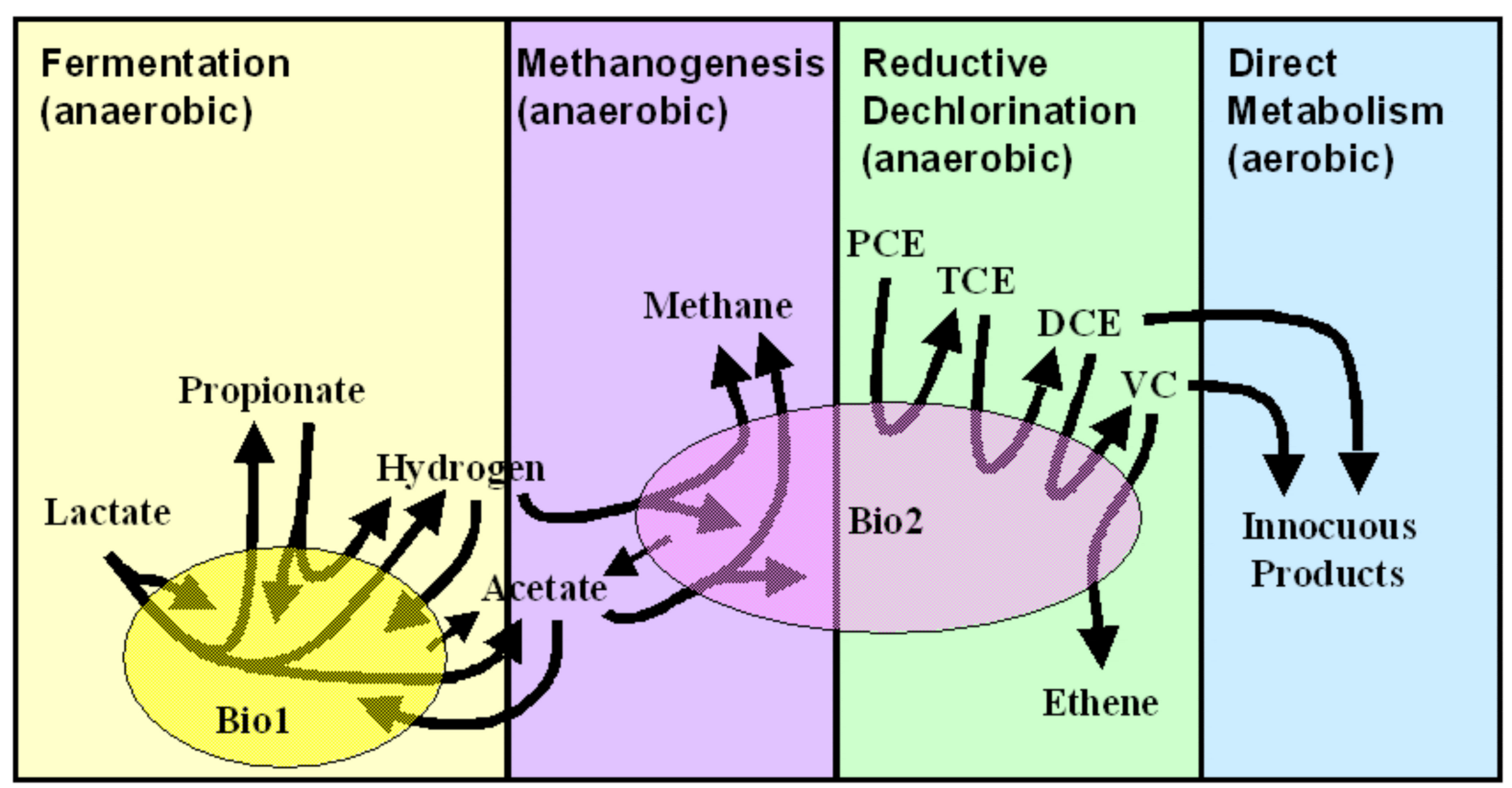

Figure 36. Conceptual Model for the Reductive Dechlorination Reactions of the SubstrateLinked Reductive Dechlorination of Chloroethenes Reaction Module

\subsection{Reaction Equations}

The basic functioning of this reaction module is described in this section for the 15 chemical species in Table 41. See Table 42 for a detailed itemization of all reaction parameters used in this reaction module.

If oxygen is present, the module first uses instantaneous (equilibrium) stoichiometric reactions (Equations 126 to 128) to deplete oxygen by reaction with the organic acids. The module has provisions to sequentially oxidize organic acids in the order of lactate, propionate, and acetate to the point where either all oxygen is consumed or all organic acids are consumed. The initial concentrations for lactate, propionate, acetate, and oxygen [Species] are reduced to the postoxidation concentrations [Species] $]_{\mathrm{ox}}$, which are used in the subsequent biomass growth and dechlorination rate calculations. The sum of the residual lactate, propionate, and acetate is calculated as the organic acid concentration [OrgAcid], which is used in the determination of the organic acid inhibition term. Oxygen, $[\mathrm{OXY}]_{\mathrm{ox}}$, inhibits anaerobic reactions and also must be present for aerobic degradation of DCE and VC. However, the module does not consider consumption of oxygen during DCE or VC oxidation. 


$$
\begin{aligned}
& 1 \mathrm{C}_{3} \mathrm{H}_{5} \mathrm{O}_{3}^{-}+1 \mathrm{H}^{+}+3 \mathrm{O}_{2} \rightarrow 3 \mathrm{CO}_{2}+3 \mathrm{H}_{2} \mathrm{O} \\
& 2 \mathrm{C}_{3} \mathrm{H}_{5} \mathrm{O}_{2}^{-}+2 \mathrm{H}^{+}+7 \mathrm{O}_{2} \rightarrow 6 \mathrm{CO}_{2}+6 \mathrm{H}_{2} \mathrm{O} \\
& 1 \mathrm{C}_{2} \mathrm{H}_{3} \mathrm{O}_{2}^{-}+1 \mathrm{H}^{+}+2 \mathrm{O}_{2} \rightarrow 2 \mathrm{CO}_{2}+2 \mathrm{H}_{2} \mathrm{O}
\end{aligned}
$$

Inhibition of biomass growth because of the presence of oxygen (InhibOxy) and organic acids (InhibOA1 and InhibOA2 for Bio1 and Bio2, respectively) is calculated based on a sigmoidal function. When the relevant concentration ([OXY $]_{\text {ox }}$ or [OrgAcid]) is at $90 \%$ of the inhibition coefficient value $\left(\mathrm{k}_{\mathrm{io}}, \mathrm{k}_{\mathrm{i} 1}\right.$, or $\left.\mathrm{k}_{\mathrm{i} 2}\right)$, the inhibition term is equal to a value of 1.0. When the relevant concentration is at $110 \%$ of the inhibition coefficient value, then the fractional inhibition term has a value of 0.0 . The fractional inhibition terms follow a sigmoidal functionality between those points, as shown in Figure 37. Conversely, the PromoOxy term acts in the opposite manner to allow aerobic reactions at concentrations above the value of $\mathrm{k}_{\mathrm{io}}$. The biomass decay rate is attenuated as the biomass concentration approaches the minimum in a similar manner by setting the $\mathrm{f}_{\mathrm{dec} 1}$ and $\mathrm{f}_{\mathrm{dec} 2}$ fractional terms for Bio1 and Bio2, respectively, to 0.0 at the minimum biomass concentration and to 1.0 at $120 \%$ of the minimum biomass concentration.

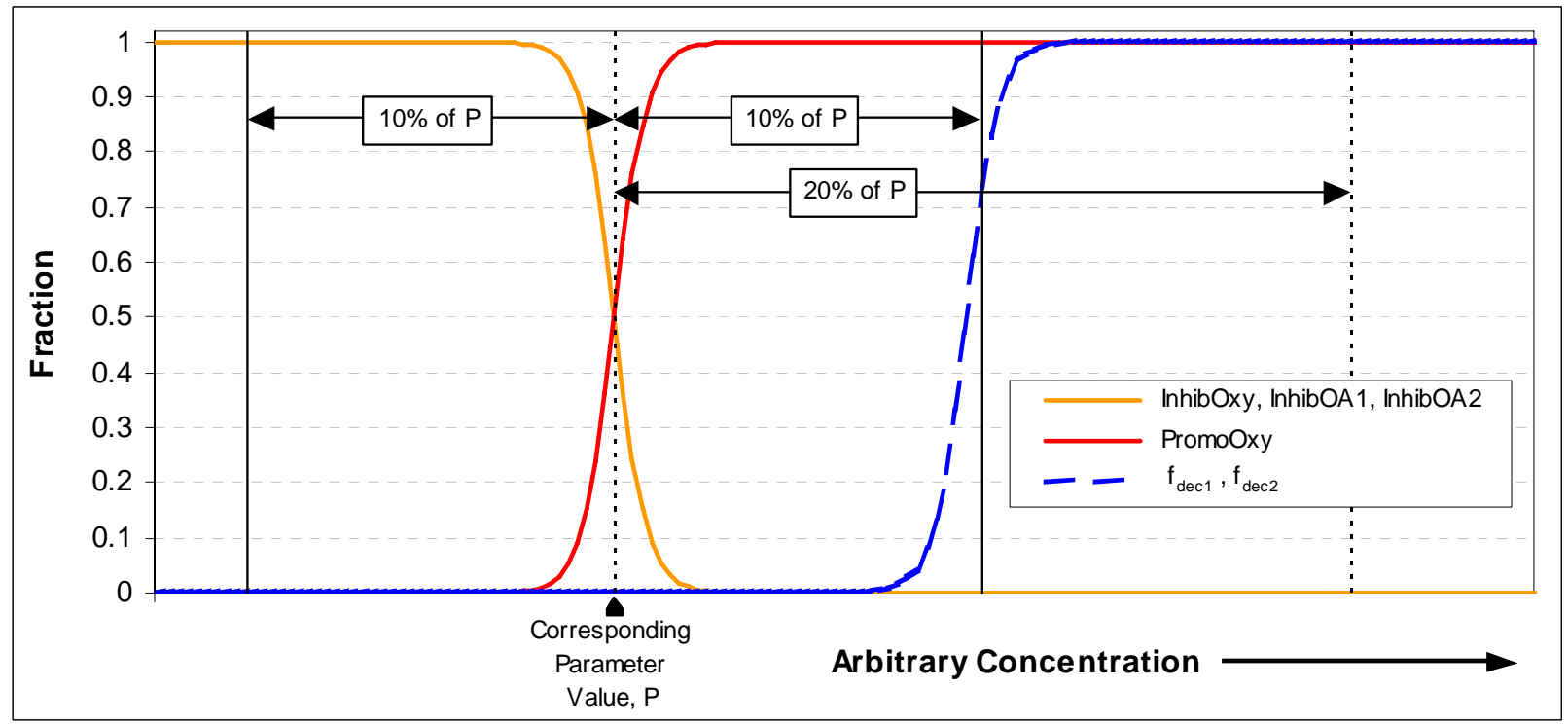

Figure 37. Conceptual Diagram of the Behavior of the Function Representing a Change in Conditions as a Smooth Transition in the Form of a Sigmoidal Curve - This diagram depicts the trend for the various groups of parameters; the actual curves will be shifted on the X-axis based on the corresponding target concentration.

Monod growth kinetics with inhibition by oxygen and organic acids are used to compute growth of fermentors (Bio1) and methanogens (Bio2) for the different potential substrates (Equations 129 through 134). 


$$
\begin{aligned}
& r_{1}=\mu_{l 1} \cdot[\text { Biol }] \cdot\left(\frac{[\text { Lac }]_{o x}}{K_{l 1}+[\text { Lac }]_{o x}}\right) \cdot \text { InhibOxy } \cdot \text { InhibOA1 } \\
& r_{2}=\mu_{p 1} \cdot[\text { Biol }] \cdot\left(\frac{[\text { Pro }]_{o x}}{K_{p 1}+[\text { Pro }]_{o x}}\right) \cdot \text { InhibOxy } \cdot \text { InhibOA1 } \\
& r_{3}=\mu_{a 2} \cdot[\text { Bio } 2] \cdot\left(\frac{[\text { Ace }]_{o x}}{K_{a 2}+[\text { Ace }]_{o x}}\right) \cdot \text { InhibOxy } \cdot \text { InhibOA2 } \\
& r_{4}=\mu_{h 2} \cdot[\text { Bio2 }] \cdot\left(\frac{[H 2]}{K_{h 2}+[H 2]}\right) \cdot \text { InhibOxy } \cdot \text { InhibOA2 } \\
& r_{5}=\mu_{a 1} \cdot[\text { Biol }] \cdot\left(\frac{[\text { Ace }]_{o x}}{K_{a 1}+[\text { Ace }]_{o x}}\right) \cdot \text { InhibOxy } \cdot \text { InhibOA1 } \\
& r_{7}=\mu_{h 1} \cdot[\text { Biol }] \cdot\left(\frac{[H 2]}{K_{h 1}+[H 2]}\right) \cdot \text { InhibOxy } \cdot \text { InhibOA1 }
\end{aligned}
$$

Equations 135 through 149 describe the rate of concentration change for each chemical species. These equations include the consumption/transformation/production based on the biomass growth, oxidation of the organic acids, biomass decay, and aerobic destruction of lesserchlorinated ethenes. Aerobic degradation of DCE and VC only occurs in the presence of oxygen (if sufficient oxygen remains after oxidation of organic acids) and is modeled as a first-order process (see the conceptual model description of the Mixed Chloroethene/ Chloroethane/Chloromethane Dechlorination reaction module for discussion on the assumption of first-order reaction kinetics). A fraction of the decayed biomass is assumed to be converted to acetate, which is then available to support biomass growth. Anaerobic dechlorination of TCE, $\mathrm{DCE}$, and VC are inhibited by the presence of higher-chlorinated ethene species proportional to the ratio of the species to the sum of the species plus all higher-chlorinated species.

$$
\begin{aligned}
& \frac{d[L A C]}{d t}=-r_{1} \cdot\left(\frac{1}{F_{X 1 / L A C}}\right) \\
& \frac{d[P R O]}{d t}=r_{1} \cdot\left(\frac{F_{P R O / L A C}}{F_{X 1 / L A C}}\right)-r_{2} \cdot\left(\frac{1}{F_{X 1 / P R O}}\right)
\end{aligned}
$$




$$
\begin{aligned}
& \frac{d[A C E]}{d t}=r_{1} \cdot\left(\frac{F_{A C E / L A C}}{F_{X 1 / L A C}}\right)+r_{2} \cdot\left(\frac{F_{A C E / P R O}}{F_{X 1 / P R O}}\right)-r_{3} \cdot\left(\frac{1}{F_{X 2 / A C E}}\right)-r_{5} \cdot\left(\frac{1}{F_{X 1 / A C E}}\right) \\
& +F_{A C E / X} \cdot f_{d k 2 a c e} \cdot\left(f_{d e c 1} \cdot k_{d e c 1} \cdot[B i o 1]+f_{d e c 2} \cdot k_{d e c 2} \cdot[B i o 2]\right) \\
& \frac{d[H 2]}{d t}=r_{1} \cdot\left(\frac{F_{H 2 / L A C}}{F_{X 1 / L A C}}\right)+r_{2} \cdot\left(\frac{F_{H 2 / P R O}}{F_{X 1 / P R O}}\right)-r_{4} \cdot\left(\frac{1}{F_{X 2 / H 2}}\right)-r_{7} \cdot\left(\frac{1}{F_{X 1 / H 2}}\right) \\
& \frac{d[M E T]}{d t}=q q=r_{3} \cdot\left(\frac{F_{M E T / A C E}}{F_{X 2 / A C E}}\right)+r_{4} \cdot\left(\frac{F_{M E T / H 2}}{F_{X 2 / H 2}}\right) \\
& \frac{d[P C E]}{d t}=-q q \cdot F_{P C E / M E T} \cdot\left(\frac{[P C E]}{K_{P C E}+[P C E]}\right) \\
& \frac{d[T C E]}{d t}=q q \cdot\left[F_{P C E / M E T} \cdot\left(\frac{[P C E]}{K_{P C E}+[P C E]}\right)-F_{T C E / M E T} \cdot\left(\frac{[T C E]}{K_{T C E}+[T C E]}\right) \cdot\left(\frac{[T C E]}{[P C E]+[T C E]}\right)\right] \\
& \frac{d[D C E]}{d t}=q q \cdot F_{T C E / M E T} \cdot\left(\frac{[T C E]}{K_{T C E}+[T C E]}\right) \cdot\left(\frac{[T C E]}{[P C E]+[T C E]}\right) \\
& -q q \cdot F_{D C E / M E T} \cdot\left(\frac{[D C E]}{K_{D C E}+[D C E]}\right) \cdot\left(\frac{[D C E]}{[P C E]+[T C E]+[D C E]}\right) \\
& -k a e_{D C E} \cdot[D C E] \cdot \text { PromoOxy } \\
& \frac{d[V C]}{d t}=q q \cdot F_{D C E / M E T} \cdot\left(\frac{[D C E]}{K_{D C E}+[D C E]}\right) \cdot\left(\frac{[D C E]}{[P C E]+[T C E]+[D C E]}\right) \\
& -q q \cdot F_{V C / M E T} \cdot\left(\frac{[V C]}{K_{V C}+[V C]}\right) \cdot\left(\frac{[V C]}{[P C E]+[T C E]+[D C E]+[\mathrm{VC}]}\right) \\
& -k e_{V C} \cdot[V C] \cdot \text { PromoOxy } \\
& \frac{d[E T H]}{d t}=q q \cdot F_{V C / M E T} \cdot\left(\frac{[V C]}{K_{V C}+[V C]}\right) \cdot\left(\frac{[V C]}{[P C E]+[T C E]+[D C E]+[\mathrm{VC}]}\right)
\end{aligned}
$$




$$
\begin{aligned}
& \frac{d[\mathrm{OXY}]}{d t}=0.0 \quad \begin{array}{l}
\text { (Oxygen is consumed by equilibrium oxidation reactions, but kinetic } \\
\text { consumption of oxygen during DCE or VC biodegradation is not tracted } \\
\text { because those are modeled as first-order processes.) }
\end{array} \\
& \frac{d[\text { Tracer }]}{d t}=0.0 \quad \text { (Conservative [non-reactive] tracer.) } \\
& \frac{d[\text { Biol }]}{d t}=r_{2}+r_{5}+r_{1}+r_{7}-f_{d e c 1} \cdot k_{d e c 1} \cdot[\text { Biol }] \\
& \frac{d[\text { Bio } 2]}{d t}=r_{3}+r_{4}-f_{d e c 2} \cdot k_{d e c 2} \cdot[\text { Bio } 2] \\
& \frac{d[\text { BioT }]}{d t}=r_{2}+r_{5}+r_{1}+r_{7}+r_{3}+r_{4}-f_{d e c 1} \cdot k_{d e c 1} \cdot[\text { Biol }]-f_{d e c 2} \cdot k_{d e c} 2 \cdot[\text { Bio } 2]
\end{aligned}
$$

\subsection{Required Input}

The reaction parameters for this reaction module are made available to RT3D as part of the input for the Reaction Package. The Reaction Package input file structure is discussed in the RT3D manual and addendum [Clement, 1997; Clement and Johnson, 2002]. The 44 reaction parameters that must be specified for this reaction module are listed in Table 42 in the required order (ID Number) with units and a description. Site-specific knowledge from field data or

\begin{tabular}{|c|c|c|c|c|}
\hline $\begin{array}{c}\text { ID } \\
\#\end{array}$ & Parameter & $\begin{array}{c}\text { Fortran } \\
\text { Variable }\end{array}$ & Units & Description \\
\hline 1 & Biol $1_{\min }$ & minbio1 & $\mathrm{mg}-\mathrm{DW} / \mathrm{L}$ & Minimum (background) biomass concentration for "fermentors" \\
\hline 2 & $B i o 2_{\min }$ & minbio2 & $\mathrm{mg}-\mathrm{DW} / \mathrm{L}$ & Minimum (background) biomass concentration for methanogens \\
\hline 3 & $k_{\text {decl }}$ & kdec1 & 1/day & First-order decay rate for biomass 1 \\
\hline 4 & $k_{d e c 2}$ & kdec 2 & 1/day & First-order decay rate for biomass 2 \\
\hline 5 & $\mu_{l 1}$ & ul1 & 1/day & Maximum growth rate for biomass 1 on lactate \\
\hline 6 & $\mu_{p 1}$ & up1 & 1/day & Maximum growth rate for biomass 1 on propionate \\
\hline 7 & $\mu_{a 2}$ & ua2 & 1/day & Maximum growth rate for biomass 2 on acetate \\
\hline 8 & $\mu_{h 2}$ & uh2 & 1/day & Maximum growth rate for biomass 2 on hydrogen \\
\hline 9 & $\mu_{a l}$ & ua1 & 1/day & Maximum growth rate for biomass 1 on acetate \\
\hline
\end{tabular}
laboratory tests should be applied to determine an appropriate model configuration for reaction parameters (i.e., the values and the spatial distribution).

Table 42. Input Parameters for the Substrate-Linked Reductive Dechlorination of Chloroethenes Reaction Module 
Table 42. (contd)

\begin{tabular}{|c|c|c|c|c|}
\hline $\begin{array}{c}\text { ID } \\
\#\end{array}$ & Parameter & $\begin{array}{l}\text { Fortran } \\
\text { Variable }\end{array}$ & Units & Description \\
\hline 10 & $\mu_{h 1}$ & uh1 & $1 /$ day & Maximum growth rate for biomass 1 on hydrogen \\
\hline 11 & $k_{i 1}$ & ki1 & $\mathrm{mg} / \mathrm{L}$ & Inhibition coefficient for organic acids on biomass 1 \\
\hline 12 & $k_{i 2}$ & ki2 & $\mathrm{mg} / \mathrm{L}$ & Inhibition coefficient for organic acids on biomass 2 \\
\hline 13 & $k_{i o}$ & kio & $\mathrm{mg} / \mathrm{L}$ & Inhibition coefficient for oxygen on anaerobic activity \\
\hline 14 & $K_{l l}$ & K11 & $\mathrm{mg} / \mathrm{L}$ & $\begin{array}{l}\text { Monod half-saturation coefficient for "fermentor" growth on } \\
\text { lactate }\end{array}$ \\
\hline 15 & $K_{p 1}$ & Kp1 & $\mathrm{mg} / \mathrm{L}$ & $\begin{array}{l}\text { Monod half-saturation coefficient for "fermentor" growth on } \\
\text { propionate }\end{array}$ \\
\hline 16 & $K_{a 2}$ & $\mathrm{Ka} 2$ & $\mathrm{mg} / \mathrm{L}$ & $\begin{array}{l}\text { Monod half-saturation coefficient for methanogen growth on } \\
\text { acetate }\end{array}$ \\
\hline 17 & $K_{h 2}$ & Kh2 & $\mathrm{mg} / \mathrm{L}$ & $\begin{array}{l}\text { Monod half-saturation coefficient for methanogen growth on } \\
\text { hydrogen }\end{array}$ \\
\hline 18 & $K_{a l}$ & Ka1 & $\mathrm{mg} / \mathrm{L}$ & $\begin{array}{l}\text { Monod half-saturation coefficient for "fermentor" growth on } \\
\text { acetate }\end{array}$ \\
\hline 19 & $K_{h 1}$ & Kh1 & $\mathrm{mg} / \mathrm{L}$ & $\begin{array}{l}\text { Monod half-saturation coefficient for "fermentor" growth on } \\
\text { hydrogen }\end{array}$ \\
\hline 20 & $K_{P C E}$ & Kpce & $\mathrm{mg} / \mathrm{L}$ & Monod half-saturation coefficient for PCE dechlorination \\
\hline 21 & $K_{T C E}$ & Ktce & $\mathrm{mg} / \mathrm{L}$ & Monod half-saturation coefficient for TCE dechlorination \\
\hline 22 & $K_{D C E}$ & Kdce & $\mathrm{mg} / \mathrm{L}$ & Monod half-saturation coefficient for DCE dechlorination \\
\hline 23 & $K_{V C}$ & Kvc & $\mathrm{mg} / \mathrm{L}$ & Monod half-saturation coefficient for $\mathrm{VC}$ dechlorination \\
\hline 24 & $f_{\text {dk2ace }}$ & fdk2ace & -- & Fraction of biomass that can decay to produce acetate \\
\hline 25 & $F_{A C E / X}$ & f_ace_x & $\mathrm{mol} / \mathrm{mol}$ & Moles of acetate formed per mole of biomass decayed \\
\hline 26 & $F_{X 1 / L A C}$ & f_x1_lac & $\mathrm{mol} / \mathrm{mol}$ & Moles of biomass 1 formed per mole of lactate \\
\hline 27 & $F_{X 1 / P R O}$ & f_x1_pro & $\mathrm{mol} / \mathrm{mol}$ & Moles of biomass 1 formed per mole of propionate \\
\hline 28 & $F_{X 1 / A C E}$ & f_xl_ace & $\mathrm{mol} / \mathrm{mol}$ & Moles of biomass 1 formed per mole of acetate \\
\hline 29 & $F_{X 1 / H 2}$ & f_x1_h2 & $\mathrm{mol} / \mathrm{mol}$ & Moles of biomass 1 formed per mole of hydrogen \\
\hline 30 & $F_{X 2 / A C E}$ & f_x2_ace & $\mathrm{mol} / \mathrm{mol}$ & Moles of biomass 2 formed per mole of acetate \\
\hline 31 & $F_{X 2 / H 2}$ & f_x2_h2 & $\mathrm{mol} / \mathrm{mol}$ & Moles of biomass 2 formed per mole of hydrogen \\
\hline 32 & $F_{X 1 / L A C}$ & f_ace_lac & $\mathrm{mol} / \mathrm{mol}$ & Moles of acetate formed per mole of lactate \\
\hline 33 & $F_{X 1 / L A C}$ & f_pro_lac & $\mathrm{mol} / \mathrm{mol}$ & Moles of propionate formed per mole of lactate \\
\hline
\end{tabular}


Table 42. (contd)

\begin{tabular}{|c|c|c|c|c|}
\hline $\begin{array}{l}\text { ID } \\
\#\end{array}$ & Parameter & $\begin{array}{l}\text { Fortran } \\
\text { Variable }\end{array}$ & Units & Description \\
\hline 34 & $F_{X 1 / L A C}$ & f_h2_lac & $\mathrm{mol} / \mathrm{mol}$ & Moles of hydrogen formed per mole of lactate \\
\hline 35 & $F_{X 1 / L A C}$ & f_ace_pro & $\mathrm{mol} / \mathrm{mol}$ & Moles of acetate formed per mole of propionate \\
\hline 36 & $F_{X 1 / L A C}$ & f_h2_pro & $\mathrm{mol} / \mathrm{mol}$ & Moles of hydrogen formed per mole of propionate \\
\hline 37 & $F_{X 1 / L A C}$ & f_met_ace & $\mathrm{mol} / \mathrm{mol}$ & Moles of methane formed per mole of acetate \\
\hline 38 & $F_{X 1 / L A C}$ & f_met_h2 & $\mathrm{mol} / \mathrm{mol}$ & Moles of methane formed per mole of hydrogen \\
\hline 39 & $F_{P C E / M E T}$ & f_pce_met & $\mathrm{mol} / \mathrm{mol}$ & $\begin{array}{l}\text { Moles of PCE dechlorinated per mole methanogenic biomass } \\
\text { increase }\end{array}$ \\
\hline 40 & $F_{T C E / M E T}$ & f_tce_met & $\mathrm{mol} / \mathrm{mol}$ & $\begin{array}{l}\text { Moles of TCE dechlorinated per mole methanogenic biomass } \\
\text { increase }\end{array}$ \\
\hline 41 & $F_{D C E / M E T}$ & f_dce_met & $\mathrm{mol} / \mathrm{mol}$ & $\begin{array}{l}\text { Moles of DCE dechlorinated per mole methanogenic biomass } \\
\text { increase }\end{array}$ \\
\hline 42 & $F_{V C / M E T}$ & f_vc_met & $\mathrm{mol} / \mathrm{mol}$ & $\begin{array}{l}\text { Moles of VC dechlorinated per mole methanogenic biomass } \\
\text { increase }\end{array}$ \\
\hline 43 & $k a e_{D C E}$ & kae_dce & $1 /$ day & First-order decay coefficient for aerobic dechlorination of DCE \\
\hline 44 & $k a e_{V C}$ & kae_vc & 1/day & First-order decay coefficient for aerobic dechlorination of VC \\
\hline
\end{tabular}

\subsection{Example Simulations}

Simulations with this reaction module were conducted with RT3D in a batch reactor (no flow) mode to show examples of how the reaction module simulates the pattern of dechlorination. The parameter values for each example simulation are listed in Tables 43 through 45 . These parameters are arbitrary values and are not directly related to any specific laboratory data. Sitespecific values would need to be determined as part of a calibration process. Results for these example batch simulations are shown in the Figures 38 through 42, respectively. 
Table 43. Parameter Values for Example Simulation 1 with the Substrate-Linked Reductive Dechlorination of Chloroethenes Reaction Module

\begin{tabular}{|c|l|c|c|c|l|c|c|}
\hline \hline ID \# & Fortran Variable & Value & Units & ID \# & Fortran Variable & Value & Units \\
\hline 1 & minbio1 & 0.5 & mgDW/L & 23 & Kvc & 10 & $\mathrm{mg} / \mathrm{L}$ \\
\hline 2 & minbio2 & 0.05 & $\mathrm{mgDW} / \mathrm{L}$ & 24 & fdk2ace & 0.2 & - \\
\hline 3 & kdec1 & 0.023 & $1 / \mathrm{day}$ & 25 & f_ace_x & 0.25 & $\mathrm{~mol} / \mathrm{mol}$ \\
\hline 4 & kdec2 & 0.002 & $1 /$ day & 26 & f_x1_lac & 0.05 & $\mathrm{~mol} / \mathrm{mol}$ \\
\hline 5 & ul1 & 0.1 & $1 /$ day & 27 & f_x1_pro & 0.1 & $\mathrm{~mol} / \mathrm{mol}$ \\
\hline 6 & up1 & 0.01 & $1 /$ day & 28 & f_x1_ace & 0.1 & $\mathrm{~mol} / \mathrm{mol}$ \\
\hline 7 & ua2 & 0.001 & $1 /$ day & 29 & f_x1_h2 & 0.01 & $\mathrm{~mol} / \mathrm{mol}$ \\
\hline 8 & uh2 & 0.1 & $1 /$ day & 30 & f_x2_ace & 0.1 & $\mathrm{~mol} / \mathrm{mol}$ \\
\hline 9 & ua1 & 0.001 & $1 /$ day & 31 & f_x2_h2 & 0.1 & $\mathrm{~mol} / \mathrm{mol}$ \\
\hline 10 & uh1 & 0.001 & $1 / \mathrm{day}$ & 32 & f_ace_lac & 0.7 & $\mathrm{~mol} / \mathrm{mol}$ \\
\hline 11 & ki1 & 500 & $\mathrm{mg} / \mathrm{L}$ & 33 & f_pro_lac & 0.4 & $\mathrm{~mol} / \mathrm{mol}$ \\
\hline 12 & ki2 & 500 & $\mathrm{mg} / \mathrm{L}$ & 34 & f_h2_lac & 0.1 & $\mathrm{~mol} / \mathrm{mol}$ \\
\hline 13 & kio & 0.1 & $\mathrm{mg} / \mathrm{L}$ & 35 & f_ace_pro & 1 & $\mathrm{~mol} / \mathrm{mol}$ \\
\hline 14 & K11 & 15 & $\mathrm{mg} / \mathrm{L}$ & 36 & f_h2_pro & 3 & $\mathrm{~mol} / \mathrm{mol}$ \\
\hline 15 & Kp1 & 15 & $\mathrm{mg} / \mathrm{L}$ & 37 & f_met_ace & 1 & $\mathrm{~mol} / \mathrm{mol}$ \\
\hline 16 & Ka2 & 15 & $\mathrm{mg} / \mathrm{L}$ & 38 & f_met_h2 & 0.25 & $\mathrm{~mol} / \mathrm{mol}$ \\
\hline 17 & Kh2 & 0.01 & $\mathrm{mg} / \mathrm{L}$ & 39 & f_pce_met & 0.4 & $\mathrm{~mol} / \mathrm{mol}$ \\
\hline 18 & Ka1 & 15 & $\mathrm{mg} / \mathrm{L}$ & 40 & f_tce_met & 0.3 & $\mathrm{~mol} / \mathrm{mol}$ \\
\hline 19 & Kh1 & 0.1 & $\mathrm{mg} / \mathrm{L}$ & 41 & f_dce_met & 0.2 & $\mathrm{~mol} / \mathrm{mol}$ \\
\hline 20 & Kpce & 10 & $\mathrm{mg} / \mathrm{L}$ & 42 & f_vc_met & 0.05 & $\mathrm{~mol} / \mathrm{mol}$ \\
\hline 21 & Ktce & 10 & $\mathrm{mg} / \mathrm{L}$ & 43 & kae_dce & 0.05 & $1 / \mathrm{day}$ \\
\hline 22 & Kdce & 10 & $\mathrm{mg} / \mathrm{L}$ & 44 & kae_vc & 0.05 & $1 / \mathrm{day}$ \\
\hline \hline
\end{tabular}


Table 44. Parameter Values for Example Simulation 2 with the Substrate-Linked Reductive Dechlorination of Chloroethenes Reaction Module

\begin{tabular}{|c|l|c|c|c|l|c|c|}
\hline \hline ID \# & Fortran Variable & Value & Units & ID \# & Fortran Variable & Value & Units \\
\hline 1 & minbio1 & 0.5 & mgDW/L & 23 & Kvc & 10 & $\mathrm{mg} / \mathrm{L}$ \\
\hline 2 & minbio2 & 0.05 & $\mathrm{mgDW} / \mathrm{L}$ & 24 & fdk2ace & 0.2 & - \\
\hline 3 & kdec1 & 0.023 & $1 / \mathrm{day}$ & 25 & f_ace_x & 0.25 & $\mathrm{~mol} / \mathrm{mol}$ \\
\hline 4 & kdec2 & 0.002 & $1 /$ day & 26 & f_x1_lac & 0.05 & $\mathrm{~mol} / \mathrm{mol}$ \\
\hline 5 & ul1 & 0.1 & $1 /$ day & 27 & f_x1_pro & 0.1 & $\mathrm{~mol} / \mathrm{mol}$ \\
\hline 6 & up1 & 0.01 & $1 /$ day & 28 & f_x1_ace & 0.1 & $\mathrm{~mol} / \mathrm{mol}$ \\
\hline 7 & ua2 & 0.001 & $1 /$ day & 29 & f_x1_h2 & 0.01 & $\mathrm{~mol} / \mathrm{mol}$ \\
\hline 8 & uh2 & 0.1 & $1 /$ day & 30 & f_x2_ace & 0.1 & $\mathrm{~mol} / \mathrm{mol}$ \\
\hline 9 & ua1 & 0.001 & $1 /$ day & 31 & f_x2_h2 & 0.1 & $\mathrm{~mol} / \mathrm{mol}$ \\
\hline 10 & uh1 & 0.001 & $1 / \mathrm{day}$ & 32 & f_ace_lac & 0.7 & $\mathrm{~mol} / \mathrm{mol}$ \\
\hline 11 & ki1 & 500 & $\mathrm{mg} / \mathrm{L}$ & 33 & f_pro_lac & 0.4 & $\mathrm{~mol} / \mathrm{mol}$ \\
\hline 12 & ki2 & 500 & $\mathrm{mg} / \mathrm{L}$ & 34 & f_h2_lac & 0.1 & $\mathrm{~mol} / \mathrm{mol}$ \\
\hline 13 & kio & 0.1 & $\mathrm{mg} / \mathrm{L}$ & 35 & f_ace_pro & 1 & $\mathrm{~mol} / \mathrm{mol}$ \\
\hline 14 & K11 & 15 & $\mathrm{mg} / \mathrm{L}$ & 36 & f_h2_pro & 3 & $\mathrm{~mol} / \mathrm{mol}$ \\
\hline 15 & Kp1 & 15 & $\mathrm{mg} / \mathrm{L}$ & 37 & f_met_ace & 1 & $\mathrm{~mol} / \mathrm{mol}$ \\
\hline 16 & Ka2 & 15 & $\mathrm{mg} / \mathrm{L}$ & 38 & f_met_h2 & 0.25 & $\mathrm{~mol} / \mathrm{mol}$ \\
\hline 17 & Kh2 & 0.01 & $\mathrm{mg} / \mathrm{L}$ & 39 & f_pce_met & 0.4 & $\mathrm{~mol} / \mathrm{mol}$ \\
\hline 18 & Ka1 & 15 & $\mathrm{mg} / \mathrm{L}$ & 40 & f_tce_met & 0.3 & $\mathrm{~mol} / \mathrm{mol}$ \\
\hline 19 & Kh1 & 0.1 & $\mathrm{mg} / \mathrm{L}$ & 41 & f_dce_met & 0.3 & $\mathrm{~mol} / \mathrm{mol}$ \\
\hline 20 & Kpce & 10 & $\mathrm{mg} / \mathrm{L}$ & 42 & f_vc_met & 0.3 & $\mathrm{~mol} / \mathrm{mol}$ \\
\hline 21 & Ktce & 10 & $\mathrm{mg} / \mathrm{L}$ & 43 & kae_dce & 0.05 & $1 / \mathrm{day}$ \\
\hline 22 & Kdce & 10 & $\mathrm{mg} / \mathrm{L}$ & 44 & kae_vc & 0.05 & $1 / \mathrm{day}$ \\
\hline \hline
\end{tabular}


Table 45. Parameter Values for Example Simulation 3 with the Substrate-Linked Reductive Dechlorination of Chloroethenes Reaction Module

\begin{tabular}{|c|l|c|c|c|l|c|c|}
\hline \hline ID \# & Fortran Variable & Value & Units & ID \# & Fortran Variable & Value & Units \\
\hline 1 & minbio1 & 0.5 & mgDW/L & 23 & Kvc & 10 & $\mathrm{mg} / \mathrm{L}$ \\
\hline 2 & minbio2 & 0.05 & $\mathrm{mgDW} / \mathrm{L}$ & 24 & fdk2ace & 0.2 & - \\
\hline 3 & kdec1 & 0.023 & $1 / \mathrm{day}$ & 25 & f_ace_x & 0.25 & $\mathrm{~mol} / \mathrm{mol}$ \\
\hline 4 & kdec2 & 0.002 & $1 /$ day & 26 & f_x1_lac & 0.05 & $\mathrm{~mol} / \mathrm{mol}$ \\
\hline 5 & ul1 & 0.05 & $1 /$ day & 27 & f_x1_pro & 0.1 & $\mathrm{~mol} / \mathrm{mol}$ \\
\hline 6 & up1 & 0.005 & $1 /$ day & 28 & f_x1_ace & 0.1 & $\mathrm{~mol} / \mathrm{mol}$ \\
\hline 7 & ua2 & 0.001 & $1 /$ day & 29 & f_x1_h2 & 0.01 & $\mathrm{~mol} / \mathrm{mol}$ \\
\hline 8 & uh2 & 0.1 & $1 /$ day & 30 & f_x2_ace & 0.1 & $\mathrm{~mol} / \mathrm{mol}$ \\
\hline 9 & ua1 & 0.0005 & $1 /$ day & 31 & f_x2_h2 & 0.1 & $\mathrm{~mol} / \mathrm{mol}$ \\
\hline 10 & uh1 & 0.0005 & $1 / \mathrm{day}$ & 32 & f_ace_lac & 0.7 & $\mathrm{~mol} / \mathrm{mol}$ \\
\hline 11 & ki1 & 500 & $\mathrm{mg} / \mathrm{L}$ & 33 & f_pro_lac & 0.4 & $\mathrm{~mol} / \mathrm{mol}$ \\
\hline 12 & ki2 & 500 & $\mathrm{mg} / \mathrm{L}$ & 34 & f_h2_lac & 0.1 & $\mathrm{~mol} / \mathrm{mol}$ \\
\hline 13 & kio & 0.1 & $\mathrm{mg} / \mathrm{L}$ & 35 & f_ace_pro & 1 & $\mathrm{~mol} / \mathrm{mol}$ \\
\hline 14 & K11 & 15 & $\mathrm{mg} / \mathrm{L}$ & 36 & f_h2_pro & 3 & $\mathrm{~mol} / \mathrm{mol}$ \\
\hline 15 & Kp1 & 15 & $\mathrm{mg} / \mathrm{L}$ & 37 & f_met_ace & 1 & $\mathrm{~mol} / \mathrm{mol}$ \\
\hline 16 & Ka2 & 15 & $\mathrm{mg} / \mathrm{L}$ & 38 & f_met_h2 & 0.25 & $\mathrm{~mol} / \mathrm{mol}$ \\
\hline 17 & Kh2 & 0.01 & $\mathrm{mg} / \mathrm{L}$ & 39 & f_pce_met & 0.4 & $\mathrm{~mol} / \mathrm{mol}$ \\
\hline 18 & Ka1 & 15 & $\mathrm{mg} / \mathrm{L}$ & 40 & f_tce_met & 0.3 & $\mathrm{~mol} / \mathrm{mol}$ \\
\hline 19 & Kh1 & 0.1 & $\mathrm{mg} / \mathrm{L}$ & 41 & f_dce_met & 0.2 & $\mathrm{~mol} / \mathrm{mol}$ \\
\hline 20 & Kpce & 10 & $\mathrm{mg} / \mathrm{L}$ & 42 & f_vc_met & 0.05 & $\mathrm{~mol} / \mathrm{mol}$ \\
\hline 21 & Ktce & 10 & $\mathrm{mg} / \mathrm{L}$ & 43 & kae_dce & 0.05 & $1 / \mathrm{day}$ \\
\hline 22 & Kdce & 10 & $\mathrm{mg} / \mathrm{L}$ & 44 & kae_vc & 0.05 & $1 / \mathrm{day}$ \\
\hline \hline
\end{tabular}




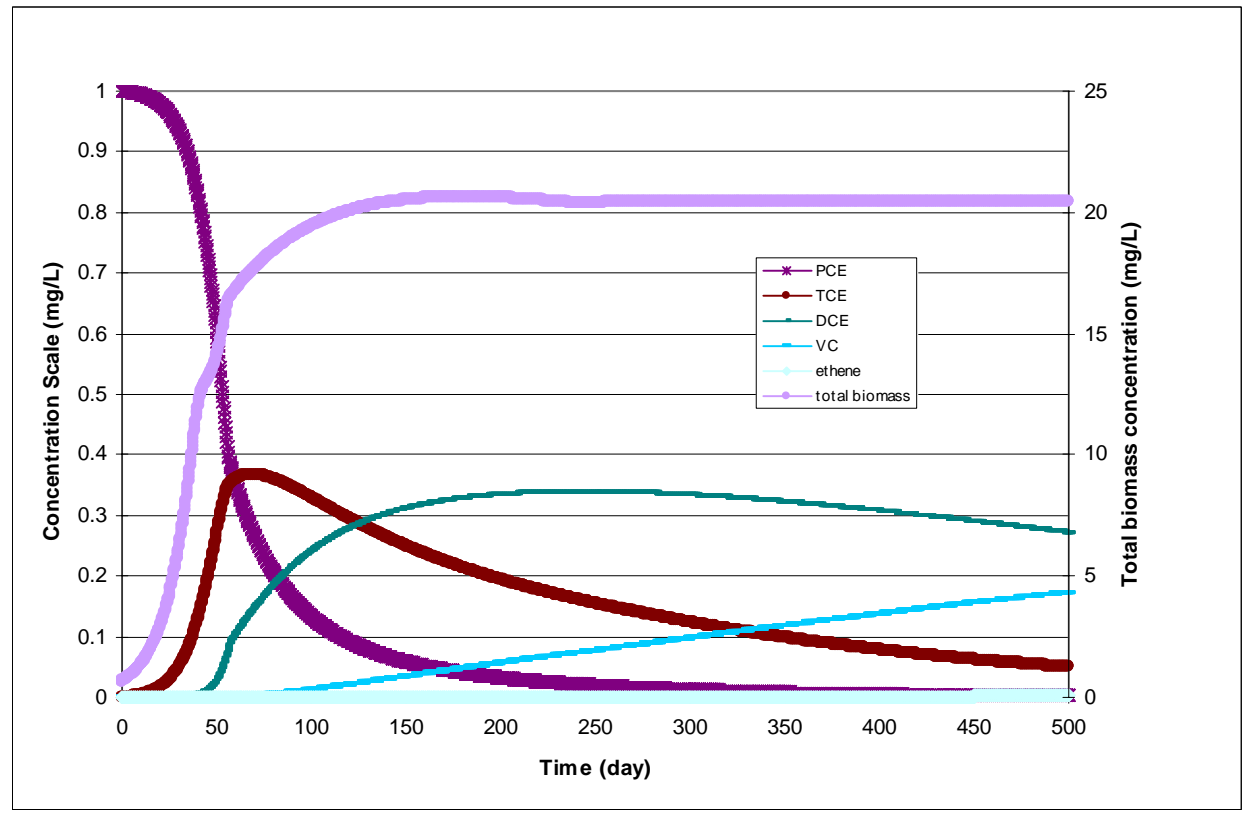

Figure 38. Dechlorination of PCE Using the Parameter Values Shown in Table 43 - The initial concentrations for PCE, lactate, oxygen, Bio1, Bio2, and BioT were 1, 200, 8, 0.6, 0.06, $0.66 \mathrm{mg} / \mathrm{L}$, respectively. All other species concentrations started at zero.

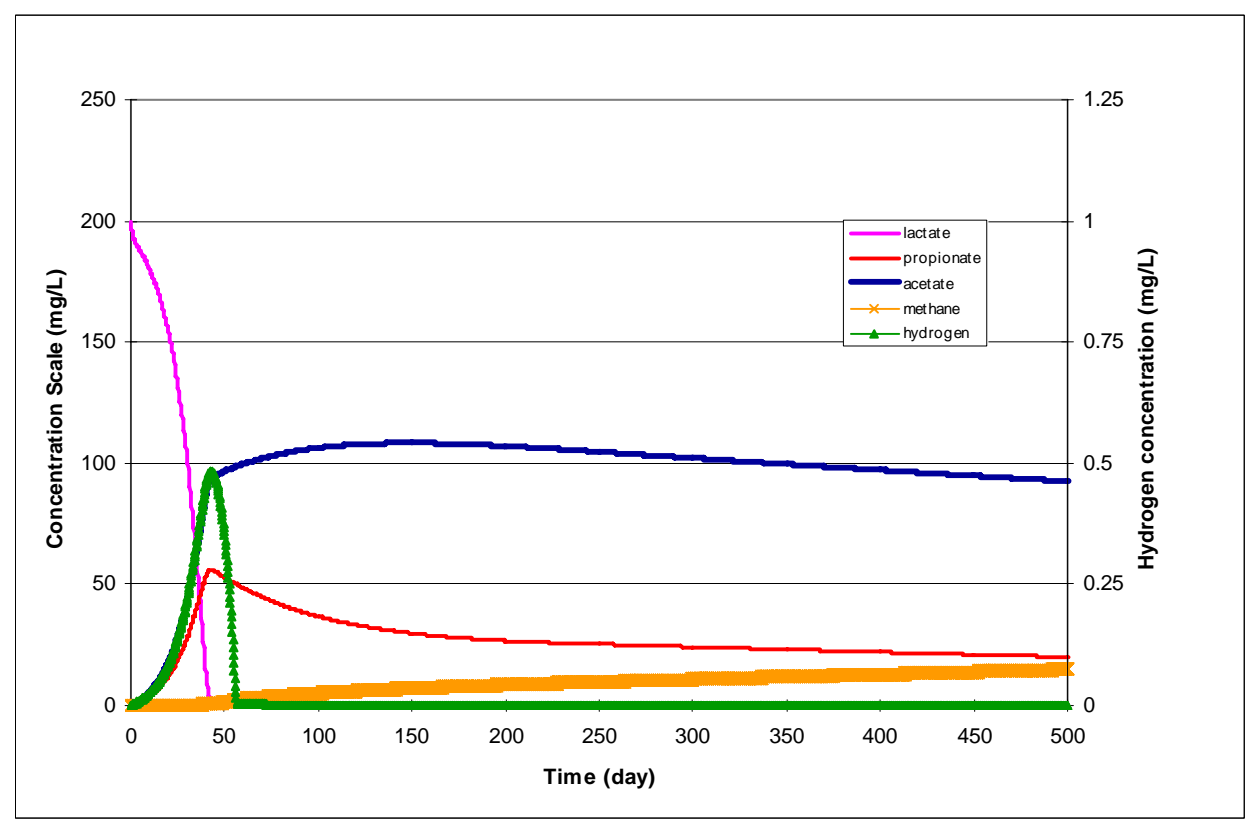

Figure 39. Concentrations of Organic Acids, Hydrogen, and Methane During Dechlorination of PCE Using the Parameter Values Shown in Table 43 - The initial concentrations for PCE, lactate, oxygen, Bio1, Bio2, and BioT were 1, 200, 8, 0.6, 0.06, $0.66 \mathrm{mg} / \mathrm{L}$, respectively. All other species concentrations started at zero. 


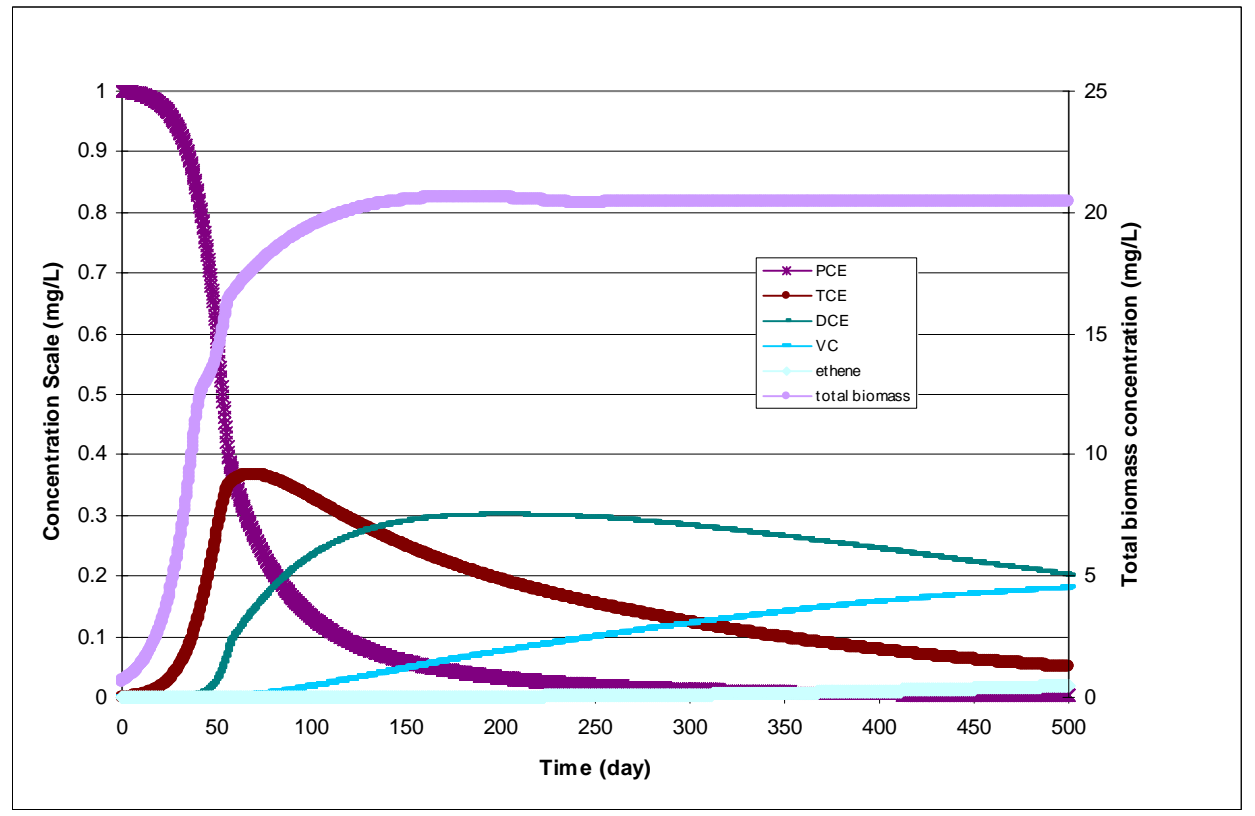

Figure 40. Dechlorination of PCE Using the Parameter Values Shown in Table 44 - The initial concentrations for PCE, lactate, oxygen, Bio1, Bio2, and BioT were 1, 200, 8, 0.6, 0.06, $0.66 \mathrm{mg} / \mathrm{L}$, respectively. All other species concentrations started at zero. The organic acids, hydrogen, and methane results are the same as shown in Figure 39.

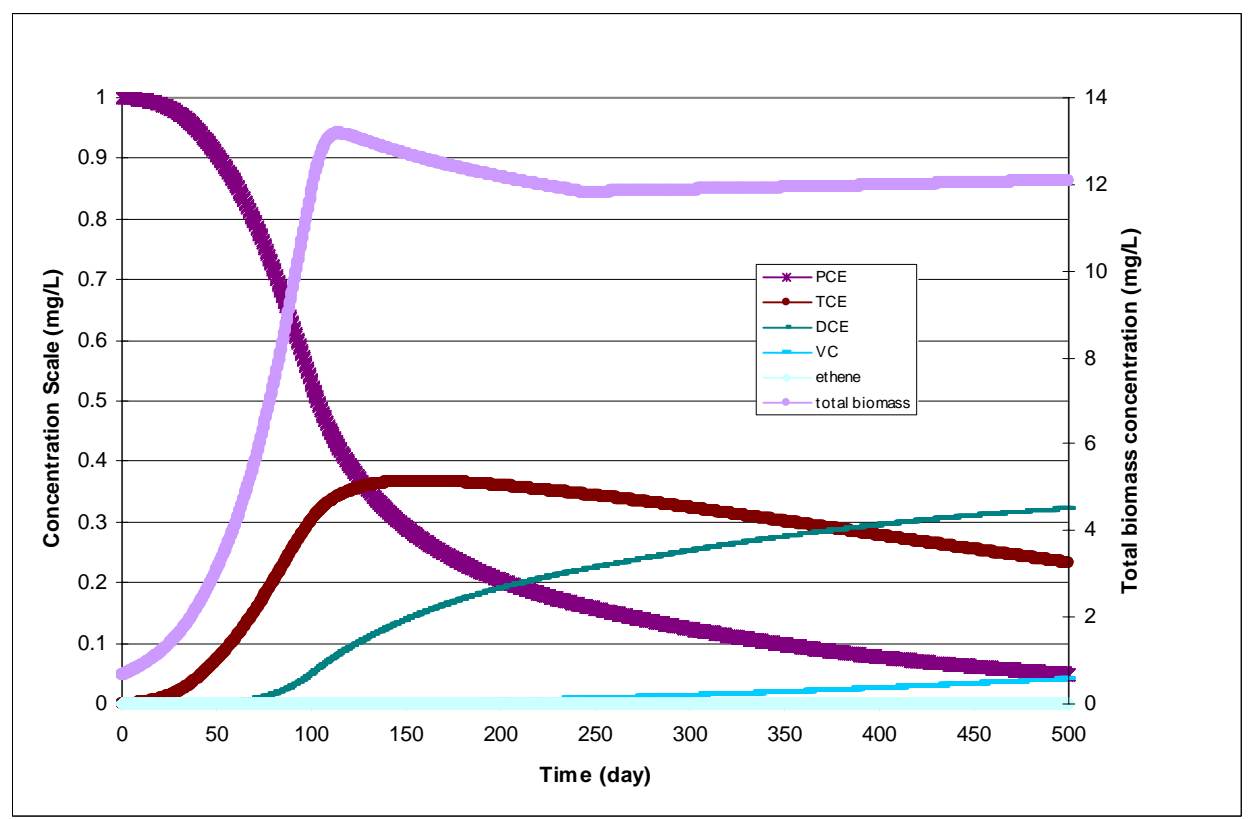

Figure 41. Dechlorination of PCE Using the Parameter Values Shown in Table 45 - The initial concentrations for PCE, lactate, oxygen, Bio1, Bio2, and BioT were 1, 200, 8, 0.6, $0.06,0.66 \mathrm{mg} / \mathrm{L}$, respectively. All other species concentrations started at zero. 


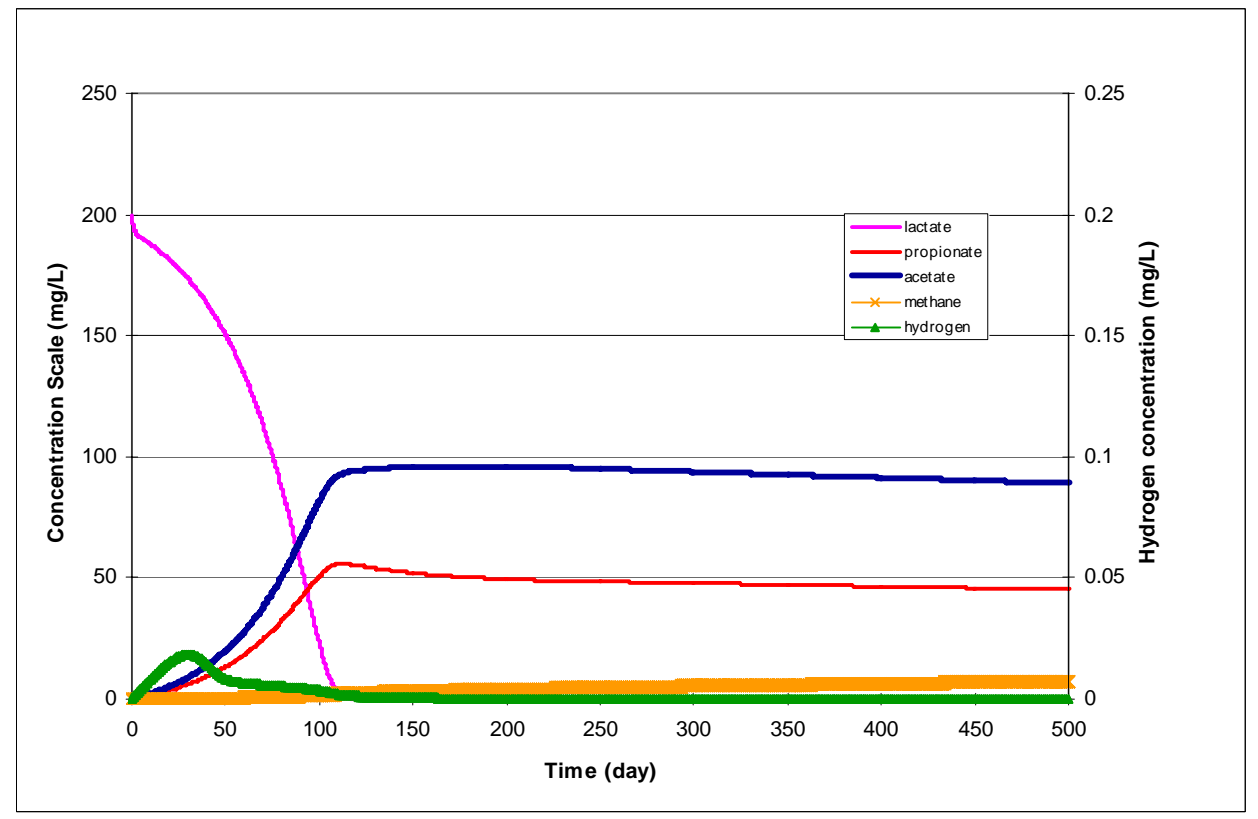

Figure 42. Concentrations of Organic Acids, Hydrogen, and Methane During Dechlorination of PCE Using the Parameter Values Shown in Table 45 - The initial concentrations for PCE, lactate, oxygen, Bio1, Bio2, and BioT were 1, 200, 8, 0.6, 0.06, $0.66 \mathrm{mg} / \mathrm{L}$, respectively. All other species concentrations started at zero. 


\subsection{Cometabolic Aerobic Dechlorination of Chloroethenes}

\subsection{Conceptual Model for Dechlorination Reactions}

This reaction module describes aerobic cometabolic degradation of trichloroethene, dichloroethene isomers, and chloroethene (vinyl chloride) by methanotrophs. The module includes an explicit description of biomass growth in response to methane and oxygen and tracks both active biomass (which is able to degrade methane and chlorinated ethenes) and total biomass (a combination of active biomass and inactive biomass, the latter of which is not able to degrade methane or chlorinated ethenes). Both types of biomass decay over time according to a user-specified decay rate. This reaction module does not account for changes in porosity/permeability resulting from biomass growth, although the total biomass is also tracked so that the modeler can assess the potential for biological fouling of the aquifer. If required, macroscopic models for biomass-affected porous media properties [Clement et al., 1996] could be combined with this module as a user-defined reaction module to account for changes in porosity/permeability. The cometabolic chlorinated ethene degradation reaction is dependent on the concentration of the chlorinated ethene compound and biomass, is inhibited by methane, requires oxygen, and deactivates biomass (i.e., the module indirectly accounts for destruction of the monooxygenase enzyme by the chlorinated ethene degradation intermediate epoxide compounds). The reaction rate expressions are based on the approach of Semprini et al. [1991], who reported kinetic expressions that include methane inhibition of chlorinated ethene degradation. The rate of chlorinated ethene degradation is described with a "transformation capacity" term [Alvarez-Cohen and McCarty, 1991; Chang and Alvarez-Cohen, 1996] incorporated to represent the inactivation of enzyme as a function of the amount of chlorinated ethene degraded. The module also allows the user to input the maximum concentration of methane and oxygen in water, making it possible to model supersaturated conditions, if desired.

Table 46 lists the chemical species included in this reaction module. Figure 43 shows the conceptual model describing the degradation reactions modeled in this reaction module. 
Table 46. Chemical Species Included in the Cometabolic Aerobic Dechlorination of Chloroethenes Reaction Module

\begin{tabular}{|c|l|l|l|c|c|c|}
\hline \hline No. & Abbreviation & \multicolumn{1}{|c|}{ Chemical Name } & Selected Alternate Name & $\begin{array}{c}\text { CAS } \\
\text { Registry } \\
\text { Number }\end{array}$ & $\begin{array}{c}\text { Molecular } \\
\text { Weight } \\
\text { c } \\
\text { (g/mol) }\end{array}$ & $\begin{array}{l}\text { Chemical } \\
\text { Formula }\end{array}$ \\
\hline 1 & MET & Methane & - & $74-82-8$ & 16.04246 & $\mathrm{CH}_{4}$ \\
\hline 2 & OXY & Oxygen (dimer) & - & $7782-44-7$ & 31.9988 & $\mathrm{O}_{2}$ \\
\hline 3 & TCE & Trichloroethene & Trichloroethylene & $79-01-6$ & 131.38834 & $\mathrm{C}_{2} \mathrm{HCl}_{3}$ \\
\hline 4 & DCE & $\begin{array}{l}\text { Dichloroethene (all } \\
\text { isomers) }\end{array}$ & Dichloroethylene & $156-59-2$ & 96.94328 & $\mathrm{C}_{2} \mathrm{H}_{2} \mathrm{Cl}_{2}$ \\
\hline 5 & VC & Chloroethene & Vinyl Chloride & $75-01-4$ & 62.49822 & $\mathrm{C}_{2} \mathrm{H}_{3} \mathrm{Cl}$ \\
\hline 6 & Tracer & Conservative Tracer & - & N/A & N/A & $\mathrm{N}^{-A}$ \\
\hline 7 & BioA & Active Biomass & Active methanotrophs & - & 113.11458 & $\mathrm{C}_{5} \mathrm{H}_{7} \mathrm{O}_{2} \mathrm{~N}$ \\
\hline 8 & BioT & Total Biomass & $\begin{array}{l}\text { Active and inactive } \\
\text { methanotrophs }\end{array}$ & - & 113.11458 & $\mathrm{C}_{5} \mathrm{H}_{7} \mathrm{O}_{2} \mathrm{~N}$ \\
\hline \hline
\end{tabular}

a These abbreviations refer to the specific chemicals listed here and should not be confused with different chemicals that may use the same abbreviation in other reaction modules.

${ }^{b} \mathrm{CAS}=$ Chemical Abstracts Service (see http://www.cas.org/EO/regsys.html)

c Based on International Union of Pure and Applied Chemistry values reported by Loss [2003].

N/A - Not Applicable
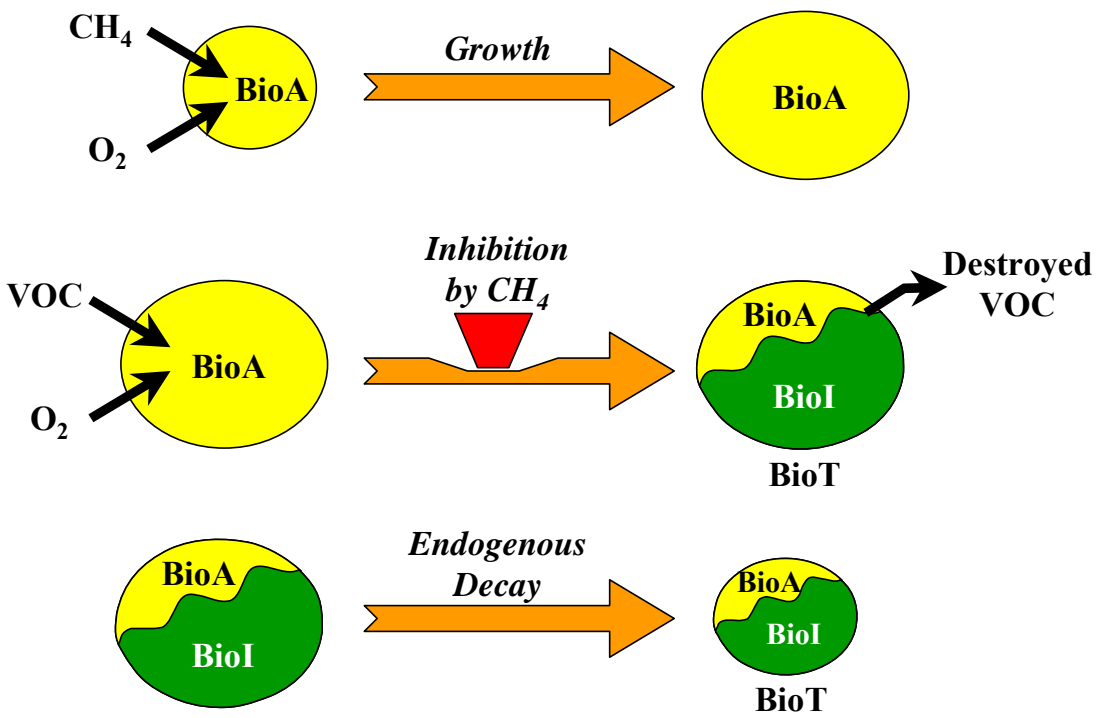

BioT

Figure 43. Conceptual Model for Biomass Growth, Decay, and Cometabolic Degradation Reactions - Active biomass (BioA) grows, contributing to the total biomass (BioT). Active biomass can destroy VOCs (i.e., TCE, DCE, and/or VC), resulting in inactivation of a portion of the biomass (BioI). The rate of VOC destruction is inhibited by the presence of methane. Biomass will also die and decay. 
The conceptual model for biomass growth and chlorinated ethene destruction requires the presence of dissolved oxygen. Methane is metabolized by the active biomass to produce additional active biomass. TCE, DCE, and VC are destroyed by active biomass, and in the process, some of the biomass is inactivated. The TCE, DCE, VC destruction process is inhibited by methane. Active and inactive biomass both decay at a user-specified first-order decay rate.

\subsection{Reaction Equations}

The reaction kinetics for the conceptual model described above are presented in Equations 150 through 157. These equations represent the change in concentration over time for the 8 chemical species in Table 46. Table 47 provides a detailed itemization of all user-specified reaction parameters used in this reaction module.

Active biomass is inactivated by the chlorinated ethene destruction reactions at a ratio defined by the user-specified transformation capacity. Monod-like terms are used to implement methane inhibition of chlorinated ethene destruction. A Monod term for methane represents its importance to biomass growth. Similarly, a Monod term for oxygen is used to require the presence of oxygen for both biomass growth and chlorinated ethene destruction. The rate of chlorinated ethene destruction depends on the concentration of the chlorinated ethenes as well. The rates of all consumption/destruction/growth reactions depend on the concentration of active biomass. The active biomass and total biomass are restricted to have a concentration of at least the user-specified minimum biomass. A logistic function is used to define $f_{\text {dec1 } 1}$ and $f_{\text {dec2 } 2}$ as fractional values ranging from 0.0 to 1.0 so that as biomass decays, the biomass concentration smoothly approaches the specified minimum. Dechlorination is allowed to proceed to the point where the active biomass is reduced to the minimum biomass concentration, but additional restrictions on the inactivation of biomass (involving maxdx in Equation 156) prevent the active biomass concentration from going below the minimum biomass. The maximum concentrations of methane and oxygen are limited to the user-specified water solubilities. It is assumed that additional methane or oxygen would volatilize and leave the system. The user can accommodate super-saturation (i.e., using pure oxygen instead of air) by setting higher water solubility limits.

$$
\begin{aligned}
& \frac{d[M E T]}{d t}=-r_{M E T} \\
& \frac{d[O X Y]}{d t}=-r_{M E T} \cdot F_{O / M} \\
& \frac{d[T C E]}{d t}=-r_{T C E}=-\mu_{T C E} \cdot\left[\frac{[T C E]}{K_{T C E} \cdot\left(\frac{K_{m}+[M E T]}{K_{m}}\right)+[T C E]}\right] \cdot\left(\frac{[O X Y]}{K_{O_{2}}+[O X Y]}\right) \cdot \max d x
\end{aligned}
$$




$$
\begin{aligned}
& \frac{d[D C E]}{d t}=-r_{D C E}=-\mu_{D C E} \cdot\left[\frac{[D C E]}{K_{D C E} \cdot\left(\frac{K_{m}+[M E T]}{K_{m}}\right)+[D C E]}\right] \cdot\left(\frac{[O X Y]}{K_{O_{2}}+[O X Y]}\right) \cdot \max d x \\
& \frac{d[V C]}{d t}=-r_{V C}=-\mu_{V C} \cdot\left[\frac{[V C]}{K_{V C} \cdot\left(\frac{K_{m}+[M E T]}{K_{m}}\right)+[V C]}\right] \cdot\left(\frac{[O X Y]}{K_{O_{2}}+[O X Y]}\right) \cdot \max d x \\
& \frac{d[\text { Tracer }]}{d t}=0.0 \\
& \frac{d[\text { BioA }]}{d t}=\operatorname{Max}\left(r_{\text {BioA }}, \quad-\operatorname{maxdx}\right) \\
& \frac{d[\text { BioT }]}{d t}=F_{X / M} \cdot r_{M E T}-f_{\text {dec } 2} \cdot k_{\text {decay }} \cdot[\text { BioT }]
\end{aligned}
$$

Where $r_{M E T}, \operatorname{maxdx}$, and $r_{B i o A}$ are defined as in Equations 158 through 160, respectively.

$$
\begin{aligned}
& r_{M E T}=\mu_{\max } \cdot[\text { BioA }] \cdot\left(\frac{[M E T]}{K_{m}+[M E T]}\right) \cdot\left(\frac{[O X Y]}{K_{O_{2}}+[O X Y]}\right) \cdot\left(\frac{1}{F_{X / M}}\right) \\
& \operatorname{maxd}=\operatorname{Max}\left([B i o A]-\text { bio }_{0}, 0.0\right) \\
& r_{B i o A}=F_{X / M} \cdot r_{M E T}-f_{d e c 1} \cdot k_{\text {decay }} \cdot[\text { BioA }]-\left(\frac{r_{T C E}}{T C_{T C E}}+\frac{r_{D C E}}{T C_{D C E}}+\frac{r_{V C}}{T C_{V C}}\right)
\end{aligned}
$$

\subsection{Required Input}

The reaction parameters for this reaction module are made available to RT3D as part of the input for the Reaction Package. The Reaction Package input file structure is discussed in the RT3D manual and addendum [Clement, 1997; Clement and Johnson, 2002]. The 18 reaction parameters that must be specified for this reaction module are listed in Table 47 in the required order (ID Number) with units and a description. Site-specific knowledge from field data or laboratory tests should be applied to determine an appropriate model configuration for reaction parameters (i.e., the values and the spatial distribution). 
Table 47. Input Parameters for the Cometabolic Aerobic Dechlorination of Chloroethenes Reaction Module

\begin{tabular}{|c|c|c|c|c|}
\hline $\begin{array}{c}\text { ID } \\
\#\end{array}$ & Parameter & $\begin{array}{l}\text { Fortran } \\
\text { Variable }\end{array}$ & Units & Description \\
\hline 1 & bio $_{0}$ & bio_0 & $\mathrm{mg} / \mathrm{L}$ & Minimum methanotroph biomass concentration \\
\hline 2 & $k_{\text {decay }}$ & kdecay & 1/day & Decay rate for methanotrophs \\
\hline 3 & $\mu_{\max }$ & uMax & 1/day & Methanotroph maximum growth rate \\
\hline 4 & $K_{m}$ & $\mathrm{Km}$ & $\mathrm{mg} \mathrm{CH} / / \mathrm{L}$ & $\begin{array}{l}\text { Monod half-saturation coefficient for methanotroph growth } \\
\text { for methane }\end{array}$ \\
\hline 5 & $K_{O_{2}}$ & Ko2 & $\mathrm{mg} \mathrm{O} / \mathrm{L}$ & $\begin{array}{l}\text { Monod half-saturation coefficient for methanotroph growth } \\
\text { for oxygen }\end{array}$ \\
\hline 6 & $K_{T C E}$ & Ktce & $\mathrm{mg} \mathrm{TCE} / \mathrm{L}$ & Monod half-saturation coefficient for TCE degradation \\
\hline 7 & $K_{D C E}$ & Kdce & $\mathrm{mg}$ DCE/L & Monod half-saturation coefficient for DCE degradation \\
\hline 8 & $K_{V C}$ & $\mathrm{Kvc}$ & $\mathrm{mg} \mathrm{VC/L}$ & Monod half-saturation coefficient for VC degradation \\
\hline 9 & $F_{o / M}$ & f_o_m & $\mathrm{mol} / \mathrm{mol}$ & Moles of oxygen consumed per mole of methane degraded \\
\hline 10 & $F_{X / M}$ & f_x_m & $\mathrm{mol} / \mathrm{mol}$ & Moles of biomass formed per mole of methane degraded \\
\hline 11 & $\mu_{T C E}$ & utce & $\begin{array}{l}\text { mg TCE / } \\
\text { mg Biomass-day }\end{array}$ & $\begin{array}{l}\text { Maximum specific TCE degradation rate coefficient per unit } \\
\text { mass of active bacteria }\end{array}$ \\
\hline 12 & $\mu_{D C E}$ & udce & $\begin{array}{c}\text { mg DCE / } \\
\text { mg Biomass-day }\end{array}$ & $\begin{array}{l}\text { Maximum specific DCE degradation rate coefficient per } \\
\text { unit mass of active bacteria }\end{array}$ \\
\hline 13 & $\mu_{V C}$ & uvc & $\begin{array}{c}\text { mg VC / } \\
\text { mg Biomass-day }\end{array}$ & $\begin{array}{l}\text { Maximum specific VC degradation rate coefficient per unit } \\
\text { mass of active bacteria }\end{array}$ \\
\hline 14 & $T C_{T C E}$ & tctce & $\begin{array}{c}\text { mol TCE / } \\
\text { mol Biomass }\end{array}$ & Transformation capacity for TCE \\
\hline 15 & $T C_{D C E}$ & tcdce & $\begin{array}{l}\text { mol DCE / } \\
\text { mol Biomass }\end{array}$ & Transformation capacity for DCE \\
\hline 16 & $T C_{V C}$ & teve & $\begin{array}{l}\text { mol VC / } \\
\text { mol Biomass }\end{array}$ & Transformation capacity for $\mathrm{VC}$ \\
\hline 17 & $\mathrm{CH}_{4 \max }$ & maxmet & $\mathrm{mg} / \mathrm{L}$ & Maximum methane concentration in water \\
\hline 18 & $O_{2 \max }$ & $\operatorname{maxoxy}$ & $\mathrm{mg} / \mathrm{L}$ & Maximum oxygen concentration in water \\
\hline
\end{tabular}

\subsection{Example Simulations}

Simulations with this reaction module were conducted with RT3D in a batch reactor (no flow) mode to show examples of how the reaction module simulates the pattern of dechlorination. The parameter values for each example simulation are listed in Table 48. These parameters are arbitrary values and are not directly related to any specific laboratory data. Site-specific values would need to be determined as part of a calibration process. Results for these example batch simulations are shown in the Figures 44 and 45, respectively. 
Table 48. Parameter Values for Example Simulations 1 and 2 with the Cometabolic Aerobic Dechlorination of Chloroethenes Reaction Module

\begin{tabular}{|c|l|c|c|c|l|c|c|}
\hline \hline ID \# & Fortran Variable & Value & Units & ID \# & Fortran Variable & Value & Units \\
\hline 1 & bio_0 & 0.01 & $\mathrm{mg} \mathrm{DW} / \mathrm{L}$ & 10 & f_x_m & 0.0467 & $\mathrm{~mol} / \mathrm{mol}$ \\
\hline 2 & kdecay & 0.00018 & $1 / \mathrm{day}$ & 11 & utce & 4.2 & $\mathrm{mg} \mathrm{TCE} /(\mathrm{mg}$ BioA·day) \\
\hline 3 & uMax & 0.7 & $1 / \mathrm{day}$ & 12 & udce & 3.1 & $\mathrm{mg} \mathrm{DCE} /(\mathrm{mg} \mathrm{BioA} \cdot \mathrm{day})$ \\
\hline 4 & Km & $1.10 \mathrm{E}-03$ & $\mathrm{mg} / \mathrm{L}$ & 13 & uvc & 2 & $\mathrm{mg} \mathrm{VC} /(\mathrm{mg} \mathrm{BioA}$ day $)$ \\
\hline 5 & Ko2 & 0.01 & $\mathrm{mg} / \mathrm{L}$ & 14 & tctce & 0.096 & $\mathrm{~mol} / \mathrm{mol}$ \\
\hline 6 & Ktce & $9.0 \mathrm{E}-03$ & $\mathrm{mg} / \mathrm{L}$ & 15 & tcdce & 0.26 & $\mathrm{~mol} / \mathrm{mol}$ \\
\hline 7 & Kdce & $6.8 \mathrm{E}-03$ & $\mathrm{mg} / \mathrm{L}$ & 16 & tcvc & 0.41 & $\mathrm{~mol} / \mathrm{mol}$ \\
\hline 8 & Kvc & $4.4 \mathrm{E}-03$ & $\mathrm{mg} / \mathrm{L}$ & 17 & maxmet & 23 & $\mathrm{mg} / \mathrm{L}$ \\
\hline 9 & f_o_m & 1.767 & $\mathrm{~mol} / \mathrm{mol}$ & 18 & maxoxy & 20 & $\mathrm{mg} / \mathrm{L}$ \\
\hline \hline
\end{tabular}

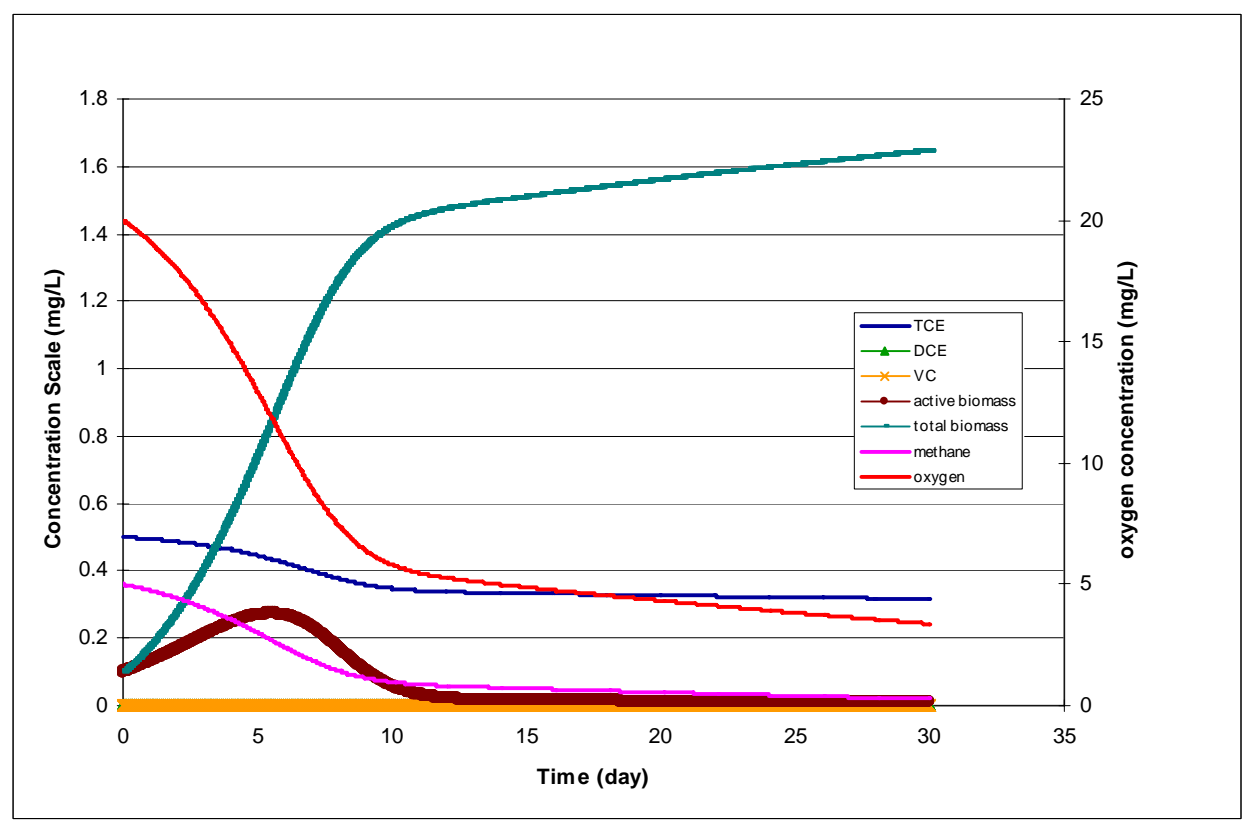

Figure 44. Dechlorination of TCE Using the Parameter Values Shown in Table 48 - The initial concentration for TCE, DCE, VC, methane, oxygen, active biomass, and total biomass were 0.5, 5, 20, 0.1, and $0.1 \mathrm{mg} / \mathrm{L}$, respectively. 


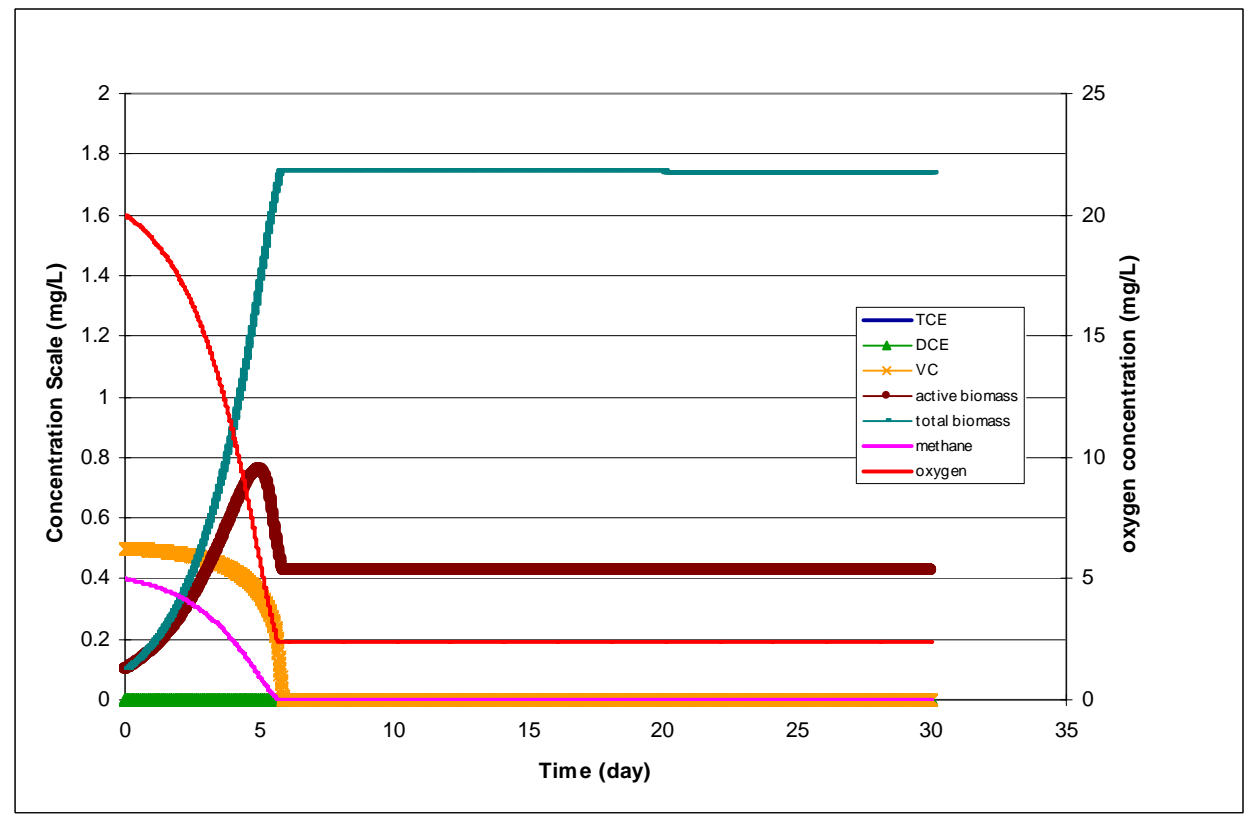

Figure 45. Dechlorination of VC Using the Parameter Values Shown in Table 48 - The initial concentration for VC, methane, oxygen, active biomass, and total biomass were 0.5, $5,20,0.1$, and $0.1 \mathrm{mg} / \mathrm{L}$, respectively. 


\subsection{References}

Alexander, M. 1985. "Biodegradation of Organic Chemicals." Environ. Sci. Technol., 18(2):106-111.

Alvarez-Cohen, L., and P.L. McCarty. 1991. "Product Toxicity and Cometabolic Competitive Inhibition Modeling of Chloroform and Trichloroethylene Transformation by Methanotrophic Resting Cells." Appl. Environ. Microbiol., 57(4):1031-1037.

Bekins, B.A., E. Warren, and E.M. Godsy. 1998. "A Comparison of Zero-Order, First-Order, and Monod Biotransformation Models." Ground Water, 36(2):261-268.

BYU. 2006. Electronic Help File for the U.S. Department of Defense Groundwater Modelling System Version 6.0. Brigham Young University, Provo, Utah.

Cervini-Silva, J., J.E. Kostka, R.A. Larson, J.W. Stucki, and J. Wu. 2003. "Dehydrochlorination of 1,1,1-Tricholoroethane and Pentachloroethane by Microbially Reduced Ferruginous Smectite." Environ. Toxicol. Chem., 22(5):1046-1050.

Chang, H., and L. Alvarez-Cohen. 1996. "Biodegradation of Individual and Multiple Chlorinated Aliphatic Hydrocarbons by Methane-Oxidizing Cultures." Appl. Environ. Microbiol., 62(9):3371-3377.

Chen, C., J.A. Puhakka, and J.F. Ferguson. 1996. "Transformations of 1,1,2,2Tetrachloroethane Under Methanogenic Conditions." Environ. Sci. Technol., 30(2):542-547.

Chiang, W-H. 2005. 3D-Groundwater Modeling with PMWIN. Springer, New York.

Clement, T.P., B.S. Hooker, and R.S. Skeen. 1996. "Macroscopic Models for Predicting Changes in Saturated Porous Media Properties Cause by Microbial Growth." Ground Water, 34(5):934-942.

Clement, T.P. 1997. RT3D-A Modular Computer Code for Simulating Reactive Multi-Species Transport in 3-Dimensional Groundwater Aquifers. PNNL-11720, Pacific Northwest National Laboratory, Richland, Washington.

Clement, T.P., Y. Sun, B.S. Hooker, and J.N. Petersen. 1998. "Modeling Multispecies Reactive Transport in Ground Water." Ground Water Monitoring Remediation, 18(2):79-92.

Clement, T.P., C.D. Johnson, Y. Sun, G.M. Klecka, and C. Bartlett. 2000. "Natural Attenuation of Chlorinated Ethene Compounds: Model Development and Field-Scale Application at the Dover Site." J. Contaminant Hydrology, 42(2-4):113-140.

Clement, T.P., and C.D. Johnson. 2002. RT3D v2.5 Update Document. Pacific Northwest National Laboratory, Richland, Washington. Available online at: http://bioprocess.pnl.gov/rt3d_down.htm\#doc. 
De Wildeman, S., and W. Verstraete. 2003. "The Quest for Microbial Reductive Dechlorination of $\mathrm{C}_{2}$ to $\mathrm{C}_{4}$ Chloroalkanes is Warranted." Appl. Microbiol. Biotechnol., 61(2):94102.

Doong, R.-a., T.-f. Chen, and Y.-w. Wu. 1997. "Anaerobic Dechlorination of Carbon Tetrachloride by Free-Living and Attached Bacteria Under Various ElectronDonor Conditions." Appl. Microbiol. Biotechnol., 47(3):317-323.

Drever, J.I. 1988. The Geochemistry of Natural Waters. Prentice Hall, Englewood Cliffs, New Jersey.

Harbaugh, A.W., E.R. Banta, M.C. Hill, and M.G. McDonald. 2000. MODFLOW-2000, the U.S. Geological Survey Modular Ground-Water Model -- User Guide to Modularization Concepts and the Ground-Water Flow Process. Open-File Report 00-92, United States Geological Survey, Reston, Virginia.

Harbaugh, A.W. 2005. MODFLOW-2005, The U.S. Geological Survey Modular Ground-Water Model-the Ground-Water Flow Process. Techniques and Methods 6-A16, United States Geological Survey, Reston, Virginia.

Harvey, R.W., and L.B. Barber. 1992. "Associations of Free-Living Bacteria and Dissolved Organic Compounds in a Plume of Contaminated Groundwater." J. Contam. Hydro., 9(1-2):91-103.

Holm, P.E., P.H. Nielsen, H. Albrechtsen, and T.H. Christensen. 1992. "Importance of Unattached Bacteria and Bacteria Attached to Sediment in Determining Potentials for Degradation of Xenobiotic Organic Contaminants in an Aerobic Aquifer." Appl. Environ. Microbiol., 58(9):3020-3026.

Hunkeler, D., R. Aravena, K. Berry-Spark, and E. Cox. 2005. "Assessment of Degradation Pathways in an Aquifer with Mixed Chlorinated Hydrocarbon Contamination Using Stable Isotope Analysis." Environ. Sci. Technol., 39(16):5975-5981.

Jeffers, P.M., L.M. Ward, L.M. Woytowltch, and N.L. Wolfe. 1989. "Homogeneous Hydrolysis Rate Constants for Selected Chlorinated Methanes, Ethanes, Ethenes, and Propanes." Environ. Sci. Technol., 23(8):965-969.

Jeffers, P.M., C. Brenner, and N.L. Wolfe. 1996. "Hydrolysis of Carbon Tetrachloride." Environ. Toxicol. Chem., 15(7):1064-1065.

Jeffers, P.M., and N.L. Wolfe. 1996. "Homogeneous Hydrolysis Rate Constants_Part II: Additions, Corrections and Halogen Effects." Environ. Toxicol. Chem., 15(7):1066-1070. 
Johnson, C.D., R.S. Skeen, M.G. Butcher, D.P. Leigh, L.A. Bienkowski, S. Granade, B. Harre, and T. Margrave. 1999. "Accelerated In Situ Bioremediation of Chlorinated Ethenes in Groundwater with High Sulfate Concentrations." In: Engineered Approches for In Situ Bioremediation of Chlorinated Solvent Contamination, A. Leeson and B.C. Alleman, eds. Battelle Press, Columbus, Ohio. pp. 165-170.

Johnson, C.D., M.J. Truex, and J.R. Spencer. 2003a. "Use of Redox Zones in Modelling Natural Attenuation of a Chlorinated Solvent Plume." In: Proceedings of the Seventh In Situ and On-Site Bioremediation Symposium, Orlando, Florida; June 25, 2003. Battelle Press, Columbus, Ohio.

Johnson, C.D., M.J. Truex, D.P. Leigh, and S. Granade. 2003b. "Successful Implementation of Aerobic Cometabolism of Vinyl Chloride Via an In Situ Biofilter." In: Proceedings of the Seventh In Situ and On-Site Bioremediation Symposium, Orlando, Florida; June 2-5, 2003. Battelle Press, Columbus, Ohio.

Johnson, C.D., M.J. Truex, and T.P. Clement. 2006. Natural and Enhanced Attenuation of Chlorinated Solvents Using RT3D. PNNL-15937, Pacific Northwest National Laboratory, Richland, Washington.

Lehman, R.M., F.S. Colwell, and G.A. Bala. 2001. "Attached and Unattached Microbial Communities in a Simulated Basalt Aquifer under Fracture- and Porous-Flow Conditions." Appl. Environ. Microbiol., 67(6):2799-2809.

Leigh, D.P., C.D. Johnson, R.S. Skeen, M.G. Butcher, L.A. Bienkowski, and S. Granade. 2000. "Enhanced Anaerobic In Situ Bioremediation of Chloroethenes at NAS Point Mugu." In: Bioremediation and Phytoremediation of Chlorinated and Recalcitrant Compounds, G.B. Wickramanayake, A.R. Gavaskar, B.C.Alleman, and V.S. Magar (eds.). Battelle Press, Columbus, OH. pp. 229-235.

Lorah, M.M., and L.D. Olsen. 1999. "Degradation of 1,1,2,2-Tetrachloroethane in a Freshwater Tidal Wetland: Field and Laboratory Evidence." Environ. Sci. Technol., 33(2):227-234.

Lorah, M.M., and M.A. Voytek. 2004. "Degradation of 1,1,2,2-Tetrachloroethane and Accumulation of Vinyl Chloride in Wetland Sediment Microcosms and In Situ Porewater: Biogeochemical Controls and Associations with Microbial Communities." J. Contam. Hydro., 70(1-2):117-145.

Loss, R.D. 2003. "Atomic Weights of the Elements 2001." Pure Appl. Chem., 75(8):1107-1122.

Lu, G., T.P. Clement, C. Zheng, and T.H. Wiedemeier. 1999. "Natural Attenuation of BTEX Compounds: Model Development and Field-Scale Application." Ground Water, 37(5):707-717. 
Mabey, W., and T. Mill. 1978. "Critical Review of Hydrolysis of Organic Compounds in Water Under Environmental Conditions." J. Phys. Chem. Ref. Data, 7(2):383-415.

Maymó-Gatell, X., T. Anguish, and S.H. Zinder. 1999. "Reductive Dechlorination of Chlorinated Ethenes and 1,2-Dichloroethane by "Dehalococcoides ethenogenes" 195." Appl. Environ. Microbiol., 65(7):3108-3113.

McDonald, M.G., and A.W. Harbaugh. 1988. "A Modular Three-Dimensional Finite-Difference Ground-Water Flow Model." In Techniques of Water-Resources Investigations of the U.S. Geological Survey, Book 6, Chapter A1. United States Geological Survey, Reston, Virginia.

Painter, R.D., S. Kochary, and T.D. Byl. 2005. "Free-Living Bacteria or Attached Bacteria: Which Contributes More to Bioremediation?" In: E.L. Kuniansky, ed. U.S. Geological Survey Karst Interest Group Proceedings, Rapid City, South Dakota, September 12-15, 2005. SIR 2005-5160, United States Geological Survey, Reston, Virginia.

Rumbaugh, J.O., and D.B. Rumbaugh. 2004. Guide to using Groundwater Vistas Version 4. Environmental Simulations Inc., Reinholds, Pennsylvania.

Schmidt, S.K., S. Simkins, and M. Alexander. 1985. "Models for the Kinetics of Biodegradation of Organic Compounds Not Supporting Growth." Appl. Environ. Microbiol., 50(2):323-331.

Scow, K.M., S. Simkins, and M. Alexander. 1986. "Kinetics of Mineralization of Organic Compounds at Low Concentrations in Soil." Appl. Environ. Microbiol., 51(5):1028-1035.

Semprini, L., G.D. Hopkins, P.V. Roberts, D. Grbic-Galic, and P.L. McCarty. 1991. "A Field Evaluation of In Situ Biodegradation of Chlorinated Ethenes: Part 3, Studies of Competitive Inhibition." Ground Water, 29(2):239-250.

Simkins, S., and M. Alexander. 1984. "Models for Mineralization Kinetics with the Variables of Substrate Concentration and Population Density." Appl. Environ. Microbiol., 47(6):1299-1306.

Skeen, R.S., J. Gao, and B.S. Hooker. 1995. "Kinetics of Chlorinated Ethylene Dehalogenation under Methanogenic Conditions." Biotech. Bioeng., 48(6):659-666.

Spencer, J.R., C.D. Johnson, M.J. Truex, and T.P. Clement. 2002. "Modeling Biological Transformation of Chlorinated Ethanes and Ethenes in Support of Natural Attenuation." In: Remediation of Chlorinated and Recalcitrant Compounds2002, A.R. Gavaskar and A.S.C. Chen (eds.). Battelle Press, Columbus, OH. Paper number 2D-09. 
Truex, M.J., C.J. Murray, C.R. Cole, R.J. Cameron, M.D. Johnson, R.S. Skeen, and C.D. Johnson. 2001. Assessment of Carbon Tetrachloride Groundwater Transport in Support of the Hanford Carbon Tetrachloride Innovative Technology Demonstration Program. PNNL-13560, Pacific Northwest National Laboratory, Richland, Washington.

Truex, M.J., C.D. Johnson, J.R. Spencer, and T.P. Clement. 2002a. "Evaluating Natural Attenuation of Chlorinated Solvents at a Complex Site." In: Remediation of Chlorinated and Recalcitrant Compounds-2002, A.R. Gavaskar and A.S.C. Chen (eds.). Battelle Press, Columbus, Ohio. Paper number 2D-06.

Truex, M.J., C.D. Johnson, D.P. Leigh, and S. Granade. 2002b. "Pulsed Injection Flow Strategy for Aerobic Co-Metabolism of Vinyl Chloride." In: Remediation of Chlorinated and Recalcitrant Compounds-2002, A.R. Gavaskar and A.S.C. Chen (eds.). Battelle Press, Columbus, OH. Paper number 2B-33.

U.S. EPA. 1998. Technical Protocol for Evaluating Natural Attenuation of Chlorinated Solvents in Ground Water. EPA/600/R-98/128, United States Environmental Protection Agency, Office of Research and Development, Washington D.C.

Vogel, T.M., C.S. Criddle, and P.L. McCarty. 1987. "Transformations of Halogenated Aliphatic Compounds." Environ. Sci. Technol., 21(8):722-736.

Washington, J.W. 1995. "Hydrolysis Rates of Dissolved Volatile Organic Compounds: Principles, Temperature Effects and Literature Review." Ground Water, 33(3):415-424.

WHI. 2005. Electronic Help File for Visual Modflow Version 4.1. Waterloo Hydrogeologic, Inc., Waterloo, Ontario, Canada.

Yolcubal, I., S.A. Pierce, R.M. Maier, and M.L. Brusseau. 2002. "Biodegradation during Contaminant Transport in Porous Media: V. The Influence of Growth and Cell Elution on Microbial Distribution." J. Environ. Qual., 31(6):1824-1830.

Zheng, C., and P.P. Wang. 1999. MT3D: A Modular Three-Dimensional Multispecies Transport Model - Documentation and User's Guide. SERDP-99-1, United States Army Corps of Engineers, Engineer Research and Development Center, Vicksburg, Mississippi. Available at: http:/hydro.geo.ua.edu/mt3d.

Zheng, C., M.C. Hill, and P.A. Hsieh. 2001. Modflow-2000, the U.S. Geological Survey Modular Ground-Water Model - User Guide to the LMT6 Package, the Linkage with MT3DMS for Multi-Species Mass Transport Modeling. Open-File Report 01-82, United States Geological Survey, Denver, Colorado. 

PNNL-15938

\section{Distribution}

No. of

Copies

OFFSITE

1 T.P. Clement

Auburn University

Department of Civil Engineering

212 Harbert Engineering Center

Auburn, AL 36849-5337

1 B.B. Looney

Savannah River National Laboratory

Bldg. 773-42A

Aiken, SC 29808

1 C.J. Newell

Groundwater Services, Inc.

2211 Norfolk, Suite 1000

Houston, TX 77098-4054

$1 \quad$ K.M. Vangelas

Savannah River National Laboratory

Bldg. 773-42A

Aiken, SC 29808
No. of

Copies

ONSITE

7 Pacific Northwest National Laboratory

T.J. Gilmore

K6-96

C.D. Johnson (2)

K6-96

M.L. Rockhold

K9-36

M.J. Truex

K6-96

Information Release Office (2) P8-55

Distr.1 